\title{
NEMATOIDES DO BRASIL. PARTE III: NEMATOIDES DE RÉPTEIS
}

\author{
Joaquim Júlio Vicente ${ }^{1}$ \\ Henrique de Oliveira Rodrigues ${ }^{1}$ \\ Delir Corrêa Gomes ${ }^{1}$ \\ Roberto Magalhães Pinto ${ }^{1}$
}

\begin{abstract}
BRAZILIAN NEMATODES. PART III: NEMATODES OF REPTILES. A survey of nematode species parasizing Brazilian reptiles is presented, with data enough to provide their specific identification. The first section refers to the catalogation of the species, related to 127 superfamilies, 23 families, 55 genera and 121 species that are figured and included in measurement tables. The second section is concerned to the catalogue of host reptiles, with 16 families, and 90 species and their respective parasite nematodes. The identification of these helminths is achieved by means of keys to the superfamilies, families and genera. Specific determination is induced through the figures and tables as above mentioned.
\end{abstract}

KEY WORDS. Nematodes, Reptiles, Brazil

\section{SUMÁRIO}

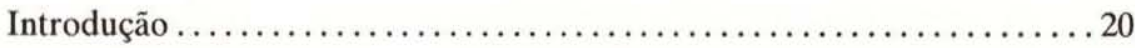

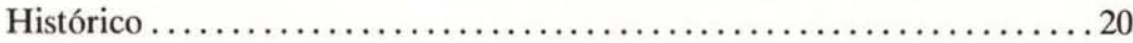

Posição sistemática das espécies de nematóides parasitos de répteis referidas

para o Brasil .................................. 20

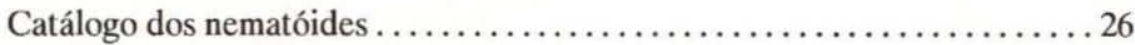

Catálogo dos répteis hospedeiros e seus respectivos parasitos ..........96

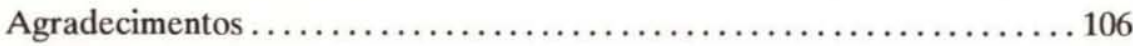

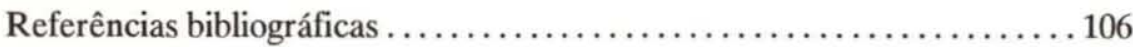

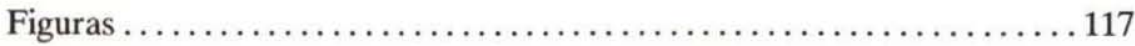

Índice dos nematóides e répteis hospedeiros $\ldots \ldots \ldots \ldots \ldots \ldots \ldots \ldots \ldots \ldots$

1) Departamento de Helmintologia, Fundação Instituto Oswaldo Cruz, Caixa Postal 926, 21041-210 Rio de Janeiro, Rio de Janeiro, Brasil. Bolsista do CNPq. 
O presente trabalho dá continuidade ao inventário dos nematóides parasitos que ocorrem no Brasil, iniciado por VICENTE et al. (1985) com os nematóides parasitas de peixes e seguido pelo catálogo dos nematóides parasitas de anfíbios.

A disposição da obra segue a mesma orientação apresentada nos trabalhos anteriores.

A sistemática de YAMAGUTI (1961) serve de base à organização dos nematóides aqui estudados, complementada com as modificações propostas por HARTWICH (1974), CHABAUD $(1975,1978)$, ANDERSON \& BAIN (1976), PETTER \& QUENTIN (1976) e DURETTE-DESSET (1983).

Como nos catálogos anteriores apresentamos chaves de determinação para superfamílias e gêneros dos nematóides. Essas chaves são em parte originais e em parte adaptadas de diversos autores.

A identificação específica é feita com auxílio de quadros de medidas em milímetros e figuras.

Para cada espécie referida no catálogo de nematóides parasitas de répteis é relacionada a bibliografia pertinente.

No catálogo dos répteis hospedeiros utilizamos como fontes de informação sobre a sua sistemática, entre outros, os trabalhos de AMARAL (1929, 1935-1936, 1937), FRÓES (1957), PETERS \& DONOSO-BARROS (1970), PETERS \& OREJAS-MIRANDA (1970) e VANZOLINI (1981).

\section{HISTÓRICO}

MARCGRAVE (1648) mencionou o encontro de pequenos nematóides de intestino de iguana, sendo esta a primeira referência de nematóides parasitos de répteis encontrados no Brasil.

No século passado vários helmintologistas europeus como Rudolphi, Diesing e Molin estudaram nematóides de répteis coletados no Brasil.

TRAVASSOS (1913) na sua revisão das espécies brasileiras da subfamília Heterakinae Railliet \& Henry, 1912, foi o primeiro brasileiro a se ocupar do estudo de nematóides parasitos de répteis.

Além de TRAVASSOS, vários outros pesquisadores brasileiros e estrangeiros dedicaram-se ao estudo desse interessante grupo de nematóides, atingindo atualmente a mais de 150 o número de trabalhos que fazem referência a nematóides de répteis do Brasil.

POSIÇĀo SISTEMÁTICA DAS ESPÉCIES DE NEMATÓIDES PARASITAS DE RÉPTEIS REFERIDAS PARA O BRASIL

Rhabditoidea

Rhabdiasidae Railliet, 1915

Rhabdias Stiles \& Hassall, 1905

labiata Pereira, 1927

vellardi Pereira, 1927

Acanthorhabdias Pereira, 1927 
acanthorhabidias Pereira, 1927

Strongyloididae Chitwood \& MacIntosch, 1934

Strongyloides Grassi, 1879

cruzi Rodrigues, 1968

ophidiae Pereira, 1929

Trichuroidea

Trichuridae Railliet, 1916

Capillaria Zeder, 1800 crotali Zeder, 1800

freitaslenti Araujo \& Gandra, 1941

Pseudocapillaria Freitas, 1959

Pseudocapillaria (Pseudocapillaria) Freitas, 1959

amarali (Freitas \& Lent, 1934) Moravec, 1982 cesarpintoi (Freitas \& Lent, 1934) Moravec, 1982

Pseudocapillaria (Ichthyocapillaria) Moravec, 1982 murinae (Travassos, 1914) Moravec, 1982

Diaphanocephaloidea

Diaphanocephalidae Travassos, 1920

Diaphanocephalus Diesing, 1851 diesingi Freitas \& Lent, 1938 galeatus (Rud., 1819) Railliet \& Henry, 1909 jacuruxi Alho, 1965

Kalicephalus Molin, 1861 appendiculatus Molin, 1861 brevipenis Molin, 1861 costatus costatus (Rud., 1819) Yorke \& Maplestone, 1926 inermis inermis Molin, 1861 rectiphilus neorectiphilus Schad, 1962 subulatus Molin, 1861

Trichostrongyloidea

Molineidae Durette-Desset \& Chabaud, 1977

Oswaldocruzia Travassos, 1917 brasiliensis Lent \& Freitas, 1935 mazzai Travassos, 1935 subauricularis (Rud., 1819) Travassos, 1917

Strongyloidea

Strongylidae Baird, 1853

Chapiniella Yamaguti, 1961 variabilis (Chapin, 1924) Yamaguti, 1961

Sauricola Chapin, 1925

sauricola Chapin, 1925 
Cosmocercoidea

Atractidae Travassos, 1919

Atractis Dujardin, 1845

cruciata Linstow, 1902

trematophila Travassos, 1934

Labiduris Schneider, 1866 gulosa (Rud., 1819) Schneider, 1866

irineuta Costa, 1961

zschokkei Linstow, 1899

Maracaya Diaz-Ungria, 1963

belemensis Adamson \& Baccan, 1988

Cobboldinidae Skrjabin, 1948

Klossinemella Costa, 1961

conciliatus Alho, 1964

travassosi Costa, Motta \& Gomes, 1968

Cosmocercidae Travassos, 1925

Aplectana Railliet \& Henry, 1916

albae Adamson \& Baccan, 1988

papillifera (Araujo, 1978)

pusilla Miranda, 1924

raillieti Travassos, 1925

travassosi (Gomes \& Motta, 1967) Baker, 1980

unguiculata (Rud., 1819) Miranda, 1924

Cosmocerca Diesing, 1861

rara Freitas \& Vicente, 1966

Dollfusnema Baker, 1981 amphisbaenia Baker, 1981

Kathlaniidae Yorke \& Maplestone, 1926

Cruzia Travassos, 1917 rudolphii Ruiz, 1947

Falcaustra Lane, 1915 mascula (Rud., 1819) Freitas \& Lent, 1941

belemensis Baker \& Bain, 1981

tikasinghi (Schoroeder, Schimidt \& Everard, 1977) Baker \& Bain, 1981

Kathlania Lane, 1914 leptura (Rud., 1819) Travassos, 1918

Oxyascaris Travassos, 1920

oxyascaris Travassos, 1920

Tonaudia Travassos, 1918

freitasi Vicente \& Santos, 1968 
Heterakoidea

Heterakidae Railliet \& Henry, 1914

Africana Travassos, 1920

chabaudi Baker, 1981

Bufonerakis Baker, 1980

rodriguesi (Vicente \& Gomes, 1971) Baker, 1980

Moaciria Freitas, 1956

alvarengai Freitas, 1956

Spinicauda Travassos, 1920

spinicauda (Olfers in Rud., 1819) Travassos, 1920

Strongyluris Mueller, 1894

oscari Travassos, 1920

Oxyuroidea

Oxyuridae Cobbold, 1864

Gynaecometra Araujo, 1978

bahiensis Araujo, 1978

Typhlonema Kreis, 1938

Pharyngodonidae Travassos, 1919

Alaeuris Thapar, 1919

caudatus (Lent \& Freitas, 1948) Peter \& Quentin, 1976

vogelsangi (Lent \& Freitas, 1948) Peter \& Quentin, 1976

Ozolaimus Dujardin, 1845

cirratus Linstow, 1906

megatyphlon (Rud., 1819) Dujardin, 1845

Pharyngodon Diesing, 1861

cesarpintoi Pereira, 1935

travassosi Pereira, 1935

Thelandros Wedl, 1862

alvarengai (Freitas, 1957) Peter \& Quentin, 1976

largitor (Alho \& Rodrigues, 1963) Peter \& Quentin, 1976

sceleratus Travassos, 1923

verrucosus (Freitas \& Dobbin Jr., 1959) Peter \& Quentin, 1976

Seuratoidea

Seuratidae Railliet, 1916

Skrjabinellazia Sypliaxov, 1930

galliardi Chabaud, 1973

intermedia (Freitas, 1941) Chabaud, 1973

Ascaridoidea

Anisakidae Skrjabin \& Karokhin, 1945

Contracaecum Railliet \& Henry, 1912

serpentis Araujo, 1970 
Sulcascaris Hartwich, 1957 sulcata (Rud., 1819) Hartwich, 1957

Terranova Leiper \& Atkinson, 1914 lanceolata (Molin, 1860) Sprent, 1979

Ascarididae Baird, 1853

Ascaridia Dujardin, 1845 flexuosa (Schneider, 1866) Railliet \& Henry, 1914

Angusticaecum Baylis, 1920 brevispiculum Chapin, 1925

Brevimulticaecum Mozgovoi in Skrjabin, Shikhobalova \& Mozgovoi, 1952 baylisi (Travassos, 1933) Sprent, 1979

gibsoni Sprent, 1979

pintoi Sprent, 1979

stekhoveni (Baylis, 1947) Sprent , 1979

Dujardinascaris Baylis, 1947 longispicula (Travassos, 1933) Baylis, 1947 paulista (Travassos, 1933) Baylis, 1947

Hexametra Travassos, 1920 boddaertii (Baird, 1860) Kreis, 1944

Ophidascaris Baylis, 1920

arndti Sprehn, 1929 cretinorum Freitas, 1968 obconica (Baird, 1860) Baylis, 1921

sicki Freitas, 1951

sprenti Araujo, 1969

travassosi Vaz, 1938 trichuriformis Vaz, 1935

Polydelphis Dujardin, 1845 quadrangularis (Schneider, 1866)

Travassosascaris Sprent, 1978 araujoi Sprent, 1978

Gnathostomatoidea

Gnathostomatidae Railliet , 1895

Ancyracanthus Diesing, 1839 pinnatifidus Diesing, 1839

Spiroxys Schneider, 1866

Camallanoidea figuereidoi Freitas \& Dobbin Jr., 1962

Camallanidae Railliet \& Henry, 1915

Camallanus Railliet \& Henry, 1915 amazonicus Ribeiro, 1940 
Serpinema Yeh, 1960

monospiculatus Freitas \& Dobbin Jr., 1962

maghati (Sprehn, 1932) Yeh, 1960

Physalopteroidea

Physalopteridae Leiper, 1908

Physaloptera Rud., 1819 liophis Vicente \& Santos, 1974

lutzi Cristofaro, Guimarães \& Rodrigues, 1976

monodens Molin, 1860

obtusissima Molin, 1860

phrynosoma Ortlepp, 1922

retusa Rud., 1819

Thubunaea Seurat, 1914

dactyluris Karve, 1938

Physalopterinae Rodrigues, 1970

Spiruroidea

Spiruridae

Spirurinae sp. Rodrigues, 1970

Diplotriaenoidea

Diplotriaenidae Anderson, 1958

Hastospiculum Skrjabin, 1923

digiticaudum Freitas, 1956

onchocercum Chitwood, 1932

Dracunculoidea

Micropleuridae Travassos, 1960

Micropleura Linstow, 1906

vazi Travassos, 1933

Filarioidea

Onchocercidae Leiper, 1911

Oswaldofilaria Travassos, 1933

azevedoi Bain, 1974

bacillaris (Molin, 1858) Travassos, 1933

belemensis Bain \& Sulahian, 1974

brevicaudata (Rhodain \& Vuylsteke, 1937) Freitas \& Lent, 1937

petersi Bain \& Sulahian, 1974

spinosa Bain \& Sulahian, 1974

Piratuba Lent \& Freitas, 1941

digiticauda Lent \& Freitas, 1941

carinii (Vaz \& Pereira, 1935) Caballero, 1954

lainsoni Bain, 1974

scaffi Bain, 1974 
shawi Bain, 1974

zeae Bain, 1974

\section{CATÁLOGO DOS NEMATÓIDES}

Os nematóides parasitos de répteis que foram referidos no Brasil pertecem a 17 superfamilias, 23 famílias, 55 gêneros e 121 espécies.

\section{Chave para identificação das superfamílias}

1. Fêmeas parasitas partenogenéticas. Geração parasitária alternando-se com a geração de vida livre $\ldots \ldots \ldots \ldots \ldots \ldots \ldots$ Rhabditoidea

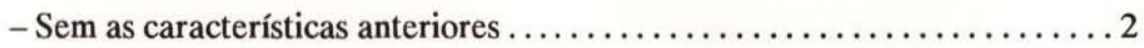

2. Esôfago constituído de um tubo estreito que se estende pelo centro de uma fileira de células na maior parte do seu comprimento...... Trichuroidea

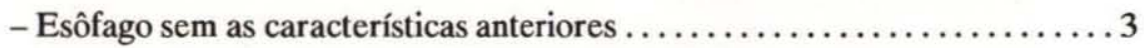

3. Machos com bolsa copuladora cuticular suportada por raios $\ldots \ldots \ldots \ldots 4$

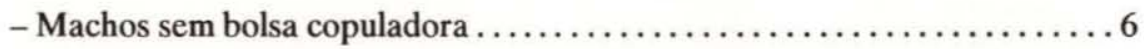

4. Corpo mais ou menos filiforme, com cápsula bucal pouco desenvolvida ou ausente $\ldots \ldots \ldots \ldots \ldots \ldots \ldots \ldots$ Trichostrongyloidea

- Corpo mais ou menos desenvolvido com cápsula bucal bem desenvolvida ... 5

5. Cápsula bucal grande e complexa, bivalvular ....... Diaphanocephaloidea

- Cápsula bucal contínua, de forma variável . . . . . . . . . . . Strongyloidea

6. Esôfago composto de corpus cilíndrico, diferenciado anteriormente em faringe, um ístmo subsférico ou alongado e bulbo com aparelho valvular e células glandulares uninucleadas .............. Cosmocercoidea

- Esôfago dilatado posteriormente em um bulbo contendo aparelho valvular e frequentemente separado do resto do esôfago por uma constricção .... Oxyuroidea

7. Machos com ventosa pré-anal circular de rebordo quitinoso ... Heterakoidea

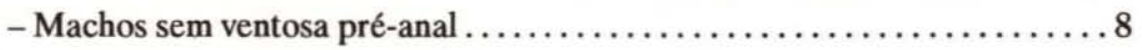

8. Esôfago curto, simples e cilíndrico ou curto e dividido em duas partes tendo ou não o mesmo diâmetro. Lábios ausentes ou reduzidos ....Seuratoidea

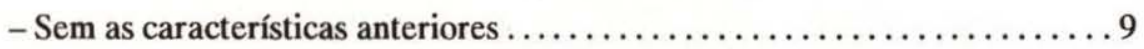

9. Boca cercada por 3 grandes lábios ou lobos, corpo relativamente robusto ... Ascaridoidea

- Boca com grandes lábios laterais trilobados cuja superfície interna possui 
fileira de dentes $\ldots \ldots \ldots \ldots \ldots \ldots \ldots \ldots \ldots$ Gnathostomatoidea

10. Cápsula bucal grande constituída de duas valvas laterais quitinizadas ..... . Camallanoidea

- Sem cápsula bucal ou cápsula bucal pouco desenvolvida

11. Boca com lábios laterais simples grandes e triangulares armados com um ou mais dentes ............................ Physalopteroidea

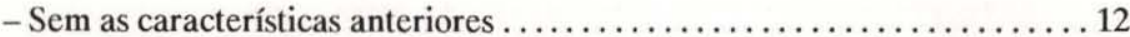

12. Nematóides grandes, geralmente com estruturas cuticulares cefálicas bem desenvolvidas em forma de tridentes . . . . . . . . . Diplotriaenoidea

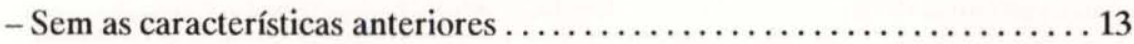

13. Fêmeas muito maiores que os machos, ânus e vulva atrofiados nas fêmeas

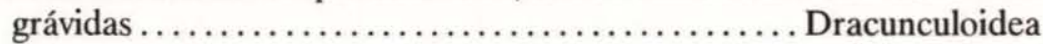

- Sem as características anteriores .......................... 14

14. Usualmente com dois lábios laterais, cavidade bucal geralmente presente, esôfago longo dividido em duas partes, a anterior mais curta e mais estreita e a posterior longa e larga ................. Spiruroidea

- Boca sem lábios, cavidade bucal ou vestibulo. Vulva na região anterior do corpo próximo ao esôfago. Fêmeas vivíparas ............. Filarioidea

\section{Rhabditoidea}

Nesta superfamília encontramos a família Rhabdiasidae Railliet, 1915 com os gêneros Rhabdias Stiles \& Hassal, 1905, e Acanthorabdias Pereira, 1927 e a família Strongyloididae com o gênero Strongyloides Grassi, 1879.

\section{Chave para identificação das famílias}

- Forma parasita com esôfago curto, com bulbo posterior, vulva perto do meio do corpo $\ldots \ldots \ldots \ldots \ldots \ldots \ldots \ldots \ldots \ldots \ldots \ldots \ldots \ldots \ldots$ Rhabdiasidae

- Forma parasita com esôfago longo sem bulbo posterior, vulva no terço posterior do corpo .......................... Strongyloididae

\section{Rhabdiasidae Railliet, 1915}

Formas parasitas com aspecto de fêmeas; apresentam esôfago curto com bulbo posterior; vulva no meio do corpo; partenogenética; formas de vida livre diferenciadas ou não em machos e fêmeas. Parasitos de anfíbios e répteis. 


\section{Chave para identificação dos gêneros}

- Boca rodeada por 6 lábios muito pequenos .................Rhabdias

- Boca cercada por sustentáculo quitinoso provido de oito formações cuticulares piramidais.................................Acanthorhabdias

\section{Rhabdias Stiles \& Hassal, 1905}

Geração parasitária com exemplares muito maiores que os de vida livre. Boca rodeada por seis lábios muito pequenos. Algumas vezes com asas laterais que são mais largas na parte anterior. Cápsula bucal em forma de taça. Esôfago pequeno, cilíndrico, terminando em uma dilatação posterior. Cauda cônica. Vulva próxima do meio do corpo. Didelfas, anfidelfas, ovíparas. Ovos de casca fina contendo uma mórula ou larva pouco desenvolvida. Geração de vida livre com sexos separados, com boca sem lábios, pequena cavidade bucal presente. Esôfago com dilatação pré-bulbar piriforme. Machos de vida livre com cauda cônica, pequeno espinho terminal e estreita asa caudal. Papilas caudais presentes. Espículos iguais, curtos e grossos. Fêmeas de vida livre com cauda cônica, vulva ligeiramente após a região mediana do corpo. Anfidelfas, com poucos ovos grandes. Embriôes desenvolvidos no útero. Parasitos do pulmão de répteis e anfíbios.

Espécie tipo: R. bufonis (Schrank, 1788) Stiles \& Hassal, 1905.

Espécies assinaladas no Brasil:

\section{R. labiata Pereira, 1927 (Tab. I, Figs 1-3)}

Hospedeiros e proveniências: Rhadinea merremii Wild, Paraná: Irati; Liophis miliaris (L.), Sẫo Paulo: Guarulhos.

Localização: pulmão.

Referência bibliográfica: 89 .

R. vellardi Pereira, 1927 (Tab. I, Figs 4-6)

Hospedeiros e proveniência: Philodrias schottii (Schlegel) (=Leimadophis poecilogynus schottii Hoge), Oxyrhopus trigeminus Dumeril, Bibron \& Dumeril, São Paulo.

Localização: pulmão.

Referência bibliográfica: 90 .

\section{Acanthorhabdias Pereira, 1927}

Boca delimitada por um sustentáculo quitinoso provido de oito formações cuticulares piramidais. Vestíbulo curto, amplo, com revestimento quitinoso. Esôfago como em Rhabdias. Vulva mediana; úteros divergentes, ocupando apenas uma quarta parte do comprimento total do corpo; ovários entrecruzando-se longamente. Machos desconhecidos. Parasitos de pulmão de ofídios. 
Tabela I. Rhabdias labiata, dados segundo Pereira, 1927 e R. vellardi, dados segundo Pereira, 1935.

\begin{tabular}{|c|c|c|c|c|c|c|}
\hline & \multicolumn{3}{|c|}{ R. labiata } & \multicolumn{3}{|c|}{ R. vellardi } \\
\hline & $\begin{array}{l}\text { Forma } \\
\text { Parasita }\end{array}$ & $\begin{array}{c}\text { Macho } \\
\text { (vida livre) }\end{array}$ & $\begin{array}{c}\text { Fêmea } \\
\text { (vida livre) }\end{array}$ & $\begin{array}{c}\text { Forma } \\
\text { parasita }\end{array}$ & $\begin{array}{c}\text { Macho } \\
\text { (vida livre) }\end{array}$ & $\begin{array}{c}\text { Fêmea } \\
\text { (vida livre) }\end{array}$ \\
\hline Comprimento & $2,2-2,4$ & $0,65-1$ & & $3,3-3$ & 0,72 & 1,04 \\
\hline Largura & $0,11-0,13$ & $0,035-0,055$ & & $0,12-0,2$ & 0,034 & 0,05 \\
\hline Cápsula bucal & & 0,010 & 0,010 & & 0,02 & 0.033 \\
\hline Lábios & 0,006 & & & & & \\
\hline Esôfago & $\begin{array}{r}0,25-0,26 x \\
0,046-0,047\end{array}$ & 0,115 & 0,125 & $0,26-0,27 \times 0,053$ & 0,15 & 0,15 \\
\hline Bulbo anterior & & 0,058 & 0,068 & & 0,085 & 0,092 \\
\hline Bulbo posterior & & $0,025 \times 0,020$ & 0,020 & & 0,02 & 0,025 \\
\hline Anel nervoso & $0,10-0,13$ & & & $0,11-0,15$ & $\begin{array}{c}\text { regiāo } \\
\text { interbulbar }\end{array}$ & $\begin{array}{c}\text { região } \\
\text { interbulbar }\end{array}$ \\
\hline $\begin{array}{l}\text { Aparelho genital: } \\
\text { extremidade anterior }\end{array}$ & 0,24 & & & & & \\
\hline $\begin{array}{l}\text { Aparelho genital: } \\
\text { extremidade posterior }\end{array}$ & $0,26-0,33$ & & & $0,61-0,67$ & & \\
\hline Vulva & $\begin{array}{l}\text { no meio do } \\
\text { corpo }\end{array}$ & & & $\begin{array}{l}\text { no meio do } \\
\text { corpo }\end{array}$ & & 0,525 \\
\hline Ânus & $0,15-0,19$ & 0,040 & 0,085 & $0,13-0,14$ & 0,050 & 0,080 \\
\hline Ovos & $\begin{array}{c}0,084-0,092 \times \\
0,053\end{array}$ & & $\begin{array}{c}0,050-0,055 \mathrm{x} \\
0,030\end{array}$ & $\begin{array}{c}0,069 \mathrm{x} \\
0,038-0,046\end{array}$ & & $0,081 \times 0,034$ \\
\hline Espiculos & & 0,035 & & & 0,035 & \\
\hline Gubernáculo & & & & & 0,012 & \\
\hline Papilas caudais & & 4 pares pré e & 1 par pós-anal & & & \\
\hline
\end{tabular}

Espécie tipo: A. acanthorhabdias Pereira, 1927.

Espécie assinalada no Brasil:

\section{A. acanthorhabdias Pereira, 1927 (Tab. II; Figs 7-8)}

Hospedeiros e proveniências: Liophis miliaris (L.), Rio de Janeiro: Maricá; Rhadinea merremii Wild, Paraná: Irati.

Localização: pulmão.

Referências bibliográficas: 48,49 .

\section{Strongyloididae Chitwood \& McIntosh, 1934}

Formas parasitas com aspectos de fêmeas. Apesentam esôfago longo, sem bulbo posterior. Vulva no terço posterior do corpo. Formas de vida livre diferenciadas ou não em machos e fêmeas. Parasitos de anfíbios, répteis, aves e mamíferos.

\section{Strongyloides Grassi, 1879}

Geração parasitária com cápsula bucal presente ou ausente. Esôfago longo e estreito, algumas vezes alargado posteriormente sem bulbo cauda curta. 
Tab. II. Acanthorhabdias acanthorhabdias, dados segundo Fernandes \& Souza, 1974 e Strongyloides cruzi, dados segundo Rodrigues, 1968.

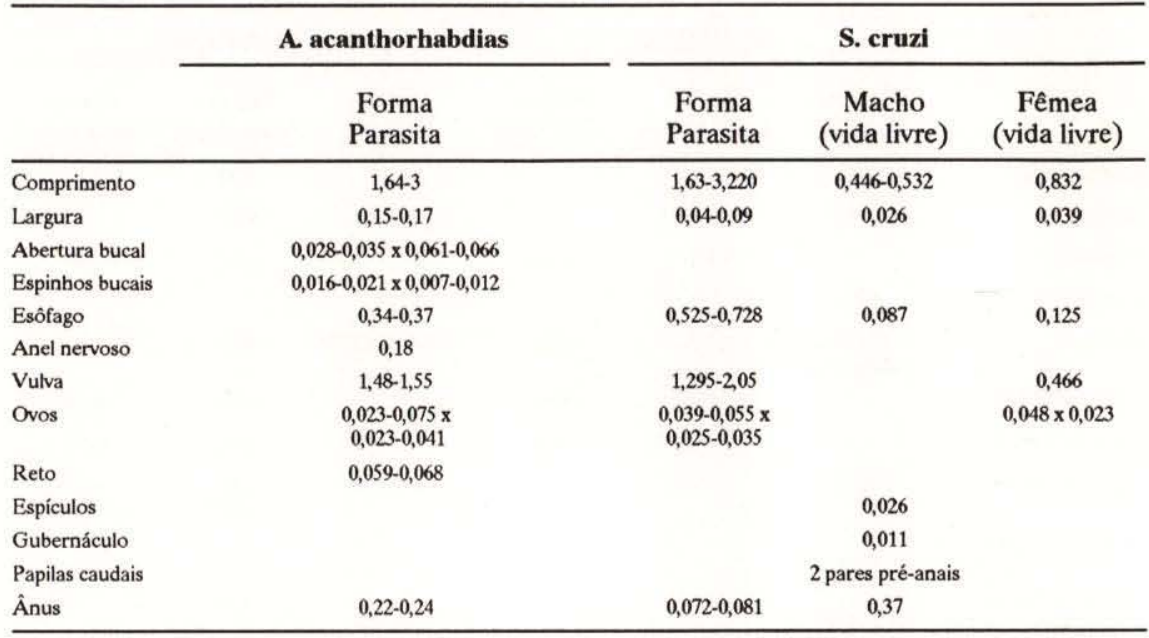

Vulva no terço posterior do corpo. Anfidelfas, ovíparas. Ovos embrionados ou contendo larvas. Geração de vida livre com cavidade bucal curta, mais ou menos infundibular, com extremidade posterior estendendo-se um pouco para o interior do esôfago. Esôfago consistindo de corpus, ístimo e bulbo com válvulas. Machos de vida livre com cauda terminando em ponta, sem asas caudais, com poucas papilas subventrais, pré-anais e pós-anais. Espículos iguais, gubernáculo presente. Fêmeas de vida livre com cauda terminando em ponta afilada. Vulva posterior à metade do corpo. Anfidelfas, ovíparas. Machos parasitos desconhecidos.

Espécie tipo: S. stercoralis (Bavay, 1876) Stiles \& Hassall, 1902.

Espécies assinaladas no Brasil:

S. cruzi Rodrigues, 1968 (Tab. II, Figs 9-12)

Hospedeiro e proveniência: Hemidactylus mabouia (M. de J.), Rio de Janeiro: Rio de Janeiro.

Localização: intestino delgado.

Referências bibliográficas: 101, 102.

S. ophidiae Pereira, 1929 (Tab. III; fig. 13)

Hospedeiro e proveniência: Dryadophis bifossatus (Raddi) (=Mastigodryas bifossatus (Raddi) Peters \& Orejas-Miranda, São Paulo: São Paulo.

Localização: intestino.

Referência bibliográfica: 91 . 


\section{Trichuroidea}

Esta superfamília encerra a família Trichuridae Railliet, 1916 com os gêneros Capillaria Zeder, 1800 e Pseudocapillaria Freitas, 1959.

\section{Trichuridae Railliet, 1915}

Nematóides de tamanho médio ou grande. A parte anterior pode ser mais longa ou mais curta que a posterior, a qual pode ser muito mais grossa ou ligeiramente mais grossa que a anterior. Boca simples, lábios pouco evidentes ou ausentes. Machos com um espículo ou raramente somente com a bainha espicular. Fêmea com a vulva perto do término do esôfago. Ovíparas. Ovos com casca grossa, em forma de barril, com opérculo em cada polo. Parasitos de vertebrados.

\section{Chave para identificação dos gêneros}

- Bainha espicular espinhosa e bolsa membranosa presente ....... Capillaria - Bainha espicular não espinhosa e bolsa membranosa ausente ou reduzida não excedendo posteriormente os lobos caudais subventrais ............ .Pseudocapillaria

\section{Capillaria Zeder, 1800}

Extremidade anterior com região cefálica não diferenciada. Corpo com a região anterior geralmente menor que a posterior. Fêmeas com muitos ovos inclusos em cápsulas. Machos sem asas caudais, com bolsa e espículo com bainha espicular espinhosa. Parasitos de vertebrados.

Espécie tipo: C. anatis (Schrank, 1790) Travassos, 1915.

Espécies assinaladas no Brasil:

C. crotali (Rud., 1819) Travassos, 1915

Sinonímia: Trichosoma crotali Rud., 1819.

Hospedeiro e proveniência: Crotalus durissus terrificus (Laur.), Brasil.

Localização: intestino.

Referência bibliográfica: 122 .

C. freitaslenti Araujo \& Gandra, 1941 (Tab. III; Figs 14-16)

Sinonímia: Echinocoleus freitaslenti Lopez-Neyra, 1946; Eucoleus freitaslenti Skrjabin \& Shikhobalova, 1954.

Hospedeiro e proveniência: Tropidurus torquatus (Wied.), Brasil.

Localização: intestino.

Referência bibliográfica: 26 . 
Tabela III. Strongyloides ophidiae, dados segundo Pereira, 1935; Capillaria freitaslenti, dados segundo Araujo \& Gandra, 1941 e Pseudocapillaria (P.) amarali, dados segundo Freitas \& Lent, 1934.

\begin{tabular}{|c|c|c|c|c|c|}
\hline & \multirow{2}{*}{$\begin{array}{c}\text { S. ophidiae } \\
\begin{array}{c}\text { Forma } \\
\text { parasita }\end{array}\end{array}$} & \multicolumn{2}{|c|}{ C. freitaslenti } & \multicolumn{2}{|c|}{ P. (P.) amarali } \\
\hline & & Macho & Fêmea & Macho & Fêmea \\
\hline Comprimento & $27-3,6$ & $6,6-9,2$ & $10,3-14,0$ & $4,8-6,7$ & $6,3-9,0$ \\
\hline Largura & 0,04 & 0,032 & 0,048 & $0,028-0,093$ & $0,048-0,053$ \\
\hline Esôfago total & $1,05-1,13$ & $2,4-4,9$ & $2,4-4,9$ & $2,8-3,6$ & $2,8-3,6$ \\
\hline Porçâo muscular do esôfago & & & & $0,20-0,34$ & $0,20-0,34$ \\
\hline Vulva & $0,8-1,2$ & & & & \\
\hline $\begin{array}{l}\text { Ramo anterior do aparelho } \\
\text { genital-esôfago }\end{array}$ & 0,3 & & & & \\
\hline $\begin{array}{l}\text { Ramo posterior do aparelho genital - } \\
\text { extremidade posterior do corpo }\end{array}$ & $0,06-0,1$ & & & & \\
\hline Ảnus & $0,07-0,1$ & & & & \\
\hline Ovos & $0,038 \times 0,015-0,023$ & & $0,053 \times 0,024$ & & $\underset{0,022-0,024}{0,054-0,057 x}$ \\
\hline Anel nervoso & & 0,134 & 0,134 & $0,05-0,18$ & $0,05-0,18$ \\
\hline Vulva-terminaçâo do esôfago & & & $0,124-0,172$ & & $0,016-0,027$ \\
\hline Vagina & & & 0,331 & & $0,08-0,11$ \\
\hline Relaçảo porçāo anterior-posterior & & $1: 1,3$ & $1: 1,2$ & $1: 2$ & 1:3 \\
\hline Bainha espicular & & 0,008 & & 0,016 & \\
\hline Bolsa (largura) & & 0,041 & & & \\
\hline Espiculo (comprimento) & & & & $0,40-0,48$ & \\
\hline Espiculo (largura) & & & & 0,008 & \\
\hline Papilas caudais & & & & 2 & \\
\hline
\end{tabular}

\section{Pseudocapillaria Freitas, 1959}

Extremidade anterior com região cefálica não diferenciada; corpo com a porção anterior maior ou menor que a região posterior; fêmeas com muitos ovos não inclusos em cápsulas; machos sem asas caudais laterais, bolsa caudal e espículo com bainha espicular nâo espinhosa.

O gênero foi subdividido por MORAVEC (1982) em Pseudocapillaria (Pseudocapillaria) Freitas, 1959 e Pseudocapillaria (Ichthyocapillaria) Moravec, 1982.

\section{Pseudocapillaria (Pseudocapillaria) Freitas, 1959}

Membrana cuticular dorsal da cauda dos machos ausente.

Espécie tipo: P. (P.) catostomi (Pearse, 1924) Moravec, 1982.

Espécies assinaladas no Brasil:

P. (P.) amarali (Freitas \& Lent, 1934) Moravec, 1982 (Tab. III, Figs 17-19)

Sinonímia: Capillaria amarali Freitas \& Lent, 1934. Janeiro.

Hospedeiro e proveniência: Liophis miliaris (L.), Rio de Janeiro: Rio de 
Localização: intestino delgado.

Referências bibliográficas: 66,86 .

P. (P.) cesarpintoi (Freitas \& Lent, 1934) Moravec, 1982, (Tab. IV; Figs 20-22)

Sinonímia: Capillaria cesarpintoi Freitas \& Lent, 1934.

Hospedeiro e proveniência: Leimadophis poecilogyrus (Wied.), Rio de Janeiro: Rio de Janeiro.

Localização: intestino.

Referências bibliográficas: 65,86 .

\section{Pseudocapillaria (Ichthyocapillaria) Moravec, 1982}

Membrana cuticular dorsal presente conectando os lobos sub-ventrais da cauda dos machos.

Espécie tipo: P. (I.) salvelini (Polysasky, 1952) Moravec, 1982.

Espécie assinalada no Brasil:

P. (I.) murinae (Travassos, 1914) Moravec. 1982 (Tab. IV, Figs 23-25)

Sinonímia: Capillaria murinae Travassos, 1914. Grosso.

Hospedeiro e proveniência: Eunectes murinus murinus (L.), Mato

Localização: estômago.

Referências bibliográficas: 86, 122 .

\section{Diaphanocephaloidea}

A superfamília encerra uma família Diaphanocephalidae Travassos, 1920 com dois gêneros Diaphanocephalus Diesing, 1851 e Kalicephalus Molin, 1861 com espécies parasitas de répteis.

Diaphanocephalidae Travassos, 1920

Cápsula bucal bivalvular e fortemente comprimida lateralmente. Esôfago fortemente muscular apresentado a luz tri-radiada e bordas espessas. Macho apresentando bolsa copuladora com raios bursais contíguos. Espículos longos, simples. Fêmea com aparelho reprodutor duplo. Vulva perto da extremidade posterior. Parasitos de estômago e intestino de cobras.

\section{Chave para identificação dos gêneros}

- Com duas margens quitinizadas nas paredes laterais da cápsula e com delicado processo quitinoso projetando-se para o interior da cápsula a partir o coxim cuticular ventral .................. Diaphanocephalus

- Com somente uma margem quitinizada na parede lateral da cápsula e sem o delicado processo quitinoso projetando-se para o interior da cápsula . . Kalicephalus 
Tabela IV. Pseudocapillaria (P.) cesarpintoi, P. (I.) murinae, dados segundo Freitas \& Lent, 1934 e 1935 e Oswaldocruzia brasiliensis, dados segundo Lent \& Freitas, 1935.

\begin{tabular}{|c|c|c|c|c|c|c|}
\hline & \multicolumn{2}{|c|}{ P. (P.) cesarpintoi } & \multicolumn{2}{|c|}{ P. (I.) murinae } & \multicolumn{2}{|c|}{ O. brasiliensis } \\
\hline & Macho & Fêmea & Macho & Fêmea & Macho & Fêmea \\
\hline Comprimento & $7,60-9,90$ & $12,5-14,50$ & $14,00-15,00$ & $18,00-23,00$ & $4,34-4,87$ & $6,97-7,47$ \\
\hline Largura & 0,056 & 0,064 & $0,031-0,071$ & $0,035-0,078$ & $0,100-0,120$ & $0,120-0,160$ \\
\hline $\begin{array}{l}\text { Dilataçảo cuticular } \\
\text { cefálica }\end{array}$ & & & & & $0,064-0,080$ & $0,064-0,080$ \\
\hline Papilas cervicais & & & & & 0,336 & 0,336 \\
\hline Esôfago total & $3,6-4,5$ & & $5,5-7,5$ & $5,5-7,5$ & $0,384-0,440$ & $0,408-0,448$ \\
\hline $\begin{array}{l}\text { Porçáo muscular do } \\
\text { esôfago }\end{array}$ & 0,312 & & 0,486 & 0,486 & & \\
\hline Vulva & & 0,016 & & 0,073 & & $2,367-2,682$ \\
\hline Vagina & & $0,120-0,128$ & & $0,18-0,24$ & & \\
\hline Ovos & & $\begin{array}{c}0,040-0,048 \times \\
0,024\end{array}$ & & $0,056 \times 0,032$ & & $0,067 \times 0,040$ \\
\hline $\begin{array}{l}\text { Relaçāo entre porçōes } \\
\text { anterior e posterior }\end{array}$ & $1: 2,3$ & $1: 3$ & $1: 1,7$ & $1: 1,4: 1,2$ & & \\
\hline $\begin{array}{l}\text { Espiculo } \\
\text { (comprim nto) }\end{array}$ & $0,56-0,57$ & & 1,20 & & & \\
\hline Espiculo argura) & 0,008 & & 0,008 & & & \\
\hline Bainha espicular & $0,59 \times 0,012$ & & 0,024 & & & \\
\hline Anel nervoso & 0,170 & 0,170 & & & $0,200-0,280$ & $0,280-0,320$ \\
\hline Ápice caudal & & & & & & 0,013-0,016 \\
\hline Ânus & & & & & & $0,136-0,144$ \\
\hline Ovejetor & & & & & & $0,320-0,336$ \\
\hline Papilas caudais & 2 & & & & & \\
\hline
\end{tabular}

\section{Diaphanocephalus Diesing, 1851}

Extremidade anterior obliquamente truncada. Boca abrindo-se livremente na face dorsal, mostrando sinais de diferenciação em forma de coroa foliácea. Cápsula bucal comprimida lateralmente consistindo de duas valvas com base muito espessas. Valvas da cápsula bucal suportadas por duas fileiras internas transversais e quitinosas das quais a anterior é paralela à margem oral. A posterior é arcada quando vista lateralmente, com suas terminações apoiadas numa espessa proteção cuticular situada entre as junções das valvas bucais. Do coxim cuticular ventral partem dois processos cuticulares membranosos que se projetam dentro da cavidade bucal. Na superfície externa de cada valva existem três faixas (estrias) parenquimatosas que se originam do colar basal. O canal da glândula esofagiana dorsal projeta-se dentro da cavidade bucal. Machos com bolsa curta, campanulada, com ligeira indicação de um lobo dorsal; raio ventral fendido, externo-lateral e outros laterais originando-se de um tronco comum; médio lateral e pós-lateral separados; externo-dorsal originando-se no ponto comum do tronco com o dorsal; dorsal curto, grosso, quase que imediatamente dividindo-se em dois ramos que por sua vez se subdividem imediatamente, sendo sua subdivisão interna bífida na extremidade. Cone genital muito longo, protuso além da bolsa. A abertura anogenital está situada na superfície ventral a alguma distância da ponta da cauda. Espículos desiguais; gubernáculo pre- 
Tabela V. Oswaldocruzia mazzai, dados segundo Vicente, 1977; O. subauricularis, dados segundo Freitas, 1955 e Diaphanocephalus diesingi, dados segundo Freitas \& Lent, 1938.

\begin{tabular}{|c|c|c|c|c|}
\hline & \multirow{2}{*}{ 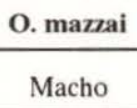 } & \multirow{2}{*}{$\frac{\text { O. subauricularis }}{\text { Macho }}$} & \multicolumn{2}{|c|}{ D. diesingi } \\
\hline & & & Macho & Fêmea \\
\hline Comprimento & $6,50-7,14$ & & $2,00-2,21$ & $1,84-2,57$ \\
\hline Largura & $0,14-0,15$ & & $0,237-0,342$ & $0,276-0,407$ \\
\hline Cápsula bucal & & & $\begin{array}{c}0,144-0,168 x \\
0,160-0,198\end{array}$ & $\begin{array}{c}0,160-0,216 x \\
0,168-0,224\end{array}$ \\
\hline Poro excretor & 0,40 & & $0,232-0,256$ & $0,216-0,256$ \\
\hline Anel nervoso & $0,18-0,19$ & & $0,192-0,240$ & $0,224-0,248$ \\
\hline Esôfago & $0,43-0,44$ & & $0,208-0,296$ & $0,248-0,280$ \\
\hline Espiculos & 0.17 & $0,24-0.25$ & & \\
\hline Bolsa copuladora & & $0.45-0.53$ & & \\
\hline $\begin{array}{l}\text { Distảncia entre a origem dos raios dor- } \\
\text { sais externos e a divisáo do raio dorsal }\end{array}$ & & 0,063 & & \\
\hline Vulva & & & & $0,36-0,64$ \\
\hline Ovejetor & & & & $0,288-0,360$ \\
\hline Ovos & & & & $\begin{array}{c}0,059-0,067 \times \\
0,032-0,038\end{array}$ \\
\hline Vagina & & & & $0,144-0,192$ \\
\hline Ânus & & & & $0,072-0,104$ \\
\hline Espiculo maior & & & $0,336-0,408$ & \\
\hline Espículo menor & & & $0,224-0,288$ & \\
\hline Relaçâo espicular & & & $1: 0,6-1: 0,7$ & \\
\hline Gubernáculo & & & $0,136-0,152$ & \\
\hline
\end{tabular}

sente. Gibosidade anterior à bolsa presente. Fêmeas de cauda curta e afilada; vulva no quarto posterior do corpo. Ovíparas. Parasitos intestinais de lagartos.

Espécie tipo D. galeatus (Rud., 1819) Railliet \& Henry, 1909.

Espécies assinaladas no Brasil:

D. diesingi Freitas \& Lent, 1938 (Tab. V; Figs 32-34) lém.

Hospedeiro e proveniência: Tupinambis nigropunctatus Spix, Pará: Be-

Localização: intestino delgado.

Referência bibliográfica: 69 .

D. galeatus (Rud., 1819) Railliet \& Henry, 1909 (Tab. VI; Figs 35-37)

Sinonímia: Strongylus galeatus Rud., 1819; Sclerostomum galeatum Dujardin, 1845; Diaphanocephalus strongyloides Diesing, 1851.

Hospedeiro e proveniência: Tupinambis teguixin (L.), Mato Grosso do Sul: Salobra.

Localização: intestino grosso.

Referência bibliográfica: 69 . 
D. jacunuxi Alho, 1965 (Tab. VI; 38-39)

Hospedeiro e proveniência: Dracaena guianensis Daudin, Pará: Ilha das Onças, Baia de Guajará.

Localização: intestino delgado.

Referência bibliográfica: 4 .

Tabela VI. Diaphanocephalus galeatus, dados segundo Freitas, 1938; D. jacuruxi, dados segundo Alho, 1965 e Kalicephalus appendiculatus, dados segundo Schad, 1962.

\begin{tabular}{|c|c|c|c|c|c|c|}
\hline & \multicolumn{2}{|c|}{ D. galeatus } & \multicolumn{2}{|c|}{ D. jacuruxi } & \multicolumn{2}{|c|}{ K. appendiculatus } \\
\hline & Macho & Fêmea & Macho & Fêmea & Macho & Fêmea \\
\hline Comprimento & $2,05-4,53$ & $2,38-5,92$ & $3,56-4,48$ & $4,84-5,91$ & $3,57-7,27$ & $4,76-8,88$ \\
\hline Largura & $0,368-0,421$ & $0,421-0,552$ & $0,19-0,26$ & $0,21-0,29$ & $0,26-0,40$ & $0,26-0,48$ \\
\hline Diâmetro da cabeça & & & & & $0,20-0,27$ & $0,22-0,31$ \\
\hline Papila cervical & & & & & $0,57-0,62$ & $0,63-0,85$ \\
\hline Cápsula bucal & $\begin{array}{c}0,216-0,280 \times x \\
0,240-0,320\end{array}$ & $\begin{array}{c}0,280-0,320 \times x \\
0,320-0,336\end{array}$ & $\begin{array}{c}0,16-0,19 \mathrm{x} \\
0,26-0,31\end{array}$ & $\begin{array}{c}0,24-0,25 \times \\
0,26-0,27\end{array}$ & $0,15-0,24$ & $0,19-0,26$ \\
\hline Eôfago & $\begin{array}{c}0,336-0,400 \times x \\
0,160-0,224\end{array}$ & $\begin{array}{c}0,368-0,400 \times x \\
0,216-0,240\end{array}$ & $\begin{array}{c}0,33-0,36 x \\
0,19-0,20\end{array}$ & $\begin{array}{c}0,38-0,40 \times x \\
0,17-0,20\end{array}$ & $0,36-0,41$ & $0,37-0,48$ \\
\hline Anel nervoso & $0,320-0,400$ & $0,344-0,400$ & $0,23-0,25$ & $0,26-0,30$ & $0,25-0,34$ & $0,26-0,34$ \\
\hline Poro excretor & $0,344-0,408$ & $0,368-0,416$ & & & $0,40-0,76$ & $0,43-0,84$ \\
\hline Vulva & & $0,520-0,872$ & & $0,78-0,94$ & & $3,8-6,4: 1$ \\
\hline Ovejetor & & $0,320-0,352$ & & $0,16-0,19$ & & \\
\hline Ovos & & $\begin{array}{c}0,065-0,073 \times \\
0,039-0,049\end{array}$ & & $\begin{array}{c}0,068-0,079 \times \\
0,036-0,046\end{array}$ & & \\
\hline Ânus & & $0,080-0,120$ & & $0,09-0,11$ & & $0,05-0,15$ \\
\hline Espiculo maior & $0,512-0,624$ & $0,910-0,990$ & & & & \\
\hline Espiculo menor & $0,336-0,432$ & $0,330-0,448$ & & & & \\
\hline Relaçâo espicular & $1: 0,65-1: 0,70$ & & & & & \\
\hline Gubernáculo & $0,168-0,232$ & $0,356-0,495$ & & & & \\
\hline Cone genital & 0,25 & & & & & \\
\hline Espiculos & & & & & $0,31-0,39$ & \\
\hline
\end{tabular}

\section{Kalicephalus Molin, 1861}

Cabeça rudimentar, com coroa foliácea presente ou ausente. Valvas bucais suportadas por uma única elevação interna transversal quitinosa em forma de V dorsal ou ventral. Ausência de processos quitinosos se projetando dentro da cavidade bucal. Luz do esôfago podendo conter três dentes. Machos sem gibosidade anterior à bolsa. Bolsa definitivamente trilobada; lobo dorsal se projetando por trás dos lobos laterais; raio interno originando-se bem no início do tronco comum; dorsal bifurcando-se distalmente em três processos digitiformes de diferentes tamanhos; cone genital geralmente longo. Espículos iguais, alados; gubernáculo e telamon presentes. Fêmeas com extremidade posterior longa e cônica. Vulva na porção posterior do corpo; ramos uterinos opostos ou parelelos. Ovíparas. Parasitos do aparelho digestivo de lagartos e cobras.

Espécie tipo: K. mucronatus Molin, 1861.

Espécies assinaladas no Brasil: 


\section{K. appendiculatus Molin, 1861 (Tab. VI; Figs 40-43)}

Sinonímia: Sclerostum appendiculatus Stossich, 1899; Diaphanocephalus appendiculatus Railliet \& Henry, 1909.

Hospedeiros e proveniência: Xenodon merremii Wagl., Xenodon severus (L.), Xenodon coerulus, Thalerophis ahaetulla, Spilotes pullatus pullatus (L.), Spilotes sp., Dryadophis bifossatus (Stuart) (=Mastigodryas bifossatus (Raddi), Dendrophidion bivittatus (Dumeril, Bibron \& Dumeril) Liophis miliaris (L.), Leimadophis reginae (L.), Clelia clelia (Daudin), Duberria cinerascens, Drymarchon corais corais (Boie), Drymarchon corais couperi (Holbrook), Leptophis sp., Bothrops jararacussu Lacerda, Coluber sp.; Brasil.

Localização: intestino.

Referência bibliográfica: 109.

K. costatus costatus (Rud., 1819) Yorke \& Maplestone, 1926 (Tab. VII, Figs 44-45)

Sinonímia: Strongylus costatus (Rud., 1819; Sclerostomum costatum Dujardin, 1845; Diaphanocephalus costatus Diesing, 1851; Kalicephalus strumosus Molin, 1861; Kalicephalus mucronatus Molin, 1861; Sclerostomum kalicephalum Stossich, 1899; Diaphanocephalus mucronatus Railliet \& Henry, 1909; Kalicephalus costatus Yorke \& Maplestone, 1926; Kalicephalus philodryadus Ortlepp, 1923.

Hospedeiros e proveniências: Chironius carinatus (L.), Chironius sp., Philodryas schottii (Schlegel) (=Leimadophis poecilogirus schottii (Hoge), Rio de Janeiro: Angra dos Reis; Crotalus durissus L., Minas Gerais: Belo Horizonte; Erythrolamprus venustissimus (Wied), Dryadophis bifossatus Stuart (=Mastigodryas bifossatus (Raddi)), Rio de Janeiro: Rio de Janeiro e Maricá, e Região Centro-Sul brasileira; Phylodryas serra (Schlegel), Espírito Santo: Linhares; Bothrops jararaca (Wied), São Paulo: Iguape, Espírito Santo: Castelo; Lystrophis semicinctus (D. \& B.), Mato Grosso: Taunay; Bothrops alternatus Dumeril, Bibron \& Dumeril, B. cotiara (Gomes), B. jararacussu Lacerda, B. pradoi (Hoge), Crotalus durissus terrificus (Laurenti), Epicrates cenchria crassus (Cope), Philodryas patagoniensis (Girard), Simophis rhinostoma (Schlegel), Wagleropsis merremii (Wagler) (=Xenodon merremii (Wagler), Xenodon neuwiedii (Gunther), X. guentheri Boulenger, Região Centro-Sul brasileira; Eudryas bifossatus (Raddi) (=Mastigodryas bifossatus (Raddi), Coluber sp., Brasil.

Localização: intestino.

Referências bibliográficas: 46, 106, 109.

K. inermis inermis Molin, 1861 (Tab. VII; Figs 47-49)

Sinonímia: Kalicephalus inermis Molin, 1861; Stronglylus costatus Schneider, 1866; Sclerostomum inerme Stossich, 1899; Diaphanocephalus inermis Railliet \& Henry, 1909; Diaphanocephalus bothropis Railliet \& Henry, 1909.

Hospedeiros e proveniências: Bothrops jararacussu Lacerda, Rio de 
Janeiro: Angra dos Reis, Região Centro-Sul brasileira; $B$. jararaca (Wied), Espírito Santo: Castelo, São Paulo: Iguape; B atrox (L.), Rio de Janeiro: Rio de Janeiro; B. alternatus Dumeril, Bibron \& Dumeril, B. cotiara (Gomes), B. pradoi (Hoge), Crotalus durissus terrificus (Laurenti), Epicrates cenchria crassus Cope, Liophis miliaris (L.), Philodryas patagoniensis (Girard), Simophis rhinostoma (Schlegel), Região Centro-Sul brasileira.

Localização: intestino.

Referências bibliográficas: 49, 109.

Tabela VII. Kalicephalus costatus costatus; $K$. inermis inermis e K. rectiphilus neorectiphilus, dados segundo Schad, 1962.

\begin{tabular}{|c|c|c|c|c|c|c|}
\hline & \multicolumn{2}{|c|}{$\begin{array}{l}\text { K. costatus } \\
\text { costatus }\end{array}$} & \multicolumn{2}{|c|}{$\begin{array}{l}\text { K. inermis } \\
\text { inermis }\end{array}$} & \multicolumn{2}{|c|}{$\begin{array}{l}\text { K. rectiphilus } \\
\text { neorectiphilus }\end{array}$} \\
\hline & Macho & Fêmea & Macho & Fêmea & Macho & Fêmea \\
\hline Comprimento & $4,88-10,38$ & $5,40-18,25$ & $7,99-12,15$ & $9,86-15,67$ & $7,74-11,03$ & $5,74-17,27$ \\
\hline Largura & $0,28-0,52$ & $0,29-0,61$ & $0,37-0,60$ & $0,53-0,82$ & $0,34-0,39$ & $0,20-0,48$ \\
\hline Diàmetro da cabeça & $0,19-0,31$ & $0,20-0,38$ & $0,24-0,30$ & $0,29-0,36$ & $0,18-0,21$ & $0,14-0,25$ \\
\hline Cápsula bucal & $0,14-0,18$ & $0,13-0,24$ & $0,15-0,18$ & $0,18-0,21$ & $0,11-0,16$ & $0,11-0,18$ \\
\hline Anel nervoso & $0,21-0,31$ & $0,20-0,40$ & $0,34-0,40$ & $0,39-0,45$ & $0,23-0,26$ & $0,20-0,28$ \\
\hline Poro excretor & $0,27-0,60$ & $0,34-0,68$ & $0,43-0,61$ & $0,49-0,67$ & $0,41-0,42$ & $0,32-0,44$ \\
\hline Papila cervical & $0,46-0,61$ & $0,39-0,79$ & & & $0,46-0,47$ & $0,43-0,48$ \\
\hline Eôfago & $0,30-0,43$ & $0,32-0,48$ & $0,49-0,51$ & $0,58-0,73$ & $0,31-0,34$ & $0,23-0,38$ \\
\hline Vulva & & $4,8-11,7: 1$ & & $1,6-2,2: 1$ & & $1,3-1,4: 1$ \\
\hline Espiculos & $0,34-0,70$ & $0,68-1,00$ & & & $0,42-0,44$ & \\
\hline Ȧnus & & $0,08-0,25$ & & $0,24-0,43$ & & $0,10-0,25$ \\
\hline
\end{tabular}

K. rectiphilus neorectiphilus Schad, 1962 (Tab. VII; Figs 50-52)

Hospedeiros e proveniências: Chironius carinatus (L.), Dryadophis bifossatus Stuart (=Mastigodryas bifossatus (Raddi), Rio de Janeiro: Angra dos Reis.

Localização: intestino.

Referência bibliográfica: 109 .

K. subulatus Molin, 1861 (Tab. VIII; Figs 53-55)

Sinonímia: Ankilostoma boae Blanchard, 1866; Ankilostomum boae Linstow, 1889; Sclerostomum subulatus Stossich, 1899; Uncinaria boae Stossich, 1899; Diaphanocephalus boae Railliet \& Henry, 1909; Strongylus boae MacCallum, 1921; Kalicephalus boae Yorke \& Maplestone, 1926; Kalicephalus chitwoodi Caballero, 1954.

Hospedeiros e proveniência: Epicrates cenchria cenchria (L.), Acre: Vale do Guaporé, Pará: Marabá; Boa constrictor L., Pará: Marabá, Amazonas: Manaus, Mato Grosso; Corallus caninus (L.), Pará: Marabá; Bothrops jararaca (Wied), Rio de Janeiro: Rio de Janeiro; Constrictor constrictor (L.) (=Boa constrictor L.), Mato Grosso, Rio de Janeiro: Zoológico do Rio de Janeiro 
(Brasil?).

Localização: intestino.

Referências bibliográficas: 49, 109.

Kalicephalus sp. Travassos, Freitas \& Mendonça, 1964

Hospedeiro e proveniência: Tupinambis teguixin (L.), Espírito Santo: Sooretama.

Localização: intestino.

Referência bibliográfica: 142 .

Tabela VIII. Kalicephalus subulatus, dados segundo Schad, 1962; Sauricola sauricola; Chapiniella variabilis, dados segundo Chapin, 1925.

\begin{tabular}{|c|c|c|c|c|c|c|}
\hline & \multicolumn{2}{|c|}{ K. subulatus } & \multicolumn{2}{|c|}{ S. sauricola } & \multicolumn{2}{|c|}{ C. variabilis } \\
\hline & Macho & Fêmea & Macho & Fêmea & Macho & Fêmea \\
\hline Comprimento & $5,62-8,31$ & $6,10-10,47$ & 10,00 & 10,00 & 8.00 & 8,00 \\
\hline Largura & $0,20-0,39$ & $0,27-0,50$ & & & & \\
\hline $\begin{array}{l}\text { Diàmetro da } \\
\text { cabeça }\end{array}$ & $0,14-0,27$ & $0.17-0,30$ & & & & \\
\hline Cápsula bucal & $0,11-0,19$ & $0,11-0,22$ & 0.1 & 0.1 & 0,010 & 0.010 \\
\hline Anel nervoso & $0,20-0,31$ & $0,23-0,38$ & 0.18 & 0,18 & & \\
\hline Poro excretor & $0,31-0,51$ & $0,40-0,53$ & & & & \\
\hline Papila cervical & $0,41-0,52$ & $0,45-0,59$ & & & & \\
\hline Esỏfago & $0,34-0,42$ & $0.35-0.49$ & 0,30 & 0,30 & 0,37 & 0,37 \\
\hline Vulva & & $1,7-2,0: 1$ & & 0.14 & & \\
\hline Ảnus & & $0,20-0.39$ & & & & 0,086 \\
\hline Espiculos & $0,51-0,65$ & & 2,36 & & 1,54 & \\
\hline Gubernáculo & & & 0,068 & & & \\
\hline Vagina & & & & 1,5 & & 0.18 \\
\hline Ovos & & & & $0.128 \times 0.057$ & & \\
\hline Vulva-annus & & & & & & 0,032 \\
\hline
\end{tabular}

\section{Trichostrongyloidea}

Esta superfamília é representada por uma única família Molineidae Durette-Desset \& Chabaud, 1977 e um único gênero Oswaldocruzia Travassos, 1917.

\section{Molineidae Durette-Desset \& Chabaud, 1977}

Corpo mais ou menos filiforme. Extremidade anterior sem anel bucal; dilatação cuticular cefálica em geral presente. Macho com bolsa copuladora bem desenvolvida, sem raio extradorsal. Espículos curtos e robustos, dotados de protuberâncias. Fêmea com vulva na parte posterior do corpo, com cauda em gerail com espinho terminal. Parasitos de anfíbios, répteis e mamíferos. 


\section{Oswaldocruzia Travassos, 1917}

Cabeça com dilatação cuticular vesiculosa, dividida em duas partes: uma anterior mais larga e outra posterior mais estreita. Cutícula com fina estriação transversal e linhas longitudinais. Boca guarnecida por lábios indistintos e limitando diminuta cavidade não esclerotizada. Asas cervicais presentes ou ausentes. Papilas cervicais delgadas abaixo do meio do esôfago. Fêmeas com vulva na metade posterior do corpo, não saliente. Aparelho genital anfidelfo. Extremidade posterior terminando por um espinho cuticular. Ovos na fase de mórula no útero. Machos com bolsa copuladora grande e com lobo dorsal triangular. Papilas pré-bursais não observadas. Raios bursais com a seguinte fórmula: ventrais contíguos, iguais, atingindo a margem; lateral anterior equidistante dos vizinhos nẩo atingindo a margem; lateral médio e lateral posterior contíguos atingindo a margem, todos mais ou menos da mesma espessura; dorsal externo nascendo por tronco comum ao dorsal, mais delgado que os outros raios; dorsal ramificado na extremidade de modo característico, formando um capitel constituído por um par de ramos laterais curvos em $\mathrm{S}$ e pela extremidade dicotomizada uma ou duas vezes. Espículos de forma complexa, constituídos por 4 ou 5 processos distais reunidos por uma membrana hialina. Gubernáculo ausente.

Espécie tipo: O. subauricularis (Rud., 1819) Travassos, 1917.

Espécies assinaladas no Brasil:

O. brasiliensis Lent \& Freitas, 1935 (Tab. IV, Figs 26-28)

Hospedeiros e proveniência: Dryadophys bifossatus bifossatus (Stuart) (=Mastigodryas bifossatus (Raddi), Hemidactylus mabouia (M. de J.), Rio de Janeiro: Rio de Janeiro.

Localização: intestino delgado.

Referências bibliográficas: 79, 107.

O. mazzai Travassos, 1935 (Tab. V, Figs 29)

Sinonímia: O. subauricularis Travassos, Freitas \& Lent, 1939.

Hospedeiro e proveniências: Tropidurus torquatus (Wied), Pará: Cachimbo, Mato Grosso do Sul: Bodoquena.

Localização: intestino delgado.

Referência bibliográfica: 152 .

O. subauricularis (Rud., 1819) Travassos, 1917 (Tab. V; Figs 30-31)

Sinonímia: Strongylus subauricularis Rud., 1819.

Hospedeiro e proveniência: Emyalius catenatus (Wied), Rio de Janeiro: Rio de Janeiro.

Localização: intestino delgado.

Referências bibliográficas: 55, 135 . 


\section{Strongyloidea}

Esta superfamília encerra a família Strongylidae Baird, 1853, com os gêneros Chapiniella Yamaguti, 1961 e Sauricola Chapin, 1925.

\section{Strongylidae Baird, 1853}

Apresentam cápsula bucal quitinosa, boca sem órgãos ventrais cortantes, mas, comumente cercada por uma coroa radiada. Parasitos do canal alimentar ou raramente do tecido renal de vertebrados.

\section{Chave para identificação dos gêneros}

- Coroa radiada simples, esôfago com três fileiras longitudinais de bossas quitinosas, papilas cervicais conspículas, raio prébursal ausente, raio dorsal com um par de ramos laterais anteriormente bifurcados em ramos terminais simples, raio externo lateral volumoso nascendo ao longo do

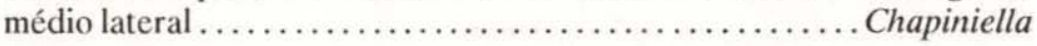

- Coroa radiada dupla; esôfago alargado anteriormente com um volumoso dente cônico; papilas cervicais ausentes; raio prébursal presente; raio dorsal dividido na extremidade de seu volumoso tronco em delicados ramos bidigitados; raio externo-lateral geralmente não delicado ........ Sauricola

\section{Chapiniella Yamaguti, 1961}

Nematóides pequenos. Cutícula com estrias transversas muito espaçadas. Colar bucal distinto, com seis papilas. Cápsula bucal curta em forma de anel com uma só coroa foliácea de dezoito elementos delgados, originando-se de sua base. Cada elemento com dobra conspícua e angular na sua porção mediana. Esôfago ligeiramente alargado na sua porção posterior. Lúmen com três fileiras longitudinais de bossas quitinosas que se estendem até três quartos de seu comprimento. Anel nervoso anterior ao meio do esôfago; poro excretor na região da válvula esôfago-intestino ou logo após. Papilas cervicais conspícuas pós esofagianas. Intestino com pequena proeminência que se estende até a porção posterior, principalmente nas fêmeas. Machos com bolsa fracamente trilobada; raios ventrais contíguos; tronco dos raios laterais grosso; externo lateral e médio-lateral bem próximos; pós-lateral grosso, separado do médio lateral; externo dorsal delgado originando-se no meio do tronco dorsal; dorsal com um par de ramos simples ou bifurcados em ramos simples terminais. Papilas prébursais ausentes. Espículos delgados, iguais, semelhantes, cada um com uma asa lateral em forma de espiral exceto nas duas extremidades. Fêmeas com cauda curta e cônica. Vulva anterior ao ânus. Úteros paralelos. Parasitos intestinais de tartarugas.

Espécie tipo: C. variabilis (Chapin, 1924) Yamaguti, 1961. 
Espécie assinalada no Brasil:

C. variabilis (Chapin, 1924) Yamaguti, 1961 (Tab. VIII; Figs 58-60)

Sinonímia: Deletrocephalus variabilis Chapin, 1924.

Hospedeiro e proveniência: Geochelone denticulata (L.), Pará.

Localização: intestino.

Referência bibliográfica: 40 .

\section{Sauricola Chapin, 1925}

Nematóides pequenos. Cutícula envolvendo a boca formando um curto colar bucal delimitado posteriormente por uma constricção anular. Seis papilas periorais. Depressão cervical e papilas ausentes. Cápsula bucal curta com duas coroas foliáceas de dezoito elementos cada. Esôfago cilíndrico, cerca de duas vezes mais longo que largo com muitos dentes cônicos, fortes na porção anterior. Machos com bolsa curta, de lobo dorsal não saliente; raio pré-bursal fendido na base; raios dorsais fortes e separados na base; externo-laterais muito delgados, originando-se de um tronco comum com os outros laterais que são grossos na metade proximal e mais finos e fendidos distalmente; externo dorsal longo, delgado, originando-se na base do tronco do dorsal; dorsal dividido na ponta de seu tronco em dois ramos delgados, divergentes, bidigitados. Espículos longos, delgados e simples. Fêmeas com cauda cônica, afilada. Vulva próxima ao ânus. Úteros paralelos. Ovíparas. Ovos de casca fina, não embrionados in útero. Parasitos intestinais de tartarugas.

Espécie tipo: $S$. sauricola Chapin, 1925.

Espécie assinalada no Brasil:

S. sauricola Chapin, 1925 (Tab. VIII, Figs 56-57)

Hospedeiro e proveniência: Geochelone denticulata (L.), Pará.

Localização: intestino.

Referência bibliográfica: 40.

\section{Cosmocercoidea}

Esta superfamília encerra as famílias Atractidae Travassos, 1919, com os gêneros Atractis Dujardin, 1845, Labiduris Schneider, 1866 e Maracaya Diaz-Ungria, 1963; Cobboldinidae Skrjabin, 1948 com o gênero Klossinemella Costa 1961; Cosmocercidae Travassos, 1925 com os gêneros Aplectana Railliet \& Henry, 1916, Cosmocerca Diesing, 1861 e Dollfusnema Baker, 1981; Kathlaniidae Yorke \& Maplestone, 1926 com gêneros Cruzia Travassos, 1917, Falcaustra Lane, 1915, Kathlania Lane, 1914, Oxyascaris Travassos, 1920 e Tonaudia Travassos, 1918. 


\section{Chave para identificação das famílias}

1. Macho com uma ou diversas ventosas pré-anais ........... Kathlaniidae

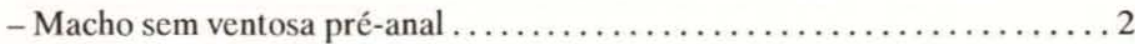

2. Fêmeas didelfas, ovíparas ou vivíparas ............... Cosmocercidae

- Fêmeas monodelfas, vivíparas . . . . . . . . . . . . . . . . . . . 3

3. Boca com 2 lábios bilobados, tendo cada lóbulo uma reentrância pequena que forma lóbulos menores entre os lábios um interlábio em forma de Y ... . Cobboldinidae

- Boca sem as características anteriores. Larvas eliminadas em avançado estágio de desenvolvimento, capazes de desenvolvimento endógeno .......... Atractidae

\section{Atractidae Travassos, 1919}

Nematóides pequenos. Boca variável. Esôfago claramente dividido em duas partes, a posterior terminando em bulbo nitidamente separado do resto do esôfago. Intestino simples, sem divertículos. Macho sem ventosa pré-anal. Espículos iguais ou desiguais. Gubernáculo presente ou ausente. Fêmea com a cauda pontuda. Ovário simples. Vulva situada na parte posterior. Vivíparas. Larvas eliminadas em adiantado estágio de desenvolvimento, possibilitando evolução endógena. Parasitos de vertebrados.

\section{Chave para identificação dos gêneros}

1. Boca com 6 lábios indistintos, cápsula bucal ausente. Macho com espículos

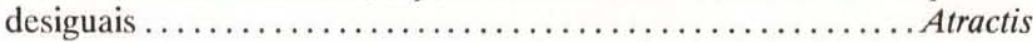

- Boca com 3 lábios proeminentes, cápsula bucal presente. Macho com espí-

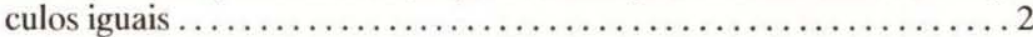

2. Cápsula bucal curta, sem peça de sustentação quitinóide, reunindo os bordos dos lábios adjacentes. Gubernáculo ausente ............. Labiduris

- Cápsula bucal com peça de sustentação quitinóide, reunindo os bordos dos lábios adjacentes. Gubernáculo presente ................... Maracaya

\section{Atractis Dujardin, 1845}

Corpo cilíndrico. Boca com seis lábios indistintos. Cápsula bucal ausente. Esôfago dividido em duas partes, sendo a anterior cilíndrica, muscular com lúmen fortemente quitinizado, circundado anteriormente por um anel nervoso e terminado num bulbo provido de aparelho valvular. Poro excretor pósesofagiano. Machos com a extremidade anterior curvada em espiral. Cauda com constricção após o ânus que forma um processo cônico subulado, longo. Asa caudal ausente. Em adição às quatro papilas caudais ventrais, há diversos pares de papilas laterais. Espículos desiguais, dissemelhantes. Gubernáculo presente. 
Tabela IX. Thelandros verrucosus, dados segundo Freitas \& Dobbin Jr., 1959; Gynaecometra bahiensis, dados segundo Araujo, 1976 e Atractis cruciata, dados segundo Vicente, 1966.

\begin{tabular}{|c|c|c|c|c|c|c|}
\hline & \multicolumn{2}{|c|}{ T. verrucosus } & \multicolumn{2}{|c|}{ G. bahiensis } & \multicolumn{2}{|c|}{ A. cruciata } \\
\hline & Macho & Fêmea & Macho & Fêmea & Macho & Fêmea \\
\hline Comprimento & $1,48-2,12$ & $3,55-7,17$ & $1,120-1,260$ & $1,587-2,106$ & $4,99-5,24$ & $5,58-6,41$ \\
\hline Largura & $0,15-0,20$ & $0,54-0,77$ & $0,052-0,062$ & $0,108-0,162$ & $0,30-0,36$ & $0,39-0,44$ \\
\hline Eôfago & $0,33-0,46$ & $1,14-1,41$ & $0,300-0,340$ & $0,421-0,494$ & $\begin{array}{l}0,44-0,51\left(1^{a} \text { parte }\right) \\
0,44-0,53\left(2^{a} \text { parte }\right)\end{array}$ & $\begin{array}{l}0,44-0,47 \text { (12parte) } \\
0,50-0,55 \text { ( } 2^{p} \text { parte) }\end{array}$ \\
\hline Bulbo esofagiano & $\begin{array}{c}0,070-0,096 \mathrm{x} \\
0,070-0,104\end{array}$ & $\begin{array}{c}0,148-0,199 \mathrm{x} \\
0,166-0,232\end{array}$ & & & & \\
\hline Anel nervoso & $0,12-0,18$ & $0,16-0,45$ & $0,104-0,124$ & & $0,53-0,59$ & $0,55-0,57$ \\
\hline Poro excretor & $0,48-0,80$ & $1,10-1,94$ & $0,368-0,400$ & $0,380-0,524$ & $0,68-0,77$ & $0,83-0,88$ \\
\hline Vulva & & $1,84-3,48$ & & $0,623-0,850$ & & $0,76-1,02$ \\
\hline Ovos & & $\begin{array}{c}0,078-0,082 \mathrm{x} \\
0,035-0,038\end{array}$ & & & & \\
\hline Ȧnus & $0,025-0,029$ & $0,23-0,40$ & $0,014-0,018$ & $0,252-0,324$ & $0,27-0,40$ & $0,50-0,63$ \\
\hline Espiculo & $0,055-0,063$ & & $0,032-0,042$ & & & \\
\hline Apêndice caudal & $0,076-0,080$ & $0,100-0,134$ & & & & \\
\hline $\begin{array}{l}\text { Dilatação cuticular } \\
\text { anterior }\end{array}$ & & & 0,038 & 0,038 & & \\
\hline Lábios & & & 0,003 & 0,003 & & \\
\hline Gubernáculo & & & $0,013-0,018$ & & & \\
\hline Duto ejaculador & & & $0,100-0,180$ & & & \\
\hline Ovejetor & & & & $0,080-0,202$ & & \\
\hline Reto & & & & & & $0,19-0,22$ \\
\hline Espículo maior & & & & & $0,41-0,45$ & \\
\hline Espículo menor & & & & & $0,22-0,23$ & \\
\hline Papilas caudais & 1 par pré, 1 ac & e 1 pós anal & & & 3 pares pré & e 4 pós anal \\
\hline
\end{tabular}

Fêmeas com cauda alongada, cônica ou subulada. Vulva próxima ao ânus. Vivíparas. Parasitos de lagartos e tartarugas.

Espécie tipo: A. dactyluris (Rud., 1819)

Espécies assinaladas no Brasil:

A. cruciata Linstow, 1902 (Tab. IX, Figs 94-96)

Hospedeiro e proveniência: Tupinambis teguixin (L.), Pará: Belém.

Localização: intestino.

Referência bibliográfica: 151 .

A. trematophila Travassos, 1934 (Tab. X, Figs 102-103)

Hospedeiro e proveniência: "tartaruga do Rio Amazonas", Pará: Rio Amazonas.

Localização: tubo digestivo do trematódeo Nematophila grande (Diesing, 1839) Travassos, 1934.

Referência bibliográfica: 134 . 
Tabela X. Atractis trematophila, dados segundo Travassos, 1934; Labduris gulosa, dados segundo Schneider, 1866 e L. irineuta, dados segundo Costa, 1961.

\begin{tabular}{|c|c|c|c|c|c|c|}
\hline & \multicolumn{2}{|c|}{ A. trematophila } & \multicolumn{2}{|c|}{ L. gulosa } & \multicolumn{2}{|c|}{ L. irineuta } \\
\hline & Macho & Fêmea & Macho & Fêmea & Macho & Fêmea \\
\hline Comprimento & 1,5 & 1,8 & $6,0-7,0$ & $7,0-8,0$ & 5,3 & $4,5-5,5$ \\
\hline Largura & 0,08 & 0,1 & 0,48 & & 0,320 & \\
\hline Esôfago & $0,20-0,22$ & $0,20-0,22$ & & & & \\
\hline Porçăo anterior do esôfago & $0,10-0,16 \times 0,03$ & & & & & \\
\hline Vestíbulo & & & & & 0,052 & 0,052 \\
\hline Ístmo & & & & & 0,520 & 0,520 \\
\hline Faringe & & & & & 0,135 & 0,135 \\
\hline Pré-bulbo & & & & & 0,078 & 0,078 \\
\hline 1" porção do esôfago & & & & & 0,504 & 0,504 \\
\hline Poro excretor & & 0,27 & 1,23 & & & \\
\hline Bulbo esofagiano & $0,05 \times 0,04-0,05$ & & & & $0,184-0,210$ & $0.185-0,210$ \\
\hline Ânus & 0,45 & 0,85 & & & & \\
\hline Vulva-extremidade posterior & & 0,10 & & 0,29 & & \\
\hline Ovos & & $\begin{array}{c}0,110-0,112 \mathrm{x} \\
0,40-0,50\end{array}$ & & & & \\
\hline Espiculo maior & $0,12-0,16$ & & & & & \\
\hline Espiculo menor & $0,045-0,050$ & & & & & \\
\hline Gubernáculo & $0,020-0,030$ & & & & & \\
\hline Espiculo & & & 0,425 & & & \\
\hline Anel nervoso & & & 0,325 & & & \\
\hline Filamento caudal & & $0,4-0,5$ & $0,9-1,1$ & & & \\
\hline Vagina & & & & 0,20 & & \\
\hline Ovejetor & & & & 0,20 & & \\
\hline
\end{tabular}

\section{Maracaya Diaz-Ungria, 1963}

Boca com três grandes lábios que apresentam reforços quitinizados reunidos em uma peça de sustentação que substitui a cápsula bucal e faringe. Esôfago formado de corpus, ístmo bem diferenciado e bulbo com válvulas. Espículos iguais bem mais longos que o gubernáculo. Vulva após o meio corpo. Monodelfas. Parasitos intestinais de répteis.

Espécie tipo: M. graciai Diaz-Ungria, 1963.

Espécie assinalada no Brasil:

M. belemensis Adamson \& Baccan, 1988 (Tab. XI, Figs 282-284)

Hospedeiro e proveniência: Amphisbaena alba L., Pará: Belém.

Localização: intestino.

Referência bibliográfica: 1 .

\section{Labiduris Schneider, 1866}

Boca com três lábios proeminentes: um dorsal e dois subventrais. Lábios subventrais separados do dorsal por depressões relativamente rasas mas profundamente dividido um do outro; com bordas medianas livres, curvadas e so- 
Tabela XI. Aplectana albae, dados segundo Adamson \& Baccam, 1988; A. pusilla, dados segundo Miranda, 1924; A. raillieti, dados segundo Travassos, 1925; A. travassosi, dados segundo Gomes \& Motta, 1967 e Maracaya belemensis, dados segundo Adamsom \& Baccan, 1988.

\begin{tabular}{|c|c|c|c|c|c|c|c|c|c|c|}
\hline & \multicolumn{2}{|c|}{ A. albae } & \multicolumn{2}{|c|}{ A. pusilla } & \multicolumn{2}{|c|}{ A. raillieti } & \multicolumn{2}{|c|}{ A. travassosi } & \multicolumn{2}{|c|}{ M. belemensis } \\
\hline & Macho & Fêmea & Macho & Fêmea & Macho & Fêmea & Macho & Fêmea & Macho & Fêmea \\
\hline Comprimento & 3,75 & 4,31 & 2,00 & 2,60 & 2,10 & 5,70 & $2,77-3,18$ & $2,90-3,12$ & 2,41 & 2,49 \\
\hline Largura & 0,18 & 0,22 & 0,24 & 0,29 & 0,20 & 0,40 & $0,13-0,19$ & $0,16-0,24$ & 0,12 & 0,15 \\
\hline Anel nervoso & 0,25 & 0,29 & 0,28 & 0,28 & & & $0,15-0,23$ & $0,22-0,25$ & 0,30 & 0,32 \\
\hline Esôfago & 0,60 & 0,73 & $\begin{array}{l}0,50 \mathrm{x} \\
0,056\end{array}$ & $\begin{array}{l}0,49 \mathrm{x} \\
0,056\end{array}$ & 0,57 & 1,00 & $0,50-0,60$ & $0,53-0,67$ & 0,65 & 0,73 \\
\hline Poro excretor & 0,53 & 0,63 & 0,50 & 0,56 & & & $0,38-0,45$ & 0,50 & 0,55 & 0,59 \\
\hline Ânus & & & 0,10 & 0,17 & 0,16 & 0,35 & $0,11-0,15$ & $0,14-0,23$ & & \\
\hline Espiculos & 0,06 & & 0,11 & & 0,240 & & $0,23-0,32$ & & 0,09 & \\
\hline Gubernáculo & 0,04 & 0,049 & & & 0,032 & & $0,07-0,08$ & & 0,04 & \\
\hline $\begin{array}{l}\text { Canal } \\
\text { ejaculador }\end{array}$ & & & 0,42 & & & & & & & \\
\hline $\begin{array}{l}\text { Bulbo } \\
\text { esofagiano }\end{array}$ & $\begin{array}{l}0,112 x \\
0,091\end{array}$ & $\begin{array}{c}0,137 \mathrm{x} \\
0,114\end{array}$ & $\begin{array}{c}0,070 \times \mathrm{x} \\
0,092\end{array}$ & $\begin{array}{c}0,092 \mathrm{x} \\
0,092\end{array}$ & 0,10 & 0,13 & & & $\begin{array}{l}0,094 \times \\
0,085\end{array}$ & $\underset{0,102 x}{0,104}$ \\
\hline Ovos & & $\begin{array}{c}0,072-0,075 \\
x \\
0,039-0,052\end{array}$ & & & & $\begin{array}{c}0,121 \\
x \\
\mathbf{x} \\
0,070\end{array}$ & & $\begin{array}{c}0,08-0,10 \\
\mathbf{x} \\
0,05\end{array}$ & & $\begin{array}{c}0,176-0,202 \\
x \\
0,085-0,123\end{array}$ \\
\hline Faringe & & & & & 0,06 & 0,06 & $0,03-0,05$ & $0,04-0,07$ & & \\
\hline $\begin{array}{l}\text { Espinbo } \\
\text { terminal }\end{array}$ & & & & & 0,032 & & & & & \\
\hline Vulva & & 286 & & & & & & $0,58-1,00$ & & 1,78 \\
\hline Ovejetor & & & & & & & & $0,25-0,27$ & & \\
\hline Reto & & & & & & & & $0,09-0,10$ & & \\
\hline Papilas caudais & $\begin{array}{r}7 \text { pares p } \\
\text { ad e } 5 p\end{array}$ & $\begin{array}{l}\text { pré-anais,11 } \\
\text { pós-anal }\end{array}$ & & & & & $\begin{array}{r}2 \text { pares pré } \\
\text { pós-2 }\end{array}$ & $\begin{array}{l}\text { ré, } 1 \text { ad e } 4 \\
\text {-anal }\end{array}$ & $\begin{array}{r}8 \text { pares p. } \\
\text { pós }\end{array}$ & $\begin{array}{l}\text { ré, } 1 \text { ad e } 4 \\
\text { anal }\end{array}$ \\
\hline
\end{tabular}

brepostas, cada uma provida posteriormente de uma franja crenulada. Cavidade bucal curta. Esôfago consistindo de duas partes; a parte posterior terminando por um bulbo que por sua vez é seguido por outro bulbo maior contendo válvulas. Machos possuindo cauda forte constricção após a cloaca, terminando em ponta delgada de comprimento variado nas espécies. De cada lado da cloaca há um processo proeminente em forma de corneta e na base desse processo há grandes papilas pares. Em adição a estas papilas existem três a quatro pares de papilas pré-anais e um certo número de pós-anais. Espículos iguais, gubernáculo ausente. Fêmeas com cauda longa cônica. Vulva próxima ao ânus. Vivíparas. Parasitos de tartarugas.

Espécie tipo: L. gulosa (Rud., 1819) Schneider, 1866.

Espécies assinaladas no Brasil:

L. gulosa (Rud., 1819) Schneider, 1866 (Tab. X, Figs 97-98)

Sinonímia: Ascaris gulosa Rud., 1819.

Hospedeiro e proveniência: Geochelone denticulata (L.), Pará.

Localização: intestino.

Referência bibliográfica: 40 . 


\section{L. irineuta Costa, 1961 (Tab. X)}

Hospedeiro e proveniência: Geochelone denticulata (L.), Rio de Janeiro: Rio de janeiro.

Localização: intestino.

Referência bibliográfica: 41 .

L. zschokkei Linstow, 1899 (Tab. XII; Figs 99-101)

Hospedeiro e proveniência: Geochelone denticulata (L.), Brasil.

Localização: intestino.

Referência bibliográfica: 113 .

\section{Cobboldinidae Skrjabin, 1948}

Boca dotada de dois lábios bilobados, cada lobo com reentrância formando lóbulos menores. Interlábio presente. Machos dotados de dois espículos desiguais e possuindo gubernáculo. Fêmeas com vulva próxima do ânus. Vivíparas. Parasitas de peixes e tartarugas.

\section{Klossinemella Costa, 1961}

Boca dotada de dois lábios bilobados, apresentando cada lóbulo reentrância pequena que forma lóbulos menores e entre os lábios possui uma formação com aspecto de Y que pode ser considerado como um interlábio muito modificado. Machos dotados de dois espículos bem desiguais, possuindo gubernáculo. Fêmeas com a vulva próxima ao ânus. Parasitos de peixes e tartaruga.

Espécie tipo:K. iheringi (Travassos, Artigas \& Pereira, 1928) Costa, 1961. Espécies assinaladas no Brasil:

K. conciliatus Alho, 1964 (Tab. XII, Figs 106-108)

Hospedeiro e proveniência: Podocnemis expansa (Schaw.), Amazonas: Rio Amazonas.

Localização: estômago.

Referências bibliográficas: 2,43 .

K. travassosi Costa, Motta \& Gomes, 1968 (Tab. XII, Figs 104-105)

Hospedeiro e proveniência: Geochelone denticulata (L.), Amazonas.

Localização: intestino grosso.

Referência bibliográfica: 43 .

\section{Cosmocercidae Travassos, 1925}

Nematóides com dimorfismo sexual acentuado. Machos sem ventosa pré-anal, com espículos sub-iguais, longos ou rudimentares; gubernáculo presente, rudimentar ou ausente. Fêmeas didelfas prodelfas ou anfidelfas; ovíparas ou vivíparas. Parasitas de anfíbios de répteis. 
Tabela XII. Labduris zschokkei, dados segundo Linstow, 1899; Klossinemella travassosi, dados segundo Costa, Motta \& Gomes, 1968 e K. conciliatus, dados segundo Alho, 1964.

\begin{tabular}{|c|c|c|c|c|c|c|}
\hline & \multicolumn{2}{|c|}{ L. zschokkei } & \multicolumn{2}{|c|}{ K. travassosi } & \multicolumn{2}{|c|}{ K. conciliatus } \\
\hline & Macho & Fêmea & Macho & Fêmea & Macho & Fêmea \\
\hline Comprimento & 7,25 & $7,00-8,00$ & $2,80-3,40$ & $3,20-3,80$ & $4,89-7,67$ & 6,67 \\
\hline Largura & 0,56 & 0,70 & $0,04-0,07$ & $0,11-0,20$ & $0,18-0,28$ & 0,33 \\
\hline Poro excretor & & 1,18 & 0,366 & 0,366 & $0,56-0,64$ & 0,64 \\
\hline Anel nervoso & 0,40 & & & & $0,33-0,39$ & 0,33 \\
\hline Bulbo anterior & & 0,090 & 0,25 & 0,25 & & \\
\hline Bulbo posterior & & $0,30-0,40$ & & & & \\
\hline Vagina & & 0,22 & & & & \\
\hline Ovejetor & & 0.15 & & & & \\
\hline Vulva-ånus & & 0,40 & & 0,054 & & \\
\hline Ànus & & $0,35-0,45$ & & & & \\
\hline Cauda & $0,095-0,150$ & $0,35-0,45$ & 0,67 & $0,85-0,95$ & & \\
\hline Espículos & 0,45 & & & & & \\
\hline Reto & & 0,24 & & & & \\
\hline $\begin{array}{l}\text { Porção anterior do } \\
\text { esófago }\end{array}$ & & & $0,15-0,18$ & $0,15-0,18$ & $0,23-0,26$ & 0,23 \\
\hline $\begin{array}{l}\text { Porçâo posterior do } \\
\text { esófago }\end{array}$ & & & $0,25-0,30$ & $0,25-0,30$ & $0,50-0,59$ & 0,52 \\
\hline Espículo maior & & & $0,320-0,360$ & & $0,541-0,594$ & \\
\hline Espiculo menor & & & 0,082 & & $0,125-0,151$ & \\
\hline Gubernáculo & & & $0,046-0,057$ & & $0,079-0,092$ & \\
\hline Papilas caudais & & & $\begin{array}{l}4 \text { pares pré, } 1 \text { ad } \\
\text { e } 3 \text { pós-anal }\end{array}$ & & $\begin{array}{c}4 \text { pares pré e } 5 \\
\text { pós anais }\end{array}$ & \\
\hline
\end{tabular}

\section{Chave para identificação dos gêneros}

1. Machos com plectanas

Cosmocerca

-Machos sem plectanas ....................................

2. Fêmeas prodelfas

Aplectana

- Fêmeas anfidelfas ............................ Dollfusnema

\section{Aplectana Railliet \& Henry, 1916}

Nematóides pequenos, fusiformes ou cilíndricos, de cor branca, dimorfismo sexual acentuado. Boca com três lábios pequenos e providos de armadura quitinosa em forma de V. Poro excretor pré-bulbar; esôfago com pequeno faringe e com bulbo posterior sem válvulas quitinosas. Vulva mediana; aparelho genital prodelfo. Machos com dois espículos sub-iguais e gubernáculo mais ou menos quitinizado, podendo em algumas espécies faltar inteiramente; cauda cônica, mais ou menos alongada e com numerosas papilas pré e pós anais.

Espécie tipo: A. acuminata (Schrank, 1788) Railliet \& Henry, 1916.

Espécies assinaladas no Brasil: 
A. albae Adamson \& Baccan, 1988 (Tab. XI, Figs 285-288)

Hospedeiro e proveniência: Amphisbaena alba L., Pará: Belém.

Localização: intestino.

Referência bibliográfica: 1 .

A. papilifera (Araujo, 1978) (Tab. XIII, Figs 115-116)

Sinonímia: Neyraplectana papilifera Araujo, 1978.

Hospedeiro e proveniência: Dromicus typhlus (D. \& B.) e Xenodon neuwiedii (Gunther), Brasil.

Referência bibliográfica: 25 .

A. pusilla Miranda, 1924 (Tab. XI, Fig. 109)

Sinonímia: Oxysomatium pusillum Baylis, 1927.

Hospedeiro e proveniência: Amphisbaena alba L., Bahia.

Localização: intestino.

Referências bibliográficas: 84, 130 .

A. raillieti Travassos, 1925 (Tab. XI, Fig. 110)

Sinonímia: Oxysomatium raillieti Baylis, 1927.

Reis.

Hospedeiro e proveniência:Amphisbaena sp., Rio de Janeiro: Angra dos

Localização: intestino.

Referências bibliográficas: 128, 130 .

A. travassosi (Gomes \& Motta, 1967) Baker, 1980 (Tab. XI, Figs 112-114)

Sinonímia: Freitasoxyascaris travassosi Gomes \& Motta, 1967. Janeiro.

Hospedeiro e proveniência: Liophis miliaris (L.), Rio de Janeiro: Rio de

Localizaçâo: intestino delgado.

Referências bibliográficas: 28,74 .

A. unguiculata (Rud., 1819) Miranda, 1924 (Tab. XIII, Fig. 111)

Sinonímia: Ascaris unguiculata Rud., 1819; Oxysomatium unguiculatum Baylis, 1927.

Hospedeiro e proveniência: Amphisbaena alba L., Bahia.

Localização: intestino.

Referência bibliográfica: 84 .

Cosmocerca Diesing, 1861

Nematóides filiformes, com dimorfismo sexual acentuado; boca trilabiada em forma de V. Poro excretor pré-bulbar; esôfago com pequeno faringe e bulbo posterior com válvula quitinosa. Vulva mediana; aparelho genital 
feminino prodelfo. Machos com dois espículos pequenos e rudimentares. Gubernáculo subtriangular protrátil. Asas caudais ausentes. Numerosas papilas pequenas na face ventral e duas séries de formações quitinosas (plectanas) características.

Espécie tipo: C. omata Diesing, 1861 nec Dujardin, 1845.

Espécie assinalada no Brasil:

C. rara Freitas \& Vicente, 1966 (Tab. XIII, Figs 117-118)

Hospedeiro e proveniência: Leposternon microcephalum Wagler, Rio de Janeiro: Rio de Janeiro.

Localização: intestino grosso.

Referências bibliográficas: 71, 46 .

Tabela XIII. Aplectana unguiculata, dados segundo Miranda, 1924; A. papillifera, dados segundo Araujo, 1978 e Cosmocerca rara, dados segundo Freitas \& Vicente, 1966.

\begin{tabular}{|c|c|c|c|c|c|}
\hline & \multicolumn{2}{|c|}{ A. unguiculata } & \multicolumn{2}{|c|}{ A. papillifera } & \multirow{2}{*}{$\begin{array}{l}\text { C. rara } \\
\text { Macho }\end{array}$} \\
\hline & Macho & Fêmea & Macho & Fêmea & \\
\hline Comprimento & $2,3-2,5$ & 3,2 & $4,426-5,221$ & $5,875-8,534$ & 2,8 \\
\hline Largura & 0,24 & 0,29 & $0,408-0,510$ & $0,414-0,716$ & 0,32 \\
\hline Vestibulo & $0,042-0,078$ & $0,042-0,078$ & & & \\
\hline Faringe & & & 0,045 & $0,052-0,640$ & \\
\hline Esōfago & $1,00-1,13$ & $1,00-1,13$ & $0,753-0,810$ & $0,842-0,988$ & 0,58 \\
\hline Bulbo esofagiano & $\begin{array}{c}0,085-0,100 x \\
1,133\end{array}$ & $\begin{array}{c}0,085-0,100 x \\
1,133\end{array}$ & $\begin{array}{l}0,170-0,162 \mathrm{x} \\
0,141-0,145\end{array}$ & $\begin{array}{c}0,162-0,218 x \\
0,145-0,194\end{array}$ & $\begin{array}{l}0,10 x \\
0,12\end{array}$ \\
\hline Anel nervoso & 0,240 & 0,240 & $0,259-0,291$ & $0,332-0,380$ & 0,25 \\
\hline Poro excretor & $0,4-0,5$ & $0,4-0,5$ & $0,542-0,591$ & $0,567-0,664$ & 0,48 \\
\hline Ảnus & 0,113 & 0.180 & 0,304 & $0,332-0,380$ & 0,11 \\
\hline Espiculos & 0,085 & & 0,400 & & 0,200 \\
\hline Gubernáculo & 0,042 & & & & 0,206 \\
\hline Ovejetor & & 0,42 & & & \\
\hline Ovos & & $0,085 \times 0,056$ & & & \\
\hline Vulva extremidade anterior & & & & $3,472-4,950$ & \\
\hline $\begin{array}{l}\text { Papilas do flagelo caudal - } \\
\text { extremidade posterior }\end{array}$ & & & $0,116-0,118$ & & \\
\hline Plectanas & & & & & 6 pares $(0,130)$ \\
\hline Filamento caudal & & & & & 0,026 \\
\hline Papilas caudais & & & & & $\begin{array}{c}1 \text { par pré e } 5 \text { pares } \\
\text { pós anal }\end{array}$ \\
\hline
\end{tabular}

\section{Dollfusnema Baker, 1981}

Lábios cefálicos separados por interlábios cuticulares. Cauda dos machos com papilas caudais simples, sem rosetas ou plectanas. Espículos curtos, iguais. Gubernáculo presente. Papilas somáticas e asa lateral presentes. Fêmeas com poucos ovos de casca fina, grandes, presentes no útero. Didelfas, anfidelfas na origem. Ambos os ovários anteriores à vulva.

Espécie tipo: D. amphisbaenia Baker, 1981.

Espécie assinalada no Brasil: 
D. amphisbaenia Baker, 1981 (Tab. XIV, Figs 119-121)

Hospedeiro e proveniência: Leposternon phocaena Dumeril \& Bibron, Pernambuco: Recife.

Localização: intestino.

Referência bibliográfica: 30 .

Tabela XIV. Dollfusnema amphisbaenia, dados segundo Baker, 1981; Strongyluris oscari, dados segundo Vicente, 1981 e Bufonerakis rodriguesi, dados segundo Vicente \& Gomes, 1971.

\begin{tabular}{|c|c|c|c|c|c|c|}
\hline & \multicolumn{2}{|c|}{ D. amphisbaenia } & \multicolumn{2}{|c|}{ S. oscari } & \multicolumn{2}{|c|}{ B. rodriguesi } \\
\hline & Macho & Fêmea & Macho & Fêmea & Macho & Fêmea \\
\hline Comprimento & 27 & 3,3 & $5,65-11,6$ & $6,10-11,90$ & 6.49 & $7,06-8,61$ \\
\hline Largura & & & $0,25-0,60$ & $0,32-0,70$ & 0.27 & $0.21-0.41$ \\
\hline Esófago & 0,642 & 0,702 & $0,21-0,73$ & $0,84-1,33$ & 1,08 & $0,91-1,26$ \\
\hline Faringe & 0,047 & 0.053 & $0,18-0,24$ & $0,18-0,29$ & 0.11 & 0.11 \\
\hline Corpus & 0,412 & 0,459 & & & & \\
\hline Ístimo & 0,058 & 0,056 & & & & \\
\hline Bulbo esofagiano & 0,125 & 0,134 & $\begin{array}{c}0,10-0,30 x \\
0,16-0,26\end{array}$ & $\begin{array}{c}0,19-0,30 x \\
0,17-0,33\end{array}$ & $\begin{array}{c}0,16 \mathrm{x} \\
0.13\end{array}$ & $\begin{array}{c}0,14-0,23 x \\
0,15 \cdot 0,19\end{array}$ \\
\hline Anel nervoso & 0,212 & 0,243 & & & 0,31 & $0,31-0,37$ \\
\hline Poro excretor & 0.456 & 0,550 & $0.75-1,10$ & $0,70-1,26$ & 0,572 & 0,572 \\
\hline Cauda & 0,200 & & & & & \\
\hline Espiculos & 0.109 & & $0,42-1,1$ & & 1,18 & \\
\hline Gubernáculo & 0,060 & & & & & \\
\hline Vulva & & 2.1 & & $3,71-7,37$ & & $3,08-3,69$ \\
\hline Vagina & & 0.30 & & & & \\
\hline Ovos & & $\begin{array}{l}0,115 \mathrm{x} \\
0,070\end{array}$ & & $\begin{array}{c}0,056-0,074 x \\
0,032-0,045\end{array}$ & & $\begin{array}{l}0,059 x \\
0,040\end{array}$ \\
\hline Ventosa & & & $\begin{array}{c}0,075-0,15 x \\
0,080-0,14\end{array}$ & & 0.037 & \\
\hline Ȧnus & & & $0,04-0,09$ & $0,20-0,33$ & & $0,24-0,25$ \\
\hline Reto & & & & & & $0.14-0.17$ \\
\hline $\begin{array}{l}\text { Ventosa-extremidade } \\
\text { posterior }\end{array}$ & & & & & 0,25 & \\
\hline Papilas caudais & & & 10 pares & & 3 pares $p$ & I pós anal \\
\hline
\end{tabular}

Kathlaniidae Yorke \& Maplestone, 1926

Boca com três ou seis lábios bem desenvolvidos, às vezes armados com dentes. Lábios intermediários presentes ou ausentes. Cápsula bucal com ou sem dentes na sua base. Faringe presente ou ausente. Esôfago com bulbo posterior usualmente precedido por uma dilatação. Intestino sem divertículo. Machos com músculos pré-anais bem desenvolvidos e usualmente formando uma ventosa alongada com ou sem anel quitinoso. Espículos iguais ou sub-iguais. Gubernáculo geralmente presente. Fêmea com a extremidade posterior pontuda. Vulva em geral posterior ao meio do corpo. Parasitos de animais de sangue frio. 


\section{Chave para identificação dos gêneros}

1. Divertículo intestinal presente ........................ Cruzia

- Divertículo intestinal ausente . . . . . . . . . . . . . . . . . . . . . 2

2. Boca com 3 lábios bem desenvolvidos apresentando entre eles lábios subsidiários ......................................

- Boca sem as características anteriores $\ldots \ldots \ldots \ldots \ldots \ldots \ldots \ldots \ldots \ldots$

3. Espículos extremamente longos $\ldots \ldots \ldots \ldots \ldots \ldots \ldots \ldots \ldots \ldots \ldots \ldots \ldots \ldots \ldots \ldots \ldots$ Tonaudia

- Espículos relativamente curtos ......................... Kathlania

4. Esôfago com uma faringe anterior e um bulbo posterior com pseudobulbo; machos com musculatura pré-anal desenvolvida formando uma

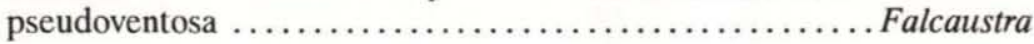

- Esôfago sem faringe e sem bulbo posterior com pseudobulbo; mas com ventrículo no fim do esôfago; machos sem pseudoventosa.... Oxyascaris

\section{Cruzia Travassos, 1917}

Boca com três lábios subtriangulares; faringe com três fileiras de ganchos longitudinais e três estruturas truncadas em forma de dente em sua base. Esôfago cilíndrico, alargado posteriormente seguido por um bulbo bem desenvolvido contendo válvulas. Intestino com ceco anterior. Machos com cauda cônica. Asa caudal muito pequena ou ausente. Cerca de nove papilas caudais das quais três pós-anais. Espículos subiguais, alados. Gubernáculo presente. Fêmeas com a cauda terminando em ponta fina. Vulva próxima ao meio do corpo. Didelfas, ovíparas. Ovos relativamente grandes, com casca espessa e rugosa, embrionados quando eliminados. Parasitos do ceco e intestino de vertebrados.

Espécie tipo: C. tentaculata (Rud., 1819) Travassos, 1917.

Espécies assinaladas no Brasil:

C. rudolphii Ruiz, 1947 (Tab. XV, Fig. 149)

Hospedeiro e proveniência: Erythrolamprus aesculapii aesculapii (L.), São Paulo: Palmar.

Localização: intestino delgado.

Referência bibliográfica: 108.

Cruzia sp. Travassos, Freitas \& Lent, 1939

Hospedeiro e proveniência: Tupinambis teguixin (L.), Mato Grosso do Sul: Salobra.

Localização: intestino.

Referência bibliográfica: 141 . 
Tabela XV. Falcaustra tikasinghi, dados segundo Baker \& Bain, 1981; Kathlania leptura, dados segundo Travassos, 1918 e Cruzia rudolphii, dados segundo Ruiz, 1947.

\begin{tabular}{|c|c|c|c|c|c|c|}
\hline & \multicolumn{2}{|c|}{ F. tikasinghi } & \multicolumn{2}{|c|}{ K. leptura } & \multicolumn{2}{|c|}{ C. rudolphii } \\
\hline & Macho & Fêmea & Macho & Fêmea & Macho & Fêmea \\
\hline Comprimento & 15,9 & 19,1 & $12,0-16,0$ & $18,0-20,0$ & 14,0 & 16,2 \\
\hline Largura & & & $0,6-0,8$ & $0,6-0,8$ & 0,393 & 0,468 \\
\hline Faringe & & & & & 0,180 & 0,171 \\
\hline Esôfago & 210 & 2,35 & $2,49-3,48$ & $2,49-3,48$ & 1,80 & 1,80 \\
\hline Anel nervoso & & & & & 0,491 & \\
\hline Cauda & 0,470 & 0,560 & & & & 0,468 \\
\hline Espículos & 0,620 & & $0,56-0,64$ & & 0,491 & \\
\hline Gubernáculo & 0,385 & & $0,36-0,39$ & & & \\
\hline Vulva & & 12,4 & & & & 8,0 \\
\hline Vestibulo & & & $0,104-0,174$ & $0,104-0,174$ & & \\
\hline Bulbo anterior & & & $\begin{array}{l}0,174-0,213 x \\
0,139-0,156\end{array}$ & $\begin{array}{c}0,174-0,213 x \\
0,139-0,156\end{array}$ & & \\
\hline Bulbo posterior & & & $0,33-0,39$ & $0,33-0,39$ & 0,27 & \\
\hline Ventosa & & & $0,38-0,46$ & & & \\
\hline $\begin{array}{l}\text { Ventosa - extremidade } \\
\text { caudal }\end{array}$ & & & $2,6-2,9$ & & & \\
\hline Ânus & & & $1,94-2,25$ & & & \\
\hline Vagina & & & & & & 0,491 \\
\hline Ovos & & & & & & $0,126 \times 0,069$ \\
\hline Papilas caudais & & & 6 pares pré, 2 & de 3 pós anal & 3 pares pré, & ad e 4 pós anal \\
\hline
\end{tabular}

\section{Falcaustra Lane, 1915}

Boca com três lábios pouco individualizados, tendo cada um duas papilas salientes. Cutícula com fina estriação transversal. Papilas cervicais não aparentes. Esôfago alongado com curto faringe e apresentando posteriormente um bulbo provido de pequena dilatação ou pseudobulbo. Extremidade posterior cônica em ambos os sexos. Fêmeas ovíparas com a vulva na metade posterior do corpo. Ovejetor simples, com dois vestíbulos longos. Úteros divergentes. Machos com musculatura pré-anal bem desenvolvida e oblíqua ao eixo longitudinal do corpo. Sem asas caudais e com uma ou mais ventosas rudimentares que podem faltar em algumas espécies. Papilas caudais presentes, pequenas, pré e pós anais. Espículos iguais, comprimidos lateralmente, falcados. Gubernáculo presente, algumas vezes pouco quitinizado. Parasitos de vertebrados de sangue frio.

Espécie tipo: $F$. falcata Linstow, 1906.

Espécies assinaladas no Brasil:

F. mascula (Rud., 1819) Freitas \& Lent, 1941 (Tab. XVI; Figs 143-144)

Sinonímia: Ascaris mascula Rud., 1819; Florencioia mascula Travassos, 1920; Florencioia nitida Travassos, 1920; Spironoura mascula Yorke \& Maplestone, 1926; Spironoura nitidum Yorke \& Maplestone, 1926; Ascaris leptodactyla Parodi in Savazzini, 1930; Spironoura mascula Walton, 1932; Falcaustra nitida 
Tabela XVI. Tonaudia freitasi, dados segundo Vicente \& Santos, 1968; Falcaustra belemensis, dados segundo Baker \& Bain, 1981 e F. mascula, dados segundo Gomes \& Vicente, 1966.

\begin{tabular}{|c|c|c|c|c|c|c|}
\hline & \multicolumn{2}{|c|}{ T. freitasi } & \multicolumn{2}{|c|}{ F. belemensis } & \multicolumn{2}{|c|}{ F. mascula } \\
\hline & Macho & Fêmea & Macho & Fêmea & Macho & Fêmea \\
\hline Comprimento & $12,79-13,06$ & $13,32-14,92$ & 6,80 & 11,00 & $8,33-9,33$ & $8,66-9,78$ \\
\hline Largura & $0,47-0,59$ & $0,53-0,61$ & & & $0,30-0,33$ & $0,32-0,42$ \\
\hline Dilataçâo cefálica & $\begin{array}{c}0,05-0,07 \times \\
0,13-0,16\end{array}$ & $\begin{array}{c}0,05-0,07 \times x \\
0,13-0,16\end{array}$ & & & & \\
\hline Faringe & & & 0,041 & 0,050 & 0,100 & $0,080-0,100$ \\
\hline Vestíbulo & $0,14-0,15$ & 0,13 & & & & \\
\hline Esôfago total & $3,86-4,26$ & $3,51-3,70$ & 0,984 & 1,425 & $1,53-1,60$ & $1,60-1,65$ \\
\hline Pré-bulbo & $\begin{array}{c}0,13-0,17 \times x \\
0,14-0,15\end{array}$ & $\begin{array}{c}0,14 \mathrm{x} \\
0,15-0,16\end{array}$ & & & $\underset{0,12-0,13 x}{0,08}$ & $\begin{array}{c}0,13 x \\
0,10\end{array}$ \\
\hline Bulbo posterior & $0,29-0,33$ & $0,35-0,43$ & 0,128 & 0,175 & $\begin{array}{c}0,17 x \\
0,15-0,17\end{array}$ & $\begin{array}{c}0,17-0,18 x \\
0,18-0,20\end{array}$ \\
\hline Anel nervoso & 0,58 & $0,50-0,54$ & 0,225 & 0,356 & 0,33 & $0,27-0,30$ \\
\hline Poro excretor & $3,33-3,41$ & $2,85-3,06$ & 0,688 & 1,019 & $1,01-1,04$ & $1,07-1,20$ \\
\hline Vulva & & $4,17-6,00$ & & 7,10 & & $2,80-3,20$ \\
\hline Ovejetor & & $2,93-3,30$ & & & & $0,35-0,38$ \\
\hline Ovos & & $\begin{array}{c}0,093-0,096 \mathrm{x} \\
0,048\end{array}$ & & & & $\begin{array}{c}0,053 \times \\
0,039\end{array}$ \\
\hline Cauda & & & 0,281 & & & \\
\hline Ânus & $1,26-1,44$ & $0,78-1,00$ & & & $0,21-0,27$ & $0,33-0,37$ \\
\hline Reto & & $0,16-0,19$ & & & & $0,17 \cdot 0,18$ \\
\hline Espiculos & $0,26-0,30$ & & 0,314 & & $0,43-0,47$ & \\
\hline Gubernáculo & & & 0,082 & & 0,10 & \\
\hline Ventosa-ânus & $0,86-0,91$ & & & & $1,07-1,33$ & \\
\hline Ventosa & 0,86 & & & & $0,30-0,33$ & \\
\hline Ânus-apêndice caudal & $0,083-0,130$ & & & & & \\
\hline Papilas caudais & $\begin{array}{l}6 \text { pares pré, } 2 \text { ad } \\
\text { e } 3 \text { pós anal }\end{array}$ & & & & $\begin{array}{c}4 \text { pares pré e } 6 \\
\text { pós anal }\end{array}$ & \\
\hline
\end{tabular}

Freitas \& Lent, 1941; Falcaustra leptodactyla Freitas \& Lent, 1941; Ascaris leptodactylus Freitas \& Lent, 1941; Florencioia masculum Skrjabin, Shikhobalova \& Mozgovoi, 1951.

Hospedeiro e proveniência: Leimadophis poecilogyrus (Wied.), Rio de Janeiro: Rio de Janeiro.

Localização: intestino.

Referência bibliográfica: 54 .

F. belemensis Baker \& Bain, 1981 (Tab. XVI, Figs 140-142)

Hospedeiro e proveniência: Neusticurus bicarinatus L., Pará: Belém.

Loalização: intestino.

Referência bibliográfica: 32 . 
F. tikasinghi (Schroeder, Schimidt \& Everard, 1977) Baker \& Bain, 1981 (Tab. XV, Figs 145-147)

Sinonímia: Spironoura tikasinghi Schroeder, Schimidt \& Everard, 1977.

Hospedeiro e proveniência: Geomyda punctularia, Pará: Belém.

Referência bibliográfica: 32 .

\section{Kathlania Lane, 1914}

Cutícula estriada transversalmente com franjas laterais. Cabeça separada do corpo por uma ligeira constricção. Cada lábio é subdividido em um lobo principal grande e quatro subsidiários, dois de cada lado do lobo principal. Entre os lábios subventrais existem cinco subsidiários. As papilas cefálicas laterais e as quatro submedianas estão em alguns dos lobos subsidiários enquanto cada lobo principal tem um par de papilas pequenas em sua face interna. Cápsula bucal presente, triangular em corte, com três estruturas em forma de dente na entrada. Esôfago cilíndrico terminando numa dobra seguida por um bulbo separada por uma constriç̧ão. Machos com cauda terminando em um longo espinho. Ventosa pré-anal sem anel quitinoso. Papilas caudais sésseis, sendo três pares pré-anais, três ad-anais, cinco pós-anais e um par ímpar pré-anal. Espículos subiguais, relativamente curtos, de asas largas. Gubernáculo em forma de Y. Fêmeas com cauda longa, subulada; vulva logo após a metade do corpo. Útero anterior retornando para trás e correndo paralelo ao posterior. Ovos de casca fina, delicadamente estriados, contendo embriões quando da postura. Parasitos do aparelho digestivo de tartarugas marinhas.

Espécie tipo: K. leptura (Rud., 1819) Travassos, 1918.

Espécie assinalada no Brasil:

K. leptura (Rud., 1819) Travassos, 1918 (Tab. XV, Fig. 148)

Sinonímia: Ascaris leptura Rud., 1819; Oxysoma lepturum Schneider, 1866; Kathlania kathlena Lane, 1914; Pseudoheterakis lepturis Travassos, 1917.

Hospedeiro e proveniência: Chelonia mydas (L.), Brasil.

Localização: intestino.

Referência bibliográfica: 123.

\section{Oxyascaris Travassos, 1920}

Asas laterais ausentes. Boca trilabiada. Ístmo bem diferenciado do corpus do esôfago. Fêmeas com ovários geralmente recurrentes, terminando no terço médio do corpo; ovário anterior não atingindo a região esofagiana; cauda digitiforme, com apêndice terminal, alongado cônico. Reto muito forte. Machos desprovidos de pseudoventosa pré-anal. Três pares de papilas pré e três pares de pós-anais. Gubernáculo ausente. Parasitos de répteis e anfíbios.

Espécie tipo: O. oxyascaris Travassos, 1920.

Espécie assinalada no Brasil: 
O. oxyascaris Travassos, 1920 (Tab. XVII, Figs 150-152)

Sinonímia: Oxyascaris nẹcopinus Freitas, 1958.

Hospedeiros e proveniências: Dryadophis bifossatus Stuart (=Mastigodryas bifossatus (Radi), Rio de Janeiro: Rio de Janeiro; Leimadophis poecilogynus (Wied) e Herpetodrias carinatus L., Rio de Janeiro: Angra dos Reis.

Localização: intestinos delgado e grosso.

Referências bibliográficas: 59, 125 .

Tabela XVII. Oxyascaris oxyascaris, dados segundo Freitas, 1956; Brevimulticaecum baylisi, dados segundo Travassos, 1933 e B. gibsoni, dados segundo Sprent, 1979.

\begin{tabular}{|c|c|c|c|c|c|}
\hline & \multicolumn{2}{|c|}{ O. oxyascaris } & \multicolumn{2}{|c|}{ B. baylisi } & \multirow{2}{*}{$\begin{array}{c}\text { B. gibsoni } \\
\text { Fêmea }\end{array}$} \\
\hline & Macho & Fêmea & Macho & Fêmea & \\
\hline Comprimento & $5,16-6,06$ & $10,52-23,28$ & $11,00-12,00$ & 17,00 & $11,00-17,00$ \\
\hline Largura & $0,27-0,33$ & $0,40-0,60$ & $0,40-0,44$ & 0,80 & \\
\hline Faringe & $0,043-0,061$ & $0,052-0,140$ & & & \\
\hline Lábios & & & $0,080-0,086$ & 0,120 & \\
\hline Esôfago & $0,60-0,83$ & $0,70-1,41$ & & 3,00 & 1,80 \\
\hline Interlábios & & & $0,04-0,06$ & & \\
\hline Bulbo (com istmo) & $\begin{array}{c}0,113-0,174 x \\
0,087-0,104\end{array}$ & $\begin{array}{l}0,174-0,226 x \\
0,096-0,157\end{array}$ & & & \\
\hline Bulbo (sem istmo) & & & $0,08-0,09$ & $0,12-0,16$ & 0,33 \\
\hline Anel nervoso & $0,26-0,31$ & $0,35-0,45$ & $0,43-0,57$ & & \\
\hline Poro excretor & $0,33-0,53$ & $0,41-0,68$ & 0,40 & 0,50 & 0,32 \\
\hline Vulva & & $4,72-9,78$ & & & $\begin{array}{l}21-26 \% \text { do comprimento } \\
\text { do corpo }\end{array}$ \\
\hline Ovos & & $\begin{array}{l}0,084-0,101 \times \\
0,059-0,067\end{array}$ & & & $\begin{array}{c}0,062-0,094 x \\
0,044-0,065\end{array}$ \\
\hline Reto & & $0,21-0,33$ & & & \\
\hline Apêndices ventriculares & & & & & $0,02-0,05$ \\
\hline Ânus & $0,20-0,32$ & $0,28-1,06$ & 0,80 & 0,26 & \\
\hline Espiculos & $0,189-0,206$ & & $6,500-8,400$ & & \\
\hline Apèndice caudal & $0,029-0,034$ & $0,029-0,042$ & & & \\
\hline Ceco esofagiano & & & $0,07-0,08$ & & 1,10 \\
\hline $\begin{array}{l}\text { Ceco intestinal-extremi- } \\
\text { dade anterior }\end{array}$ & & & $0,4-0,8$ & $0,1-2,0$ & \\
\hline Ovos & & & & $0,056 \times 0,064$ & \\
\hline Gubernáculo & & & $0,14-0,17$ & & \\
\hline Vagina & & & & & 0.5 \\
\hline Papilas caudais & 3 pares pr & 3 pós anal & 6 pares pr & 7 pós anal & \\
\hline
\end{tabular}

\section{Tonaudia Travassos, 1918}

Asas laterais presentes. Cabeça separada do corpo por uma constricção bem marcada. Machos com cauda terminada em um longo espinho dorsal. Ventosa pré-anal sem anel quitinoso. Oito pares de papilas cloacais e uma papila pré-anal presentes. Espículos extremamente longos e delgados. Estreita asa alcançando a região mediana do esôfago. Gubernáculo presente, em forma de Y fracamente quitinizado. Vulva logo após o meio do esôfago. Vagina muito longa, sinuosa. Parasitos do aparelho digestivo de tartarugas marinhas. 
Espécie tipo: T. tonaudia (Lane, 1914) Travassos, 1918.

T. freitasi Vicente \& Santos, 1968 (Tab. XVI, Figs 136-139)

Hospedeiro e proveniência: Chelonia mydas (L.), Ceará: Aracatí.

Localização: estômago.

Referência bibliográfica: 159 .

\section{Heterakoidea}

Esta superfamília é representada pela família Heterakidae Railliet \& Henry, 1914 com os gêneros: Africana Travassos, 1920, Bufonerakis Baker, 1980, Moaciria Freitas, 1956, Spinicauda Travassos, 1920 e Strongyluris Mueller, 1894 que têm espécies parasitas de répteis.

\section{Heterakidae Railliet \& Henry, 1914}

Boca com três lábios bem definidos; vestíbulo ausente; esôfago com uma faringe na parte anterior e uma parte posterior longa terminando em um bulbo. Intestino simples sem divertículo. Macho com ventosa preanal circular com anel quitinoso; espículos iguais ou desiguais. Fêmeas com cauda alongada, dois ovários, vulva geralmente perto do meio do corpo; ovíparas. Parasitas de anfíbios, répteis e mamíferos.

\section{Chave para identificação dos gêneros}

1. Machos sem asa caudal ........................... Spinicauda

- Machos com asa caudal ................................

2. Asa caudal nâo suportada por papilas $\ldots \ldots \ldots \ldots \ldots \ldots \ldots \ldots+$ fricana

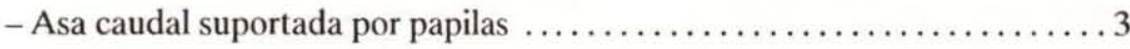

3. Extremidade anterior do esôfago dividida em três lobos suportados por espessa cutícula que se projeta na cavidade bucal ......... Bufonerakis

- Extremidade anterior do esôfago sem as características anteriores . ......4

4. Gubernáculo presente $\ldots \ldots \ldots \ldots \ldots \ldots \ldots \ldots \ldots \ldots \ldots \ldots \ldots \ldots \ldots \ldots \ldots \ldots \ldots \ldots$

- Gubernáculo ausente .......................... Strongyluris

\section{Africana Travassos, 1920}

Lábios bem desenvolvidos, subglobulares, expandidos anteriormente e lateralmente em asas cuticulares. Faringe presente; esôfago com bulbo posterior. Machos com cauda não curvada, cônica; asa caudal reduzida, estendendo-se um pouco além da cloaca; papilas sésseis, em sua maioria pequenas. Espículos longos, afilados, iguais ou desiguais; gubernáculo ausente. Fêmeas com a vulva na região mediana do corpo; ramos uterinos aparentemente opos- 
tos; ovos de casca espessa. Parasitos do tubo digestivo de répteis e anfíbios.

Espécie tipo: A. africana (Gendre, 1909).

Espécie assinalada no Brasil:

A. chabaudi Baker, 1981 (Tab. XVIII, Figs 130-132)

Hospedeiro e proveniência: Uranoscodon superciliosa (L.), Pará: Belém.

Localização: intestino.

Referência bibliográfica: 31 .

Tabela XVIII. Spinicauda spinicauda, dados segundo Pereira, 1935; Africana chabaudi, dados segundo Baker, 1981 e Moaciria alvarengai, dados segundo Freitas, 1956.

\begin{tabular}{|c|c|c|c|c|c|c|}
\hline & \multicolumn{2}{|c|}{ S. spinicauda } & \multicolumn{2}{|c|}{ A. chabaudi } & \multicolumn{2}{|c|}{ M. alvarengai } \\
\hline & Macho & Fêmea & Macho & Fêmea & Macho & Fêmea \\
\hline Comprimento & $2,80-3,30$ & $4,50-5,30$ & 6,80 & 7,90 & $3,01-3,93$ & $4,12-5,49$ \\
\hline Largura & 0,50 & $0,50-0,60$ & & & $0,20-0,27$ & $0,38-0,51$ \\
\hline Faringe & 0,037 & 0,037 & & & $\begin{array}{c}0,046-0,059 \times \\
0,021-0,023\end{array}$ & $\begin{array}{r}0,052-0,070 \\
0,026-0,029\end{array}$ \\
\hline Esôfago & $0,69-0,72$ & 0,85 & 1,238 & 1,169 & $0,51-0,66$ & \\
\hline Bulbo esofagiano & 0,16 & 0,20 & & & $\begin{array}{c}0,08-0,10 x \\
0,09-0,13\end{array}$ & $\begin{array}{c}0,13-0,15 \times x \\
0,15-0,17\end{array}$ \\
\hline Poro excretor & 0,54 & 0,54 & 0,706 & 0,612 & & \\
\hline Ventosa & $0,08-0,09$ & & 0,050 & & $0,042-0,050$ & \\
\hline Ventosa-ânus & $0,024-0,034$ & & & & & \\
\hline Espiculos & $0,35-0,40$ & & 0,806 & & $0,23-0,29$ & \\
\hline Gubernáculo & $0,18-0,19$ & & & & $0,15-0,16$ & \\
\hline Ânus & & $0,50-0,60$ & & & 0,042 & $0,50-0,65$ \\
\hline Vulva & & $1,70-2,40$ & & 3,50 & & $1,91-2,41$ \\
\hline Ovos & & $0,074 \times 0,053$ & & & & $0,076 \times 0,04$ \\
\hline Anel nervoso & & & 0,381 & 0,444 & $0,20-0,24$ & 0,31 \\
\hline Cauda & & & 0,344 & 0,362 & & \\
\hline Ovejetor & & & & & & 0,46 \\
\hline Reto & & & & & & 0,16 \\
\hline Apêndice caudal & & & & & $0,11-0,13$ & \\
\hline Papilas caudais & & & 10 pares & & 7 pares $\mathrm{e}$ & 3 impares \\
\hline
\end{tabular}

\section{Bufonerakis Baker, 1980}

Cabeça sem cordões e interlábios. Extremidade anterior do esôfago dividida em três lobos suportados por espessa cutícula projetando-se na cavidade bucal. Cada lobo contém processos semelhantes a dentes. Cutícula da superfície sub-ventral da região caudal inflada formando uma asa caudal. Asa caudal suportada por muitas papilas de tamanhos e forma variáveis. Espículos iguais, de estrutura simples. Gubernáculo não observado. Fêmeas com vulva em forma de fenda não coberta por aba da cutícula e uma vagina dobrada, muscular de onde origina o útero dirigido para diante e para trás. Ambos os ovários são anteriores à vulva. Parasitos de répteis na regiấo Neotropical.

Espécie tipo: B. andersoni Baker, 1980. 
Espécie assinalada no Brasil:

B. rodriguesi (Vicente \& Gomes, 1971) Baker, 1980 (Tab. XIV, Figs 124-126)

Sinonímia: Meteterakis rodriguesi Vicente \& Gomes, 1971.

Hospedeiro e proveniência: Pseudoboa trigemina (Dumeril \& Bibron), Amazonas: Manaus.

Localização: intestino

Referências bibliográficas: 29, 153 .

\section{Moaciria Freitas, 1956}

Cutícula estriada transversalmente. Boca trilabiada. Esôfago com faringe e com bulbo posterior. Asas laterais presentes. Fêmeas didelfas, anfidelfas, ovíparas com a vulva na parte média do corpo, com a cauda truncada em pequeno apêndice caudal. Machos com asa caudal suportada por papilas curtas e grossas. Ventosa pré-anal presente, circular, de rebordo quitinoso, ânus imediatamente após a ventosa. Asas caudais presentes, pequenas, sustentadas por papilas. Espículos simples, iguais. Gubernáculo presente. Parasitō̄ de répteis.

Espécie tipo: M. alvarengai Freitas, 1956.

Espécie assinalada no Brasil:

\section{M. alvarengai Freitas, 1956 (Tab. XVIII, Figs 133-135)}

Hospedeiro e proveniência: Mabuya maculata (Gray), Pernambuco: Fernando de Noronha.

Localização: intestino grosso.

Referência bibliográfica: 57 .

\section{Spinicauda Travassos, 1920}

Campos laterais conspícuos, compostos de uma fileira única de células grandes. Lábios subtriangulares expandidos anterior e lateralmente sem cordōes. Faringe presente; esôfago com bulbo posterior. Machos com cauda longa, subulada, sem asa. Papilas pequenas, sésseis, ventrais presentes. Espículos curtos subiguais; gubernáculo presente. Fêmeas com cauda longa; vulva próxima ao meio do corpo. Ramos uterinos paralelos. Ovíparas. Ovos de casca espessa e frequentemente rugosa. Parasitos do canal alimentar de répteis e anfíbios.

Espécie tipo: $S$. spinicauda (Olfers in Rud., 1819) Travassos, 1920. Espécie assinalada no Brasil:

S. spinicauda (Olfers in Rud., 1819) Travassos, 1920 (Tab. XVIII; Figs 127-129)

Sinonímia: Ascaris spinicauda Olfers in Rud., 1819; Heterakis turgida Schneider, 1866; Heterakis campanulata Linstow, 1899; Heterakis campanula Travassos, 1913; Strongyluris campanulata Seurat, 1917; Spinicauda amarali Pereira, 1935. 
Hospedeiros e proveniências: Tupinambis teguixin L. (=Tejus teguixin L.), Rio de Janeiro: Rio de Janeiro, Ceará: Fortaleza; Ameiva ameiva ameiva (L.), Rio de Janeiro: São Gonçalo.

Localização: intestino grosso.

Referências bibliográficas: 56, 104.

Strongyluris Mueller, 1894

Extremidade anterior sem dilatação cuticular cefálica. Boca trilabiada. Vestíbulo ausente. Esôfago com faringe anterior e bulbo posterior. Intestino simples, sem divertículo. Machos com asas caudais estreitas e espessas e com ventosa pré-anal presente, circular, de rebordo quitinoso, imediatamente anterior ao ânus, com espículos iguais ou subiguais, raramente desiguais e com cauda truncada. Fêmeas didelfas, anfidelfas, ovíparas, com vulva na parte média do corpo e com cauda subulada. Parasitos de répteis e anfíbios e acidentalmente de mamíferos.

Espécie tipo: S. brevicaudata Mueller, 1894.

Espécies assinaladas no Brasil:

S. oscari Travassos, 1923 (Tab. XIV, Figs 122-123)

Sinonímia: Strongyluris sai Travassos, 1926; Strongyluris travassosi Alho, 1969; Strongyluris freitasi Alho, 1969.

Hospedeiros e proveniências: Tropidurus sp., Mato Grosso do Sul: São João; Tropidurus torquatus (Wied.), Rio de Janeiro: Rio de Janeiro, Paraíba: Umbuseiro, Goiás: Santa Maria e Xavantina, Distrito Federal: Brasília, Bahia: Salvador, Espírito Santo: Conceição da Barra, São Paulo: Ilha Seca e Lussanvira, Pará: Cachimbo e Belém, Ceará: Fortaleza; Tropidurus spinulosus (Cope), Mato Grosso do Sul: Salobra; camaleão verde indeterminado [provavelmente Ameiva ameiva (L.)], Rio de Janeiro: Angra dos Reis.

Localização: intestinos grosso e delgado.

Referências bibliográficas: $5,78,152$.

Strongyluris sp. Travassos, Freitas \& Lent, 1939

Hospedeiros e proveniência: Tropidurus torquatus (Wied.) e Tropidurus spinulosus (Cope), Mato Grosso do Sul: Salobra.

Localização: intestino.

Referência bibliográfica: 141 .

\section{Oxyuroidea}

Esta superfamília encerra as famílias Oxyuroidae Cobbold, 1864 com os gêneros Gynaecometra Araújo, 1978 e Typhlonema Kreis, 1938 e Pharyngodonidae Travassos, 1919 com os gêneros Alaeuris Thapar, 1919, Ozolaimus Dujardin, 1845, Pharyngodon Diesing, 1861 e Thelandros Wedl, 1862. 


\section{Chave para identificação das famílias}

- Cone genital suportado por uma estrutura quitinosa em forma de $\mathrm{V}$........ . Pharyngodonidae - Sem as características anteriores $\ldots \ldots \ldots \ldots \ldots \ldots \ldots \ldots \ldots$ Oxyuridae

\section{Oxyuridae Cobbold, 1864}

Nematóides de tamanho pequeno ou médio. Boca variável. Esôfago terminando em um bulbo, frequentemente claramente separado do resto do esôfago. Intestino simples sem divertículo. Macho sem ventosa preanal ou algum desenvolvimento especial dos músculos pré-anais. Espículo simples ou dois espículos iguais. Gubernáculo presente ou ausente. Fêmea com cauda usualmente longa e subulada, apresenta dois ovários, vulva situada geralmente na parte anterior do corpo, mas algumas vezes na parte posterior. Usualmente ovíparas, raramente vivíparas. Ovos elipsóides, geralmente mais compridos e assimétricos. Parasitos de vertebrados.

\section{Chave para identificação dos gêneros}

- Fêmeas vivíparas com vulva adiante do meio do corpo ....... Gynaecometra

- Fêmeas ovovivíparas com vulva imediatamente anterior ao bulbo esofagiano . Typhlonema

\section{Gynaecometra Araújo, 1978}

Cutícula com fina estriação transversal. Asas laterais ausentes. Extremidade anterior com dimorfismo sexual; presença de seis lábios cônicos nas fêmeas e ausência de lábios nos machos; ligeira dilatação cuticular na extremidade anterior dos machos, ausente nas fêmeas. Cápsula bucal presente nas fêmeas, ausente nos machos. Esôfago com bulbo posterior, contendo aparelho valvular. Poro excretor ao nível do bulbo esofagiano nas fêmeas. Machos com a cauda apresentando o aspecto de retângulo quando observada ventral ou dorsalmente. Espículo robusto; gubernáculo presente, bem quitinizado. Fêmeas com cauda subulada e ponteaguda. Vulva adiante do meio do corpo; ovejetor curto; dois ovários curtos, digitiformes; opistodelfas, vivíparas. Parasitas de répteis.

Espécie tipo: G. bahiensis Araújo, 1978.

Espécie que ocorre no Brasil:

\section{G. bahiensis Araújo, 1978 (Tab. IX, Figs 91-93)}

Hospedeiro e proveniência: Polichrus acutirostris Spix, Bahia: XiqueXique.

Localização: intestino.

Referência bibliográfica: 24 . 


\section{Typhlonema Kreis, 1938}

Corpo delgado, cutícula estriada transversalmente. Boca com três lábios; cavidade bucal pequena, de forma prismática. Esôfago com bulbo posterior contendo aparelho valvular e separado do resto do ístmo onde falta musculatura. Anel nervoso situado cerca de 1/3 do comprimento do corpo a partir da extremidade anterior; poro excretor na região esofagiana, anterior à vulva. Extremidade posterior terminando em ponta cônica e afilada, não subulada; abertura anal não observada. Vulva imediatamente anterior ao bulbo esofagiano. Ovejetor longo; vagina fortemente musculosa; ovários pares, ovos grandes, subglobulares, de casca grossa, com espessamento nodular em um dos polos. Ovovivíparas. Machos desconhecidos. Parasitos do intestino de lagartos.

Espécie tipo: T. salomonis Kreis, 1938.

Espécie assinalada no Brasil:

Typhlonema sp. Travassos, Freitas \& Lent, 1939

Hospedeiro e proveniência: Tropidurus spinulosus (Cope), Mato Grosso do Sul: Salobra.

Referência bibliográfica: 141.

\section{Pharyngodonidae Travassos, 1919}

Boca com seis lábios. Cutícula espessada com estriaçōes transversais distintas. Macho com cauda truncada, com papilas caudais, apresentando um espículo, raramente com gubernáculo; geralmente dotado de formaçōes quitinosas e apêndice caudal quase sempre delgado e longo. Parasitos de anfíbios e répteis.

\section{Chave para identificação dos gêneros}

1. Macho com gubernáculo .......................... Alaris

- Macho sem gubernáculo .............................

2. Esôfago dividido em duas partes $\ldots \ldots \ldots \ldots \ldots \ldots \ldots \ldots \ldots$ Ozolaimus

- Esôfago não dividido em duas partes $\ldots \ldots \ldots \ldots \ldots \ldots \ldots \ldots \ldots \ldots \ldots \ldots \ldots \ldots \ldots$

3. Extremidade posterior do macho romba com um longo processo que se inicia dorsalmente na linha mediana, espículo curto e acicular vulva posterior ao meio do corpo $\ldots \ldots \ldots \ldots \ldots \ldots \ldots \ldots \ldots \ldots \ldots \ldots$ Thelandros

- Extremidade posterior do macho subulada sem um processo que se inicia dorsalmente na linha mediana, espículo curto e ligeiramente quitinizado; vulva anterior ao meio do corpo.................. Pharyngodon

\section{Alaeuris Thapar, 1919}

Vermes pequenos ou de tamanho médio. Asas laterais presentes. Boca com três lábios, esôfago alongado, provido posteriormente de um bulbo con- 
tendo aparelho valvular. Machos com a extremidade posterior truncada ventralmente após a cloaca e terminando em uma cauda cônica provida de uma asa caudal alargada, com três pares de papilas circun-anais e um par de papilas próximas à ponta da cauda; espículo longo, afilado, acicular; gubernáculo presente em forma de V. Fêmeas com cauda curta e cônica; vulva após a metade do corpo; ovejetor longo; útero e ovários duplos, convolutos próximos à vulva. Ovíparas; útero contendo ovos segmentados. Parasitos de répteis.

Espécie tipo: A. alaeuris Thapar, 1925.

Espécies assinaladas no Brasil:

A. caudatus (Lent \& Freitas, 1948) Peter \& Quentin, 1976 (Tab. XIX, Figs 65-68)

Sinonímia: Pseudoalaeuris caudatus Lent \& Freitas, 1948.

Hospedeiro e proveniência: Iguana iguana (L.), Pernambuco: Exú.

Localização: intestino grosso.

Referências bibliográficas: 81, 97.

A. vogelsangi (Lent \& Freitas, 1948) Peter \& Quentin, 1976 (Tab. XX,Figs 69-72)

Sinonímia: Pseudoalaeuris vogelsangi Lent \& Freitas, 1948.

Hospedeiro e proveniência: Iguana iguana (L.), Pernambuco: Exú.

Localização: intestino grosso.

Referências bibliográficas: 81, 97.

\section{Ozolaimus Dujardin, 1845}

Boca alongada dorsoventralmente, com dois lábios laterais. Esôfago muito longo, consistindo de uma porção anterior forte, curta com uma dobra fusiforme e uma porção posterior delgada terminando em bulbo distinto. Intestino dilatado anteriormente. Asas laterais ausentes. Machos com cauda curta, truncada, espículo longo. Fêmeas com a cauda afilando-se gradualmente; ânus próximo à extremidade posterior do corpo; genitália na porção anterior. Ovos grandes. Parasitos intestinais de Iguanidade.

Espécie tipo: O. megatyphlon (Rud., 1819) Dujardin, 1845.

Espécies assinaladas no Brasil:

O. cirratus Linstow, 1906 (Tab. XIX, Figs 61-62)

Hospedeiro e proveniência: Iguana iguana (L.), Paraíba: Santa Luzia.

Localização: intestino grosso.

Referência bibliográfica: 92 .

O. megatyphlon (Rud., 1819) Dujardin, 1845 (Tab. XIX, Figs 63-64)

Sinonímia: Ascaris megatyphlon Rud., 1819.

Hospedeiro e proveniência: Iguana iguana (L.), Paraíba: Santa Luzia.

Localização: intestino grosso.

Referência bibliográfica: 92 . 
Tabela XIX. Ozolaimus cirratus, O. megatyphlon, dados segundo Pereira, 1935 e Alaeuris caudatus, dados segundo Lent \&Freitas, 1948.

\begin{tabular}{|c|c|c|c|c|c|c|}
\hline & \multicolumn{2}{|c|}{ O. cirratus } & \multicolumn{2}{|c|}{ O. megatyphlon } & \multicolumn{2}{|c|}{ A. caudatus } \\
\hline & Macho & Fêmea & Macho & Fêmea & Macho & Fêmea \\
\hline Comprimento & $4,30-4,50$ & $4,40-5,90$ & $3,90-5,10$ & $5,80-6,20$ & $1,48-1,58$ & $2,31-2,62$ \\
\hline Largura & 0,49 & $0,70-0,76$ & $0,43-0,50$ & $0,70-0,76$ & $0,087-0,104$ & $0,149-0,199$ \\
\hline 1 porção do esôfago & $\begin{array}{c}0,70-0,76 x \\
0,16-0,18\end{array}$ & $\begin{array}{c}0,92-0,98 x \\
0,21\end{array}$ & $0,80-1,00$ & 1,00 & & \\
\hline $2^{2}$ porção do esôfago & $0,52-0,60 \times 0,06$ & $0,60-0,70 \times 0,08$ & $0,55-0,98$ & $1,20-1,30$ & & \\
\hline Esôfago total & $1,50-2,00$ & & & & $0,43-0,46$ & $0,56-0,61$ \\
\hline Bulbo esofagiano & $\begin{array}{c}0,21 x \\
0,10-0,13\end{array}$ & $\begin{array}{l}0,27 x \\
0,21\end{array}$ & & 0,21 & $\begin{array}{c}0,052-0,070 x \\
0,052-0,061\end{array}$ & $\begin{array}{c}0,070-0,087 \times x \\
0,078-0,087\end{array}$ \\
\hline Anel nervoso & 0,24 & 0,24 & 0,26 & & $0,12-0,13$ & $0,13-0,14$ \\
\hline Poro excretor & $1,50-1,63$ & $1,20-2,00$ & 1,80 & 1,60 & $0,68-0,78$ & $0,68-0,78$ \\
\hline Espiculo & $1,60-1,90$ & & $0,98-1,10$ & & $0,080-0,088$ & \\
\hline Gubernáculo & & & & & $0,017-0,019$ & \\
\hline Ânus & & $0,32-0,38$ & & $0,24-0,34$ & $0,046-0,055$ & $0,36-0,39$ \\
\hline Vulva & & $1,30-1,40$ & & $1,30-1,60$ & & $1,06-1,18$ \\
\hline Vagina & & 1,45 & & & & $0,24-0,26$ \\
\hline Estincter & & 0,50 & & & & \\
\hline Vestíbulo & & 0,70 & & & & \\
\hline Ovos & & $\begin{array}{c}0,131 x \\
0,057-0,061\end{array}$ & & $\begin{array}{c}0,131 \times \\
0,065\end{array}$ & & $\begin{array}{c}0,157-0,165 x \\
0,078-0,104\end{array}$ \\
\hline Ovejetor & & & & & & $0,35-0,39$ \\
\hline Reto & & & & & & $0,14-0,15$ \\
\hline Papilas caudais & & & & & 1 par prée & 3 pós anal \\
\hline
\end{tabular}

\section{Pharyngodon Diesing, 1861}

Cutícula com estriações transversais distintas; com ou sem asas laterais. Boca com três lábios indistintos, sem cavidade bucal. Esôfago com bulbo posterior. Machos com cauda abruptamente comprimida ao nível do orifício ano-genital e continuada por um longo processo cônico dirigido dorsalmente. Asa caudal pequena. Um par de papilas pré-anais sésseis e dois pares pós-anais pedunculados, dos quais o posterior localiza-se próximo ao limite da asa. Espículo simples de ponta afilada, imperfeitamente quitinizado ou ausente. Fêmeas com a cauda terminando por uma abrupta constricção após o ânus em forma de aguilhão terminal, algumas vezes com espinhos. Vulva na metade anterior do corpo, pós-esofagiana. Ramos uterinos estreitos, paralelos. Ovíparas. Ovos alongados, estreitos, operculados em cada extremidade, não segmentados. Parasitos de répteis e anfíbios.

Espécie tipo: P. spinicauda (Dujardin, 1845) Seurat, 1917

Espécies assinaladas no Brasil:

P. cesarpintoi Pereira, 1935 (Tab. XX, Figs 73-74)

Hospedeiros e proveniência: Cnemidophorus lemniscatus (Daudin) e Ameiva ameiva (L.), Paraíba: Juazeiro.

Localização: intestino grosso.

Referências bibliográficas: 7, 92 . 
P. travassosi Pereira, 1935 (Tab. XX, Figs 75-77)

Hospedeiro e proveniência: Ameiva sp., Paraíba: Areia.

Localizaçāo: intestino grosso.

Referência bibliográfica: 92 .

Pharyngodon sp. Guimarães, 1975

Hospedeiro e proveniência: Tropidurus torquatus Wied, Bahia: Salvador.

Localização: intestino delgado.

Referência bibliográfica: 96 .

\section{Thelandros Wedl, 1862}

Boca trilabiada; cada lábio geralmente bilobado. Seis papilas labiais presentes. Esôfago com bulbo posterior. Asas laterais ausentes. Fêmeas didelfas, prodelfas, ovíparas. Ovos assimétricos. Machos com um espículo. Gubernáculo ausente. Cauda truncada, com apêndice caudal dorsal. Geralmente três pares de papilas caudais assim distribuídos: um pré-anal, um pós-anal e um no apêndice caudal. Parasitos de répteis e acidentamente de aves.

Espécie tipo: T. alatus Wedl, 1862.

Espécies assinaladas no Brasil:

T. alvarengai (Freitas, 1957) Peter \& Quentin, 1976 (Tab. XXI, Figs 78-80)

Sinonímia: Parapharyngodon alvarengai Freitas, 1957.

Hospedeiros e proveniências: Mabuya maculata (Gray), Pernambuco: Fernando de Noronha; Ameiva ameiva (L.), Rio de Janeiro: Itaguaí.

Localização: intestino grosso.

Referência bibliográfica: 58 .

T. largitor (Alho \& Rodigues, 1963) Peter \& Quentin, 1976 (Tab. XXI, Figs 81-83)

Sinonímia: Parapharyngodon largitor Alho \& Rodrigues, 1963

Hospedeiros e proveniência: Hemidactylus mabouia (M. de J.) e Ameiva ameiva (L.), Rio de Janeiro: Rio de Janeiro.

Localização: intestino grosso.

Referências bibliográficas: 9, 102 .

T. sceleratus Travassos, 1923 (Tab. XXI, Figs 84-86)

Sinonímia: Pseudothelandros sceleratus Read, Amrein \& Walton, 1952; Parapharyngodon sceleratus Freitas, 1957.

Hospedeiros e proveniências: Hemidactylus mabouia (M. de J.), e Ameiva ameiva (L.), Rio de Janeiro: Rio de Janeiro; Tropidurus torquatus (Wied), Bahia: Salvador e Canudos, Pará: Cachimbo, Rio de Janeiro: Rio de Janeiro e Arraial do Cabo, Mato Grosso do Sul: Salobra, Paraíba: Mogeiro, Lagoa do Remígio, Umbuseiro e João Pessoa, Rio Grande do Norte: Currais 
Tabela XX. Alaeuris vogelsangi, dados segundo Lent \& Freitas, 1948; Pharyngodon cesarpintoi e P. travassosi, dados segundo Pereira, 1935.

\begin{tabular}{|c|c|c|c|c|c|c|}
\hline & \multicolumn{2}{|c|}{ A. vogelsangi } & \multicolumn{2}{|c|}{ P. cesarpintoi } & \multicolumn{2}{|c|}{ P. travassosi } \\
\hline & Macho & Fêmea & Macho & Fêmea & Macho & Fêmea \\
\hline Comprimento & $1,54-2,02$ & $2,29-2,87$ & $1,61-1,81$ & $2,40-2,80$ & $1,74-1,96$ & $3,70-5,29$ \\
\hline Largura & $0,166-0,183$ & $0,199-0,249$ & $0,14-0,16$ & 0,43 & 0,21 & $0,50-0,60$ \\
\hline Esôfago & $0,78-0,88$ & $0,93-1,01$ & $0,21-0,26$ & $0,28-0,32$ & $0,30-0,38$ & $0,48-0,54$ \\
\hline Bulbo esofagiano & $\begin{array}{c}0,096-0,113 \times \\
0,104-0,113\end{array}$ & $\begin{array}{c}0,122-0,130 x \\
0,17-0,19\end{array}$ & $0,06-0,07$ & $0,08-0,09$ & 0,08 & 0,12 \\
\hline Anel nervoso & $0,16-0,17$ & $0,17-0,19$ & 0,13 & 0,13 & $0,14-0,15$ & 0,18 \\
\hline Poro excretor & \multicolumn{2}{|c|}{ ao nível do anel nervoso } & $0,44-0,48$ & $0,50-0,80$ & $0,50-0,64$ & $0,60-0,90$ \\
\hline Vulva & & $1,01-1,31$ & & & & \\
\hline Ovejetor & & $0,35-0,48$ & & & & $\begin{array}{c}0,40 \text { (jovem) } \\
0,72 \text { (madura) }\end{array}$ \\
\hline Vagina & & 0,22 & & & & \\
\hline Reto & & $0,16-0,17$ & & & & \\
\hline Ȧnus & & $0,26-0,28$ & & $0,60-0,74$ & & $0,50-0,98$ \\
\hline Espiculo & $0,19-0,21$ & & & & & \\
\hline Gubernácul . & $0,046-0,051$ & & & & & \\
\hline Filamento c iudal & & & 0,16 & & 0,10 & \\
\hline Cone genital & & & $0,024-0,008$ & & & \\
\hline Vulva-poro excretor & & & & 0,07 & & \\
\hline Ovos & & & & $0,132 \times 0,037$ & & $0,157 \times 0,045$ \\
\hline Papilas caudais & 2 pares pré & 2 pós anal & & & 1 par ad & 2 pós anal \\
\hline
\end{tabular}

Novos, Ceará Mirin, Pernambuco: Garanhuns; Tropidurus spinulosus (Cope), Mato Grosso do Sul: Salobra; Tropidurus sp., Goiás: Xavantina; Tapinurus scutipunctatus Amaral, Brasil.

Localização: intestino grosso.

Referências bibliográficas: 8, 58, 92, 102, 127, 152.

T. verrucosus (Freitas \& Dobbin Jr., 1959) Peter \& Quentin, 1976 (Tab. IX, Figs 87-90)

Sinonímia: Parapharyngodon verrucosus Freitas \& Dobbin Jr., 1959.

Hospedeiro e proveniência: Diploglossus lessonae Peracca, Pernambuco: Joāo Alfredo.

Localização: intestino delgado e grosso.

Referência bibliográfica: 61 .

Thelandros sp. Travassos, Freitas \& Lent, 1939

Hospedeiros e proveniência:Ameiva ameiva (L.) e Tropidurus spinulosus (Cope), Mato Grosso do Sul: Salobra.

Localização: intestino.

Referência bibliográfica: 141 .

Thelandros sp. Travassos, Freitas, Mendonça \& Rodrigues, 1960 
Tabela XXI. Thelandros alvarengai, dados segundo Freitas, 1957; T. largitor, dados segundo Alho \& Rodrigues, 1963 e T. sceleratus, dados segundo Vicente, 1981.

\begin{tabular}{|c|c|c|c|c|c|c|}
\hline & \multicolumn{2}{|c|}{ T. alvarengai } & \multicolumn{2}{|c|}{ T. largitor } & \multicolumn{2}{|c|}{ T. sceleratus } \\
\hline & Macho & Fêmea & Macho & Fêmea & Macho & Fêmea \\
\hline Comprimento & $1,05-2,82$ & $2,38-7,54$ & $1,49 \cdot 2,76$ & $4,70-5,42$ & $2,14-3,06$ & $5,27-8,87$ \\
\hline Largura & $0,15-0,43$ & $0,47-0,94$ & $0,14-0,19$ & $0,49-0,69$ & $0,26-0,49$ & $0,78-1,32$ \\
\hline Esôfago total & $0,33-0,50$ & $0,80-1,34$ & $0,24-0,34$ & $1,26-1,57$ & $0,26-0,42$ & $0,63-1,27$ \\
\hline Bulbo esofagiano & $0,08-0,11$ & $0,17-0,25$ & $\begin{array}{c}0,069-0,097 \times \\
0,072-0,108\end{array}$ & $\begin{array}{c}0,150-0,195 x \\
0,195-0,210\end{array}$ & $\begin{array}{c}0,082-0,110 \times \\
0,090-0,110\end{array}$ & $\begin{array}{c}0,160-0,190 \times \\
0,210-0,260\end{array}$ \\
\hline Anel nervoso & $0,14-0,17$ & $0,17-0,27$ & & & $0,098-0,110$ & $0,22-0,49$ \\
\hline Poro excretor & & $0,73-1,67$ & $0,32-0,36$ & $1,57-1,92$ & $0,45-0,65$ & $1,82-2,38$ \\
\hline Vulva & & $1,27-3,58$ & & $2,62-3,30$ & & $2,89-4,69$ \\
\hline Ovejetor & & $0,38-0,83$ & & 0,38 & & $1,16-1,18$ \\
\hline Ovos & & $\begin{array}{c}0,078-0,087 x \\
0,039-0,052\end{array}$ & & $\begin{array}{c}0,072-0,082 \times \\
0,032-0,033\end{array}$ & & $\begin{array}{c}0,080-0,093 \times \\
0,035-0,043\end{array}$ \\
\hline Reto & & $0,13-0,23$ & & $0,226-0,315$ & & $0,25-0,35$ \\
\hline Ânus & $0,017-0,025$ & $0,080-0,300$ & & & & $0,440-0,510$ \\
\hline Apêndice caudal & $0,059-0,084$ & $0,080-0,200$ & & & & $0,160-0,250$ \\
\hline Espiculo & $0,080-0,100$ & & $0,054-0,068$ & & $0,082-0,100$ & \\
\hline Papilas caudais & $\begin{array}{l}1 \text { par ad, } 1 \text { pré } \\
\text { e } 1 \text { pós anal }\end{array}$ & & $\begin{array}{l}2 \text { pares ad, } 1 \text { pós e } 1 \\
\text { impar pós anal }\end{array}$ & & $\begin{array}{l}1 \text { par pré, } 1 \text { ad, } 2 \text { pós } \\
\text { e } 1 \text { impar pós anal }\end{array}$ & \\
\hline
\end{tabular}
Frio.

Hospedeiro e proveniência: Ameiva ameiva (L.), Rio de Janeiro: Cabo

Localização: intestino.

Referência bibliográfica: 143 .

Thelandros sp. Travassos, Freitas, Mendonça \& Rodrigues, 1962

Hospedeiros e proveniência: Tropidurus torquatus (Wied) e Ameiva ameiva (L.), Rio de Janeiro: Cabo Frio, RJ.

Localização: intestino grosso.

Referência bibliográfica: 144 .

Thelandros sp. (Cristofaro, Guimarães \& Rodrigues, 1976) 1976.

Sinonímia: Parapharyngodon sp. Cristofaro, Guimarães \& Rodrigues,

Hospedeiros e proveniência: Tropidurus torquatus (Wied) e Ameiva ameiva (L.), Bahia: Ondina, Salvador.

Localização: intestinos delgado e grosso.

Referência bibliográfica: 44 .

Thelandros sp. (Rodrigues, 1986)

Sinonímia: Parapharyngodon sp. Rodrigues, 1986.

Hospedeiro e proveniência: Hemidactylus mabouia (M. de J.), Rio de Janeiro: Nova Iguaçu.

Localização: intestino grosso.

Referência bibliográfica: 103. 
Thelandros sp. (Rodrigues, Rodrigues \& Faria, 1990)

Sinonímia: Parapharyngodon sp. Rodrigues, Rodrigues \& Faria, 1990.

Hospedeiro e proveniência: Hemidactylus mabouia (M. de J.), Rio de Janeiro: Maricá.

Localização: intestino grosso.

Referência bibliográfica: 106 .

\section{Seuratoidea}

Nesta superfamília encontramos a família Seuratidae Railliet, 1916 com o gênero Skrjabinellazia Sypliaxov, 1930.

\section{Seuratidae Railliet, 1916}

Boca cercada por dois lábios laterais, sem vestíbulo. Esôfago muito curto, em forma de clava e totalmente muscular. Papilas cervicais simétricas e atrás do anel nervoso. Cutícula com finas estriações transversais e 64 bandas longitudinais escuras.

\section{Skrjabinellazia Sypliaxov, 1930}

Extremidade cefálica apresentado pequena coroa constituída de lamelas na face interna do vestíbulo. Esôfago dividido em duas porções. Cauda dos machos sem asas, com dois espículos desiguais e um gubernáculo. Vulva situada na parte anterior do corpo ao nível do esôfago. Ovos embrionados quando da postura. Parasitos do intestino de répteis.

Espécie tipo: $S$. taurica Sypliaxov, 1930

Espécies assinaladas no Brasil:

S. galliardi Chabaud, 1973 (Tab. XXII, Figs 229-231) Belém.

Hospedeiro e proveniência: Gonatodes humeralis (Guichenot), Pará:

Localização: estômago.

Referência bibliográfica: 37 .

S. intermedia (Freitas, 1941) Chabaud, 1973 (Tab. XXIII, Figs 232-233)

Sinonímia: Salobrella intermedia Freitas, 1941.

Hospedeiros e proveniências: Tropidurus torquatus (Wied), Bahia: Salvador; Tropidurus spinulosus (Cope), Mato Grosso do Sul: Salobra.

Localização: intestinos delgado e grosso.

Referências bibliográficas: 37, 51, 152.

\section{Ascaridoidea}

Esta superfamília encerra as familias Anisakidae Skrjabin \& Karokhin, 1945 com os gêneros Contracaecum Railliet \& Henry, 1912, Sulcascaris 
Tabela XXII. Camallanus amazonicus, dados segundo Ribeiro, 1940; Ancyracanthus pinnatifidus, dados segundo Gomes \& Kohn, 1970 e Skrjabinelazia galliardi, dados segundo Chabaud, 1973

\begin{tabular}{|c|c|c|c|c|c|c|}
\hline & \multicolumn{2}{|c|}{ C. amazonicus } & \multicolumn{2}{|c|}{ A. pinnatifidus } & \multicolumn{2}{|c|}{ S. galliardi } \\
\hline & Macho & Fêmea & Macho & Fêmea & Macho & Fêmea \\
\hline Comprimento & 11,95 & $15,08-17,91$ & 48,40 & $57,50-62,75$ & 16,00 & 8,25 \\
\hline Largura & 0,40 & $0,53-0,68$ & 1,30 & $1,10-1,15$ & 0,34 & 0,20 \\
\hline $\begin{array}{l}\text { Distância entre estrias do } \\
\text { corpo }\end{array}$ & 0,008 & 0,008 & & & & \\
\hline Valvas bucais laterais & $\begin{array}{c}0,17 x \\
0,18\end{array}$ & $\begin{array}{l}0,204-0,208 x \\
0,226-0,239\end{array}$ & & & & \\
\hline Tridentes (corpo basal) & $0,087 \times 0,069$ & & & & & \\
\hline Dente médio & 0,069 & $0,078-0,087$ & & & & \\
\hline Anel quitinoso das valvas & $0,043 \times 0,104$ & $0,056 \times 0,139$ & & & & \\
\hline Esôfago total & 1,14 & $1,35-1,40$ & 4,452 & $5,998-6,691$ & 1,00 & 0,77 \\
\hline Porçăo anterior do esôfago & 0,61 & $0,73-0,75$ & & & & \\
\hline Porçáo posterior do esōfago & 0,53 & $0,63-0,65$ & & & & \\
\hline Anel nervoso & 0,40 & 0,426 & 1,093 & $1,226-1,466$ & 0,220 & 0,240 \\
\hline Poro excretor & & & & & 0,220 & 0,280 \\
\hline Vulva & & $8,640-9,170$ & & $9,650-9,746$ & 0,300 & 0,390 \\
\hline Vagina & & & & 1,706 & & \\
\hline Larvas & & $0,252 \times 0,008$ & & & & \\
\hline Cauda & & & & & 0.570 & 0,485 \\
\hline Reto & & 0,18 & & 0,133 & & \\
\hline Ânus & 0,13 & 0,21 & $0,396-0,549$ & $0,399-0,583$ & & \\
\hline Espiculo maior & 0,57 & & & & & \\
\hline Espiculo menor & 0,24 & & & & & \\
\hline Espículos & & & $3,665-4,764$ & & & \\
\hline $\begin{array}{l}\text { Apêndices quitinizados } \\
\text { cefálicos }\end{array}$ & $3,25-3,76$ & & & & & \\
\hline Ovos & & & & $\begin{array}{c}0,045-0,051 \times \\
0,033-0,036\end{array}$ & $\begin{array}{c}0,095-0,108 x \\
0,070-0,075\end{array}$ & 0,095 \\
\hline $\begin{array}{l}\text { Apêndices quitinosos } \\
\text { cefálicos }\end{array}$ & $3,25-3,75$ & & & & & \\
\hline Papilas caudais & $\begin{array}{c}7 \text { pares pré e } 2 \\
\text { pós anal }\end{array}$ & & $\begin{array}{l}3 \text { pares pré e } 1 \\
\text { pós anal }\end{array}$ & & & \\
\hline
\end{tabular}

Hartwich, 1957 e Terranova Leiper \& Atkinson, 1914 e a familia Ascarididae Baird, 1853 com os gêneros Angusticaecum Baylis, 1920, Ascaridia Dujardin, 1845, Brevimulticaecum Mozgovoi in Skrjabin, Shikhobalova \& Mozgovoi, 1952, Dujardinascaris Baylis, 1947, Hexametra Travassos, 1920, Ophidascaris Baylis, 1920, Polidelphis Dujardin, 1845 e Travassosascaris Sprent, 1978.

\section{Chave para identificação das famílias}

- Sistema excretor com um só ramo à esquerda. Esôfago com ventrículo sem apêndice ou com um apêndice ventral ................Anisakidae

- Sistema excretor em forma de diapasão. Esôfago com ou sem ventrículo; este sem apêndice ou às vezes com dois apêndices anteriores e três apêndices

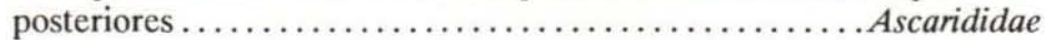


Tabela XXIII. Skrjabinelazia intermedia, dados segundo Freitas, 1941; Oswaldofilaria azevedoi, dados segundo Bain, 1974 e O. bacillaris, dados segundo Travassos, 1933.

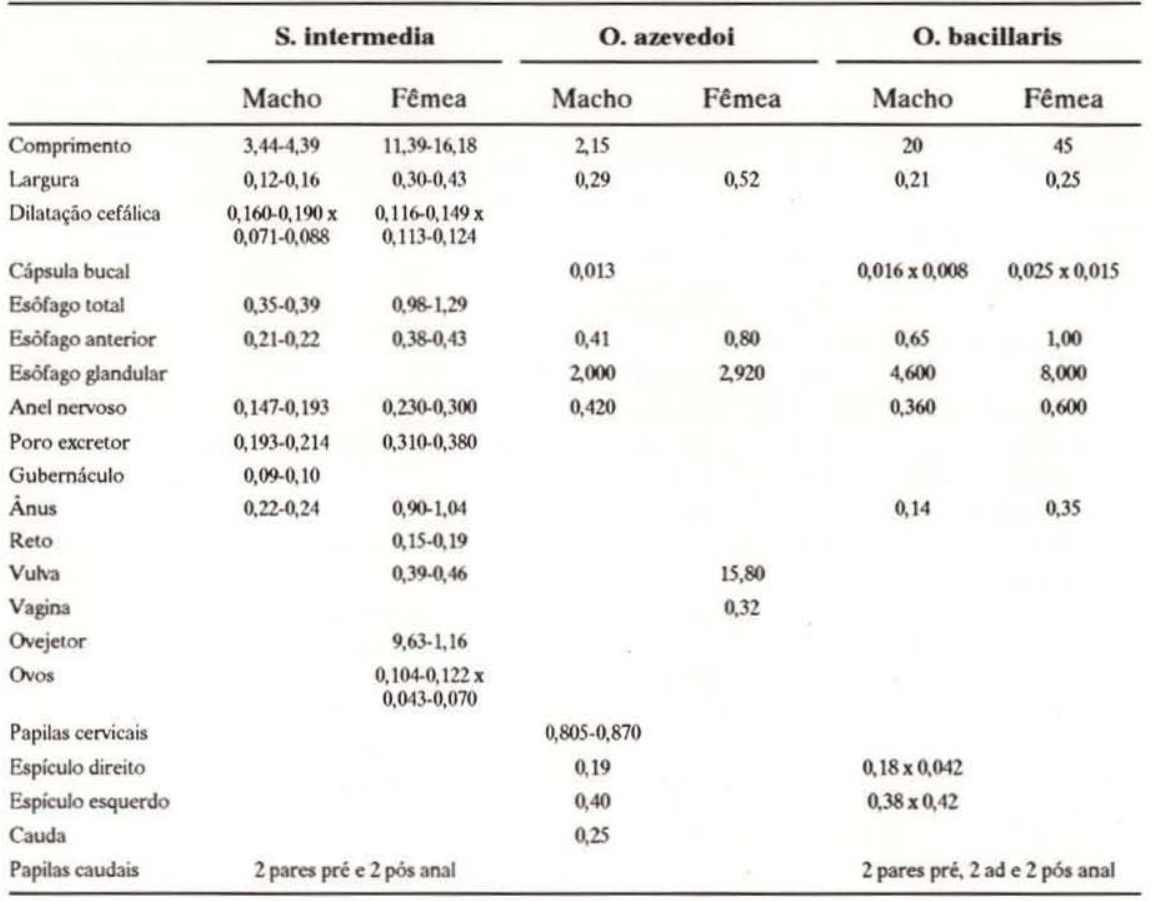

Anisakidae Skrjabin \& Karokhin, 1945

Lábios muito variáveis, mas não nuito pequenos. Sistema excretor com um só ramo à esquerda. Poro excretor na base do interlábio ventral ou ao nível do anel nervoso. Cutícula às vezes armada de espinhos. Esôfago com um ventrículo provido ou desprovido de um apêndice ventral. Ceco intestinal dorsal presente ou ausente. Gubernáculo ausente. Didelfas. Parasitos de mamíferos, aves, répteis e peixes.

\section{Chave para identificação dos gêneros}

1. Interlábios ausentes .............................. Terranova

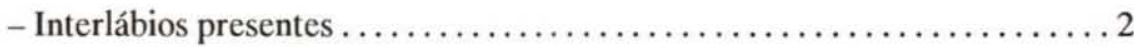

2. Lábios sem fileiras de dentes .................. Contracaecum

- Lábios com fileiras de dentes ..................... Sulcascaris

\section{Contracaecum Railliet \& Henry, 1912}

Lábios sem fileiras de dentes; interlábios presentes bem desenvolvidos. Ventrículo reduzido, com apêndice posterior dilatado. Ceco intestinal presente. 
Machos sem asa caudal definida, dotados de papilas pré-anais numerosas. Papilas pós-anais em número maior que sete pares, parcialmente laterais e subventrais. Espículos longos, alados, iguais ou subiguais. Gubernáculo ausente. Fêmeas com a vulva na região anterior do corpo. Ovíparas. Parasitos de répteis, peixes, aves e mamíferos piscívoros.

Espécie tipo: C. (C.) spiculigerum (Rud., 1819) Railliet \& Henry, 1912. Espécie assinalada no Brasil:

C. serpentis Araujo, 1970 (Tab. XXIV; Figs 164-165)

Hospedeiro e proveniência: Lojosophis gigas, Mato Grosso.

Localização: estômago.

Referência bibliográfica: 18 .

\section{Sulcascaris Hartwich, 1957}

Vermes de tamanho médio com o corpo não enrolado; machos não marcadamente menores que as fêmeas. Lábios robustos; fileiras de dentes com pequenos dentes afilados; interlábios presentes; profunda goteira pós-labial separando os lábios do corpo. Papila cervical após o anel nervoso. Esôfago seguido por um alongado ventrículo contendo glândulas esofagianas. Glândula esofagiana dorsal abrindo-se na extremidade posterior do mesmo. Pequeno ceco intestinal geralmente presente. Poro excretor abrindo-se na goteira póslabial atrás do interlábio; sistema excretor bilateral, com o lado esquerdo alargado após o esôfago e o lado direito reduzido. Asa cervical ausente. Machos com espículos alados. Fêmeas com vulva sem lábios conspícuos; dois ramos uterinos.

Espécie tipo: S. sulcata (Rud., 1819) Hartwich, 1957.

Espécie assinalada no Brasil:

S. sulcata (Rud., 1819) Hartwich, 1957 (Tab. XXVI, Figs 174-176)

Sinonímia: Ascaris sulcata Rud., 1819; Porrocaecum sulcatum Baylis, 1923. Janeiro.

Hospedeiro e proveniência: Chelonia mydas (L.), Rio de Janeiro: Rio de

Localização: estômago.

Referências bibliográficas: 13,77 .

\section{Terranova Leiper \& Atkinson, 1914}

Nematóides de tamanho médio, com a mesma largura em todo o corpo. Lábios relativamente pequenos e arredondados, com dentículos na parte mediana da extremidade anterior. Interlábios ausentes. Asa cervical ausente; papilas próximas ao anel nervoso; filamento excretor somente do lado esquerdo, alargando-se após em uma estrutura semelhante a armadura contendo núcleos. Ventrículo alongado, contendo núcleos das glândulas esofagianas; ceco intestinal presente. Fêmeas com a vulva no terço médio do corpo. Didelfas, 
Tabela XXIV. Brevimulticaecum pintoi, B. stekhoveni, dados segundo Sprent, 1979 e Contracaecum serpentis, dados segundo Araujo, 1970.

\begin{tabular}{|c|c|c|c|c|c|c|c|}
\hline & \multicolumn{3}{|c|}{ B. pintoi } & \multicolumn{2}{|c|}{ B. stekhoveni } & \multicolumn{2}{|c|}{ C. serpentis } \\
\hline & Macho & $\begin{array}{l}\text { Fêmea } \\
\text { imatura }\end{array}$ & $\begin{array}{l}\text { Fêmea } \\
\text { adulta }\end{array}$ & Macho & Fêmea & Macho & Fêmea \\
\hline Comprimento & $10,80-13,40$ & 8,50 & 14,60 & $13,00-30,00$ & $14,00-32,00$ & $24,20-30,50$ & 34,00 \\
\hline Largura & $0,27-0,29$ & 0,20 & 0.34 & 0,73 & 0,80 & $0,62-0,64$ & 0,96 \\
\hline Lábios & $0,05-0,07$ & 0,05 & 0,08 & 0,12 & 0,19 & 0.088 & 0,128 \\
\hline Interlábios & 0,02 & 0,02 & 0,03 & 0,06 & 0,06 & & \\
\hline Anel nervoso & $0,40-0,44$ & 0,29 & 0,43 & 0,48 & 0,47 & $0,360-0,372$ & 0,444 \\
\hline Poro excretor & 0,40 & 0,26 & 0,37 & 0,41 & 0,38 & & \\
\hline Esôfago & 1,80 & 1,50 & 2,30 & \multirow{2}{*}{\multicolumn{2}{|c|}{$15-21 \%$ comprimento do corpo }} & $1,92-2,004$ & 2,424 \\
\hline Ceco & 1,10 & 1,00 & 1,50 & & & $0,180-0,310$ & 0,360 \\
\hline Vulva & & 4,3 & 6,9 & & $\begin{array}{c}36-53 \% \text { com- } \\
\text { primento do corpo }\end{array}$ & & 12,3 \\
\hline Espiculos & $1,10-1,80$ & & & $0,50-1,00$ & & $2,472-2,616$ & \\
\hline Gubernáculo & $0,14-0,18$ & & & 0,15 & & & \\
\hline Duto ejaculador & 0,91 & & & & & & \\
\hline Cauda & $0,06-0,07$ & 0,12 & 0,18 & & & & \\
\hline Ovos & & & $\begin{array}{c}0,058-0,089 x \\
0,042-0,063\end{array}$ & & $\begin{array}{c}0,071-0,093 x \\
0,056-0,082\end{array}$ & & $\begin{array}{c}0,0527-0,0620 \\
x \\
0,0465-0,0558\end{array}$ \\
\hline Vagina & & & & & $1,4-2,4$ & & \\
\hline $\begin{array}{l}\text { Lobos do } \\
\text { ventriculo }\end{array}$ & & & & $0,02-0,06$ & & & \\
\hline Papilas cervicais & & & & & & 0,480 & 0,540 \\
\hline Ceco intestinal & & & & & & $0,960-1,440$ & 1,608 \\
\hline Ânus & & & & & & $0,136-0,168$ & 0,440 \\
\hline Papilas caudais & & & & & & $\begin{array}{l}40 \text { pares pré } \\
\text { impar p }\end{array}$ & $\begin{array}{l}\text { é, } 12 \text { pós e } 1 \\
\text { ós anal }\end{array}$ \\
\hline
\end{tabular}

opistodelfas; parte não dividida do útero maior que os ramos uterinos. Machos com os espículos delgados. Gubernáculo presente ou ausente. Placas cuticulares presentes no lábio posterior da cloaca. Cauda com espessamentos laterais da cutícula, com ou sem cavidade ventral.

Espécie tipo: T. decipiens (Krabbe, 1878) Baylis, 1916.

Espécie assinalada no Brasil:

T. lanceolata (Molin, 1860) Sprent, 1979 (Tab. XXV, Figs 166-167)

Sinonímia: Physaloptera mucronata Diesing, 1851; Ascaris lanceolata Molin, 1860; Angusticaecum braziliensis Schuurmans-Stekhoven, 1937; Metangusticaecum braziliensis Skrjabin, Shikhobalova \& Mozgovoi, 1951; Terranova braziliensis Hartwich, 1957.

Hospedeiro e proveniência: Melanosuchus niger (Spix), Brasil.

Localização: estômago.

Referência bibliográfica: 120 . 


\section{Ascarididae Baird, 1853}

Lábios proeminentes. Sistema excretor em forma de diapasão. Poro excretor ao nível do anel nervoso. Cutícula não espinhosa. Esôfago com ou sem ventrículo. Este desprovido de apêndice ventral ou por vezes com dois apêndices anteriores e três posteriores. Gubernáculo presente ou ausente. Didelfas ou polidelfas. Parasitas de mamíferos, aves, répteis, anfíbios e raramente de peixes.

\section{Chave para identificação dos gêneros}

1. Macho com ventosa precloacal com anel quitinoso .............Ascaridia

- Macho sem ventosa precloacal com anel quitinoso $\ldots \ldots \ldots \ldots \ldots \ldots \ldots 2$

2. Esôfago com ventrículo ..................... Brevimulticaecum

- Esôfago sem ventrículo ...............................

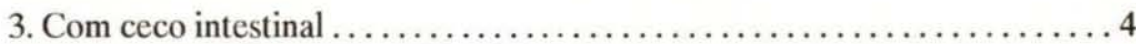

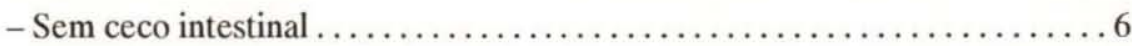

4. Vulva na parte posterior do corpo .................Angusticaecum

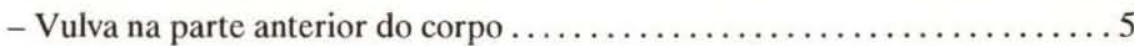

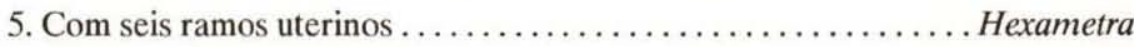

- Com dois ramos uterinos $\ldots \ldots \ldots \ldots \ldots \ldots \ldots \ldots \ldots \ldots$ Dujardinascaris

6. Fêmeas com dois ramos uterinos $\ldots \ldots \ldots \ldots \ldots \ldots \ldots$ Ophidascaris

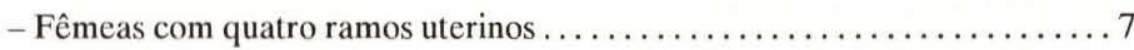

7. Lábios com fileiras dentígeras .................. Travassosascaris

- Lábios sem fileiras dentígeras ...................... Polydelphis

\section{Ascaridia Dujardin, 1845}

Franjas laterais cuticulares presentes lábios sem interlábios. Esôfago em forma de clava, sem bulbo posterior. Machos com ventosa pré-cloacal, com anel quitinoso. Asa caudal estreita; papilas relativamente grandes. Espículos iguais ou subiguais. Gubernáculo ausente. Fêmeas com úteros opostos. Vulva próxima ao meio do corpo. Ovíparas; ovos de casca espessa.

Espécie tipo: A. hermafrodita (Froelich, 1789) Dujardin, 1845.

Espécie assinalada no Brasil:

A. flexuosa (Schneider, 1866) Railliet \& Henry, 1914

Sinonímia: Heterakis flexuosa Schneider, 1866.

Hospedeiros e proveniência: Crotalus sp. e Crotalus durissus terrificus (Laur.), Brasil. 
Tabela XXV. Terranova lanceolata, dados segundo Sprent, 1979; Dujardinascaris longispicula e D. paulista, dados segundo Travassos, 1933.

\begin{tabular}{|c|c|c|c|c|c|c|}
\hline & \multicolumn{2}{|c|}{ T. lanceolata } & \multicolumn{2}{|c|}{ D. longispicula } & \multicolumn{2}{|c|}{ D. paulista } \\
\hline & Macho & Fêmea & Macho & Fêmea & Macho & Fêmea \\
\hline Comprimento & $31-36$ & 37.45 & $7-8$ & 25.26 & $9-11$ & $20-22$ \\
\hline Largura & 0,96 & $1,10-1,30$ & 0,20 & $1,00-1,20$ & $0,30-0,31$ & $0,80-1,00$ \\
\hline Anel nervoso & $0,40-0,47$ & $0,44-0,71$ & 0,31 & 0,54 & $0,29-0,36$ & $0,44-0,48$ \\
\hline Papila cervical & $0,50-0,59$ & $0,50-0,80$ & & & & \\
\hline Esôfago & $3,6-3,9$ & $4,2-5,2$ & 1,6 & $1,9-3,3$ & $1,6-2,1$ & 3,3 \\
\hline Bulbo esofagiano & & & & & $\begin{array}{c}0,056-0,064 x \\
0,080-0,088\end{array}$ & $\begin{array}{c}0,096-0,120 x \\
0,120-0,160\end{array}$ \\
\hline Ventrículo & $0,74-0,94$ & $1,00-1,20$ & & & & \\
\hline Ceco & $1,9-2,5$ & $2,4-2,8$ & 1,0 & 1,0 & $0,9-1,2$ & $1,8-2,3$ \\
\hline Cauda & $0,24-0,26$ & $0,29-0,36$ & & & & \\
\hline Espículos & $0,22-0,28$ & & $3,60-3,80$ & & $0,64-0,80$ & \\
\hline Duto ejaculador & $2,1-3,0$ & & & & & $0,8-1,1$ \\
\hline Vulva & & $12,5-18,9$ & & & & \\
\hline Lábios & & & 0,048 & $0,06-0,14$ & 0,07 & 0,11 \\
\hline Interlábios & & & & & $0,040-0,048$ & 0,064 \\
\hline Poro excretor & & & 0,36 & $0,40-0,71$ & $0,35-0,43$ & $0,44-0,48$ \\
\hline Ảnus & & & & 0,22 & $0,11-0,17$ & $0,25-0,28$ \\
\hline Ovos & & & & & $\begin{array}{c}0,068 \mathrm{x} \\
0,072\end{array}$ & $\begin{array}{c}0,048-0,056 x \\
0,068-0,072\end{array}$ \\
\hline Gubernáculo & & & $0,06-0,10$ & & 0,12 & \\
\hline Canal deferente & & & 0,7 & & & \\
\hline Ovejetor & & & & & & 0,72 \\
\hline Papilas caudais & & & 4 pares $p$ & pós anal & 2 pares pré, 3 & d e 2 pós anal \\
\hline
\end{tabular}

Localização: intestino.

Referência bibliográfica: 161 .

Angusticaecum Baylis, 1920

Lábios com fileiras de dentes; interlábios ausentes. Esôfago sem ventrículo ou bulbo posterior. Ceco intestinal presente, grande e afilado. Machos com asa caudal presente ou ausente. Seis ou sete pares de papilas pré-anais e um número variável de pós-anais. Espículos iguais; gubernáculo ausente. Fêmeas com a vulva na parte posterior do corpo. Parasitos de répteis.

Espécie tipo: A. holoptera (Rud., 1819) Baylis, 1920.

Espécie assinalada no Brasil:

A. brevispiculum Chapin, 1925 (Tab. XXVI)

Hospedeiro e proveniência: Geochelone denticulata (L.), Pará.

Localização: intestino.

Referência bibliográfica: 40 . 
Tabela XXVI. Sulcascaris sulcata, dados segundo Freitas \& Lent, 1946; Angusticaecum brevispiculum, dados segundo Chapin, 1925 e Ophidascaris arndti, dados segundo Freitas, 1968.

\begin{tabular}{|c|c|c|c|c|c|c|}
\hline & \multicolumn{2}{|c|}{ S. sulcata } & \multicolumn{2}{|c|}{ A. brevispiculum } & \multicolumn{2}{|c|}{ O. arndti } \\
\hline & Macho & Fêmea & Macho & Fêmea & Macho & Fêmea \\
\hline Comprimento & $40,40-100,00$ & $63,20-105,00$ & 120,00 & 120,00 & $46,03-51,82$ & $56,04-69,95$ \\
\hline Largura & $0,59-1,30$ & $0,87-2,01$ & 3,00 & 3,00 & $0,90-1,04$ & $1,04-1,27$ \\
\hline Lábio dorsal & $\begin{array}{c}0,17-0,36 \times \\
0,19-0,40\end{array}$ & $\begin{array}{c}0,26-0,49 x \\
0,23-0,43\end{array}$ & & & & \\
\hline Lábios látero-ventrais & $\begin{array}{c}0,19-0,41 x \\
0,22-0,45\end{array}$ & $\begin{array}{l}0,25-0,49 x \\
0,22-0,43\end{array}$ & & & & \\
\hline Intertábios & $\begin{array}{l}0,10-0,18 x \\
0,11-0,22\end{array}$ & $\begin{array}{l}0,14-0,26 x \\
0,17-0,35\end{array}$ & & & $0,033-0,034$ & $0,041-0,058$ \\
\hline Esôfago & $3,55-3,57$ & $3,43-3,87$ & \multicolumn{2}{|c|}{ 1/5 do comprimento total } & 2,31 & $2,54-2,62$ \\
\hline Ventrículo & $\begin{array}{l}0,65-1,17 x \\
0,25-0,43\end{array}$ & $\begin{array}{c}0,84-1,17 x \\
0,37-0,50\end{array}$ & & & & \\
\hline Ceco intestinal & $0,16-0,26$ & $0,30-0,50$ & & & & \\
\hline Anel nervoso & $0,60-1,24$ & $0,76-1,16$ & & & $0,58-0,66$ & $0,60-0,70$ \\
\hline Papilas cervicais & $0,66-1,44$ & & & & & \\
\hline Poro excretor & $0,78-0,83$ & 1,13 & & & $0,61-0,63$ & $0,63-0,73$ \\
\hline Vulva & & $19,03-40,03$ & & no meio do corpo & & $22,95-33,33$ \\
\hline Ovejetor & & 13,76 & & & & $1,33-1,91$ \\
\hline Ovos & & $\begin{array}{c}0,084-0,088 x \\
0,050-0,059\end{array}$ & & $\begin{array}{l}0,114-0,142 \mathrm{x} \\
0,071-0,085\end{array}$ & & $\begin{array}{c}0,070-0,087 x \\
0,061-0,070\end{array}$ \\
\hline Reto & & $0,38 \times 0,06$ & & & & 0,40 \\
\hline Ânus & $0,22-0,28$ & $0,41-0,53$ & 0,15 & 1,00 & $0,14-0,18$ & $0,38-0,46$ \\
\hline Espiculos & $1,51-3,15$ & & 1,30 e 1,40 & & $1,81-1,91$ & \\
\hline Papilas caudais & \multicolumn{2}{|c|}{ 53-71 pares pré e 6 pós anal } & & & \multicolumn{2}{|c|}{$\begin{array}{l}29 \text { pares pré, } 5 \text { pós anal e } 1 \\
\text { impar no bordo do ánus }\end{array}$} \\
\hline Vagina & & & & 4 & & \\
\hline Ponta da cauda & & & & & $0,039-0,043$ & $0,035-0,043$ \\
\hline
\end{tabular}

\section{Brevimulticaecum Mozgovoi, 1952}

Lábios volumosos com margens aladas; sem fileiras de dentes; goteiras pós-labiais; processos de conexão ausentes. Interlábios conspícuos. Poro excretor ao nível do anel nervoso. Sistema excretor bilateral. Prolongamentos anteriores da célula excretora ausentes. Asas cervicais presentes ou ausentes. Esôfago terminando em ventrículo com apêndices curtos. Ceco intestinal presente. Fêmeas maduras com vulva sem lábios salientes ou papilas; opistodelfas ou anfidelfas. Machos com gubernáculo delgado; espículos alados e asa caudal ausente.

Espécie tipo: B. baylisi (Travassos, 1933) Sprent, 1979.

Espécies assinaladas no Brasil:

B. baylisi (Travassos, 1933) Sprent, 1979 (Tab. XVII, Figs 153-155)

Sinonímia: Multicaecum baylisi Travassos, 1933; Multicaecum (M.) baylisi Mozgovoi in Skrjabin \& Mozgovoi, 1951; Multicaecum acuticauda SchuurmansStekhoven, 1937 (in part); Multicaecum (B.) acuticauda Mozgovoi in Skrjabin, 
1951 (in part).

Hospedeiros e proveniências: Caiman crocodilus crocodilus (L.), São Paulo: Rio Claro, Mato Grosso do Sul: Salobra; Melanosuchus niger (Spix), Amazonas: Rio Trombetas, Óbidos.

Localização: estômago.

Referências bibliográficas: 119, 131.

B. gibsoni Sprent, 1979 (Tab. XVII, Figs 156-157)

Hospedeiro e proveniência: Melanosuchus niger (Spix), Amazonas: Borba Rio Madeira.

Localização: estômago.

Referência bibliográfica: 119 .

B. pintoi Sprent, 1979 (Tab. XXIV, Figs 158-160)

Sinonímia: Multicaecum agile Pinto \& Barbosa, 1972 nec (Wedl, 1861) Baylis, 1923.

Hospedeiros e proveniências: Caiman crocodilus crocodilus (L.), Rio Paraguai; Caiman latirostris (Daud.), São Paulo: Morro Agudo.

Localização: esôfago e estômago.

Referências bibliográficas: 98, 119 .

B. stekhoveni (Baylis, 1947) Sprent, 1979 (Tab. XXIV, Figs 161-163)

Sinonímia: Multicaecum helicina Schuurmans-Stekhoven , 1937 nec Molin, 1860; Multicaecum stekhoveni Baylis, 1947; Multicaecum (B.) stekhoveni Mozgovoi in Skrjabin \& Mozgovoi, 1951.

Hospedeiros e proveniência: Melanosuchus niger (Spix) e Caiman crocodilus crocodilus (L.), Amazonas: Rio Trombetas, Óbidos.

Referência bibliográfica: 119.

\section{Dujardinascaris Baylis, 1947}

Lábios sem fileiras de dentes mas com a cutícula de suas superfícies internas transformadas em grandes estruturas em forma de dentes aparentemente capazes de se engrenarem. Essas estruturas são apoiadas por três lobos cuticulares na margem anterior de cada lábio. Interlábios presentes com fendas bem marcadas indo dos interlábios às bases dos lábios. Esôfago com pequeno bulbo esférico posterior sem ventrículo. Ceco intestinal presente. Machos com asa caudal presente na região da cloaca. Poucas papilas caudais. Espículos iguais, delgados; gubernáculo geralmente presente . Fêmeas com vulva na metade anterior do corpo, abrindo-se num átrio muscular quase em forma de ventosa. Vagina longa, delgada. Dois ramos uterinos. Ovíparas. Ovos subglobulares, com casca muito fina, contendo massa embrionária não segmentada quando eliminados. Parasitos de répteis e peixes.

Espécie tipo: D. dujardini (Travassos, 1920) Baylis, 1947. 
Espécies assinaladas no Brasil:

D. longispicula (Travassos, 1933) Baylis, 1947 (Tab. XXV, Figs 168-170)

Sinonímia: Dujardinia longispicula Travassos, 1933.

Hospedeiro e proveniência: Caiman crocodilus crocodilus (L.), Mato Grosso do Sul: Rio São Lourenço.

Localização: estômago.

Referência bibliográfica: 133 .

D. paulista (Travassos, 1933) Baylis, 1947 (Tab. XXV, Figs 171-173)

Sinonímia: Dujardinia paulistấ Travassos, 1933

Hospedeiro e proveniência: Caiman crocodilus crocodilus (L.), São Paulo: Rio Claro.

Localização: estômago.

Referência bibliográfica: 131 .

\section{Hexametra Travassos, 1920}

Asas cervicais ausentes. Lábios mais ou menos quadrados, frequentemente mais largos na base que na borda livre anterior. Lábio dorsal normalmente menor que os lábios subventrais. Interlábios e sulcos sublabiais ausentes. Esôfago curto, sem bulbo ou ventrículo. Ceco intestinal eventualmente presente e rudimentar. Machos de cauda romba; espículos iguais ou subiguais. Gubernáculo ausente. Fêmeas com a vulva geralmente na região anterior do corpo; vagina dirigida para trás. Seis ramos uterinos. Parasitos de lagartos e cobras.

Espécie tipo: H. hexametra (Gedoelst, 1916) Travassos, 1920.

Espécie assinalada no Brasil:

\section{H. boddaertii (Baird, 1860) Kreis, 1944 (Tab. XXVII, Figs 194-196)}

Sinonímia: Ascaris quadrangularis Schneider, 1866 in part; Hexametra hexauterina Skrjabin, 1916; Hexametra quadricornis Araujo, 1969 nec Wedl, 1861.

Hospedeiro e proveniência: Crotalus durissus terrificus (Laurenti), Brasil. Localização: estômago.

Referências bibliográficas: 16, 20, 21.

\section{Ophidascaris Baylis, 1920}

Corpo forte, alongado, com a cutícula estriada transversalmente e com extremidades atenuadas. Boca trilabiada. Lábios quase quadrados, com ângulos arredondados. Lábio dorsal, em geral, levemente menor que os ventro-laterais. Interlábios presentes, geralmente bem desenvolvidos. Serrilha de dentes labiais presentes ou não. Sulcos transversais pós-labiais presentes. Esôfago relativamente curto, claviforme. Ventrículo ausente. Cecos esofagiano e intestinal 
Tabela XXVII. Hexametra boddaertii; Travassosascaris araujoi, dados segundo Sprent, $1978 \mathrm{e}$ Spiroxys figueiredoi, dados segundo Vicente, 1966.

\begin{tabular}{|c|c|c|c|c|c|c|}
\hline & \multicolumn{2}{|c|}{ H. boddaertii } & \multicolumn{2}{|c|}{ T. araujoi } & \multicolumn{2}{|c|}{ S. figueiredoi } \\
\hline & Macho & Fêmea & Macho & Fêmea & Macho & Fêmea \\
\hline Comprimento & $46,00-101,00$ & $52,00-187,00$ & $44,00-95,00$ & $44,00-95,00$ & $28,00-42,00$ & $37,36-57,40$ \\
\hline Largura & $0,69-1,80$ & $1,20-2,60$ & $0,69-2,00$ & $0,69-2,00$ & $0,49-0,52$ & $0,64-0,80$ \\
\hline Lábio subventral & $0,14-0,25$ & $0,14-0,27$ & $0,10-0,24$ & $0,10-0,24$ & & \\
\hline Anel nervoso & $0,61-1,10$ & $0,76-1,30$ & $0,53-1,00$ & $0,53-1,00$ & 0,80 & $0,79-0,89$ \\
\hline Poro excretor & $0,77-1,50$ & $1,00-1,50$ & $0,61-1,20$ & $0,61-1,20$ & 0,80 & $0,96-1,05$ \\
\hline Esôfago & $3,60-6,10$ & $3,80-6,70$ & $3,70-6,70$ & $3,70-6,70$ & $3,15-4,00$ & $4,15-4,48$ \\
\hline Vulva & & $29,00-92,00$ & & $42,00-65,00$ & & $19,42-24,21$ \\
\hline Cauda & $0,16-0,29$ & $0,22-0,55$ & $0,18-0,39$ & $0,46-0,79$ & & \\
\hline Espículos & $0,75 \cdot 1,50$ & & $1,60-3,00$ & & $3,27-3,30$ & \\
\hline Canal ejaculador & $1,10-2,50$ & & $0,91-2,10$ & & & \\
\hline Ovos & & $\begin{array}{c}0,078-0,088 x \\
0,062-0,086\end{array}$ & & $\begin{array}{l}0,084-0,093 x \\
0,078-0,090\end{array}$ & & $0,061-0,043$ \\
\hline $\begin{array}{l}\text { Lobo mediano dos } \\
\text { lábios }\end{array}$ & & & & & $0,05-0,06$ & $0,05-0,06$ \\
\hline Reforço quitinoso & & & & & $0,08-0,09$ & $0,08-0,09$ \\
\hline Papilas cervicais & & & & & 1,20 & 1,35 \\
\hline Reto & & & & & & 0,41 \\
\hline Ảnus & & & & & $0,28-0,31$ & $0,44-0,51$ \\
\hline Gubernáculo & & & & & $0,22-0,23$ & \\
\hline Pseudoventosa & & & & & $0,34-0,36$ & \\
\hline
\end{tabular}

ausentes. Aparelhos genitais em ambos os sexos, situados, em geral somente na porção posterior do corpo. Fêmeas didelfas, opistodelfas, ovíparas. Vulva de situação variável, porém geralmente situada na metade posterior do corpo. Ovos de casca rugosa ou esculturada; cauda pouco atenuada. Machos com dois espículos desiguais, geralmente providos de asas. Gubernáculo ausente. Asas caudais em geral ausentes. Papilas caudais presentes. Numerosos pares préanais, ad-anais raras e geralmente seis pares pós anais. Heteroxenos, evoluindo em anfíbios. Parasitos de répteis.

Espécie tipo: O. filaria (Dujardin, 1845) Baylis, 1921.

Espécies assinaladas no Brasil:

O. arndti Sprehn, 1929 (Tab. XXVI; Figs 178-180)

Hospedeiros e proveniências: Xenodon merremii (Wagler), Goiás: Chavantina (Rio das Mortes); Xenodon severus (L.) e Bothrops atrox (L.), Brasil.

Localização: estômago.

Referência bibliográfica: 53 .

O. cretinorum Freitas, 1968 (Tab. XXVIII, Figs 181-182)

Hospedeiro e proveniência: Ophidia indet. (cobra coral), Maranhão.

Localização: estômago.

Referência bibliográfica: 60 . 
Tabela XXVIII. Ophidascaris cretinorum, dados segundo Freitas, 1968; O. obconica, dados segundo Baylis, 1916 e O. sicki, dados segundo Freitas, 1951.

\begin{tabular}{|c|c|c|c|c|c|}
\hline & \multirow{2}{*}{$\frac{\text { O. cretinorum }}{\text { Macho }}$} & \multicolumn{2}{|c|}{ O. obconica } & \multicolumn{2}{|c|}{ O. sicki } \\
\hline & & Macho & Fêmea & Macho & Fêmea \\
\hline Comprimento & $17,92-23,28$ & & 50,00 & $26,70-39,53$ & $36,68-42,95$ \\
\hline Largura & $0,37-0,50$ & & 2,00 & $0,57-0,60$ & $0,67-0,70$ \\
\hline Lábios & $0,088-0,109$ & & & $0,096-0,104$ & $0,139-0,157$ \\
\hline Interlábios & $0,029-0,034$ & & & 0,035 & 0,052 \\
\hline Esôfago & $\begin{array}{c}1,37-2,51 x \\
0,12-0,15\end{array}$ & & $200-3,00$ & $\begin{array}{c}1,68-1,99 \times \\
0,10-0,12\end{array}$ & $\begin{array}{c}1,97-2,06 x \\
0,15-0,51\end{array}$ \\
\hline Anel nervoso & $0,40-0,51$ & & & & \\
\hline Poro excretor & $0,51-0,63$ & & & $0,51-0,56$ & $0.51-0.53$ \\
\hline Espiculos & $0,96-1,28$ & $2,48 \times 0,08$ & & $0,87-0,96$ & \\
\hline Ảpice caudal & $0,050-0,066$ & & & 0,035 & $0,043-0,048$ \\
\hline Ânus & $0,15-0,18$ & & & & $0,21-0,23$ \\
\hline Lábio dorsal & & & 0,17 & & \\
\hline Vulva & & & 15,00 & & $16,92-19,60$ \\
\hline Ovos & & & 0,10 & & $\begin{array}{c}0,070-0,078 x \\
0,061-0,065\end{array}$ \\
\hline Ovejetor & & & & & $1,08-1,23$ \\
\hline Reto & & & & & 0,33-0,35 \\
\hline Papilas caudais & $\begin{array}{c}\text { 24-31 pares pré e } 6 \\
\text { pós anal }\end{array}$ & 40 pares & pós anal & $\begin{array}{c}35 \text { pares pré, } 1 \text { ad e } \\
7 \text { pós anal }\end{array}$ & \\
\hline
\end{tabular}

O. obconica (Baird, 1860) Baylis, 1921 (Tab. XXVIII, Figs 183-184)

Sinonímia: Ascaris obconica Baird, 1860.

Hospedeiro e proveniência: Helicops angulatus (L.), Brasil.

Localização: estômago e intestino.

Referência bibliográfica: 60 .

O. sicki Freitas, 1951 (Tab. XXVIII, Figs 185-186)

Hospedeiros e proveniência: Xenodon merremii (Wagler) e Xenodon severus (L.), Goiás: Chavantina (Rio das Mortes).

Localização: estômago.

Referências bibliográficas: 52, 60 .

O. sprenti Araujo, 1969 (Tab. XXIX, Figs 187-188)

Hospedeiro e proveniência: Crotalus durissus terrificus (Laurenti), Brasil.

Localização: intestino.

Referência bibliográfica: 15 .

O. travassosi Vaz, 1938 (Tab. XXIX, Figs 189-191)

Hospedeiro e proveniência: Crotalus durissus terrificus (Laurenti), Brasil.

Localização: estômago.

Referências bibliográficas: 60, 148 . 
O. trichuriformis Vaz, 1935 (Tab. XXIX, Figs 192-193)

Hospedeiros e proveniência: Liophis miliaris (L.), Xenodon merremii (Wagler) e Crotalus durissus terrificus (Laurenti), São Paulo.

Localização: estômago.

Referências bibliográficas: 60, 147

\section{Polydelphis Dujardin, 1845}

Asas cervicais ausentes. Lábios mais ou menos quadrados, frequentemente mais largos na base que na margem livre. Lábio dorsal normalmente menor que os lábios subventrais. Interlábios na base dos lábios, raramente presente. Esôfago curto, sem bulbo ou ventrículo. Ceco intestinal ausente. Machos de cauda romba; papilas caudais como em Ophidascaris; espículos iguais ou subiguais; gubernáculo ausente. Fêmeas com vulva geralmente na região anterior, raramente após o meio do corpo; vagina dirigida posteriormente. Quatro ramos uterinos. Parasitos de cobras.

Espécie tipo: P. anoura Dujardin, 1845.

Espécie assinalada no Brasil:

\section{P. quadrangularis (Schneider, 1866)}

Sinonímia: Ascaris quadrangularis Schneider, 1866; Ascaris (P.) quadrangularis Schneider, 1866; Polydelphis quadricornis Wedl, 1861.

Hospedeiro e proveniência: Crotalus durissus terrificus (Laurenti), Brasil.

Localização: intestino e estômago.

Referências bibliográficas: 22, 23 .

\section{Travassosascaris Sprent, 1978}

Lábios dilatados, com estreita ligação com o corpo. Prolongamentos anteriores da polpa em forma de martelo; fileiras dentígeras presentes. Cavidade pós-labial e interlábios presentes. Asas laterais estreitas, com estrias cuticulares estendendo-se da regiẫo do anel nervoso além do nível da junção esôfago-intestino. Papilas cervicais após o poro excretor. Esôfago torcido posteriormente, com a porção dorsal disposta lateralmente. Porção final do esôfago contendo núcleos de glândulas esofagianas. Ventrículo ausente. Glândula esofagiana dorsal estendendo-se através do esôfago, com duto entre o anel nervoso e o lábio dorsal. Glândulas subventrais abrindo-se perto dos núcleos. Ceco intestinal ausente. Sistema excretor bilateral; poro excretor logo após o anel nervoso. Núcleo excretor no filamento esquerdo estendendo-se até a comissura. Fêmeas maduras com vulva ligeiramente anterior ao meio do corpo; quatro ramos uterinos presentes. Machos com espículos alados, sem gubernáculo. Parasitos de ofídios.

Espécie tipo: T. araujoi Sprent, 1978.

Espécie assinalada no Brasil: 
Tabela XXIX. Ophidascaris sprenti, dados segundo Araujo, 1969; O. travassosi e O. trichuriformis, dados segundo Vaz, 1938 e 1935, respectivamente.

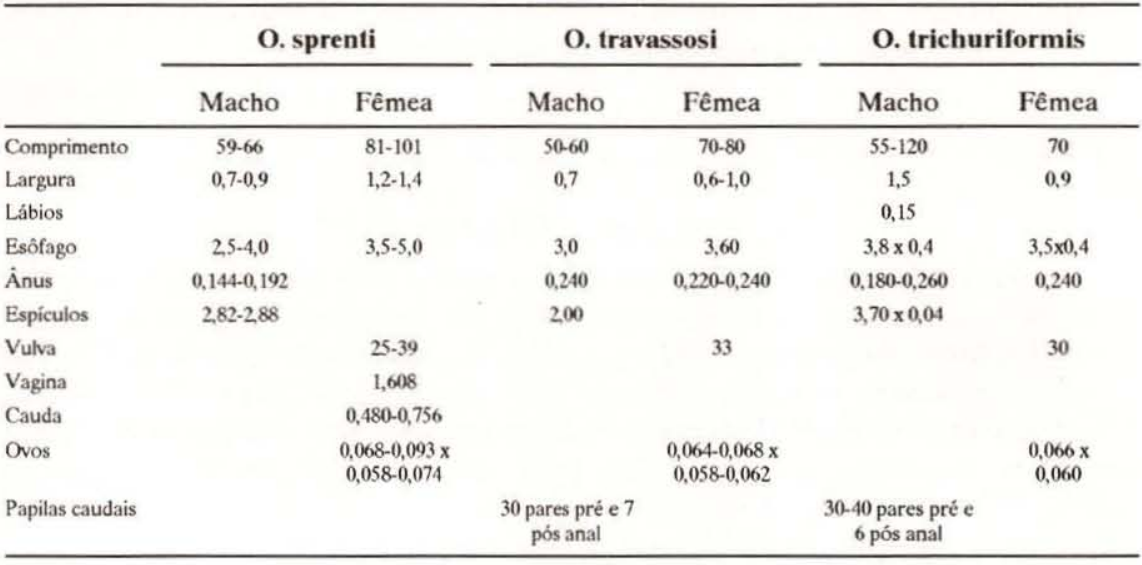

T. araujoi Sprent, 1978 (Tab. XXVII, Figs 197-199)

Sinonímia: Polydelphis quadrangularis Araujo, 1969 nec Schneider, 1866.

Hospedeiro e proveniência: Crotalus durissus terrificus (Laurenti), Brasil.

Localização: intestino e estômago.

Referência bibliográfica: 118 .

\section{Gnathostomatoidea}

Esta família é representada pela família Gnathostomatidae Railliet, 1895 com os gêneros Ancyracanthus Diesing, 1839 e Spiroxys Schneider, 1866.

\section{Gnathostomatidae Railliet, 1895}

Boca com dois grandes lábios laterais nitidamente trilobados, tendo a cutícula das suas superfícies internas espessadas e geralmente dotadas de margens denteadas. Atrás dos lábios existe um bulbo cefálico cuticular dotado ou de nítidas estrias transversais ou de fileiras de dentes dirigidos para trás e contendo quatro balonetes membranosos submedianos, os quais se comunicam com quatro prolongamentos cervicais que terminam em fundo de saco e que ficam pendentes na cavidade do corpo. O macho apresenta asas caudais sustentadas por papilas pedunculadas alargadas. Espículos iguais ou diferentes. Fêmea com vulva na metade posterior do corpo; vagina dirigida para a parte de trás e formando de dois a quatro úteros. Ovíparas. Ovos com casca fina ornamentados externamente com granulações finas. 


\section{Chave para identificação dos gêneros:}

- Extremidade anterior com dois pares de apêndices quitinizados, iguais, ramificados, em forma de pena e dirigido para trás ...............

Ancyracanthus

- Extremidade anterior sem essas características

Spiroxys

\section{Ancyracanthus Diesing, 1839}

Nematóides de corpo cilíndrico; cutícula estriada transversalmente. Extremidade anterior com dois pares de apêndices quitinizados iguais, ramificados em forma de pena e dirigidos para trás. Esôfago longo, glandular. Fêmeas didelfas, prodelfas, ovíparas. Vulva no terço posterior do corpo. Ovos elíticos. Machos com dois espículos iguais. Gubernáculo ausente. Extremidade caudal com asas pouco desenvolvidas. Três pares de papilas pré-anais e um par de pós-anais. Parasitos de tartarugas.

Espécie tipo: A. pinnatifidus Diesing, 1839.

Espécie assinalada no Brasil:

A. pinnatifidus Diesing, 1839 (Tab. XXII, Figs 226-228)

Sinonímia: Ancyracanthus pectinatus Diesing, 1838 nom nud.

Hospedeiros e proveniência: Podocnemys expansa (Schw.), Podocnemys dumeriliana (Schw.), Brasil.

Localização: estômago e intestino.

Referência bibliográfica: 73 .

\section{Spiroxys Schneider, 1866}

Corpo liso. Lábios grandes, com cutícula interna espessa e um dente bem definido. Colar cuticular rudimentar ou ausente. Cavidade bucal abrindo-se em um curto vestíbulo. Esôfago cilíndrico. Machos com cauda cônica; asa caudal bem desenvolvida; dobra vesicular pré-anal presente, bem como algumas vezes, uma depressão pré-anal em forma de ventosa. Onze pares de papilas caudais dos quais dois são ventrais e sésseis, um anterior e outro posterior à cloaca. Espículos subiguais, delicados. Gubernáculo ausente. Fêmeas com a vulva no meio do corpo e vagina dirigida para diante. Úteros opostos. Ovíparas. Ovos de casca fina; incolores. Parasitos do estômago de tartarugas e anfíbios.

Espécie tipo: S. contorta (Rud., 1819) Schneider, 1866.

Espécie assinalada no Brasil:

S. figueiredoi Freitas \& Dobbin Jr., 1962 (Tab. XXVII, Figs 200-202)

Hospedeiro e proveniências: Kinosternon scorpioides scorpioides (L.), Pernambuco: Açude de São João da Várzea, Recife, Pará: Rio Bujarú, Anajás e Mocoōes, Ilha de Marajó.

Localização: estômago.

Referências bibliográficas: 3, 63, 64, 150. 


\section{Camallanoidea}

Esta superfamília encera a família Camallanidae Railliet \& Henry, 1915 com os gêneros Camallanus Railliet \& Henry, 1915 e Serpinema Yeh, 1960.

\section{Camallanidae Railliet \& Henry, 1915}

Boca alongada dorso ventralmente; cápsula bucal quitinosa, contínua ou consistindo de duas válvulas laterais em forma de concha. Esôfago composto de uma porção muscular anterior e uma longa porção glandular posterior. Macho com a extremidade posterior curvada ventralmente; asas caudais presentes. Número variável de papilas caudais, a maioria pedunculada e projetando-se dentro das asas; espículos desiguais e dissemelhantes. Fêmea com vulva próxima ao meio do corpo, vagina dirgindo-se para a região posterior, úteros opostos, a alça posterior terminando sem formar um ovário. Vivíparas. Parasitos de animais de sangue frio.

\section{Chave para identificaçạ̃o dos gêneros:}

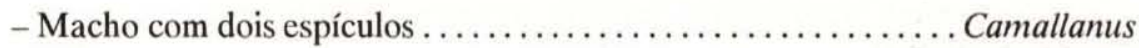

- Macho com um espículo ............................ Serpinema

\section{Camallanus Railliet \& Henry, 1919}

Boca em forma de fenda. Cápsula bucal consistindo de duas valvas laterais quitinizadas com espessamentos internos em forma de estrias. Do ponto de junção das valvas dorsal e ventralmente um processo quitinoso em forma de tridente se dirige para trás. Anel quitinoso na junção das valvas com o esôfago. Esôfago formado por uma porção muscular anterior curta e uma porção glandular posterior longa, alargada posteriormente. Machos com a extremidade posterior enrolada ventralmente; pequena asa caudal presente; cerca de sete pares de papilas pré-anais, dois pequenos pares ad-anais e outros tantos pares pós-anais. Espículos geralmente desiguais e dissemelhanes, um fracamente quitinizado; gubernáculo ausente. Fêmeas com vulva no meio do corpo; úteros opostos. Ausência de ovário posterior. Vivíparas. Parasitos do estômago e intestino de répteis, anfíbios e peixes.

Espécie tipo: C. lacustris Zoega, 1776.

Espécie assinalada no Brasil:

C. amazonicus Ribeiro, 1940 (Tab. XXII, Figs 222-225)

Hospedeiro e proveniência: Podocnemis expansa (Schw.), Pará: Belém.

Localização: intestino delgado.

Referência bibliográfica: 100 . 


\section{Serpinema Yeh, 1960}

Extremidade anterior truncada em ambos os sexos. Extremidade cefálica provida de boca bivalva e de dois tridentes. Fêmeas vivíparas, didelfas, prodelfas, vagina dirigida para trás. Machos com um só espículo. Gubernáculo ausente. Asas caudais presentes bem desenvolvidas. Cauda curvada ventralmente e com forte musculatura transversal. Parasitos de répteis.

Espécie tipo: S. intermedius (Hsu \& Hoeppli, 1931) Yeh, 1960.

Espécies assinaladas no Brasil:

S. monospiculatus Freitas \& Dobbin Jr., 1962 (Tab. XXX, Figs 208-209)

Hospedeiros e proveniências: Batrachemys tuberculata (Luederwalt), Pernambuco: Jaboatão; Batrachemys nasuta e Phrynops geoffroana geoffroana (Schweigger), Pernambuco: Cortês, Recife.

Localização: intestino delgado.

Referências bibliográficas: 62,64 .

\section{S. maghati (Sprehn, 1932) Yeh, 1960 (Tab. XXX, Figs 204-207)}

Sinonímia: Camallanus maghati Sprehn, 1932; Camallanus parvus Caballero, 1939.

Hospedeiro e proveniências: Kinosternon scorpioides scorpioides (L.), Pernambuco: Barra do Cordeiro, Recife, Açude São João da Várzea e São Lourenço da Mata, Pará: Rios Mocoões e Anajás, Ilha de Marajó.

Localização: intestino delgado.

Referências bibliográficas: 64, 162 .

\section{Physalopteroidea}

Esta superfamília encerra a família Physalopteridae Leiper, 1908 com os gêneros Physaloptera Rud., 1819 e Tubunaea Seurat, 1914.

\section{Physalopteridae Leiper, 1908}

Boca com grandes lábios triangulares simples armados com um ou mais dentes; cutícula formando um colar cefálico que passa por trás dos lábios; cordões cutâneos ou dragonas ausentes, usualmente sem um vestíbulo; esôfago dividido em duas porções. Macho com asas caudais bem desenvolvidas, usualmente unidas ventralmente diante do orifício ano genital e sustentadas por longas papilas pedunculadas. Parasitos de vertebrados.

\section{Chave para identificação dos gêneros:}

- Com colarete cefálico; vestíbulo ausente ...............Physaloptera

-Sem colarete cefálico; vestíbulo presente .............. Thubunaea 
Tabela XXX. Serpinema magathi e S. monospiculatus, dados segundo Freitas \& Dobbin Jr., 1971 e 1962, respectivamente; Physaloptera liophis, dados segundo Vicente \& Santos, 1974.

\begin{tabular}{|c|c|c|c|c|c|c|}
\hline & \multicolumn{2}{|c|}{ S. magathi } & \multicolumn{2}{|c|}{ S. monospiculatus } & \multicolumn{2}{|c|}{ P. liophis } \\
\hline & Macho & Fêmea & Macho & Fêmea & Macho & Fêmea \\
\hline Comprimento & $8,34-8.93$ & 12,58 & $9,55-10,92$ & $17,08-18,69$ & $12,18-13,80$ & 12.78 \\
\hline Largura & $0,26-0,29$ & $0,29-0,36$ & $0,23-0,26$ & $0,30-0,36$ & $0,50-0,52$ & 0,51 \\
\hline Valvas bucais & $\begin{array}{c}0,097 x \\
0,119-0,133\end{array}$ & $\begin{array}{l}0,108 \mathrm{x} \\
0,144\end{array}$ & $\begin{array}{c}0,108-0,112 \mathrm{x} \\
0,144-0,237\end{array}$ & $\begin{array}{c}0,115-0,137 x \\
0,173-0,198\end{array}$ & & \\
\hline $\begin{array}{l}\text { Ramos medianos dos } \\
\text { tridentes }\end{array}$ & 0,061 & 0,072 & $0,072-0,076$ & $0,072-0,076$ & & \\
\hline $\begin{array}{l}\text { Ramos laterais dos } \\
\text { tridentes }\end{array}$ & $0,076-0,079$ & 0,086 & $0,058-0,065$ & & & \\
\hline $\begin{array}{l}\text { Anel quitinoso das } \\
\text { valvas }\end{array}$ & $\begin{array}{c}0,018-0,022 x \\
0,086-0,090\end{array}$ & $\begin{array}{c}0,018-0,022 \mathrm{x} \\
0,101-0,108\end{array}$ & $\begin{array}{c}0,025-0,029 x \\
0,076-0,079\end{array}$ & $\begin{array}{c}0,022-0,029 \times \mathrm{x} \\
0,072-0,090\end{array}$ & & \\
\hline Esôfago total & $1,08-1,13$ & $1,14-1,23$ & $1,16-1,24$ & $1,33-1,71$ & & \\
\hline Esôfago muscular & $0,41-0,42$ & $0,43-0,45$ & $0,50-0,53$ & $0,55-0,74$ & $0,31-0,35$ & 0,36 \\
\hline Esôfago glandular & $0,66-0,71$ & $0,71-0,78$ & $0,63-0,71$ & $0,71-1,00$ & $0,34-0,38$ & 0,39 \\
\hline Anel nervoso & $0,099-0,132$ & 0,139 & $0,112-0,132$ & $0,132-0,165$ & 0,26 & 0,31 \\
\hline Vulva & & 7,13 & & $6,21-8,87$ & & 7,07 \\
\hline Ânus & $0,09-0,13$ & 0,22 & $0,09-0,13$ & $0,20-0,23$ & & 0,39 \\
\hline Espiculos & $0,54-0,59$ & & 0,43 & & $0,25-0,26$ & \\
\hline Reto & & & & $0,108-0,144$ & & \\
\hline Ovos & & & & & & $0,050 \times 0,020$ \\
\hline Papilas caudais & $\begin{array}{l}7 \text { pares pré e } 7 \\
\text { pós anal }\end{array}$ & & $\begin{array}{l}\text { 6 pares pré, } 1 \text { ad } \\
\text { e } 3 \text { pós anal }\end{array}$ & & $\begin{array}{c}10 \text { pares e } 3 \\
\text { impares }\end{array}$ & \\
\hline
\end{tabular}

\section{Physaloptera Rud., 1819}

Dois grandes lábios laterais simples, triangulares, cada um apicalmente ou internamente provido de um número variável de dentes e externamente com papilas. Cutícula geralmente dobrada sobre os lábios formando um grande colarete cefálico. Papilas cervicais posteriores ao anel nervoso. Cavidade bucal pequena ou ausente; esôfago consistindo de uma parte anterior muscular e uma posterior glandular. Machos com asas caudais largas, unindo-se ventralmente em frente ao ânus; três a sete pares de grandes papilas na região cloacal e um número variável de papilas sésseis das quais algumas ao redor da abertura cloacal e as outras distribuídas aos pares na cauda. Espículos iguais ou desiguais, similares. Fêmeas com vulva anterior ou posterior ao meio do corpo. Úteros em número de dois, quatro ou mais, paralelos. Ovíparas. Ovos ovais, de casca espessa, embrionados quando da postura.

Espécie tipo: $P$. clausa Rud., 1819.

Espécies assinaladas no Brasil:

P. liophis Vicente \& Santos, 1974 (Tab. XXX, Figs 210-212)

Hospedeiro e proveniência: Liophis miliaris (L.), Rio de Janeiro: Volta Redonda.

Localização: estômago.

Referência bibliográfica: 160 . 
P. lutzi Cristófaro, Guimarâes \& Rodrigues, 1976 (Tab. XXXI, Figs 213-214)

Hospedeiros e proveniências: Ameiva ameiva (L.), Bahia: Salvador; Tropidurus torquatus (Wied), Bahia: Salvador, Serrinha e Canudos, Pará: Cachimbo, Espírito Santo: Conceição da Barra; Tropidurus spinulosus (Cope), Mato Grosso do Sul: Salobra, Porto Esperança e Chavantina.

Localização: estômago.

Referências bibliográficas: 44, 152 .

Tabela XXXI. Physaloptera lutzi, dados segundo Cristofaro, Guimarães \& Rodrigues, 1976; P. monodens e P. obtusissima, dados segundo Ortlepp, 1922.

\begin{tabular}{|c|c|c|c|c|c|c|}
\hline & \multicolumn{2}{|c|}{ P. lutzi } & \multicolumn{2}{|c|}{ P. monodens } & \multicolumn{2}{|c|}{ P. obtusissima } \\
\hline & Macho & Fêmea & Macho & Fêmea & Macho & Fêmea \\
\hline Comprimento & $12,21-18,15$ & $11,88-15,93$ & $18,00-23,00$ & $25,00-40,00$ & $20,00-32,00$ & $28,00-47,00$ \\
\hline Largura & $0,35-0,69$ & $0,39-0,66$ & $0,71-0,77$ & $0,85-0,96$ & $0,70-0,72$ & $0,65-0,72$ \\
\hline Papilas cervicais & $0,16-0,24$ & $0,16-0,25$ & & & & \\
\hline Esôfago muscular & $0,40-0,46$ & $0,35-0,48$ & & & & \\
\hline Esôfago total & $2,40-3,33$ & $2,40-3,30$ & & & & \\
\hline Poro excretor & $0,48-0,56$ & $0,46-0,58$ & & & & \\
\hline Anel nervoso & $0,35-0,36$ & $0,33-0,36$ & & & & \\
\hline Ànus & $0,52-0,72$ & $0,23-0,26$ & & & & \\
\hline Espiculo maior & $0,46-0,56$ & & 0,415 & & 0,430 & \\
\hline Espiculo menor & $0,25-0,28$ & & 0,362 & & 0,385 & \\
\hline Vulva-cauda & & 0,78 & & & & \\
\hline Ovos & & $\begin{array}{l}0,032-0,040 \times x \\
0,020-0,028\end{array}$ & & $\begin{array}{c}0,045 x \\
0,026\end{array}$ & & $\begin{array}{l}0,045 x \\
0,026\end{array}$ \\
\hline Vagina & & & & 1,6 & & 1,5 \\
\hline Papilas caudais & $\begin{array}{l}4 \text { pares pré, } 7 \text { ad } \\
\text { e } 3 \text { pós anal }\end{array}$ & & & & & \\
\hline
\end{tabular}

P. monodens Molin, 1860 (Tab. XXXI, Fig. 215)

Hospedeiro e proveniência: Constrictor constrictor (L.) (=Boa constrictor L.), Brasil.

Localização: estômago.

Referência bibliográfica: 112 .

P. obtusissima Molin, 1860 (Tab. XXXI, Fig. 216) Brasil.

Hospedeiros e proveniências: Bothrops jararaca (Wied), Cloelia sp.,

Localização: estômago.

Referência bibliográfica: 112 .

P. phrynosoma Ortlepp, 1922 (Tab. XXXII, Figs 217-218)

Brasil.

Hospedeiros e proveniência: Phrynosoma cornutum, Phrynosoma regale,

Localização: estômago.

Referência bibliográfica: 112 . 
Tabela XXXII. Physaloptera phrynosoma, dados segundo Ortlepp, 1922; P. retusa, dados segundoVicente, 1981 e Thubunaea dactyluris, dados segundo Fabio \& Rolas, 1974.

\begin{tabular}{|c|c|c|c|c|c|c|}
\hline & \multicolumn{2}{|c|}{ P. phrynosoma } & \multicolumn{2}{|c|}{ P. retusa } & \multicolumn{2}{|c|}{ T. dactyluris } \\
\hline & Macho & Fêmea & Macho & Fêmea & Macho & Fêmea \\
\hline Comprimento & 11,00 & $18,00-23,00$ & $9,82-12,92$ & $11,39-13,26$ & $7,60-13,36$ & $14,85-22,29$ \\
\hline Largura & 0,47 & $0,61-0,76$ & $0,34-0,40$ & $0,44-0,47$ & $0,23-0,52$ & $0,32-0,65$ \\
\hline Espiculo maior & 0,530 & & $0,240-0,290$ & & $0,087-0,091$ & \\
\hline Espículo menor & 0,180 & & $0,240-0,260$ & & $0,057-0,072$ & \\
\hline Vagina & & 0,38 & & & & \\
\hline Ovos & & $\begin{array}{c}0,050 \times \\
0,036\end{array}$ & & $\begin{array}{c}0,039-0,043 x \\
0,021-0,025\end{array}$ & & $\begin{array}{c}0,031-0,040 \times \\
0,020-0,026\end{array}$ \\
\hline Esôfago anterior & & & $0,29-0,35$ & $0,33-0,35$ & $0,17-0,30$ & $0,24-0,33$ \\
\hline Esôfago posterior & & & $2,10-2,40$ & $2,10-2,86$ & $1,45-2,13$ & $2,24-3,22$ \\
\hline Anel nervoso & & & $0,25-0,30$ & $0,28-0,29$ & $0,20-0,23$ & $0,17-0,29$ \\
\hline Ânus & & & $0,40-0,56$ & $0,28-0,30$ & $0,10-0,17$ & $0,07-0,10$ \\
\hline Vulva & & & & $30,00-50,00$ & & $1,14-2,09$ \\
\hline Reto & & & & $0,20-0,21$ & & $0,14-0,19$ \\
\hline Vestibulo & & & & & $0,019-0,028$ & $0,024-0,033$ \\
\hline Poro excretor & & & & & $0,22-0,24$ & $0,19-0,29$ \\
\hline Ovejetor & & & & & & $1,03-1,49$ \\
\hline Papilas caudais & & & $\begin{array}{l}2 \text { pares pré, } 1 \text { ad, } 1 \\
\text { pós anal e } 1 \text { impar }\end{array}$ & & $\begin{array}{l}4 \text { pares pré e } 5 \\
\text { pós anal }\end{array}$ & \\
\hline
\end{tabular}

P. retusa Rud., 1819 (Tab. XXXII, Fig. 219)

Sinonímia: Spiroptera retusa Dujardin, 1845; Physaloptera mucronata Leidy, 1856; Physaloptera lagarda Sprehn, 1932.

Hospedeiros e proveniência: Tropidurus torquatus (Wied), São Paulo: Ilha Seca, Bahia: Salvador, Espírito Santo: Conceição da Barra, Pará: Belém, Cachimbo.

Localização: estômago.

Referências bibliográficas: 152, 158 .

Physaloptera sp. Travassos, Freitas \& Lent, 1939

Hospedeiros e proveniência: Tropidurus torquatus (Wied), Tupinambis teguixin (L.) e Ameiva ameiva (L.), Espírito Santo: Salobra.

Localização: estômago.

Referência bibliográfica: 141 .

Physaloptera sp. Travassos, 1941

Hospedeiro e proveniência: Ameiva ameiva (L.), Mato Grosso do Sul: Salobra, MS.

Localização: estômago.

Referência bibliográfica: 136 . 
Physaloptera sp. Travassos \& Freitas, 1941

Hospedeiros e proveniência:Tropidurus spinulosus (Cope), Tupinambis teguixin (L.), Polychrus acutirostris (Spix), Xenodon merremii (Wagler), Mato Grosso do Sul: Salobra.

Localização: estômago.

Referência bibliográfica: 137.

Physaloptera sp. Travassos \& Freitas, 1943

Hospedeiros e proveniência: Phylodrias sp., Ameiva sp., Tupinambis teguixin (L.), Polychrus acutirostris (Spix), Mato Grosso do Sul: Salobra.

Localização: estômago.

Referência bibliográfica: 140 .

Physaloptera sp. Travassos, Freitas, Mendonça \& Rodrigues, 1960

Hospedeiro e proveniência: Ameiva ameiva (L.), Rio de Janeiro: Cabo Frio.

Localização: estômago.

Referência bibliográfica: 143 .

Physaloptera sp. Travassos, Freitas \& Mendonça, 1964

Hospedeiro e proveniência: Tupinambis teguixin (L.), Espírito Santo: Sooretama.

Localização: estômago.

Referência bibliográfica: 142 .

\section{Thubunaea Seurat, 1914}

Boca com dois lábios laterais simples e arredondados cujas superfícies internas apresentam três dentes proeminentes e um par de papilas submedianas. Asas laterais ausentes. Papilas cervicais imediatamente após o anel nervoso. Cavidade bucal curta, cilíndrica, comprimida lateralmente e com paredes delicadas. Esôfago curto com uma porção muscular anterior e uma glandular posterior. Machos com extremidade posterior arredondada ou afilada, terminando num pequeno processo cônico; asa caudal bem desenvolvida com aparência verrucosa; quatro pares de papilas pré-anais, quatro ou cinco pósanais penduculadas e além destas cerca de doze papilas sésseis ao redor do ânus. Espículos curtos, subiguais. Fêmeas com extremidade posterior curta terminando numa pequena ponta cônica. Vulva no quinto anterior do corpo; ovejetor longo. Ovíparas. Ovos de casca espessa, embrionados quando eliminados. Parasitos de répteis.

Espécie tipo: T. pudica Seurat, 1914.

Espécie assinalada no Brasil: 
T. dactyluris Karve, 1938 (Tab. XXXII, Figs 220-221)

Hospedeiro e proveniência: Ameiva ameiva (L.), Rio de Janeiro: Magé (Praia do Anil).

Localização: estômago.

Referência bibliográfica: 47 .

Physalopterinae sp. Rodrigues, 1970

Hospedeiro e proveniência: Hemidactylus mabouia (M. de J.), Rio de Janeiro: Rio de Janeiro.

Localização: estômago.

Referênica bibliográfica: 102 .

\section{Spiruroidea}

Esta superfamília encerra a família Spiruridae Oerley, 1885 com uma única referência Spirurinae sp. Rodrigues, 1970.

\section{Spiruridae Oerley, 1885}

Boca geralmente com lábios laterais trilobados, ocasionalmente pequenos lábios dorsais e ventrais podem estar presentes ou ainda, não existirem. Atrás da cavidade bucal geralmente existe um vestíbulo. $\mathrm{O}$ esôfago é longo e dividido em uma parte anterior curta muscular e uma parte posterior mais longa glandular. Papilas cervicais geralmente presentes, junto do anel nervoso. Asas laterais presentes ou não. Macho com asas caudais bem desenvolvidas e sustentadas por papilas pedunculadas. Fêmeas com vulva geralmente próxima do meio do corpo. Ovíparas. Parasitos de vertebrados.

Spirurinae sp. Rodrigues, 1970

Hospedeiro e proveniência: Hemidactylus mabouia (M. de J.), Rio de Janeiro: Rio de Janeiro.

Localização: estômago, intestino delgado e pulmão.

Referência bibliográfica: 102 .

\section{Diplotriaenoidea}

Esta superfamília é representada pela familia Diplotriaenidae Anderson, 1958 com o gênero Hastospiculum Skrjabin, 1923.

\section{Diplotriaenidae Anderson, 1958}

Boca simples, sem anel peribucal quitinoso ou estruturas semelhantes a dragonas, com estrutura quitinosa em forma de tridente em cada lado da extremidade anterior do esôfago. Espículos desiguais. Vulva na região do esôfago. Ovíparos. 


\section{Hastospiculum Skrjabin, 1923}

Boca oval com longo eixo dorso-ventral cercada de cada lado por um processo quitinoso protuso ou lábio, externo ao qual existem espessas estruturas cuticulares em forma de dragona terminando em três processos externos e possuindo um anfídeo lateral e dois pares de papilas submedianas. Esôfago distintamente dividido em duas partes: a anterior curta e estreita e a posterior larga e muito longa. Machos com cauda cônica, truncada, com asa caudal larga, unida posteriormente atrás do ápice da cauda com um certo número de papilas pedunculadas das quais três pares pré-anais e um pós-anal são maiores que as outras. Espículos alados, muito desiguais, o maior delicado e o menor mais ou menos espesso. Fêmeas com extremidade posterior arredondada. Ânus atrofiado, com abertura terminal. Vulva ligeiramente após a terminação da porção anterior do esôfago. Anfidelfas, ovíparas; ovos embrionados in útero. Parasitos de membrana serosa de répteis.

Espécie tipo: $H$. varani Skrjabin, 1923.

Espécies assinaladas no Brasil:

H. digiticaudum Freitas, 1956 (Tab. XXXIII, Figs 274-276)

Hospedeiro e proveniência: Philodrias aestivus Dumeril, Bibron \& Dumeril, Rio de Janeiro: Rio de Janeiro.

Localização: cavidade geral.

Referências bibliográficas: 54,154 .

H. onchocercum Chitwood, 1932 (Tab. XXXIII, Figs 277-278)

Hospedeiro e proveniência: Crotalus durissus terrificus (Laurenti), Pernambuco: Recife.

Localização: cavidade geral.

Referência bibliográfica: 161 .

\section{Dracunculoidea}

Esta superfamília é representada pela família Micropleuridae Travassos, 1960 com o gênero Micropleura Linstow, 1906.

\section{Micropleuridae Travassos, 1960}

Macho muito menor que a fêmea. Cutícula lisa ou com bossas, estriada transversalmente. Boca simples, sem lábios, cercada por papilas laterais e submedianas, com ou sem margem peribucal quitinosa, mas sem nenhuma estrutura semelhante a dragonas. Sem cápsula bucal. Esôfago dividido em duas partes. Vários pares de papilas caudais. Espículos iguais ou subiguais; vulva pouco nítida, na região mediana do corpo. Parasitos de répteis.

\section{Micropleura Linstow, 1906}

Cutícula com série de dois a sete pequenos tubérculos distribuídos longitudinalmente. Duas papilas cefálicas laterais e quatro (ou oito) subme- 
Tabela XXXIII. Piratuba zeae, dados segundo Bain, 1974; Hastospiculum digiticaudum, dados segundo Freitas, 1956 e H. onchocercum, dados segundo Chitwood, 1932.

\begin{tabular}{|c|c|c|c|c|c|c|}
\hline & \multicolumn{2}{|c|}{ P. zeae } & \multicolumn{2}{|c|}{ H. digiticaudum } & \multicolumn{2}{|c|}{ H. onchocercum } \\
\hline & Macho & Fêmea & Macho & Fêmea & Macho & Fêmea \\
\hline Comprimento & $1,26-1,64$ & 19,74 & $38,59-53,17$ & 66,88 & $58,00-72,00$ & 634,00 \\
\hline Largura & 0,24 & 0,30 & $0,57-0,78$ & 0,80 & $0,58-0,65$ & 2,00 \\
\hline Cápsula bucal & 0,013 & 0,012 & & & & \\
\hline Anel nervoso & 0,240 & 0,225 & $0,220-0,230$ & 0,250 & $0,215-0,442$ & 0,44 \\
\hline Esófago muscular & 0,400 & 0,250 & $0,230-0,336 \times 0,08$ & $0,330 \times 0,100$ & 0,350 & 0,800 \\
\hline Esôfago glandular & 0,800 & 0,885 & $\begin{array}{l}6,700-9,210 \times \\
0,270-0,430\end{array}$ & $\begin{array}{l}8,710 x \\
0,300\end{array}$ & $7,650-0,300$ & 18,200 \\
\hline Vulva & & 6,14 & & 0,73 & & 0,90 \\
\hline Cauda & 0,180 & 0,250 & & & & \\
\hline Espiculo direito & 0,125 & & 0,230 & & 0,300 & \\
\hline Espículo esquerdo & 0,162 & & 0,970 & & 2,750 & \\
\hline $\begin{array}{l}\text { Dilataçōes laterais } \\
\text { cefálicas }\end{array}$ & $0,021-0,340$ & 0,017 & & & & \\
\hline Ovejetor & & & & 0,91 & & \\
\hline Relação espicular & & & $1: 4,2: 4,6$ & & & \\
\hline Ânus & & & $0,07-0,09$ & & & \\
\hline Ovos & & & & & & $\begin{array}{c}0,040-0,045 \times \\
0,02-0,05\end{array}$ \\
\hline
\end{tabular}

dianas. Esôfago com uma pequena parte anterior e uma longa e larga porção posterior glandular. Machos com a extremidade posterior enrolada em espiral; cauda cônica afilada; estreita asa caudal que pode ser bem desenvolvida apenas de um lado. Sete pares de papilas caudais das quais três pré-anais e quatro pós-anais. Espículos pequenos, delgados, iguais e similares; gubernáculo presente. Placas pré-anais presentes ou ausentes. Fêmeas de cauda cônica, arredondada na extremidade. Vulva na região mediana do corpo, inconspícua. Vagina praticamente ausente; ramos uterinos opostos, bem largos. Ovários relativamente curtos. Vivíparas. Parasitos da cavidade geral e serosas de jacarés.

Espécie tipo: M. vivipara Linstow, 1906

Espécies assinaladas no Brasil:

M. vazi Travassos, 1933 (Tab. XXXIV, Figs 253-255)

Hospedeiro e proveniências: Caiman crocodilus crocodilus (L.), Rio de Janeiro: Rio de Janeiro; Mato Grosso do Sul: Porto Esperança; São Paulo: Rio Claro.

Localização: cavidade geral.

Referências bibliográficas: 132, 154 .

Micropleura sp. Travassos, Freitas \& Lent, 1939

Hospedeiro e proveniência: Caiman crocodilus crocodilus (L.), Mato Grosso do Sul: Salobra.

Localização: cavidade geral.

Referência bibliográfica: 141 . 
Micropleura sp. Travassos, 1941

Hospedeiro e proveniência: Caiman crocodilus crocodilus (L.), Mato Grosso do Sul: Salobra.

Localização: cavidade geral.

Referência bibliográfica: 137 .

Tabela XXXIV. Oswaldofilaria spinosa, dados segundo Bain \& Sulahian, 1974; Micropleura vazi, dados segundo Travassos, 1933; Piratuba digiticauda, dados segundo Lent \& Freitas, 1941 e P. carinii, dados segundo Vaz \& Pereira, 1935.

\begin{tabular}{|c|c|c|c|c|c|c|c|c|}
\hline & \multicolumn{2}{|c|}{ O. spinosa } & \multicolumn{2}{|c|}{ M. vazi } & \multicolumn{2}{|c|}{ P. digiticauda } & \multicolumn{2}{|c|}{ P. carinii } \\
\hline & Macho & Fêmea & Macho & Fêmea & Macho & Fêmea & Macho & Fêmea \\
\hline Comprimento & $14,00-16,50$ & 34,00 & 6,00 & 25,00 & $12,06-13,23$ & $19,56-22,44$ & $31,50-32,60$ & $54,40-59,80$ \\
\hline Largura & 0,23 & 0,13 & 0,70 & 1,00 & $0,20-0,23$ & $0,33-0,37$ & $0,26-0,38$ & $0,50-0,54$ \\
\hline Anel nervoso & $0,20-0,27$ & 0,22 & & & $0,25-0,31$ & $0,25-0,28$ & & \\
\hline Cápsula bucal & 0,012 & 0,013 & & & & & $0,26-0,30$ & \\
\hline Esôfago total & & & & & 0,95 & $0,96-1,13$ & & \\
\hline Esôfago muscular & 0,28 & 0,34 & 0,33 & 0,60 & & & 0,80 & 0,98 \\
\hline Esôfago posterior & $0,61-0,86$ & 2,15 & 0,93 & 1,60 & & & & \\
\hline Vulva & & 16,60 & & & & & $9,21-10,79$ & \\
\hline Ovejetor & & 1,6 & & & & & & \\
\hline Cauda & 0,26 & 0,34 & & & & & & \\
\hline Espiculo esquerdo & 0,298 & & & & & & $0,22-0,26$ & \\
\hline Espículo direito & 0,098 & & & & & & 0,14 & \\
\hline Bossas cuticulares & & & $0,040-0,064$ & $0,040-0,064$ & & & & \\
\hline Ânus & & & 0,29 & 0,50 & & & & 0,24 \\
\hline Espiculos & & & 0,168 & & $0,157-0,174$ & & & \\
\hline Gubernáculo & & & 0,056 & & & & & \\
\hline Papilas caudais & & & $\begin{array}{l}7 \text { pares pré e } \\
4 \text { pós anal }\end{array}$ & & $\begin{array}{l}5 \text { pares pré e } \\
\text { 5-6 pós anal }\end{array}$ & & & \\
\hline
\end{tabular}

Micropleura sp. Travassos \& Freitas, 1941

Hospedeiro e proveniência: Tupinambis teguixin (L.), Mato Grosso do Sul: Salobra.

Localização: cavidade geral.

Referência bibliográfica: 138 .

\section{Filarioidea}

Esta superfamília encerra a família Onchocercidae Leiper, 1911 com os gêneros Oswaldofilaria Travassos, 1933 e Piratuba Freitas \& Lent, 1947.

\section{Onchocercidae Leiper, 1911}

Boca simples sem um anel peribucal quitinoso ou estruturas laterais em forma de dragona, sem estruturas quitinossas em forma de tridente de cada lado da extremidade anterior do esôfago. Cutícula reforçada por espessamento 
anular externo ou interno. Espículos desiguais. Vulva na região esofagiana.

\section{Chave para identificação dos gêneros}

- Espículos desiguais em tamanho e forma ................ Oswaldofilaria

- Espículos similares em tamanho e forma ...................Piratuba

\section{Oswaldofilaria Travassos, 1933}

Cutícula lisa; boca simples, seguida de pequena cápsula bucal. Esôfago extremamente longo, diferenciado em uma porção anterior ou faringe. Fêmeas opistodelfas; vulva situada pouco acima do meio do corpo; ovejetor muito longo e simples; extremidade caudal digitiforme; vivíparas. Machos com a extremidade posterior digitiforme, sem asas laterais e com sete pares de papilas muito nítidas. Espículos curtos, fortes e de tamanho e forma diversos.

Espécie tipo: O. bacillaris (Molin, 1858) Travassos, 1933.

Espécies assinaladas no Brasil:

O. azevedoi Bain, 1974 (Tab. XXIII, Figs 236-239)

Hospedeiro e proveniência: Polychrus marmoratus (L.), Pará: Belém.

Localização: cavidade geral.

Referência bibliográfica: 33 .

O. bacillaris (Molin, 1858) Travassos, 1933 (Tab. XXIII, Figs 234-235)

Sinonímia: Filaria bacillaris Molin, 1858.

Hospedeiros e proveniência: Caiman crocodilus crocodilus (L.), Rio de Janeiro: Rio de Janeiro; Melanosuchus niger (Spix), Pará: Belém.

Localização: cavidade geral.

Referência bibliográfica: 132 .

O. belemensis Bain \& Sulahian, 1974 (Tab. XXXV, Figs 240-242)

Hospedeiro e proveniência: Dracaena guyanensis Daudin, Pará: Belém.

Localização: coração, aorta e veia cava.

Referência bibliográfica: 33 .

O. brevicaudata (Rhodhain \& Vuylsteke, 1937) Freitas \& Lent, 1937 (Tab. XXXV, Figs 243-245)

Sinonímia: Breinlia brevicaudata Rhodhain \& Vuylsteke, 1937.

Hospedeiro e proveniências: Iguana tuberculata (Laur.), Pará: Ilha de Marajó; Pernambuco: Exú.

Localização: cavidade geral.

Referência bibliográfica: 68 . 
O. petersi Bain \& Sulahian, 1974 (Tab. XXXV, Figs 246-248) lém.

Hospedeiro e proveniência: Tupinambis nigropunctatus Spix, Pará: Be-

Localização: mesentério.

Referência bibliográfica: 33 .

O. spinosa Bain \& Sulahian, 1974 (Tab. XXXIV, Figs 249-251)

Hospedeiro e proveniência: Mabuya mabouya mabouya (Lacépède), Pará: Belém.

Localização: axila, aponeurose ao longo da coluna, raramente livre na cavidade geral.

Referência bibliográfica: 33 .

\section{Piratuba Lent \& Freitas, 1941}

Corpo com cutícula estriada longitudinalmente. Boca simples. Cápsula bucal rudimentar. Esôfago dividido em duas partes: uma anterior muscular e outra posterior glandular. Fêmeas anfidelfas, com vulva situada no meio do corpo e ovejetor longo, com cauda digitiforme; vivíparas. Machos com extremidade posterior digitiforme, com deza onze pares de papilas, sem gubernáculo e bossas ventrais e com espículos iguais não filiformes. Parasitos de répteis.

Espécie tipo: $P$. digiticauda Lent \& Freitas, 1941.

Espécies assinaladas no Brasil:

P. digiticauda Lent \& Freitas, 1941 (Tab. XXXIV, Figs 256-258)

Hospedeiros e proveniências: Tropidurus torquatus (Wied), Bahia: Salvador, Pará: Piratuba; Tropidurus spinulosus (Wied), Mato Grosso do Sul: Salobra.

Localização: cavidade abdominal.

Referência bibliográfica: 80 .

P. carinii (Vaz \& Pereira, 1935) Caballero, 1954 (Tab. XXXIV, Figs 279-281)

Sinonímia: Macdonaldius carinii Vaz \& Pereira, 1935

Hospedeiro e proveniência: Elapomorphus tricolor Duméril, Bibron \& Duméril, São Paulo: São Paulo.

Localização: coração.

Referência bibliográfica: 149 .

P. laisoni Bain, 1974 (Tab. XXVI, Figs 259-262)

Hospedeiros e proveniência: Polychrus marmoratus (L.), Anolis punctatus Daudin, Pará: Belém.

Localização: cavidade geral.

Referência bibliográfica: 33 . 
Tabela XXXV. Oswaldofilaria belemensis, dados segundo Bain \& Sulahian, 1974; O. brevicaudata, dados segundo Freitas \& Lent, 1937 e O. petersi, dados segundo Bain \& Sulahian, 1974.

\begin{tabular}{|c|c|c|c|c|c|c|}
\hline & \multicolumn{2}{|c|}{ O. belemensis } & \multicolumn{2}{|c|}{ O. brevicaudata } & \multicolumn{2}{|c|}{ O. petersi } \\
\hline & Macho & Fêmea & Macho & Fêmea & Macho & Fêmea \\
\hline Comprimento & $59,00-63,00$ & 115,00 & $16,03-18,94$ & $37,61-42,87$ & $22,10-26,20$ & $59,00-64,00$ \\
\hline Largura & $0,325-0,375$ & 0,450 & $0,171-0,210$ & $0,447-0,500$ & 0,260 & 0,450 \\
\hline Anel nervoso & 0,32 & 0.35 & & & 0,30 & 0,38 \\
\hline Cápsula bucal & 0,020 & 0,025 & $0,016 \times 0,110$ & $0,016 \times 0,110$ & 0,017 & 0,017 \\
\hline Esôfago total & & & $2,81-3,21$ & $4,14-4,22$ & & \\
\hline Esôfagomuscular & 0,380 & 0,360 & $0,368-0,496$ & $0,456-0,560$ & 0,380 & 0,480 \\
\hline Esôfago glandular & 1,930 & 1,950 & & & 1,370 & 2,090 \\
\hline Vulva & & 27,00 & & 12,75 & & 15,6 \\
\hline Ovejetor & & 5,6 & & & & 4,1 \\
\hline Cauda & 0,26 & 0,48 & & & 0,15 & 0,26 \\
\hline Espiculo esquerdo & 0,465 & & & & $0,330-0,380$ & \\
\hline Espiculo direito & 0.180 & & & & $0,090-0,120$ & \\
\hline Ânus-cauda & & & $0,160-0,200$ & $0,352-0,408$ & & \\
\hline Papilas caudais & & & $\begin{array}{r}4 \text { pares pré, } 1 \text { ac } \\
\text { pré }\end{array}$ & $\begin{array}{l}3 \text { pós e } 1 \text { impar } \\
\text { nal }\end{array}$ & & \\
\hline
\end{tabular}

P. scaffi Bain, 1974 (Tab. XXXVI Figs 263-265)

Hospedeiro e proveniência: Ameiva ameiva ameiva (L.), Pará: Belém.

Localização: cavidade geral.

Referência bibliográfica: 33 .

P. shawi Bain, 1974 (Tab. XXXVI, Figs 266-269)

Hospedeiro e proveniência: Kentropix calcaratus Spix, Pará: Belém.

Localização: cavidade geral.

Referência bibliográfica: 33 .

P. zeae Bain, 1974 (Tab. XXXIII, Figs 270-273)

Hospedeiro e proveniência: Mabuya mabouya mabouya (Lacépède), Pará: Belém.

Localização: mesentério abdominal.

Referência bibliográfica: 33 . 
Tabela XXXVI. Piratuba lainsoni, P. scaffi e P. shawi, dados segundo Bain, 1974.

\begin{tabular}{|c|c|c|c|c|c|c|}
\hline & \multicolumn{2}{|c|}{ P. lainsoni } & \multicolumn{2}{|c|}{ P. scaffi } & \multicolumn{2}{|c|}{ P. shawi } \\
\hline & Macho & Fêmea & Macho & Fêmea & Macho & Fêmea \\
\hline Comprimento & 1,24 & 2,30 & 1,56 & 2,70 & 2.50 & 4,05 \\
\hline Largura & 0,38 & 0,45 & 0,13 & 0,41 & 0,41 & 0,60 \\
\hline Cápsula bucal & 0,012 & 0,019 & 0,012 & 0,015 & 0,015 & 0,015 \\
\hline Anel nervoso & 0,320 & 0,350 & 0,320 & 0,300 & 0,410 & 0,355 \\
\hline Esôfago muscular & 0,385 & 0,390 & 0,310 & 0,330 & 0,420 & 0,400 \\
\hline Esôfago glandular & 0,600 & 0,620 & 1,360 & 0,975 & 1,055 & 0,680 \\
\hline Vulva & & 9,40 & & 12,15 & & 18,2 \\
\hline Vagina & & 0,040 & & & & \\
\hline Ovário anterior-cabeça & & 13,30 & & & & \\
\hline Ovário posterior-ânus & & 0,90 & & & & \\
\hline Cauda & 1,350 & 0,235 & 0,190 & & 0,230 & \\
\hline Espiculo direito & 1,250 & & 0,142 & & & \\
\hline Espiculo esquerdo & 0,140 & & 0,148 & & & \\
\hline Papila cervical & & & 0,825 & & & \\
\hline Espiculos & & & & & 0,170 & \\
\hline
\end{tabular}

\section{CATÁLOGO DOS RÉPTEIS HOSPEDEIROS E SEUS RESPECTIVOS PARASITOS}

Testudines

Kinosternidae

Kinosternon scorpioides scorpioides (L.) - muçuã, jurara:

Serpinema maghati (Sprehn, 1932) Yeh, 1960

Spiroxys figueiredoi Freitas \& Dobbin Jr., 1962

Testudinidae

Geochelone denticulata $(\mathrm{L}).(=$ Testudo denticulat $a$ L.; $=$ Testudo tabulata (Walb.); = Chelonoides denticulata L.) - Jaboti, jabota, carumbê, jaboti piranga, jabotitinga:

Angusticaecum brevispiculum Chapin, 1925

Chapiniella variabilis (Chapin, 1925) Yamaguti, 1961

Kolossinemella travassosi Costa, Motta \& Gomes, 1968

Labduris gulosa (Rud., 1819) Schneider, 1866

Labduris irineuta Costa, 1961

Labduris zschokkei Linstow, 1899

Sauricola sauricola Chapin, 1925

Geoemyda punctularia:

Falcaustra tikasinghi (Schroeder, Schimidt \& Everard, 1977) Baker \& Bain, 1981

Cheloniidae

Chelonia mydas $(\mathrm{L}).(=$ Chelone mydas $(\mathrm{L})=$. Testudo mydas - tartaruga, tartaruga do mar:

Kathlania leptura (Rud., 1819) Travassos, 1918 
Sulcascaris sulcata (Rud., 1819) Hartwich, 1957

Tonaudia freitasi Vicente \& Santos, 1968

Pelomedusidae

Podocnemis expansa (Schw.) - tartaruga, tartaruga do Amazonas, jurara-açú, capitari:

Ancyracanthus pinnatifidus Diesing, 1839

Camallanus amazonicus Ribeiro, 1940

Klossinemella conciliatus Alho, 1964

"Tartaruga do Rio Amazonas":

Atractis trematophila Travassos, 1934

Podocnemis dumeriliana (Schw.) [=Podocnemis tracaxa (Spix)]:

Ancyracanthus pinnatifidus Diesing, 1839

Chelidae

Batrachemys nasuta (Schw.) [ = Rhinemys nasuta (Schw.)]:

Serpinema monospiculatus Freitas \& Dobbin Jr., 1962

Batrachemys tuberculata (Luederwalt):

Serpinema monospiculatus Freitas \& Dobbin Jr., 1962

Phrynops geoffroanus (Schw.)[ = Phrynops geoffroana geofroana (Schw.)]

- cágado de barbelas pintado, cágado pintado:

Serpinema monospiculatus Freitas \& Dobbin Jr., 1962

Lacertilia

Gekgonidae

Gonatodes humeralis (Guichenot):

Skrjabinelazia galliardi Chabaud, 1973

Hemydactylus mabouia (M. de J.) - lagartixa:

Oswaldocruzia brasiliensis Lent \& Freitas, 1935

Physalopterinae sp. Rodrigues, 1970

Spirurinae sp. Rodrigues, 1970

Strongyloides cruzi Rodrigues, 1968

Thelandros largitor (Alho \& Rodrigues, 1963) Peter \& Quentin, 1976

Thelandros sceleratus Travassos, 1923

Thelandros sp. (Rodrigues, 1986)

Thelandros sp. (Rodrigues, Rodrigues \& Faria, 1990)

Iguanidae

Anolis punctatus Daudin:

Piratuba lainsoni Bain, 1974

Enyalius catenatus (Wied) - camaleão comum:

Oswaldofilaria subauricularis (Rud., 1819)

Iguana iguana (L.) [ = Iguana tuberculata (Laur.)] - iguana, camaleão, sinimbu:

Alaeuris caudatus (Lent \& Freitas, 1948) Peter \& Quentin, 1976 
Alaeuris vogelsangi (Lent \& Freitas, 1948) Peter \& Quentin, 1976 Oswaldofilaria brevicaudata (Rhodain \& Vuylsteke, 1937) Freitas \& Lent, 1937.

Ozolaimus cirratus Linstow, 1906

Ozolaimus megatyphlon (Rud., 1819) Dujardin, 1845

Polychrus acutirostris Spix - camaleão:

Gynaecometra bahiensis Araujo, 1978

Physaloptera sp. Travassos \& Freitas, 1941

Physaloptera sp. Travassos \& Freitas, 1943

Polychrus marmoratus (L.):

Oswaldofilaria azevedoi Bain, 1974

Piratuba lainsoni Bain, 1974

Tropidurus semitaeniatus (Spix) (= Tapinurus scutipunctatus Amaral):

Thelandros sceleratus Travassos, 1923

Tropidurus torquatus (Wied.) - camaleão, lagartinho, calango, taraguira:

Capillaria freitaslenti Araujo \& Gandra, 1941

Oswaldofilaria mazzai Travassos, 1935

Pharyngodon sp. Guimarães, 1975

Piratuba digiticauda Lent \& Freitas, 1941

Physaloptera sp. Travassos, Freitas \& Lent, 1939

Physaloptera lutzi Cristofaro, Guimarães \& Rodrigues, 1976

Physaloptera retusa Rud., 1819

Skrjabinellazia intermedia (Freitas, 1941) Chabaud, 1973

Strongyluris sp. Travassos, Freitas \& Lent, 1939

Strongyluris oscari Travassos, 1923

Thelandros sp. Travassos, Freitas, Mendonça \& Rodrigues, 1962

Thelandros sp. Cristofaro, Guimarães \& Rodrigues, 1976

Thelandros sceleratus Travassos, 1923

Tropidurus spinulosus (Cope) - camaleão, lagartinho, calango:

Physaloptera sp. Travassos, Freitas \& Lent, 1939

Physaloptera sp. Travassos \& Freitas, 1939

Physaloptera lutzi Guimarães, Cristofaro \& Rodrigues, 1976

Physaloptera retusa Rud., 1819

Piratuba digiticauda Lent \& Freitas, 1941

Skrjabinellazia intermedia (Freitas, 1941) Chabaud, 1973

Strongyluris sp. Travassos, Freitas \& Lent, 1939

Strongyluris oscari Travassos, 1923

Thelandros sceleratus Travassos, 1923

Thelandros sp. Travassos, Freitas \& Lent, 1939

Typhlonema sp. Travassos, Freitas \& Lent, 1939

Tropidurus sp.: 
Strongyluris oscari Travassos, 1923

Thelandros sceleratus Travassos, 1923

Uranoscodon superciliosa (L.):

Africana chabaudi Baker, 1981

Anguidae

Diploglossus lessonae Peracca

Thelandros verrucosus (Freitas \& Dobbin Jr., 1959) Peter \& Quentin, 1976

Teiidae

Ameiva ameiva ameiva (L.) - camaleão verde, camaleão, tijubinha:

Pharyngodon cesarpintoi Pereira, 1935

Physaloptera lutzi Cristofaro, Guimarães \& Rodrigues, 1976

Physaloptera sp. Travassos, Freitas \& Lent, 1939

Physaloptera sp. Travassos, 1941

Physaloptera sp. Travassos, Freitas, Mendonça \& Rodrigues, 1960

Piratuba scaffi Bain, 1974

Spinicauda spinicauda (Olfers in Rud., 1819) Travassos, 1920

Strongyluris oscari Travassos, 1923

Thelandros alvarengai (Freitas, 1957) Peter \& Quentin, 1976

Thelandros largitor (Alho \& Rodrigues, 1963)

Thelandros sceleratus Travassos, 1923

Thelandros sp. Travassos, Freitas \& Lent, 1939

Thelandros sp. Travassos, Freitas, Mendonça \& Rodrigues, 1960

Thelandros sp. Travassos, Freitas, Mendonça \& Rodrigues, 1962

Thelandros sp. (Cristofaro, Guimarães \& Rodrigues, 1976)

Thubunaea dactyluris Karve, 1938

Ameiva sp.:

Pharyngodon travassosi Pereira, 1935

Physaloptera sp. Travassos \& Freitas, 1943

Cnemidophorus lemniscatus (Daudin):

Pharyngodon cesarpintoi Pereira, 1935

Dracaena guianensis Daud. (=Thorictis dracaena Wagl.):

Diaphanocephalus jacuruxi Alho, 1965

Oswaldofilaria belemensis Bain \& Sulahian, 1974

Kentropyx calcaratus Spix:

Piratuba shawi Bain, 1974

Neusticurus bicarinatus L.:

Falcaustra belemensis Baker \& Bain, 1981

Tupinambis nigropunctatus Spix:

Diaphanocephalus diesingi Freitas \& Lent, 1938

Oswaldofilaria petersi Bain \& Sulahian, 1974 
Tupinambis teguixin (L.) (= Tejus teguixin L.) - teiu, teju:

Atractis cruciata Linstow, 1902

Cruzia sp. Travassos, Freitas \& Mendonça, 1939

Diaphanocephalus galeatus (Rud., 1819) Railliet \& Henry, 1909

Kalicephalus sp. Travassos, Freitas \& Mendonça, 1964

Micropleura sp. Travassos \& Freitas, 1941

Physaloptera retusa Rud., 1819

Physaloptera sp. Travassos, Freitas \& Lent, 1939

Physaloptera sp. Travassos \& Freitas, 1941

Physaloptera sp. Travassos \& Freitas, 1943

Physaloptera sp. Travassos, Freitas \& Mendonça, 1964

Spinicauda spinicauda (Olfers in Rud., 1819) Travassos, 1920

Amphisbaenidae

Amphisbaena alba L. - cobra de duas cabeças:

Aplectana albae Admson \& Baccan, 1988

Aplectana pusilla Miranda, 1924

Aplectana raillieti Travassos, 1925

Aplectana unguiculata (Rud., 1819) Miranda, 1924

Maracaya belemensis Adamson \& Baccan, 1988

Amphisbaena sp.:

Aplectana raillieti Travassos, 1925

Leposternon microcephalum Wagler (=Leposternon phocaena Dumeril \& Bibron):

Cosmocerca rara Freitas \& Vicente, 1966

Dollfusnema amphisbaenia Baker, 1981

\section{Scincidae}

Mabuya mabouya mabouya (Lacepéde):

- Oswaldofilaria spinosa Bain \& Sulahian, 1974

Piratuba zeae Bain, 1974

Mabuya maculata (Gray):

Moaciria alvarengai Freitas, 1956

Thelandros alvarengai (Freitas, 1957) Peter \& Quentin, 1976

\section{Crocodilia}

Alligatoridae

Caiman crocodilus crocodilus (L.) [=Caiman sclerops (Gray)] - jacaretinga:

Brevimulticaecum baylisi (Travassos, 1933) Sprent, 1979

Brevimulticaecum pintoi Sprent, 1979

Brevimulticaecum stekhoveni (Baylis, 1947) Sprent, 1979

Dujardinascaris longispicula (Travassos, 1933) Baylis, 1947

Dujardinascaris paulista (Travassos, 1933) Baylis, 1947 
Micropleura sp. Travassos, Freitas \& Lent, 1939

Micropleura sp. Travassos, 1941

Micropleura vazi Travassos, 1933

Oswaldofilaria bacillaris (Molin, 1858) Travassos, 1933

Caiman latirostris (Daud.) - jacaré de papo amarelo:

Brevimulticaecum pintoi Sprent, 1979

Melanosuchus niger (Spix) (=Caiman niger; =Champsa nigra) - jacaréaçú:

Brevimulticaecum baylisi (Travassos, 1933) Sprent, 1979

Brevimulticaecum gibsoni Sprent, 1979

Brevimulticaecum stekhoveni (Baylis, 1947) Sprent, 1979

Oswaldofilaria bacillaris (Molin, 1858) Travassos, 1933

Terranova lanceolata (Molin, 1860) Sprent, 1979

Ophidia

Boidae

Boa constrictor L. $[$ = Constrictor constrictor $($ L.) ] - jiboia:

Kalicephalus subulatus Molin, 1861

Physaloptera monodens Molin, 1860

Corallus caninus (L.) (=Boa canina L.) - periquitamboia, araramboia:

Kalicephalus subulatus Molin, 1861

Eunectes murinus murinus (L.) (=Eunectes murinus $\mathrm{L} . ;=$ Eunectes $\mathrm{sp}$.

- sucuri, sucuriu, sucuriju, sucurijuba, boiuna, boiussu, boi-açú, boiguaçu, viborão, boitiaboia:

Pseudocapillaria (I.) murinae (Travassos, 1914) Moravec, 1982

Epicrates cenchria cenchria $(\mathrm{L}$.):

Kalicephalus subulatus Molin, 1861

Epicrates cenchria crassus (Cope) - salamanta, jiboia vermelha:

Kalicephalus costatus costatus (Rud., 1819) Yorke \& Maplestone, 1926

Kalicephalus inermis inermis Molin, 1861

Colubridae

Chironius carinatus $(\mathrm{L}$.$) (= Herpetodryas carinatus var. vicenti Boul.):$

Kalicephalus costatus costatus (Rud., 1819)

Kalicephalus rectiphilus neorectiphilus Schad, 1962

Oxyascaris oxyascaris Travassos, 1920

Chironius sp.:

Kalicephalus costatus costatus (Rud., 1819) Yorke \& Maplestone, 1926

Clelia clelia (Daudin) - muçurana:

Kalicephalus appendiculatus Molin, 1861

Clelia sp.:

Physaloptera obtusissima Molin, 1860 
Coluber sp.:

Kalicephalus appendiculatus Molin, 1861

Kalicephalus costatus costatus (Rud., 1819) Yorke \& Maplestone, 1926

Dendrophidion bivittatus (Dumeril, Bibron \& Dumeril):

Kalicephalus appendiculatus Molin, 1861)

Dromicus typhlus (D. \& B.):

Aplectana papillifera (Araujo 1978)

Drymarchon corais corais (Boie) - papa-ovo:

Kalicephalus appendiculatus Molin, 1861

Drymarchon corais couperi (Holbrook):

Kalicephalus appendiculatus Molin, 1861

Elapomorphus tricolor Dumeril, Bibron \& Dumeril - falsa coral:

Piratuba carinii (Vaz \& Pereira, 1935) Caballero, 1954

Erithrolamprus aesculapii aesculapii (L.):

Cruzia rudolphii (Ruiz, 1947)

Erythrolamphrus venustissimus (Wied):

Kalicephalus costatus costatus (Rud., 1819) Yorke \& Maplestone, 1926

Helicops angulatus (L.):

Ophidascaris obconica (Baird, 1860)

Leimadophis poecilogyrus (Wied) - cobra de lixo, cobra de capim, cobra verde:

Falcaustra mascula (Rud., 1819)

Pseudocapillaria (P.) cesarpintoi (Freitas \& Lent, 1934) Moravec, 1982:

Oxyascaris oxyascaris Travassos, 1920

Leimadophis poecilogyrus Hoge [ = Philodryas schottii (Schlegel)]:

Kalicephalus costatus costatus (Rud., 1819) Yorke \& Maplestone, 1926

Rhabdias vellardi Pereira, 1927

Leimadophis reginae (L.):

Kalicephalus appendiculatus Molin, 1861

Leptophis sp.:

Kalicephalus appendiculatus Molin, 1861

Liophis miliaris (L.) - cobra d'água

Lystrophis semicinictus (D. \& B.):

Kalicephalus costatus costatus (Rud., 1819) Yorke \& Maplestone, 1926

Acanthorhabdias acanthorhabdias Pereira, 1927

Aplectana travassosi (Gomes \& Motta, 1967) Baker, 1980

Kalicephalus appendiculatus Molin, 1861

Kalicephalus costatus costatus (Rud., 1819) Yorke \& Maplestone, 
1926

Kalicephalus inermis inermis Molin, 1861

Ophidiascaris trichuriformis Vaz, 1935

Physaloptera liophis Vicente \& Santos, 1974

Pseudocapillaria (P.) amarali (Freitas \& Lent, 1934) Moravec, 1982

Rhabdias labiata Pereira, 1927

Mastigodryas bifossatus (Raddi) [ = Dryadophis bifossatus Stuart; $=$ Eudryas bifossatus (Raddi)] - cobra nova, jararaca do banhado, jararacussú do brejo, limpa campo:

Kalicephalus appendiculatus Molin, 1861

Kalicephalus costatus costatus (Rud., 1819) Yorke \& Maplestone, 1926

Kalicephalus rectiphilus neorectiphilus Schad, 1962

Oswaldocruzia brasiliensis Lent \& Freitas, 1935

Oxyascaris oxyascaris Travassos, 1920

Strongyloides ophidiae Pereira, 1929

Spilotes pullatus pullatus (L.) - caninana, caninana preta, cainana, iacaninã, araboia:

Kalicephalus appendiculatus Molin, 1861

Spilotes sp.

Kalicephalus appendiculatus Molin, 1861

Physaloptera liophis Vicente \& Santos, 1974

Pseudocapillaria (P.) amarali (Freitas \& Lent, 1934) Moravec, 1982

Rhabdias labiata Pereira, 1927

Oxyrhopus trigeminus Dumeril, Bibron \& Dumeril

Rhabdias vellardi Pereira, 1927

"Cobra coral":

Ophidascaris cretinorum Freitas, 1968

Philodryas aestivus Dumeril, Bibron \& Dumeril - cobra cipó, cobra verde das árvores:

Hastospiculum digiticaudum Freitas, 1956

Philodryas patagoniensis (Girard) - parelheira:

Kalicephalus costatus costatus (Rud., 1819) Yorke \& Maplestone, 1926

Kalicephalus inermis Molin, 1861

Philodryas serra (Schlegel):

Kalicephalus costatus costatus (Rud., 1819) Yorke \& Maplestone, 1926

Philodryas sp.:

Physaloptera sp. Travassos \& Freitas, 1943

Pseudoboa trigemina (Duméril \& Bibron) - falsa coral:

Bufonerakis rodriguesi (Vicente \& Gomes, 1971) Baker, 1980 
Rhadinea merremii Wild - jararaquinha do campo: Acanthorhabdias acanthorabdias Pereira, 1927

Rhabdias labiata Pereira, 1927

Simophis rhinostoma (Schlegel):

Kalicephalus costatus costatus (Rud., 1819) Yorke \& Maplestone, 1926

Kalicephalus inermis inermis Molin, 1861

Xenodon coerulus:

Kalicephalus appendiculatus Molin, 1861

Xenodon guentheri Boul - chata:

Kalicephalus costatus costatus (Rud., 1819) Yorke \& Maplestone, 1926

Xenodon merremii (Wagl.) [=Ophis merremii Wagl.; = Waglerophis merremii (Wagl.)] - boipeva, capitão do mato, pepeva, jaracambeva, jararacussú tipiti:

Kalicephalus appendiculatus Molin, 1861

Kalicephalus costatus costatus (Rud., 1819) Yorke \& Maplestone, 1926

Kalicephalus inermis inermis Molin, 1861

Ophidascaris arndti Sprehn, 1929

Ophidascaris sicki Freitas, 1951

Ophidascaris trichuriformis Vaz, 1935

Physaloptera sp. Travassos \& Freitas, 1941

Xenodon neuwidii (Gunther)

Aplectana papillifera (Araujo, 1978)

Kalicephalus costatus costatus (Rud., 1819) Yorke \& Maplestone, 1926

Xenodon severus (L.):

Kalicephalus appendiculatus Molin, 1861

Ophidascaris arndti Sprehn, 1929

Ophidascaris sicki Freitas, 1951

Viperidae

Bothrops alternatus Dumeril, Bibron \& Dumeril - urutú cruzeiro:

Kalicephalus costatus costatus (Rud., 1819) Yorke \& Maplestone, 1926

Kalicephalus inemis inermis Molin, 1861

Bothrops atrox (L.) - caissaca, jararaca:

Kalicephalus inermis inermis Molin, 1861

Ophidascaris amdti Sprehn, 1929

Bothrops cotiara (Gomes) - cotiara, jararaca:

Kalicephalus costatus costatus (Rud., 1819) Yorke \& Maplestone, 1926 
Kalicephalus inermis inermis Molin, 1861

Bothrops jararaca (Wied.) - jararaca, jaraca, jaracá, dormideira, jararaca preguiçosa, jararaca da mata virgem, jararaca do cerrado, jararaca do campo:

Kalicephalus costatus costatus (Rud., 1819) Yorke \& Maplestone, 1926

Kalicephalus inermis inermis Molin, 1861

Kalicephalus subulatus Molin, 1861

Physaloptera obtusissima Molin, 1860

Bothrops jararacussu Lacerda - jararacussú, jararacussú verdadeiro, jararacussú malha de sapo, cabeça de sapo, patrona, surucucú tapete, urutú dourado, urutú amarelo, urutú estrela, surucucú dourado:

Kalicephalus appendiculatus Molin, 1861

Kalicephalus costatus costatus (Rud., 1819) Yorke \& Maplestone, 1926

Kalicephalus inermis inermis Molin, 1861

Bothrops pradoi (Hoge) - jararaca:

Kalicephalus inermis inermis Molin, 1861

Kalicephalus costatus costatus (Rud., 1819) Yorke \& Maplestone, 1926

Crotalidae

Crotalus durissus L.:

Kalicephalus costatus costatus (Rud., 1819) Yorke \& Maplestone, 1926

Crotalus durissus terrificus (Laurenti) - cascavel:

Ascaridia flexuosa (Schneider, 1866) Railliet \& Henry, 1914

Capillaria crotali (Rud., 1819) Travassos, 1915

Hastospiculum onchocercum Chitwood, 1932.

Hexametra boddaertii (Baird, 1860) Kreis, 1944

Kalicephalus costatus costatus (Rud., 1819) Yorke \& Maplestone, 1926

Kalicephalus inermis inermis (Molin, 1861)

Ophidascaris sprenti Araujo, 1969

Ophidascaris travassosi Vaz, 1938

Ophidascaris trichuriformis Vaz, 1935

Polydelphis quadrangularis (Schneider, 1866)

Travassosascaris araujoi Sprent, 1978

Crotalus sp. - cascavel:

Ascaridia flexuosa (Schneider, 1866) Railliet \& Henry, 1914

Lachesis muta rhombeata (Wied.) - surucucú:

Kalicephalus subulatus Molin, 1861. 
AGRADECIMENTOS. Queremos registrar nossos agradecimentos aos funcionários do Setor de Programação Visual/SICT/FIOCRUZ sob a direção de Genilto José Vieira que com a maior eficiência realizaram o trabalho de revisão de todas as figuras apresentadas neste trabalho.

\section{REFERÊNCIAS BIBLIOGRÁFICAS}

1. ADAMSON, M.L. \& D. BACCAN. 1988. Systematic revision of the atractidae sensu Chabaud (1978) (Nematoda; Cosmocercoidea): Maracaia belemensis, n.sp. and Aplectana albae, n.sp. from Amphisbaena alba in Brazil. Can. J. Zool. 66: 1857-1864.

2. ALHO, C.J.R. 1964. Sobre uma nova espécie do gênero "Klossinemella" Costa, 1964 (Nematoda). Atas Soc. Biol., Rio de Janeiro, 8 (1-2):1-4.

3. 1965a. Contribuição ao conhecimento da fauna helmintológica de quelônios do Estado do Pará, Brasil. Bol. Mus. Paraense Emílio Goeldi 58: 1-8.

4. 1965b. Sobre uma nova espécie do gênero Diaphanocephalus Dies ing, 1851, parasita de lagarto da Amazônia (Dracaena guianensis Daudin) (Nematoda, Strongyloidea). Bol. Mus Paraense Emílio Goeldi 59: 1-3.

5. 1969. Oxyurata de lagartos do Planalto Central. Sobre o gênero "Strongyluris" Mueller, 1894, com descrição de duas espécies novas (Nematoda, Subuluroidea). Rev. brasil. Biol. 29 (1): 65-74.

6. 1970. Frequency of infestation by Strongyluris freitasi Alho, 1969 in Tropidurus torquatus (Wied). Rev. brasil. Biol. 30 (4): 539-542.

7. ALHO, C.J.R. \& V.P. MOURA. 1970. Oxyurata de lagartos do Planalto Central. Ocorrência de Pharyngodon cesarpintoi Pereira, 1935 (Nematoda, Subuluroidea). Atas Soc. Biol., Rio de Janeiro, 13 (1-2): 67-69.

8. ALHO, C.J.R. \& H.O. RODRIGUES. 1963a. Sobre um novo hospedeiro de Parapharyngodon sceleratus (Travassos, 1923) Freitas, 1957, com redescrição da espécie (Nematoda, Oxyuroidea). Atas Soc. Biol., Rio de Janeiro, 7 (4): 4-6.

9. 1963b. Nova espécie do gênero Parapharyngodon Chatterji, 1933 (Nematoda, Oxyuroidea). Atas Soc. Biol., Rio de Janeiro, 7 (4): 10-12.

10. AMARAL, A. 1929. Estudos sobre ophidios neotrópicos XVIII - Lista remissiva dos ophidios da região neotrópica. Mem. Inst. Butantan 4: 129-271.

11. 1935-1936. Contribuição ao conhecimento dos ophidios do Brasil VIII. Lista remissiva dos ophidios do Brasil. $2^{\text {a }}$ edição. Mem. Inst. Butantan 10: 87-162.

12. 1937. Estudo sobre lacertílios neotropicais. 4. Lista Remissiva dos lacertílios do Brasil. Mem. Inst. Butantan 11: 167-204.

13. AMATO, J.F.R. \& S.B. AMATO. 1982. Sulcascaris sulcata (Nematoda, Anisakidae) infecting sea scallops being exported from Southearstern Brazil. Arq. Univ. Fed. Rur. Rio de Janeiro, Itaguaí, 5 (1): 61-67.

14. ANDERSON, R.C. \& O. BAIN. 1976. Keys to the genera of the order 
Spirurida. Diplotriaenoidea, Aproctoidea and Filarioidea. In: ANDERSON, CHABAUD \& WILLMONT (eds) CIH Keys to the nematode parasites of vertebrates 3. Part 3. England, Commonwealth Agricultural Bureaux, Farnham Royal Bucks, 59-116.

15. ARAUJO, P. 1969a. Nouvelle espéce d'Ophidascaris Baylis, 1921, Parasite du serpent crotale (Crotalus durissus terrificus). Ann. Parasit. Hum. Comp., Paris, 44 (4): 441-449.

16. $1969 \mathrm{~b}$. Sobre a conceituação de hemintos pertencentes à subfamília Ascarinae Travassos, 1913, parasitos de ofídios e lacertílios. Rev. Fac. Far. Bioquim. Univ. S. Paulo 7 (1): 55-94.

17. 1970a. Considerações sobre o gênero Contracaecum Railliet \& Henry, 1912 (Nematoda, Ascaridoidea). Rev. Far. Bioquim. Univ. S. Paulo 8 (1): 103-113.

18. 1970b. Uma nova espécie de Contracaecum Railliet \& Henry, 1912 (Nematoda: Ascaroidea) parasita de ofídio. Rev. Farm. Bioquim. Univ. S. Paulo 8 (1): 115-120.

19. 1970c. Considerações sobre Hastospiculum onchocercum major Desportes, 1941, parasita da serpente Crotalus durissus terrificus. Rev. Farm. Bioquim. Univ. S. Paulo 8 (1): 121-124.

.20. 1970d. Consideraçōes sobre a evolução de Hexametra quadricornis (Wedl, 1861) (Nematoda), parasita de ofídios. Rev. Farm. Bioquim. Univ. S. Paulo 8 (2): 193-242.

21. 1971a. Considerations sur la deuxiéme mue des larves d'Ascarides de serpentes. Ann. Parasit. Hum. Comp., Paris, 46 (5): 605-612.

22. 1971b. Observations sur le development de l'ébauche genitale chez des larves du 3e estade de Polydelphis quadrangularis (Schneider, 1866) (Nematoda: Ascaridoidea). Ann. Parasit. Hum. Comp., Paris, 46 (6): 699-707.

23. 1972. Observations sur le biologie de l'Ascaride Polydelphis quadrangularis (Schneider, 1866), parasite du serpent crotale. Ann. Parasit. Hum. Comp., Paris, 47 (1): 91-120.

24. 1978a. Um novo oxyurideo, Gynaecometra bahiensis n. gen. n.sp. (Nematoda: Oxyuroidea: Oxyuridae) encontrado em lacertílio. Mem. Inst. Butantã, São Paulo, 40/41: 251-257.

25. 1978b. Uma nova espécie do gênero Neyraplectana (Nematoda: Subuluroidea: Cosmocercidae), encotrada em ofídios. Mem. Inst. Butantã, São Paulo, 40/41: 259-264.

26. ARAUJO, T.L. \& Y. GANDRA. 1941. Sobre uma nova espécie do gênero Capillaria e observações helmintológicas. Rev. Fac. Med. Vet. S. Paulo 2 (1): 29-32.

27. ARTIGAS, P.T. \& A. GRAEIRO. 1973. Redescriçâo de Acanthorhabdias acanthorhabdias Pereira, 1927 (Nematoda: Rhabditoidea). Arq. Inst. Biol., São Paulo, 40 (1): 33-37.

28. BAKER, M.R. 1980a. Revision of old world species of the genus Aplectana 
Railliet \& Henry, 1916 (Nematoda: Cosmocercidae). Bull. Mus. natn. Hist. nat. Paris, 4e sér. 2, sect. A., 4: 955-998.

29. BAKER, M.R. 1980b. Bufonerakis andersoni n.gen. (Nematoda: Heterakoidea) from Bufo arenarum of South America. J. Helminth. 54 (1): 49-53.

30. 1981a. Dollfusnema amphisbaenia n.gen. n.sp. (Nematoda: Cosmocercinae) from the lizard Leposternon phocaena (Amphisbaenia) of Brazil. Canad. J. Zool. 59 (1): 138-140.

31. 1981b. Africana chabaudi n.sp. (Nematoda, Heterakidae) in Brazilian iguana. Bull. Mus. natn. Hist. nat. Paris, 4e sér., 3 (3): 783-787.

32. BAKER, M.R. \& O. BAIN. 1981. Falcaustra belemensis n.sp. (Nematoda, Kathlaniinae) from the lizard Neusticurus bicarinatus L. (Teiidae) of Brazil. Bull. Mus. natn. Hist. nat. Paris, 4e sér., 3 (2): 117-121.

33. BAIN, O. 1974. Description de nouvelles filaires Oswaldofilariinae de lézards sud-américains; Hypothése sur l'evolution des filaires de Reptiles. Bull. Mus. natn. Hist. nat. Paris, Zool., 138 (108): 169-200.

34. BAIN, O. \& A.G. CHABAUD. 1975. Dévelopment chez des moustiques de trois filaires de lézards sud-américains du genre Oswaldofilaria. Ann. Parasit. Hum Comp., Paris, 50 (2): 209-221.

35. BAIN, O. \& A. SULAHIAN. 1974. Trois nouvelles Filaires du genre Oswaldofilaria chez des Lézards sud-américains; essai de classification des Oswaldofilariinae. Bull. Mus. natn. Hist. nat., Paris, 3e sér., $n^{\circ} 232$, Zool., 156: $827-841$.

36. CARVALHO, J.C. 1940. Contribuição para o conhecimento da fauna helmintológica de Minas Gerais. Ceres, Viçosa, 5 (1): 411-423.

37. CHABAUD, A.G. 1973. Skrjabinelazia Sypliaxov, 1930 ( = Salobrella Freitas, 1940) genre de transition entre Cosmocercides et Spirurides. Ann. Parasit. Hum. Comp., Paris, 48 (2): 329-334.

38. 1975. Key to the genera of the order Spirurida. Part. I. Camallanoidea, Dracunculoidea, Gnathostomatoidea, Physalopteroidea, Rictularoidea and Thelazoidea. In: ANDERSON, CHABAUD \& WILLMOTT (eds) CIH Keys to the nematode parasites of vertebrates 3. Part I. England, Commonwealth Agricultural Bureaux, Farnham Royal Bucks, 27p.

39. 1978. Keys to the genera of the superfamily Cosmocercoidea, Seuratoidea, Heterakoidea and Subuluroidea. In: ANDERSON, CHABAUD \& WILLMOTT (eds) CIH Keys to the nematode parasites of vertebrates 6. England, Commonwealth Agricultural Bureaux, Farnham Royal, Bucks, 71p.

40. CHAPIN, E.A., 1925, Nematode parasites of the Brasilian landtortoise, Testudo denticulata. Proc. U.S. Nat. Mus., 65: 1-5.

41. COSTA, S.C.G., 1961-a. Nota prévia sobre um novo nematódeo do gênero Labduris Schneider, 1866 (Atractoidea). Atas Soc. Biol. Rio de Janeiro, 5(4): 17-19. 
42. 1961-b. Sobre a sistemática da família Cobboldinidae Skrjabin, 1948 (Nematoda). Atas Soc. Biol. Rio de Janeiro, 5(5): 30-32.

43. COSTA, S.C.G., C.S. MOTTA \& D.C. GOMES. 1968. Revisão do gênero Klossinemella Costa, 1961 (Nematoda, Cobboldinidae) com descrição de uma nova subfamília e de nova espécie. Mem. Inst. Oswaldo Cruz, 66(2): 169-179.

44. CRISTOFARO, R.; J.F. GUIMARÃES \& H.O RODRIGUES. 1976. Alguns nematóides de Tropidurus torquatus (Wied) e Ameiva ameiva (L.) Fauna helmintológica de Salvador, Bahia. Atas Soc. Biol. Rio de Janeiro 18: 65-70.

45. DURETTE-DESSET, M.C. 1983. Keys to the genera of superfamily Trichostrongyloidea In: Anderson \& Chabaud (eds). CIH Keys to the nematode parasites of vertebrates 10. England, Commonwealth Agricultural Bureaux, Farnham Royal, Bucks, 86p.

46. FABIO, S.P. \& ROLAS, F.J.T. 1974a. Sobre alguns helmintos parasitos de Dryadophis bifossatus (Raddi). Mem. Inst. Oswaldo Cruz, 72 (1-2): 49-53.

47. 1974b. Contribuição ao conhecimento de Thubunea dactyluris Karve, 1938 (Nematoda, Spiruroidea). Mem. Inst. Oswaldo Cruz 72 (3-4): 283-290.

48. FERNANDES, B.M.M. \& S.V. SOUZA. 1974. Redescrição de Acanthorhabdias acanthorhabdias Pereira, 1927. Mem. Inst. Oswaldo Cruz 72 (3-4): 291-292.

49. FERNANDES, M.P.M. \& P.T ARTIGAS. 1975. Kalicephalus subulatus Molin, 1861 (Nematoda, Diaphanocephalidae). Confirmação desta espécie; informações sobre sua dispersão geográfica e enumeração de serpentes parasitadas. Mem. Inst. Butantã , São Paulo, 39: 103-121.

50. 1978. Kalicephalus inermis Molin, 1861 (Nematoda: Diaphanocephalidae). Redescrição e confirmação desta espécie; informações de natureza biológica e crítica do grupo "inermis" proposto por Shaad. Mem. Inst Butantã, São Paulo, 40/41: 281-297.

51. FREITAS, J.F.T. 1940. Sobre interessante nematódeo parasito de réptil (Spiruroidea). Mem. Inst. Oswaldo Cruz 35 (3): 603-605.

52. 1951. "Ophidascaris sicki" n. sp. (Nematoda, Ascaroidea). Rev. Brasil. Biol. 11 (3): 255-258.

53.1955a. Redescrição de Ophidascaris arndti Sprent, 1929 (Nematoda, Ascaridoidea). Rev. Iber. Parasit., Tomo extraord.: 17-22.

54.1955b. Nota sobre a fauna helmintológica de répteis brasileiros. Rev. Brasil. Biol. 15 (3): 279-284.

55. 1956a. Observações sobre as espécies Sul-Americanas do gênero "Oswaldocruzia" Travassos, 1917. Rev. Brasil. Biol. 16 (3): 309-315.

56. 1956b. Notas sobre "Heterakidae" Railliet \& Henry, 1914. Rev. Brasil. Biol. 16 (4): 461-482.

57. 1956c. Novo parasito de réptil da Ilha de Fernando de Noronha "Moaciria alvarengai" g.n., sp.n. (Nematoda, Subuluroidea). Rev. Brasil. Biol. 
16 (3): 335-339.

58. 1957. Sobre os gêneros Thelandros Wedl, 1862 e Parapharyngodon Chatterji, 1933, com descrição de Parapharyngodon alvarengai sp. $\mathrm{n}$. (Nematoda, Oxyuroidea). Mem. Inst. Oswaldo Cruz 55 (1): 21-45.

59. 1958. Estudos sobre "Oxyascarididae" (Travassos, 1920) (Nematoda, Subuluroidea). Mem Inst. Oswaldo Cruz 56: 489-515.

60. 1968. Revisão do gênero Ophidascaris Baylis, 1921 (Nematoda, Ascarioidea). Mem. Inst. Oswaldo Cruz 66 (1): 1-83.

61. FREITAS, J.F.T. \& J.E. DOBBIN JR. 1959. Nova espécie do gênero Parapharyngodon Chatterji, 1933 (Nematoda, Oxyuroidea). An. Soc. Biol. Pernambuco 16: 23-33.

62. 1962a. Novo nematódeo camalanídeo parasito de quelônio. Atas Soc. Biol. Rio de Janeiro 6 (1-2): 5-7.

63. 1962b. Novo nematódeo do gênero Spiroxys Schneider, 1866. Atas Soc. Biol. Rio de Janeiro 6 (1-2): 12-14.

64. 1971. Contribuição ao conhecimento da fauna helmintológica de quelônios no Estado de Pernambuco, Brasil. Mem. Inst. Oswaldo Cruz 69 (1): 33-39.

65. FREITAS, J.F.T. \& H. LENT. 1934a. Capillaria cesarpintoi n. sp. parasita de Leimadophis poecilogyrus (Wied.). Mem. Inst. Oswaldo Cruz 28 (2): 263-265.

66. 1934b. Capillaria amarali n. sp. parasita de Liophis miliaris miliaris (L.). Mem. Inst Oswaldo Cruz 28 (2): 271-272.

67. 1935. Capillariinae de sangue frio (Nematoda: Trichuroidea). Mem. Inst. Oswaldo Cruz 30 (2): 241-284.

68. 1937. Sobre Oswaldofilaria brevicaudata Rhodhain \& Vuyulsteke, 1937) n. comb. (Nematoda: Filarioidea). Mem. Inst. Oswaldo Cruz 32 (3): 439-442.

69. 1938. Pesquisas helmintológicas realizadas no Estado do Pará. V. gênero Diaphanocephalus Diesing, 1851 (Nematoda: Strongyloidea). Mem. Inst. Oswaldo Cruz 33 (3): 423-432.

70. 1945. "Porrocaecum sulcatum" (Rudolphi, 1819) (Nematoda, Ascaroidea). Rev. Brasil. Biol. 6 (2): 235-238.

71. FREITAS, J.F.T. \& J.J. VICENTE. 1966. Novo nematódeo do gênero "Cosmocerca" Diesing, 1861, parasito de anfisbaenideo. Atas Soc. Biol. Rio de Janeiro 10 (5): 109-111.

72. FROES, O.M. 1958. Notas quelonógicas I. Atualização da nomenclatura dos quelônios brasileiros. Iheringia, Ser. Zool., (2): 1-24.

73. GOMES, D.C. \& A. KOHN. 1970. Sobre a subfamilia Ancyracanthinae Yorke \& Maplestone, 1926 (Nematoda, Spiruroidea). Atas Soc. Biol. Rio de Janeiro 13 (3-4): 83-88.

74. GOMES, D.C. \& C.S. MOTTA. 1967. Sobre um novo gênero e uma nova espécie de Oxyascarididae (Travassos, 1920) Freitas, 1958 (Nematoda, Subuluroidea). Mem. Inst. Oswaldo Cruz 65 (1): 29-31. 
75. GOMES, D.C. \& J.J. VICENTE. 1966. Ocorrência de "Falcaustra mascula" (Rudolphi, 1819) em "Crossodactylus gaudichaudii" Dum. \& Bibr. (Nematoda, Kathlaniidae). Atas Soc. Biol. Rio de Janeiro 10 (5): 113-116.

76. GUIMARÃES, J.F. 1975. Contribuição ao estudo da fauna helmintológica do Estado da Bahia. Bol. Inst Biol. Bahia 14 (1): 44-47.

77. HARTWICH, G. 1974. Keys to the genera of the Ascaridoidea. In: ANDERSON, CHABAUD \& WILLMOTT (eds). Keys to the nematode parasites of vertebrates 2. England, Commonwealth Agricultural Bureaux. Farnham Royal Bucks, 27p.

78. KOHN, A.; R.M. PINTO \& B.M.M. FERNANDES. 1973. Contribuição ao conhecimento de Strongyluris oscari Travassos, 1923 (Nematoda, Subuluroidea). Mem. Inst. Oswaldo Cruz 71 (3): 219-225.

79. LENT, H. \& J.F.T. FREITAS. 1935. Sobre uma nova espécie do gênero Oswaldocruzia Travassos, 1917. Mem. Inst. Oswaldo Cruz 30 (3): 379-386.

80. 1941. Sobre os filarideos parasitos de lacertídeos neotrópicos. Rev. Brasil. Biol. 1 (4): 383-386.

81. 1948. Uma coleção de nematódeos parasitos de vertebrados do Museu de História Natural de Montevidéo. Mem. Inst. Oswaldo Cruz 46 (1): $1-71$.

82. LICHTENFELS, J.R. 1980a. Keys to the genera of the superfamily Strongyloidea. In: ANDERSON, CHABAUD \& WILLMONT (eds). Keys to the nematode parasites of vertebrates, 7. England, Commonwealth Agricultural Bureaux, Farnham Royal, Bucks, 41p.

83. 1980b. Keys to the genera of the superfamilies Ancylostomatoidea and Diaphanocephaloidea. I $n$ : ANDERSON, CHABAUD \& WILLMOTT (eds). Keys to the nematode parasites of vertebrates, 8. England, Commonwealth Agricultural Bureaux, Farnham Royal, Bucks, 26p.

84. MIRANDA, C. 1924. Alguns nematódeos do gênero Aplectana Railliet \& Henry, 1916. Mem. Inst. Oswaldo Cruz 17 (1): 45-48.

85. MOLIN, R. 1861. Il sottordine degli acrofalli ordinato scientificamente secondo i risultamenti delle indagini anatomiche ed embriogeniche. Mem. reale ist Veneto sci. lettere ed art (1860) 9: 427-633.

86. MORAVEC, F. 1982. Proposal of a new systematic arrangement of nematodes of the family Capillariidae. Folia Parasit., Praha, 29: 119-132.

87. MOZGOVOY, A.A. 1953. Ascaridata dos animais e do homem e doenças causadas por eles, Pt. II. In: SKRJABIN, K.I. (ed.) Princípios de nematologia, 2. Moscou, Akad. Nauk. SSSR, 616p.

88. PADILHA, T.N. \& M.J.F. DUARTE. 1979. Ocorrência de Parapharyngodon alvarengai Freitas, 1957, em Ameiva ameiva (L.) no Estado do Rio de Janeiro (Nematoda, Oxyuroidea). Atas Soc. Biol. Rio de Janeiro 20: $21-22$.

89. PEREIRA, C. 1927a. Fauna helmintológica de ophidios brasileiros. Bol. Biol. S. Paulo 10 (35): 179-185.

90. 1927b. Fauna helmintológica dos ofídios brasileiros (2º Rhabdias 
vellardi n. sp. Bol. Biol. São Paulo 11: 13-22.

91. 1929. Strongyloides ophidiae n. sp. Bol. Biol. S. Paulo 15: 16-17.

92. 1935. Os Oxyurata parasitos de lacertilia do Nordeste brasileiro.

Arq. Inst. Biol. S. Paulo 6: 5-27.

93. 1937. On Thelandros sceleratus Travassos, 1923. Rabot. Gelm. Skrjabin: 463-466.

94. PETERS, J.A. \& R. DONOSO-BARROS. 1970. Catalogue of the Neotropical Squamata: Part II. Lizards and Amphisbaenians. U. S. Nat. Mus. Bull. 297: III + 293p.

95. PETERS, J.A. \& B. OREJAS-MIRANDA. 1970. Catalogue of the Neotropical Squamata: Part I. Snakes. U. S. Nat Mus. Bull. 297: III + 347p.

96. PETTER, A.J. 1969. Deux cas de Poeciologye chez les Oxyures parasites D'Iguana iguana (L.). Bull. Mus. nat. Hist. nat. Paris, 2e sér., 41 (5): $1252-1260$.

97. PETTER, A.J. \& QUENTIN, J.C., 1976. Key to the genera of Oxyuroidea. In: ANDERSON, CHABAUD \& WILLMOTT (eds). Keys to the nematode parasites of vertebrates, 4. England, Commonwealth Agricultural Bureaux, Farnham Royal, Bucks, 30p.

98. PINTO, R.M. \& M.A. BARBOSA. 1972. Da ocorrência de Multicaecum agile (Wedl., 1862) Baylis, 1923 no Brasil (Nematoda, Ascaridoidea). Atas Soc. Biol. Rio de Janeiro 15 (3): 125-127.

99. ORTLEPP, M.A. 1922. The nematoda genus Physaloptera. Rud. Proc. Zool. Soc. London 2: 999-1107.

100. RIBEIRO, D.J. 1940. Pesquisas helmintológicas realizadas no Estado do Pará. VIII. Camallanus amazonicus n. sp. parasito de Podocnemis expansa (Schw.). Mem, Inst. Oswaldo Cruz 35 (4): 723-728.

101. RODRIGUES, H.O. 1968. Sobre nova espécie do gênero "Strongyloides" Grassi, 1879 (Nematoda, Rhabdiasoidea). Atas Soc. Biol. Rio de Janeiro 12 (1): $31-32$.

102. 1970. Estudo da fauna helmintológica de "Hemidactylus mabouia" (M. \& J.) no Estado da Guanabara. Atas Soc. Biol. Rio de Janeiro 12 (Suplemento): 15-23.

103. 1986. Contribuição ao estudo da fauna helmintológica de vertebrados de Nova Iguaçu, RJ. Atas Soc. Biol. Rio de Janeiro 26: 27-28.

104. RODRIGUES, H.O. \& L.MF. FEIJÓ. 1976. Redescrição de Spinicauda spinicauda (Olfers, 1819) Travassos, 1920 (Nematoda, Oxyuroidea). Atas Soc. Biol. Rio de Janeiro 18: 59-63.

105. RODRIGUES, H.O. \& R.M. PINTO. 1967. Ocorrência de dois faringodonídeos em "Ameiva ameiva" (L.) no Estado da Guanabara (Nematoda, Oxyuroidea). Atas Soc. Biol. Rio de Janeiro 11 (3): 123-125.

106. RODRIGUES, H.O.; S.S. RODRIGUES \& Z.FARIA. 1990. Contribution to the knowledge of the helminthological fauna of Maricá, Rio de Janeiro State, Brazil. Mem. Inst. Oswaldo Cruz 85 (1): 115-116.

107. RODRIGUES, H.O. \& E. SANTOS. 1974. Notas sobre dois helmintos 
parasitos de répteis. Atas Soc. Biol. Rio de Janeiro 17 (2): 44-58.

108. RUIZ, J.M., 1947, Revisão do gênero Cruzia (Nematoda, Oxyuroidea) e estudo das espécies brasileiras. Tese, não publicada, Universidade de São Paulo, São Paulo, 105p.

109. SCHAD, G.A. 1962. Studies on the Genus Kalicephalus (Nematoda, Diaphanocephalidae). II. A taxonomic revision of the genus Kalicephalus Molin, 1861. Can. J. Zool. 40: 1035-1165.

110. SCHOENECKER, S.A.; G.D. SCHMIDT \& C.O.R. EVERARD. 1977. Spironoura tikasinghi sp. n. (Nematoda: Kathlaniidae) from a turtle in Trinidad, W. I. J. Parasitol. 63: 341-343.

111. SCHUURMANS-STEKHOVEN, J.H. 1937. Resultats scientifiques des Croisiéres du Navire-Escole "Mercator" Vol. 1. III; Nematoda Parasitica. Mem. Mus. Royal Hist. Nat. Belgique, ser. 2 (9): 27-42.

112. SKRJABIN, K.I. \& A.A. SOBOLEV. 1964. Tratado de Nematodologia. Spirurata dos animais e do homem e doenças causadas por eles. $2^{\mathrm{a}} \mathrm{pt}$., Fisalopterideos. Moscou, Akad. Nauk SSSR ed., 334p.

113. SKRJABIN, K.I.; N.P. SHIKHOBALOVA \& E.A. LAGODOVSKAYA. 1964. Oxyurata dos animais e do homem, $3^{a}$ pt. In: SKRJABIN, K.I. (ed.). Tratado de Nematodologia 13. Moscou, Akad. Nauk. SSSR ed., 468p. 114. SKRJABIN, K.I.; N.P. SHIKHOBALOVA \& A.A. MOZGOVOY. 1951.

Key to Parasitic Nematodes. Vol. II. Oxyurata and Ascaridata. Moscou, Akad Nauk. SSSR ed., 631p.

115. SKRJABIN, K.I.; N.P. SHIKHOBALOVA \& I.V. ORLOF. 1957. Tratado de Nematodologia. Vol. 6 Trichocephalata e Capilariata dos animais e do homem e doenças causadas por eles. Moscou, Akad. Nauk. SSSR ed., 587p. 116. SPRENT, J.F.A., 1977a. Ascarioid nematodes of amphibians and reptiles: Dujardinascaris. J. Helminthol., 51(3): 251-285.

117. 1977b. Ascaridoid nematodes of amphibians and reptiles: Sulcascaris. J. Helminthol. 51 (4): 379-387.

118. 1978. Ascaridoid nematodes of amphibians and reptiles:

Polidelphis, Travassosascaris n. g. and Hexametra.J. Helminthol. 52: 355-384. 119. 1979a. Ascaridoid nematodes of amphibians and reptiles: Multicaecum and Brevimulticaecum. J. Helminthol. 53 (1): 91-116.

120. 1979b. Ascaridoid nematodes of amphibians and reptiles: Terranova. J. Helminthol. 53 (3): 265-282.

121. TRAVASSOS, L., 1913. Sobre as espécies brasileiras da subfamília Heterakinae Railliet \& Henry. Mem Inst Oswaldo Cruz 5 (3): 271-318.

122. 1915. Contribuição para o conhecimento da fauna helmintológica, brasileira V. Sobre as espécies brasileiras do gênero"Capillaria" Zeder, 1800.

Mem. Inst. Oswaldo Cruz 7 (2): 146-172.

123. 1918. Informaçōes sobre a família Kathlanidae n. nom. Rev. Brasil. Sci., 2: 83-88.

124. 1920. Esboço de uma nova chave geral de nematódeos parasitas.

Rev. Vet. Zoot. Rio de Janeiro 10: 59-70. 
125. 1920a. Contribuição para o conhecimento da fauna helmintológica brasileira. Arch. Esc. Sup. Agric. Med. Vet. 4 (1): 17-20.

126. 1920b. Contribuições para o conhecimento da fauna helmintológica brasileira. Sobre as espécies dogênero Spinicauda n.g. Mem. Inst. Oswaldo Cruz, 12: 44-49.

127. 1923. Informações sobre a fauna helmintológica de Mato Grosso. Folha Médica 4 (8): 58.

128. 1925. Aplectana raillieti n. sp. C. R. Soc. Biol. Paris 93: 973-974.

129. 1930. Pesquisas helmintológicas realizadas em Hamburgo. VII. Notas sobre os Rhabdiasoidea Railliet, 1916 (Nematoda). Mem. Inst. Oswaldo Cruz 24 (3): 161-181.

130. 1931. Pesquisas helmintológicas realizadas em Hamburgo. IX. Ensaio monográfico da família Cosmocercidae Travassos, 1925 (Nematoda). Mem. Inst. Oswaldo Cruz 25 (3): 237-298.

131. 1933a. Sobre os Ascaridoidea parasitos dos crocodilos sulamericanos. An. Acad. Brasil. Ci. 5 (3): 153-163.

132. 1933b. Filarides des crocodiles sud-americains. C. R. Soc. Biol. Paris 113: 218-219.

133. 1933c. Ascarides des crocodiles sud-americains. C. R. Soc. Biol. Paris 114: 833-834.

134. 1934. Atractis trematophila n. sp. nematódeo parasito do ceco de um trematódeo Paramphistomoidea. Mem. Inst Oswaldo Cruz 28 (2): 267-269.

135. 1937. Revisão da família Trichostrongilidae Leiper, 1912. Monografia do Inst. Oswaldo Cruz 1: VII + 512p.

136. 1941. Relatório da quarta excursão do Instituto Oswaldo Cruz à zona da Estrada de Ferro Noroeste do Brasil, realizada em agosto e setembro de 1940. Mem Inst. Oswaldo Cruz 35 (4): 697-722.

137. TRAVASSOS, L. \& J.F.T. FREITAS. 1941a. Relatório da excursão científica realizada na zona da Estrada de Ferro Noroeste do Brasil em Julho de 1939. Mem. Inst Oswaldo Cruz 35 (3): 525-556.

— 138. 1941b. Relatório da terceira excursão à zona da Estrada de Ferro Noroeste do Brasil, realizada em fevereiro e março de 1940. Mem. Inst. Oswaldo Cruz 35 (3): 607-696.

- 139. 1942. Relatório da sexta excursão do Instituto Oswaldo Cruz, realizada à zona da Estrada de Ferro Noroeste do Brasil em novembro de 1941. Mem. Inst. Oswaldo Cruz 37 (3): 259-285.

140. 1943. Relatório da sétima excursão cientifíca do Instituto Oswaldo Cruz realizada à zona da Estrada de Ferro Noroeste do Brasil, em maio de 1942. Mem. Inst. Oswaldo Cruz 38 (3): 385-412.

141. TRAVASSOS, L.; J.F.T. FREITAS \& H. LENT. 1939. Relatório da excursão científica do Instituto Oswaldo Cruz, realizada na zona da Estrada de Ferro Noroeste do Brasil em outubro de 1938. II. Pesquisas helmintológicas. Bol. Biol. 4 (2): 221-249. 
142. TRAVASSOS, L.; J.F.T. FREITAS \& J.M. MENDONÇA. 1964. Relatório da excursão do Instituto Oswaldo Cruz ao Parque Reserva e Refúgio Soóretama, no Estado do Espírito Santo, em outubro de 1963. Bol. Mus. Biol. Mello-Leitão, Zool., 23: 1-26.

143. TRAVASSOS, L.; J.F.T. FREITAS; J.M. MENDONÇA \& H.O. RODRIGUES. 1960. Excursão a Cabo Frio, Estado do Rio de Janeiro. Atas Soc. Biol. Rio de Janeiro 4 (5): 70-71.

144. 1962. Segunda excursão a Cabo Frio, Estado do Rio de Janeiro. Atas Soc. Biol. Rio de Janeiro 6 (4): 37-38.

145. UNGRIA, C.D. 1963. Nématodes parasites nouveaux ou interéssants du Venezuela. Ann. Parasitol. Hum. Comp. 38: 893-914.

146. VANZOLINI, P.E. 1981. Reptilia. In: HURLBERT, RODRIGUEZ \& SANTOS (eds). Aquatic Biota of Tropical South America. Part 2. Anarthropoda. San Diego, San Diego State University, 246-261p.

147. VAZ, Z. 1935. Lesōes produzidas no estômago de cobras por um novo nematódeo Ophidascaris trichuriformis n. sp. Arq. Inst. Biol. S. Paulo 6: 41-45.

148. 1938. Nova espécie do gênero Ophidascaris parasita de cascavel (Crotalus terrificus). Livro Jubilar Prof. Lauro Travassos, 495-499.

149. VAZ, Z. \& C. PEREIRA. 1935. Some new Brazilian nematodes. Trans. Micr. Soc., Wash., 54 (1): 36-40.

150. VICENTE, J.J. 1966a. Contribuição ao Estudo de "Spiroxys figueiredoi" Freitas \& Dobbin Jr., 1962 (Nematoda, Spiruroidea). Atas Soc. Biol. Rio de Janeiro 10 (1): 7-8.

151. 1966b. Redescrição de "Atractis cruciata" Linstow, 1902, em novo hospedeiro (Nematoda, Atractoidea). Atas Soc. Biol. Rio de Janeiro 10 (2): 41-43.

152. 1981. Helmintos de Tropidurus (Lacertilia, Iguanidae) da Coleção Helmintológica do Instituto Oswaldo Cruz, II. Nematoda. Atas Soc. Biol. Rio de Janeiro 22: 7-18.

153. VICENTE, J.J. \& GOMES, D.C., 1971. Sobre Meteterakis rodriguesi sp. n. parasito de falsa coral (Nematoda, Subuluroidea). Atas Soc. Biol. Rio de Janeiro 14 (5-6): 145-147.

154. VICENTE, J.J. \& C.R. JARDIM. 1980. Filarídeos da Coleção Helmintológica do Instituto Oswaldo Cruz. Atas Soc. Biol. Rio de Janeiro, 21: 47-57.

155. VICENTE, J.J. \& R.M. PINTO. 1981. Nematoda, Zooparasitic forms 136-145p. In: HURLBERT, S.H., G. RODRIGUES \& N. SANTOS (eds). Aquatic Biota of Tropical South America. Part 2: Anarthropoda. San Diego, San Diego State University, XII + 298p.

156. VICENTE, J.J.; H.O. RODRIGUES \& D.C. GOMES. 1985. Nematóides do Brasil. $1^{\text {a }}$ parte: Nematóides de peixes. Atas Soc. Biol. Rio de Janeiro 25: 1-79.

157. VICENTE, J.J.; H.O. RODRIGUES; D.C. GOMES \& R.M. PINTO. 1990. 
Nematóides de anfíbios. Revta bras. Zool. 7 (4): 549-626.

158. VICENTE, J.J. \& E. SANTOS. 1967. Ocorrência de "Physaloptera retusa" Rudolphi, 1819, em novo hospedeiro. Atas Soc. Biol. Rio de Janeiro 11 (2): 75-77.

159. 1968. Terceira espécie do gênero "Tonaudia" Travassos, 1918, (Nematoda, Kathlaniidae). Atas Soc. Biol. Rio de Janeiro 12 (2): 55-56.

160. 1974. Sobre um novo nematódeo do gênero Physaloptera Rudolphi, 1819, parasito de cobra d'água (Nematoda, Spiruroidea). Atas Soc. Biol. Rio de Janeiro 17 (2): 69-71.

161. YAMAGUTI, S. 1961. Sistema Helminthum. 3. The Nematodes of vertebrates. New York, Interscience Publishers, Parts I and II, 1261p.

162. YEH, L.S. 1960. On a reconstruction of the Camallanus Railliet \& Henry, 1915. J. Helminthol. 34 (1-2): 117-123.

Recebido em 28XI.1991; aceito em 25.XL.1993. 

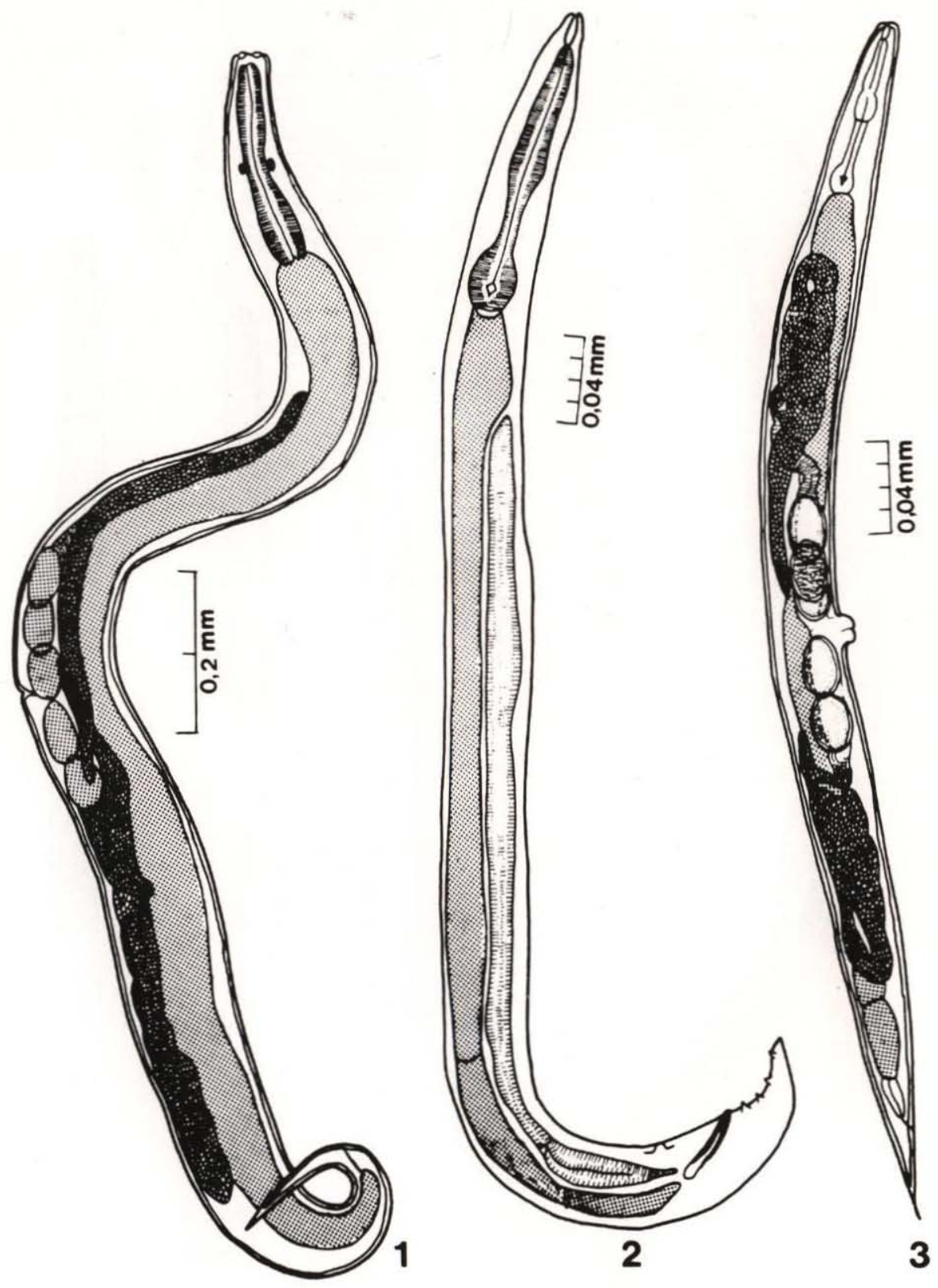

Figs 1-3. Rhabdias labiata. (1) Fêmea parasita; (2) macho de vida livre; (3) fêmea de vida livre (segundo Pereira, 1927). 

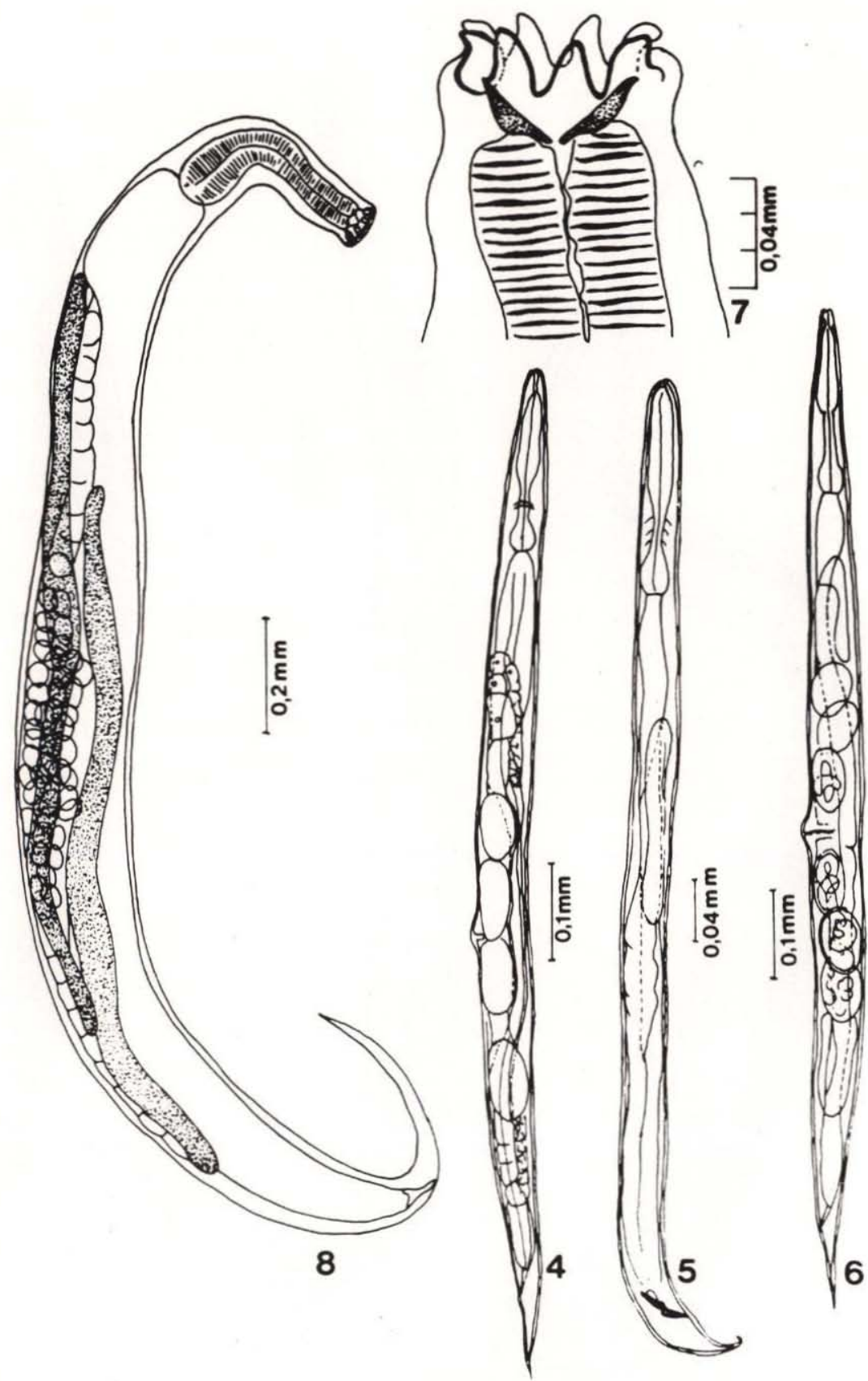


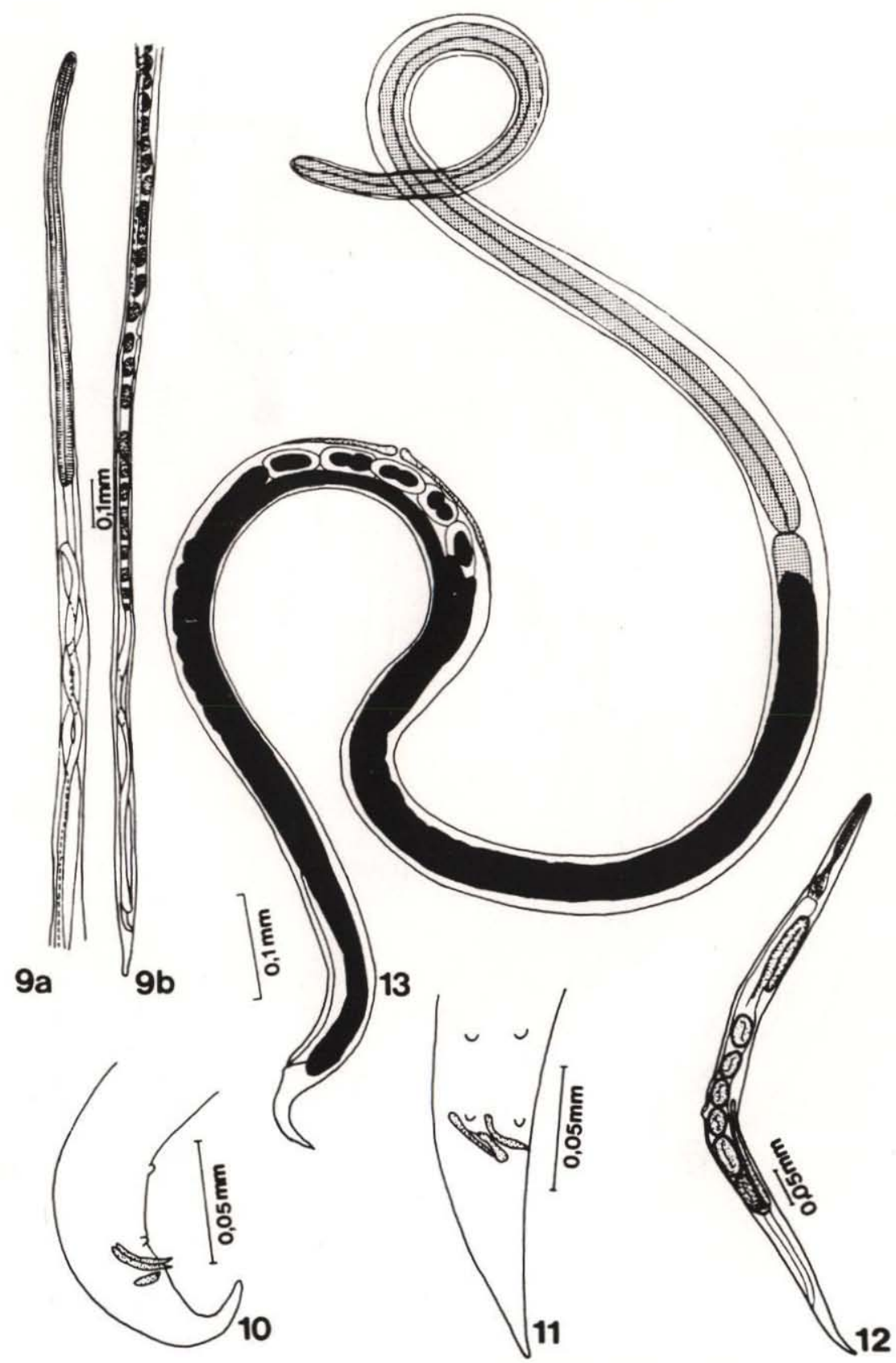

Figs 9-13. Strongyloides cruzi. (9a-b) Fêmea parasita, total; (10) macho de vida livre, extremidade caudal, vista lateral; (11) macho de vida livre, vista ventral; (12) fêmea da vida livre, total (segundo Rodrigues, 1968). Strongyloides ophidiae. (13) Fêmea parasita, total (segundo Pereira, 1935). 

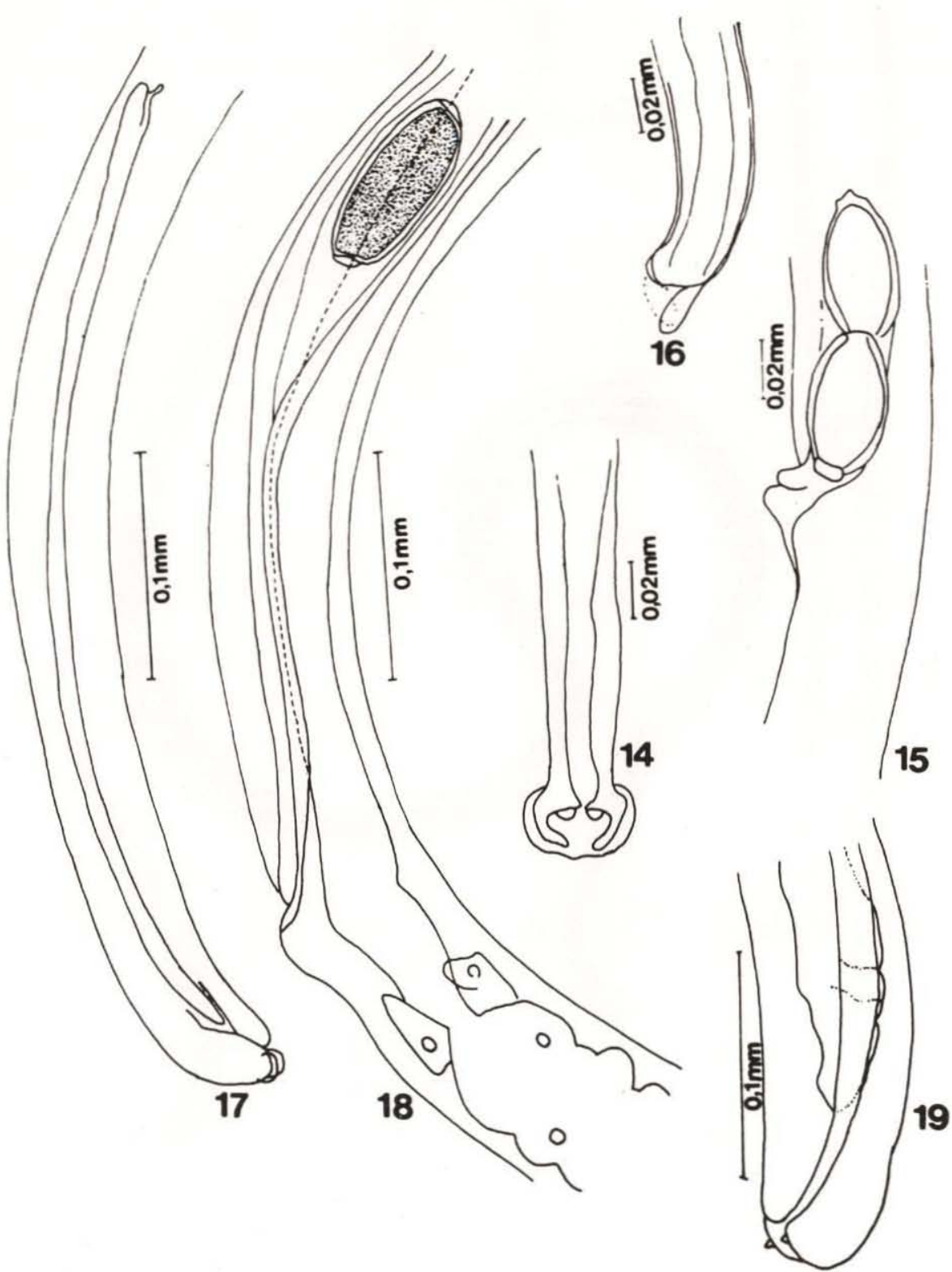

Figs 14-19. Capillaria freitaslenti. (14) Extremidade caudal do macho, vista ventral; (15) região vulvar da fêmea; (16) extremidade caudal do macho, vista lateral (segundo Araujo \& Gandra, 1941). Pseudocapillaria (P.) amarali. (17) Cauda do macho, vista lateral; (18) região vulvar da fêmea; (19) extremidade caudal da fêmea (segundo Freitas \& Lent, 1934). 

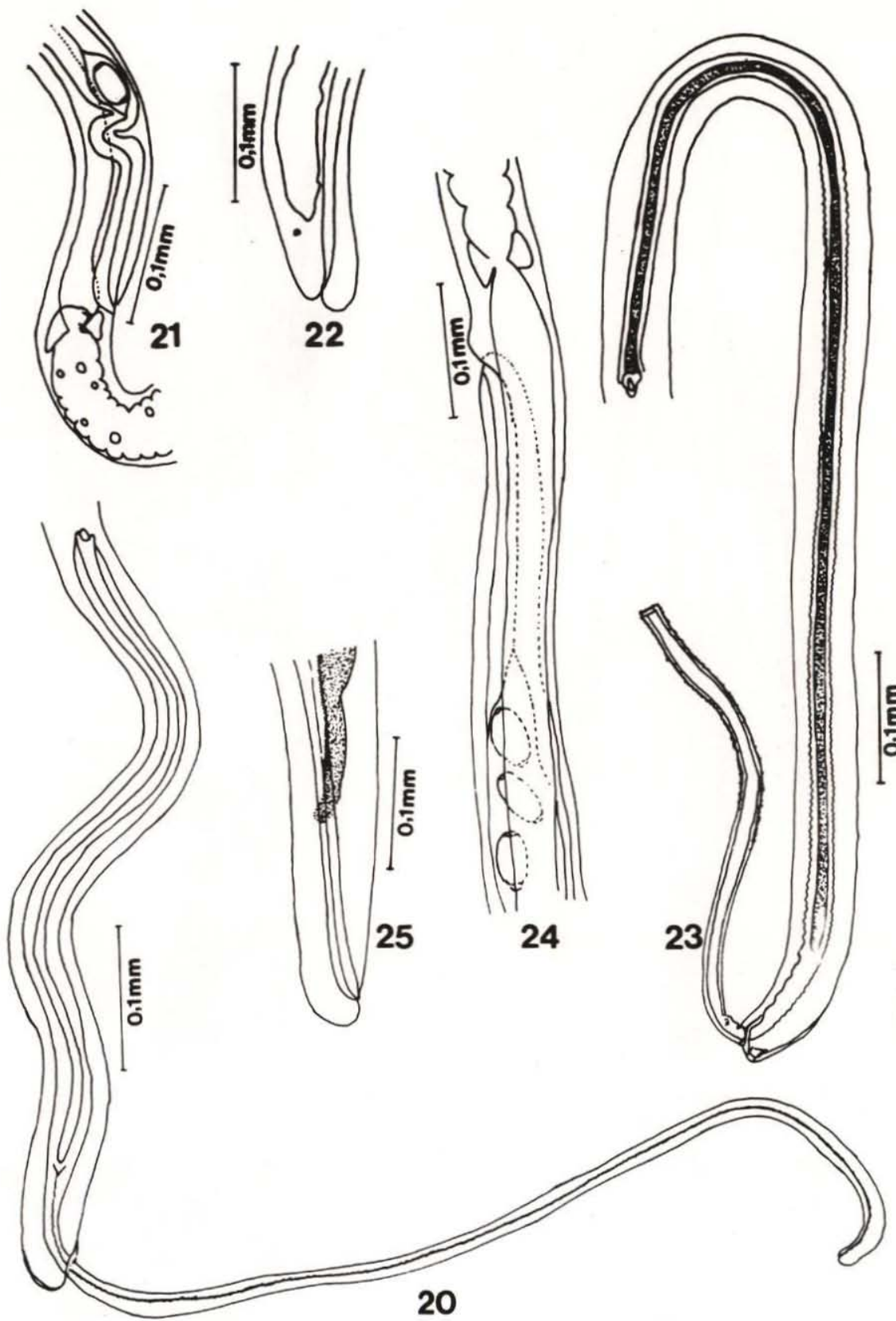

Figs 20-25. Pseudocapillaria (P.) cesarpintoi. (20) Extremidade caudal do macho; (21) região vulvar da fêmea; (22) extremidade caudal da fêmea. Pseudocapillaria (I.) murinae. (23) Extremidade caudal do macho; (24) região vulvar da fêmea; (25) extremidade caudal da fêmea (segundo Freitas \& Lent, 1934, 1935). 

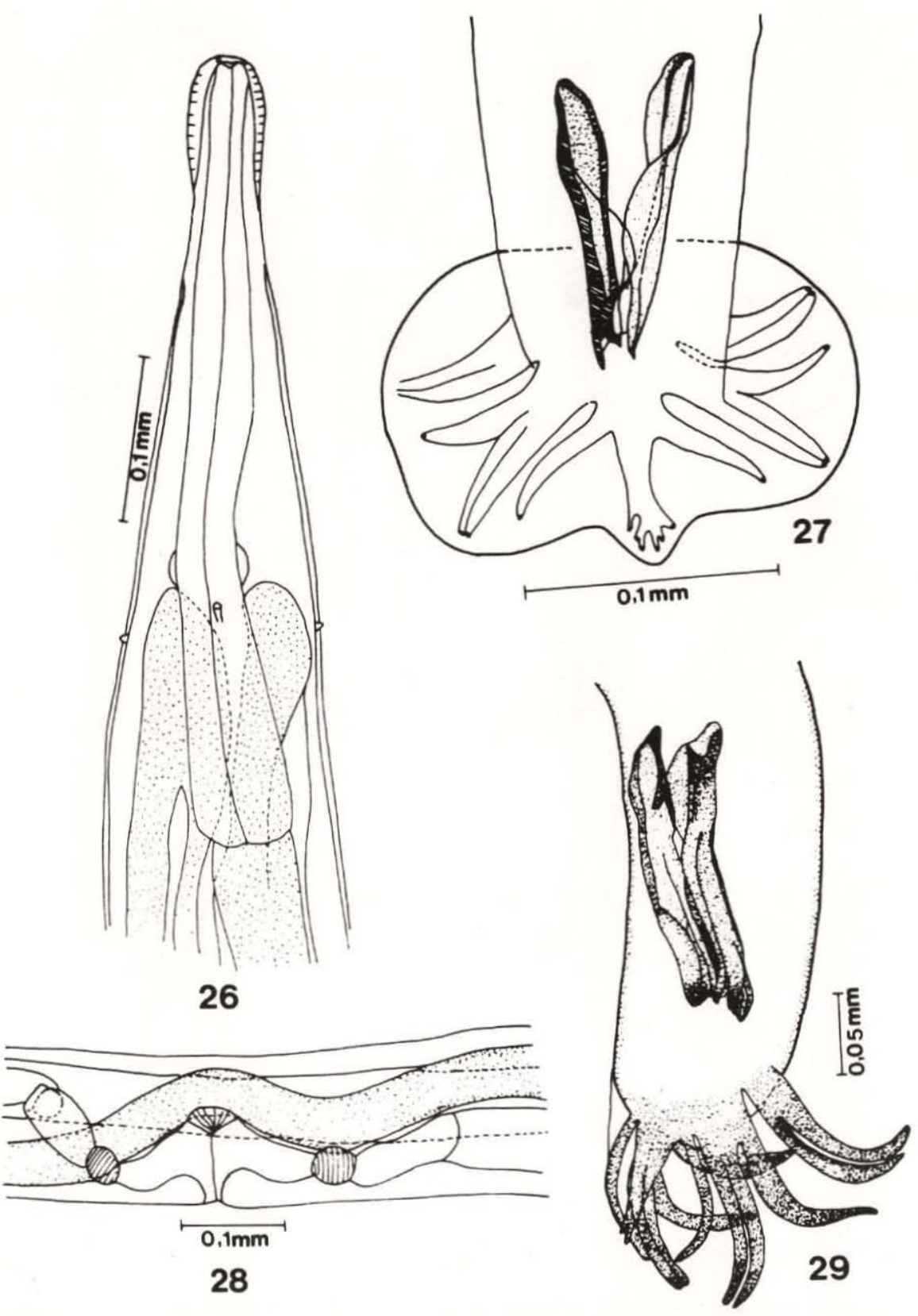

Figs 26-29. Oswaldocruzia brasiliensis. (26) Extremidade cefálica, de face; (27) extremidade caudal dọ macho, vista ventral; (28) região vulvar (segundo Freitas \& Lent, 1935). Oswaldocruzia mazzai. (29) Extremidade caudal do macho. Segundo Vicente, 1981. 

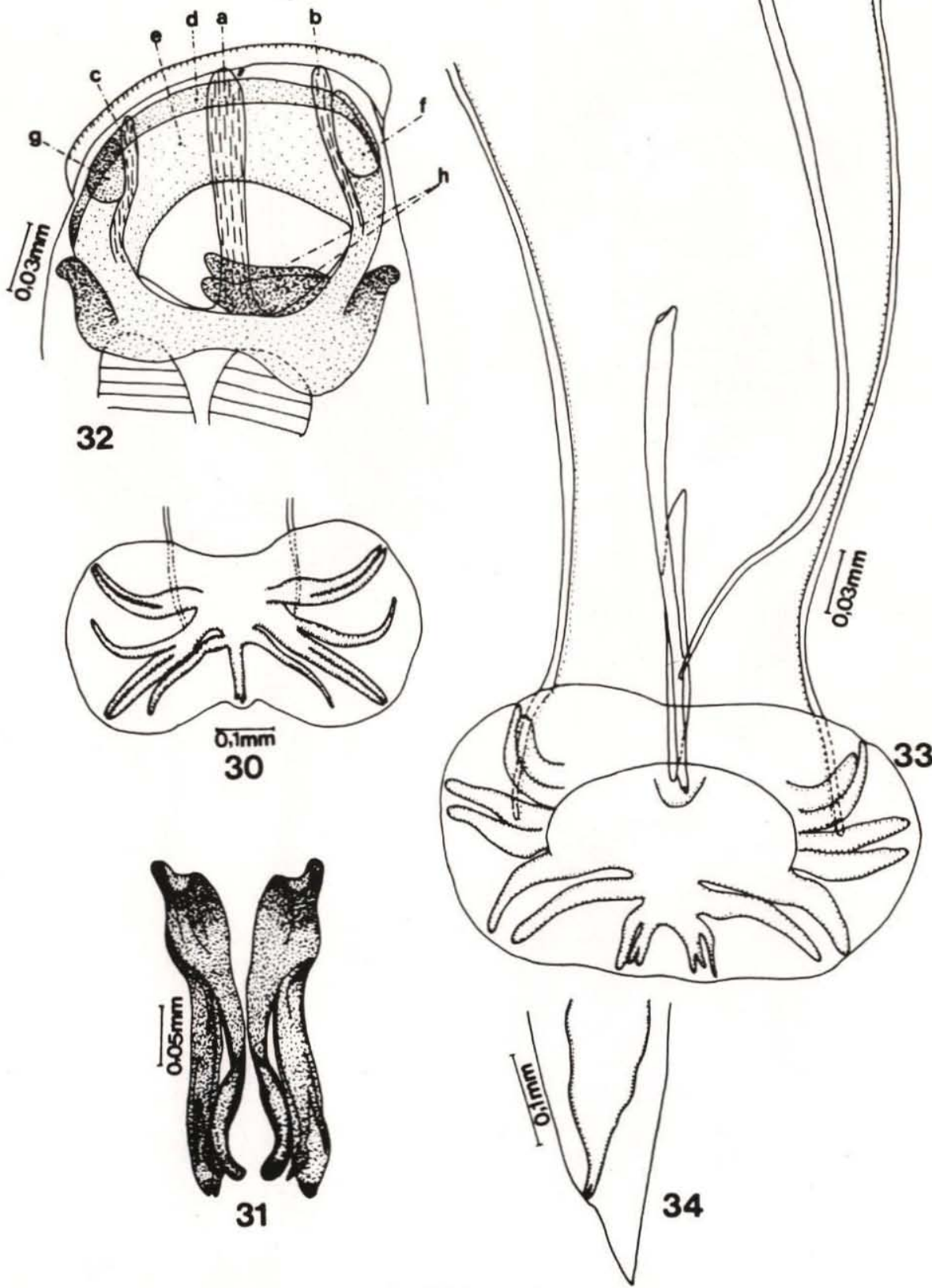

Figs 30-34. Oswaldocruzia subauricularis. (30) Extremidade caudal do macho, vista ventral; (31) espículos (segundo Freitas, 1955). Diaphanocephalus diesingi. (32) Cápsula bucal, vista lateral; (33) extremidade caudal do macho; (34) extremidade caudal da fêmea (segundo Freitas \& Lent, 1938). 

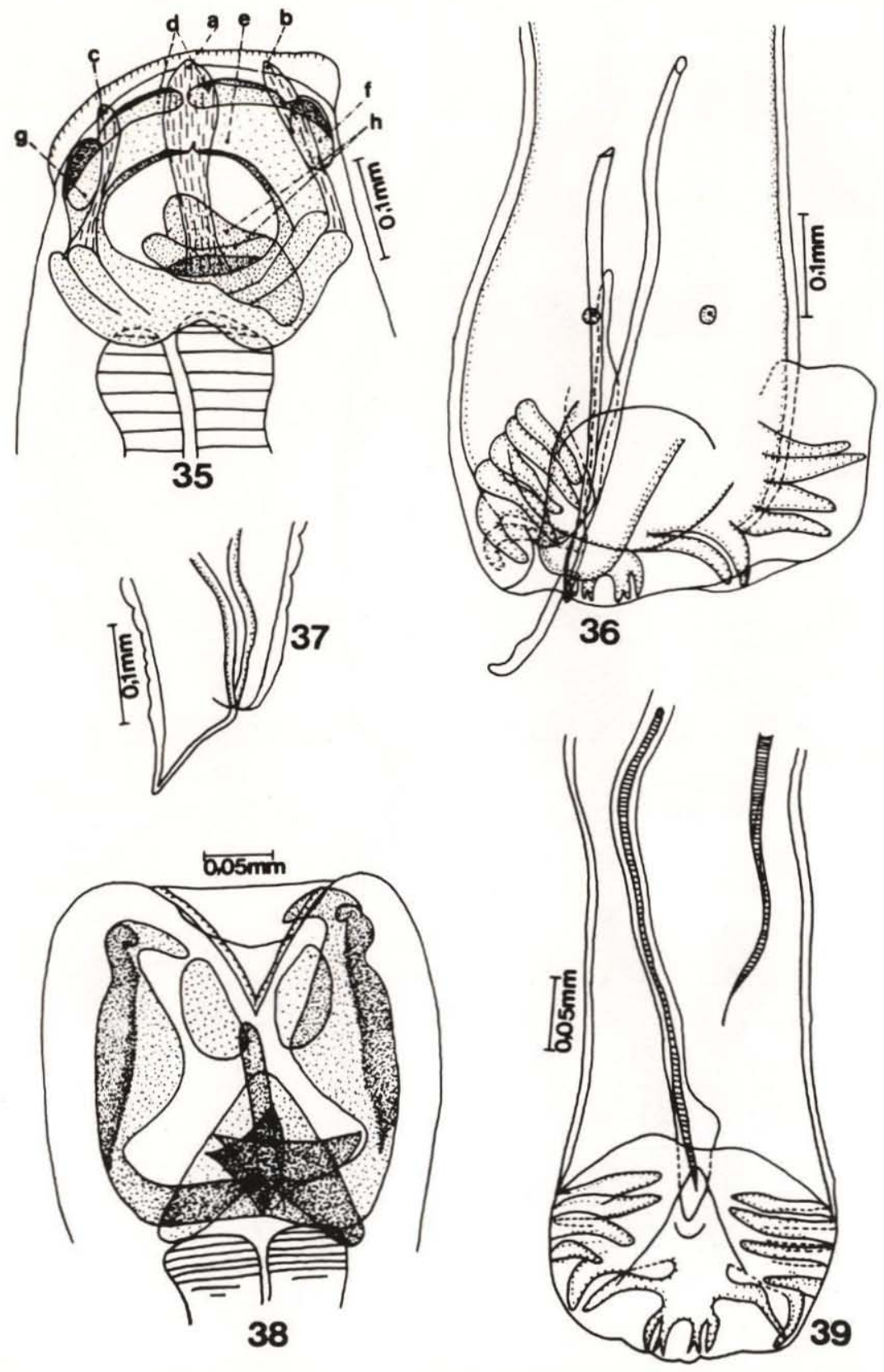

Figs 35-39. Diaphanocephalus galeatus. (35) Cápsula bucal, vista lateral; (36) extremidade caudal do macho; (37) extremidade caudal da fêmea (segundo Freitas \& Lent, 1938). Diaphanocephalus jacuruxi. (38) Cápsula bucal; extremidade caudal do macho (segundo Alho, 1965). 

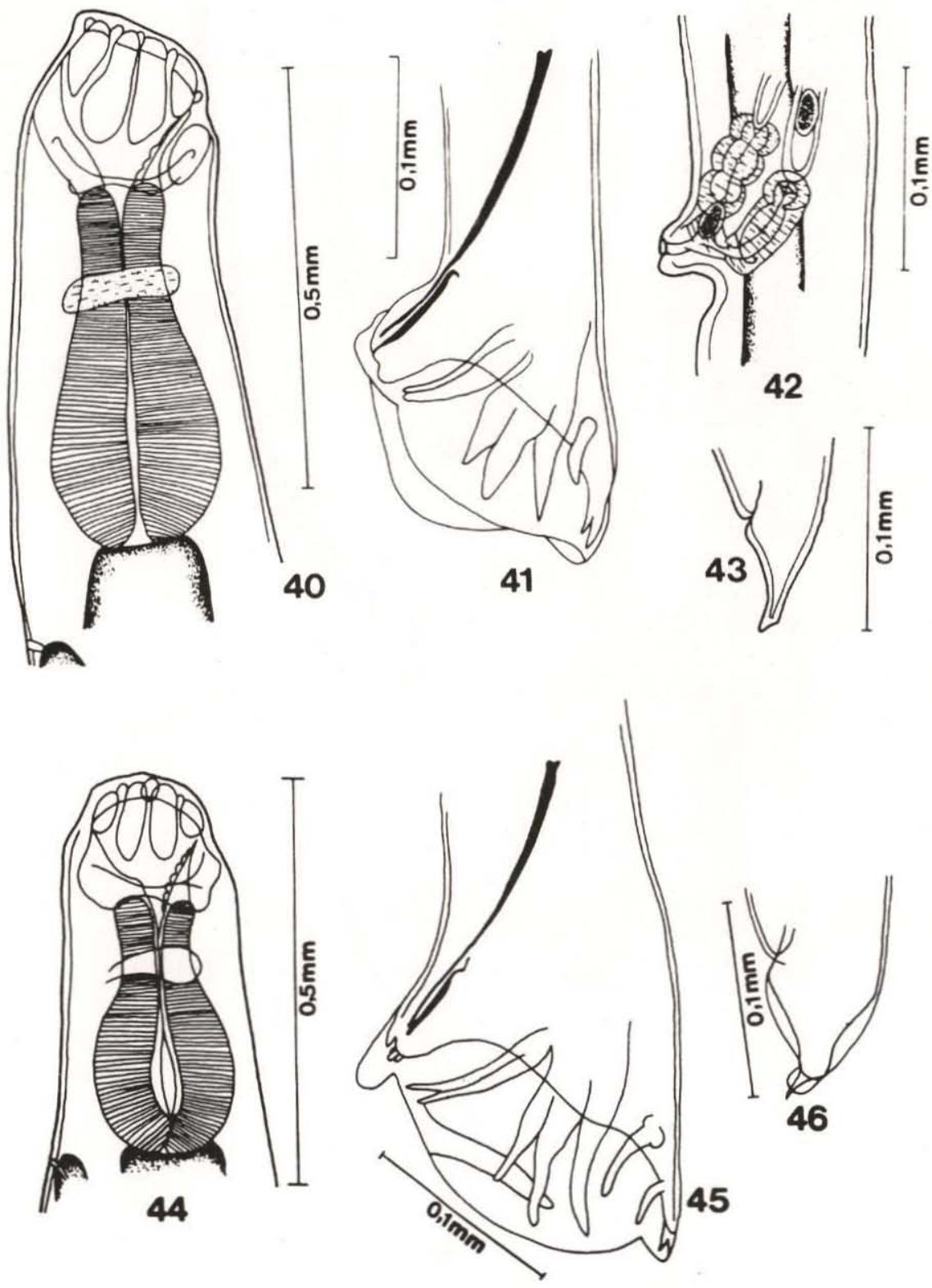

Figs 40-46. Kalicephalus appendiculatus. (40) Extremidade anterior; (41) extremidade caudal; (42) região vulvar da fêmea; (43) extremidade caudal da fêmea. Kalicephalus costatus costatus. (44) Extremidade anterior; (45) extremidade caudal do macho; (46) extremidade caudal da fêmea (segundo Schad, 1962). 


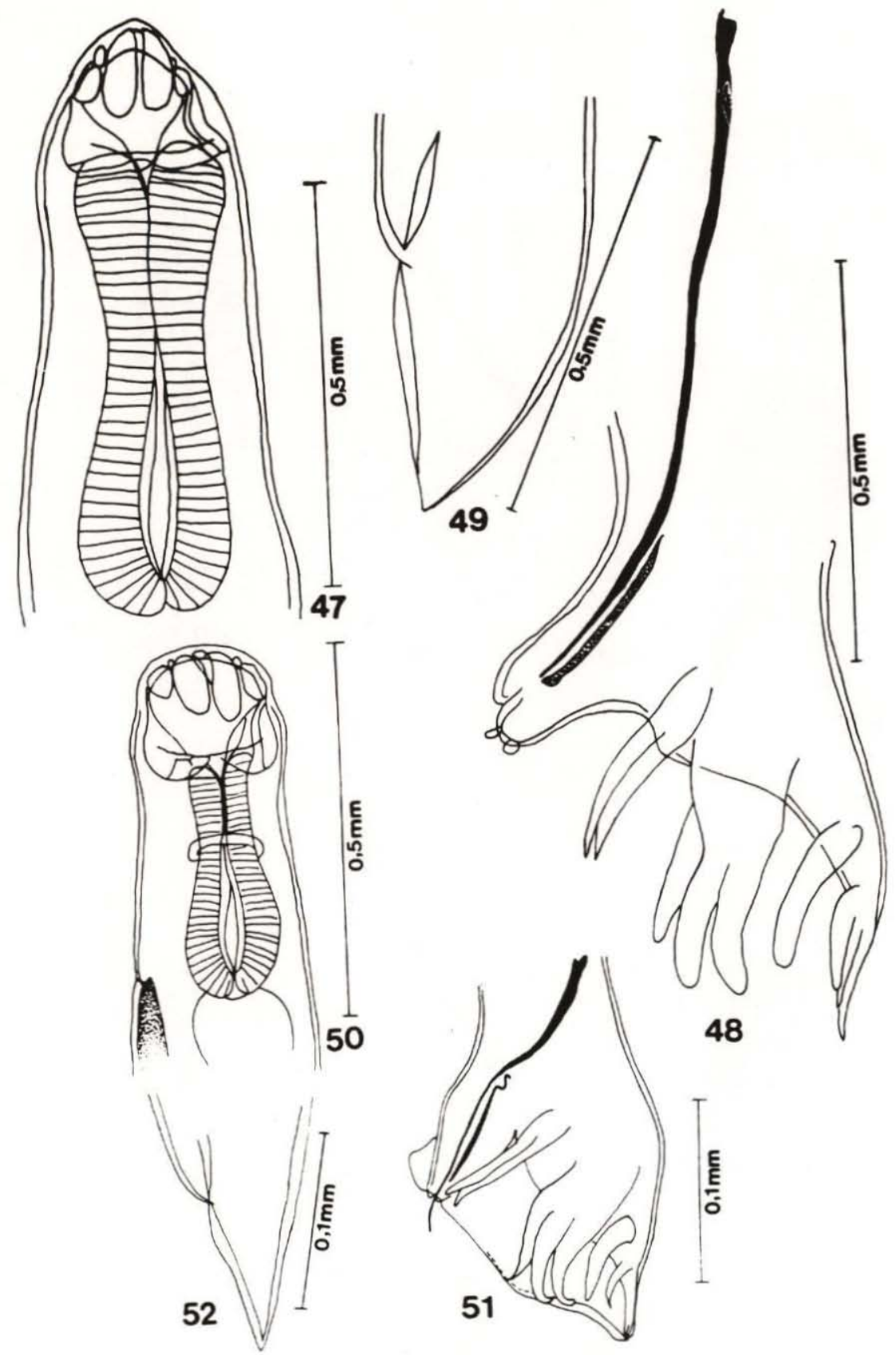

Figs 47-52. Kalicephalus inermis inermis. (47) Extremidade anterior; (48) extremidade caudal do macho; (49) extremidade caudal da fêmea. Kalicephalus rectiphilus neorectiphilus. (50) Extremidade anterior; (51) extremidade caudal do macho; (52) extremidade caudal da fêmea (segundo Schad, 1962). 

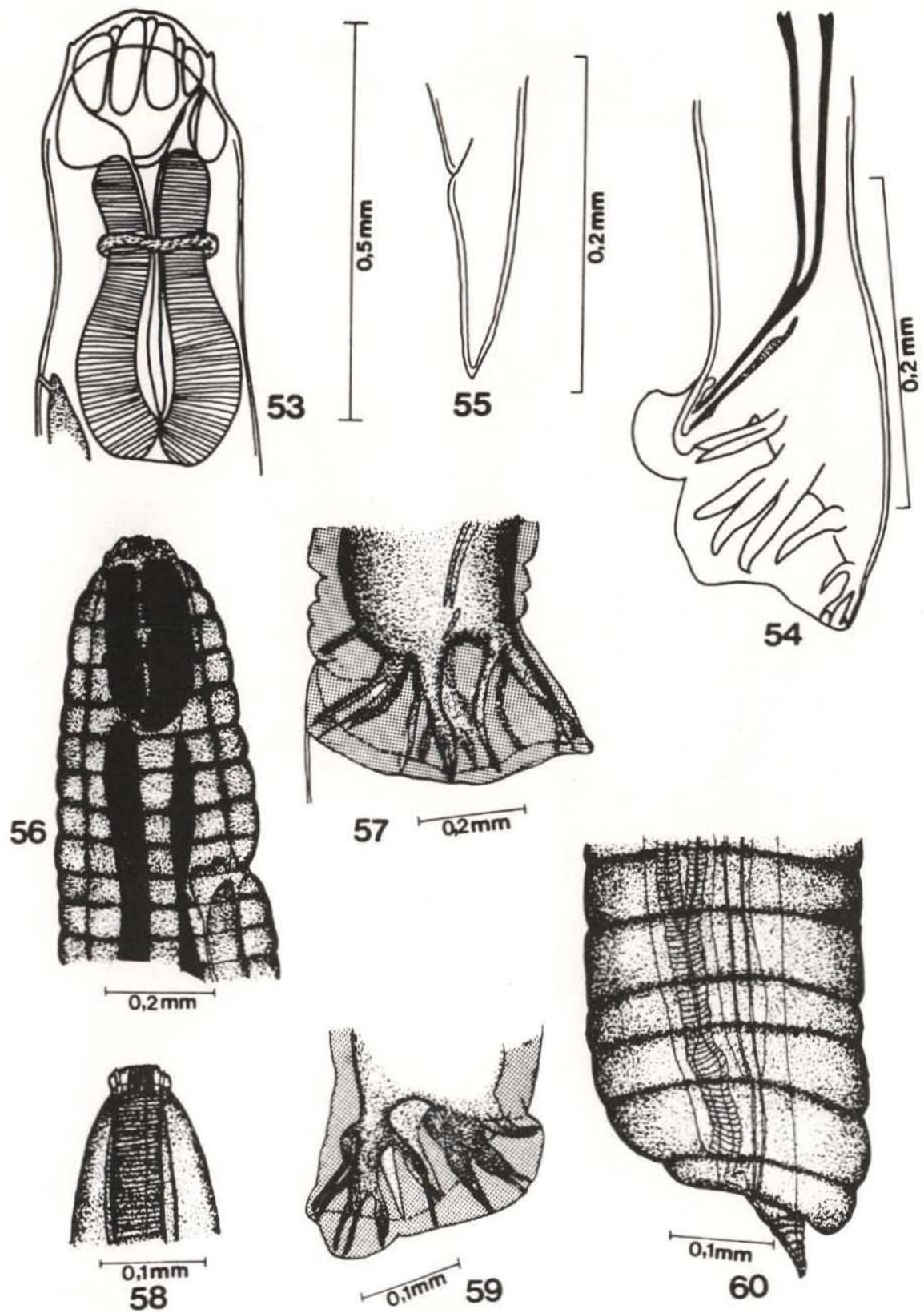

Figs 53-60. Kalicephalus subulatus. (53) Extremidade anterior; (54) extremidade caudal do macho; (55) extremidade caudal da fêmea (segundo Schad, 1962). Sauricola sauricola. (56) Extremidade anterior; (57) extremidade caudal (segundo Chapin, 1925). Chapiniella variabilis. (58) Extremidade anterior; (59) extremidade caudal do macho; (60) extremidade caudal da fêmea (segundo Chapin, 1925). 


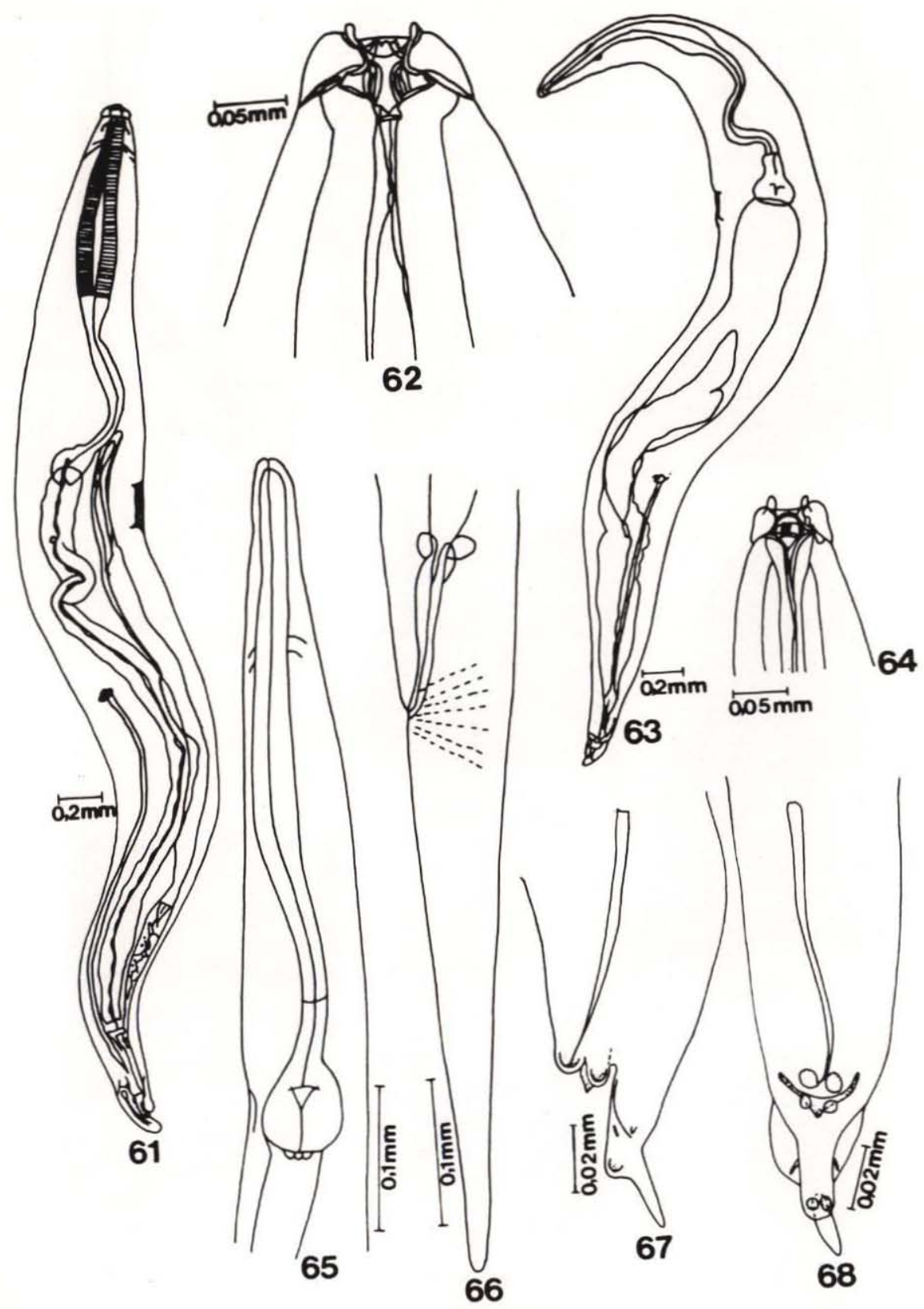

Figs 61-68. Ozolaimus cirratus. (61) Macho total; (62) extremidade anterior. O. megatyphlon. (63) Macho, total; (64) extremidade anterior (segundo Pereira, 1935). Alaeuris caudatus. (65) Extremidade anterior; (66) extremidade caudal da fêmea; (67) extremidade caudal do macho, vista lateral; (68) extremidade caudal do macho, vista ventral (segundo Lent \& Freitas, 1948). 


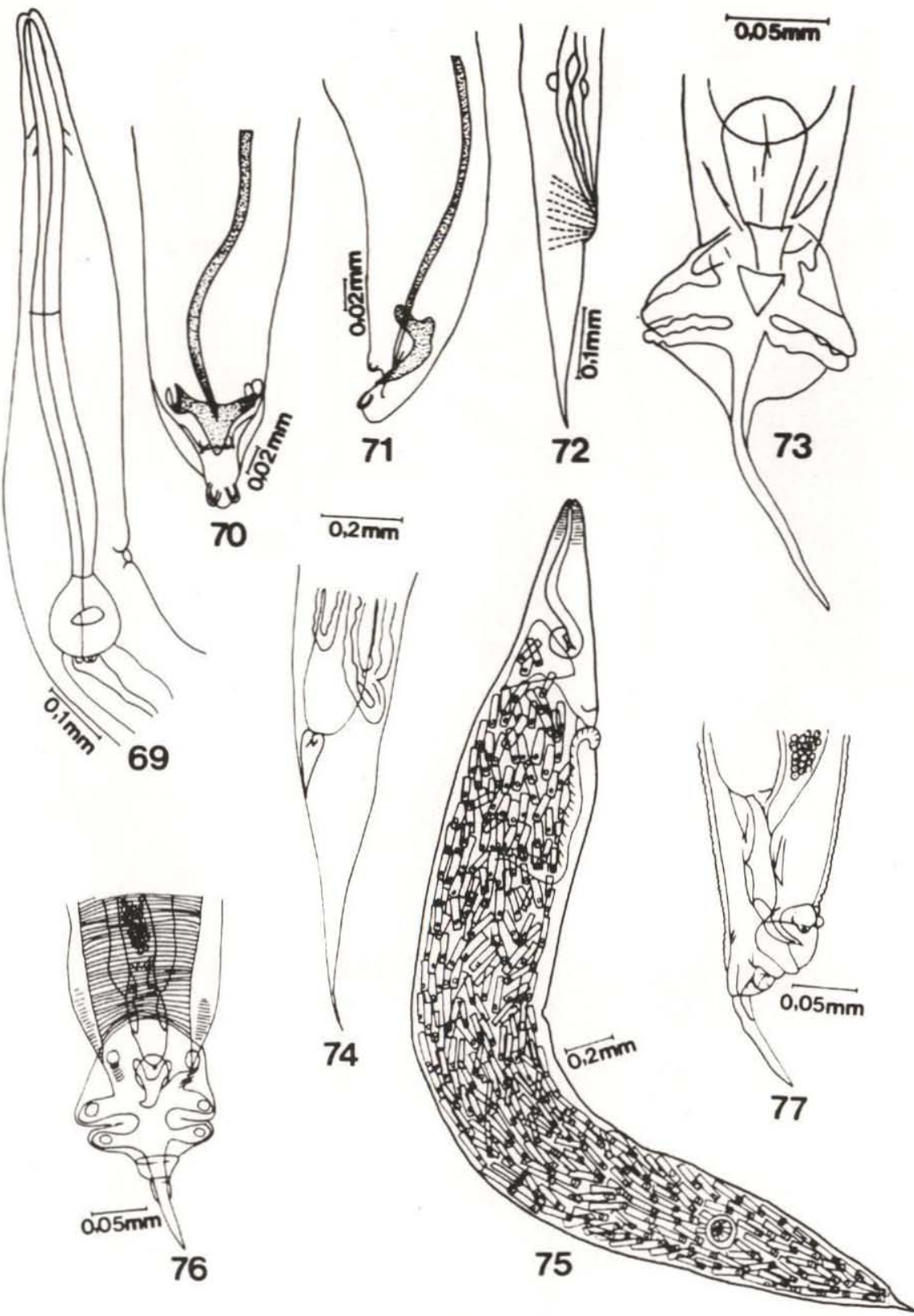

Figs 69-77. Alaeuris vogelsangi. (69) Extremidade anterior; (70) extremidade caudal do macho, vista ventral; (71) extremidade caudal do macho vista lateral; (72) extremidade caudal da fêmea (segundo Lent \& Freitas, 1948). Pharyngodon cesarpintoi. (73) cauda do macho, vista ventral; (74) cauda da fêmea. P. travassosi. (75) Fêmea, total; (76) cauda do macho, vista ventral; (77) extremidade caudal do macho, vista lateral (segundo Pereira, 1935). 

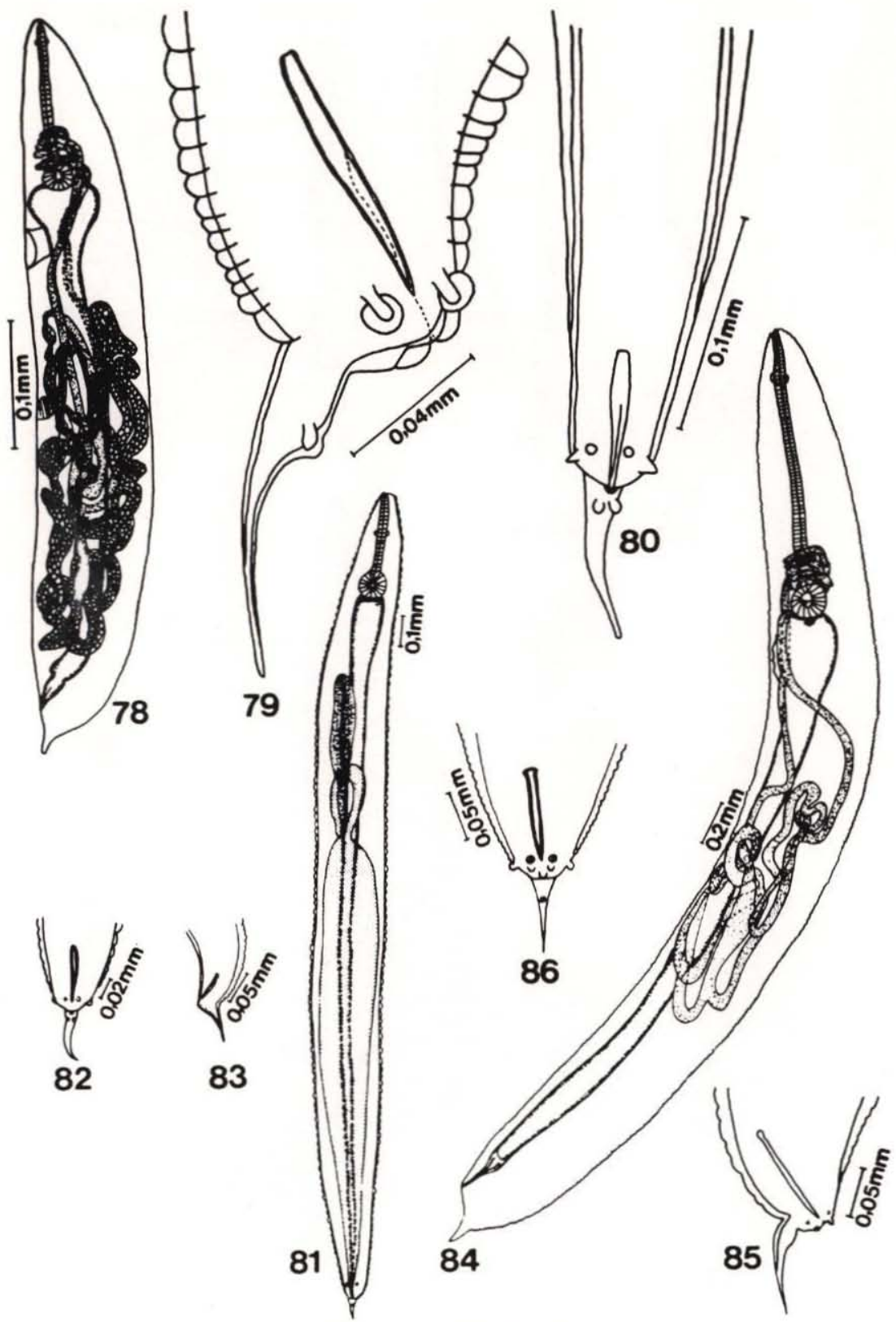

Figs 78-86. Thelandros alvarengai. (78) Fêmea, total; (79) cauda do macho, vista lateral; (80) cauda do macho vista ventral (segundo Freitas, 1957). T. largitor. (81) Macho, total; (82) cauda do macho, vista ventral; (83) cauda do macho, vista lateral (segundo Alho \& Rodrigues, 1963). T. sceleratus. (84) Fêmea, total; (85) cauda do macho, vista lateral; (86) cauda do macho, vista ventral (segundo Alho, 1963). 


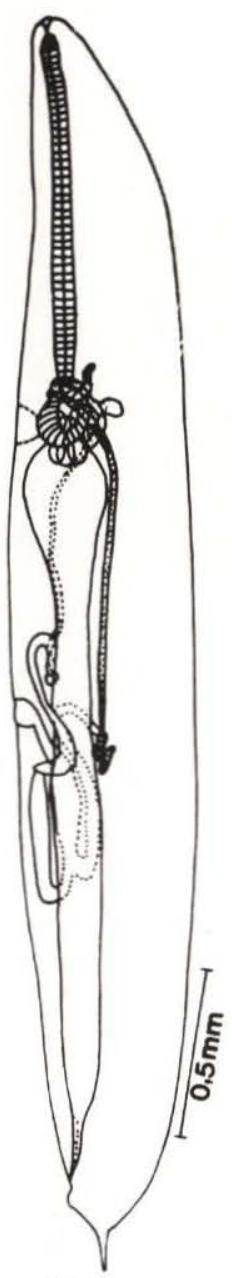

87
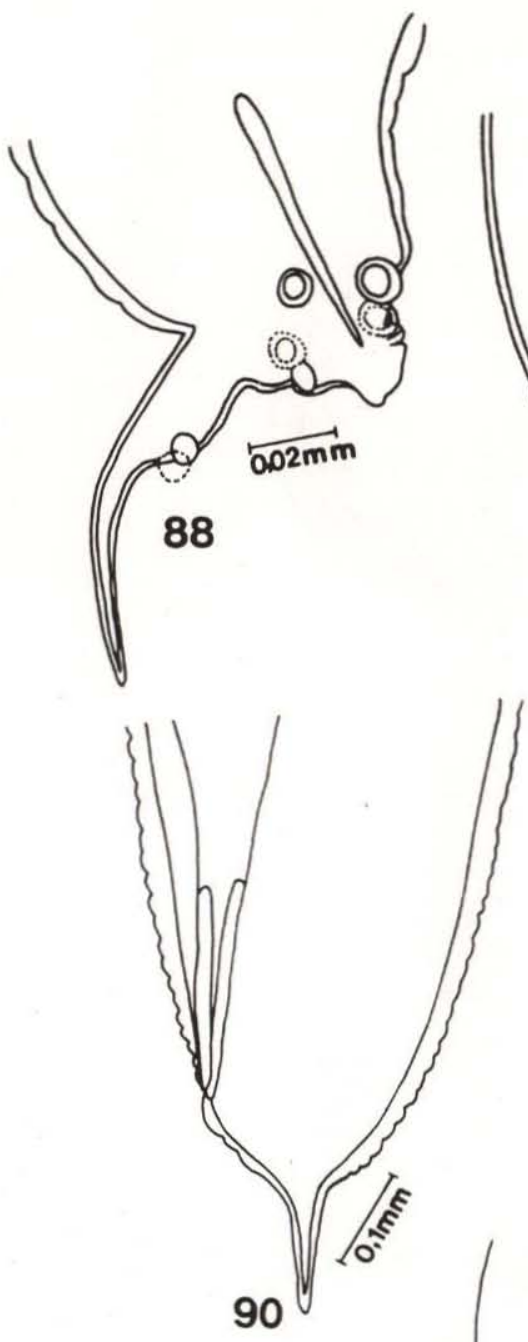
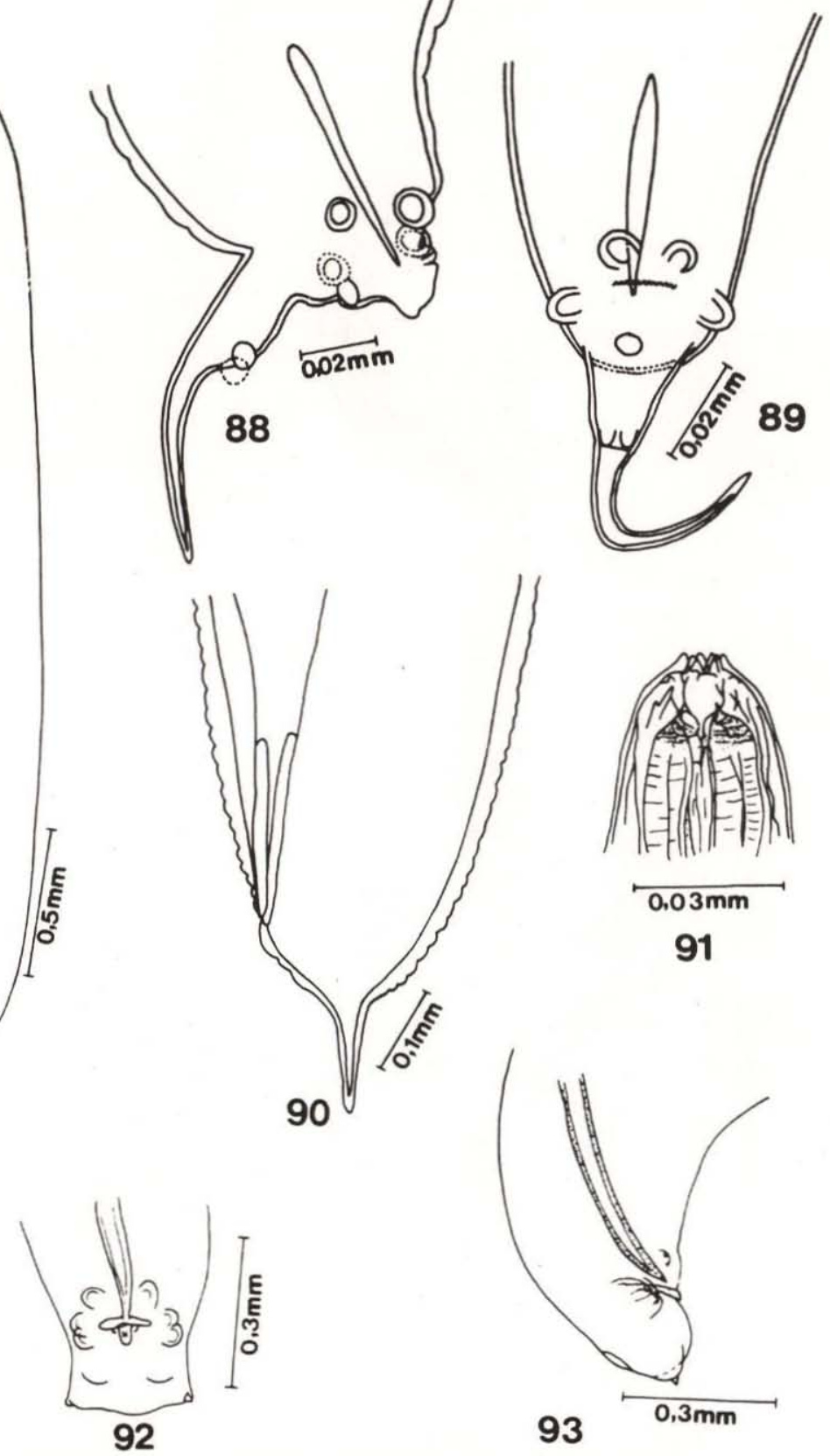

Figs 87-93. Thelandros verrucosus. (87) Fêmea, total; (88) cauda do macho, vista lateral; (89) cauda do macho, vista ventral; (90) cauda da fêmea, vista lateral (segundo Freitas \& Dobbin Jr., 1959). Gynaecometra bahiensis. (91) Extremidade anterior; (92) cuada do macho, vista ventral; (93) cauda do macho, vista lateral (segundo Araujo, 1978). 


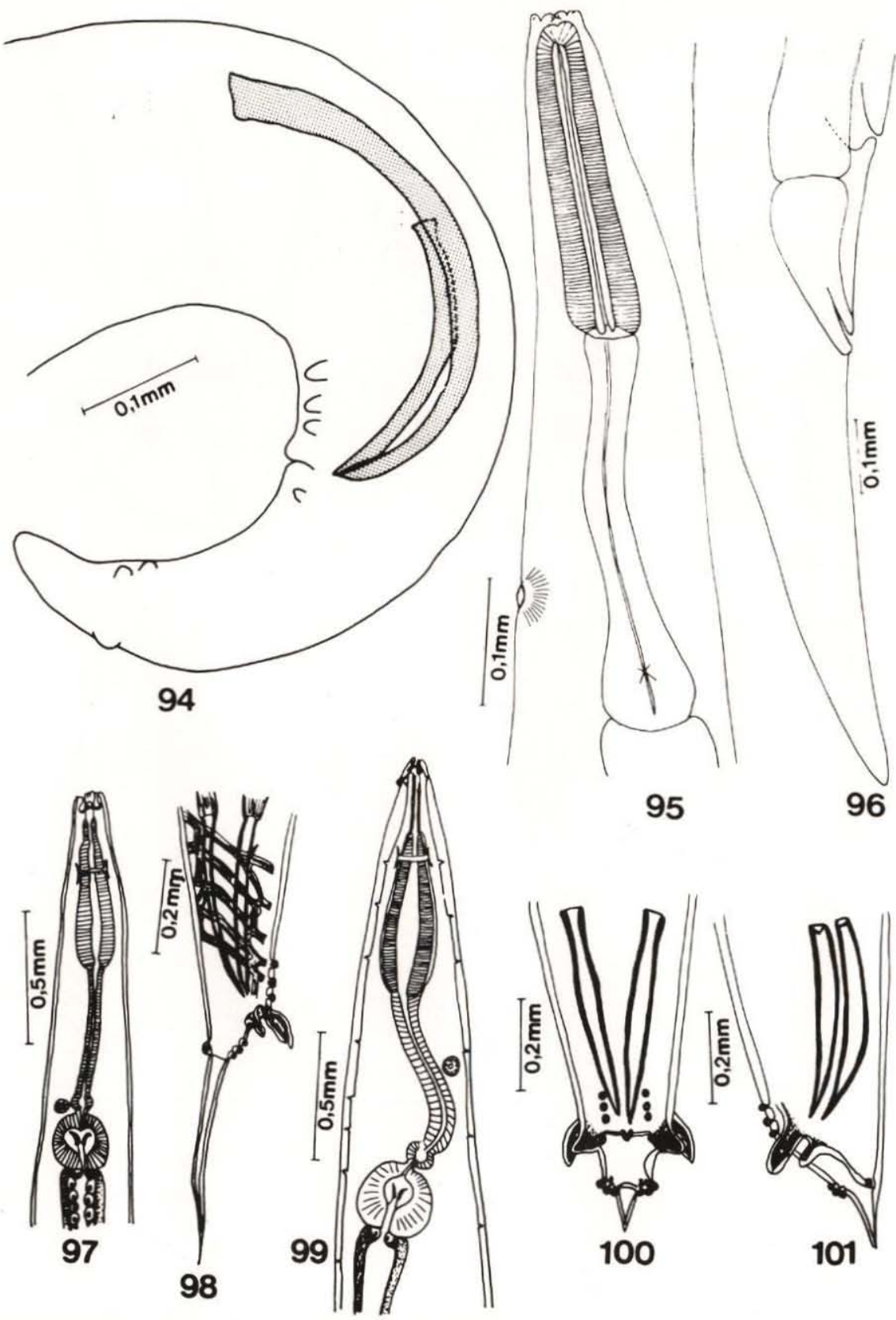

Figs 94-101. Atractis cruciata. (94) Cauda do macho, vista lateral; (95) extremidade anterior; (96) extremidade caudal da fêmea, vista lateral (segundo Vicente, 1966). Labduris gulosa. (97) Extremidade anterior; (98) extremidade caudal do macho, vista lateral. Labduris zschokkei. (99) Extremidade anterior; (100) extremidade caudal do macho, vista ventral; (101) extremidade caudal do macho, vista lateral (segundo Thapar, 1925). 


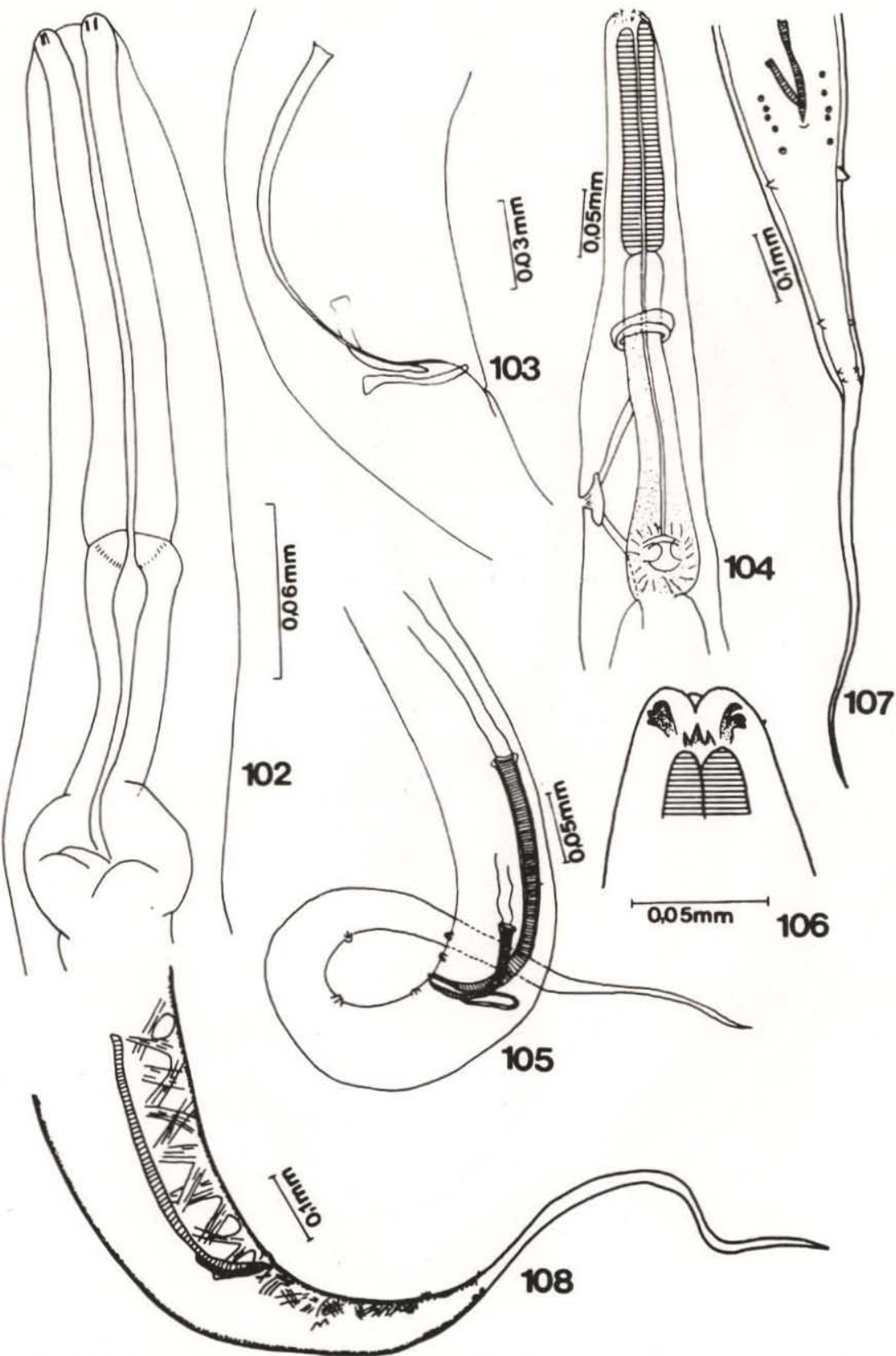

Figs 102-108. Atractis trematophila. (102) Extremidade anterior; (103) extremidade caudal do macho (segundo Travassos, 1934). Klossinemella travassosi. (104) Extremidade anterior; (105) extremidade posterior do macho, vista lateral (segundo Costa, Motta \& Gomes, 1968). K. conciliatus. (106) Regiấo cefálica; (107) cauda do macho, vista ventral; (108) cauda do macho, vista lateral (segundo Alho, 1964). 


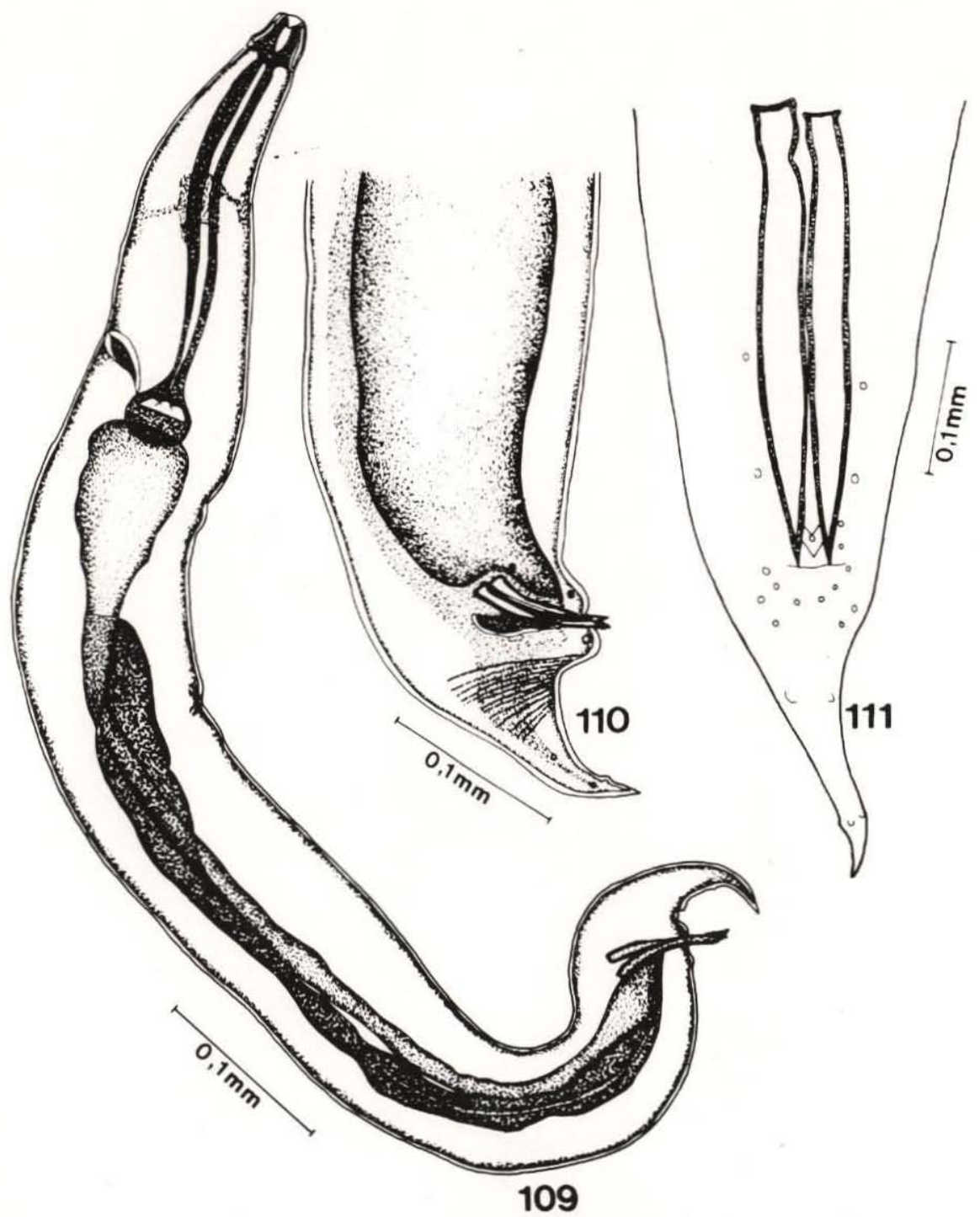

Figs 109-111. Aplectana pusilla. (109) Macho, total (segundo Miranda, 1924. A. raillieti. (110) Extremidade caudal do macho, vista lateral. A. unguiculata. (111) Extremidade caudal do macho, vista ventral (segundo Travassos, 1925). 


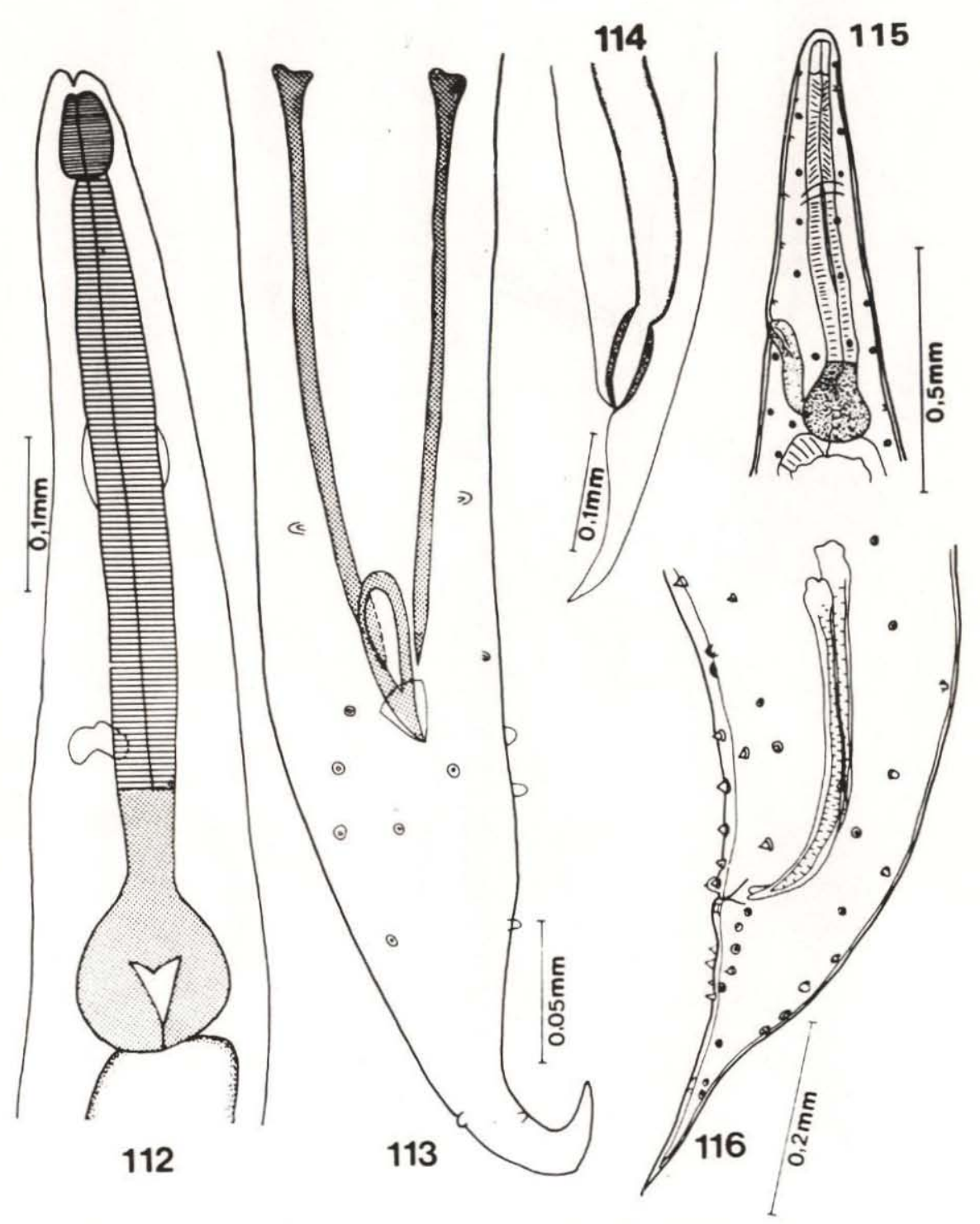

Figs 112-116. Aplectana travassosi. (112) Extremidade anterior; (113) extremidade caudal do macho, vista ventral; (114) extremidade caudal da fêmea (segundo Gomes \& Motta, 1967). A. papillifera. (115) Extremidade anterior; (116) extremidade caudal do macho (segundo Araujo, 1976). 


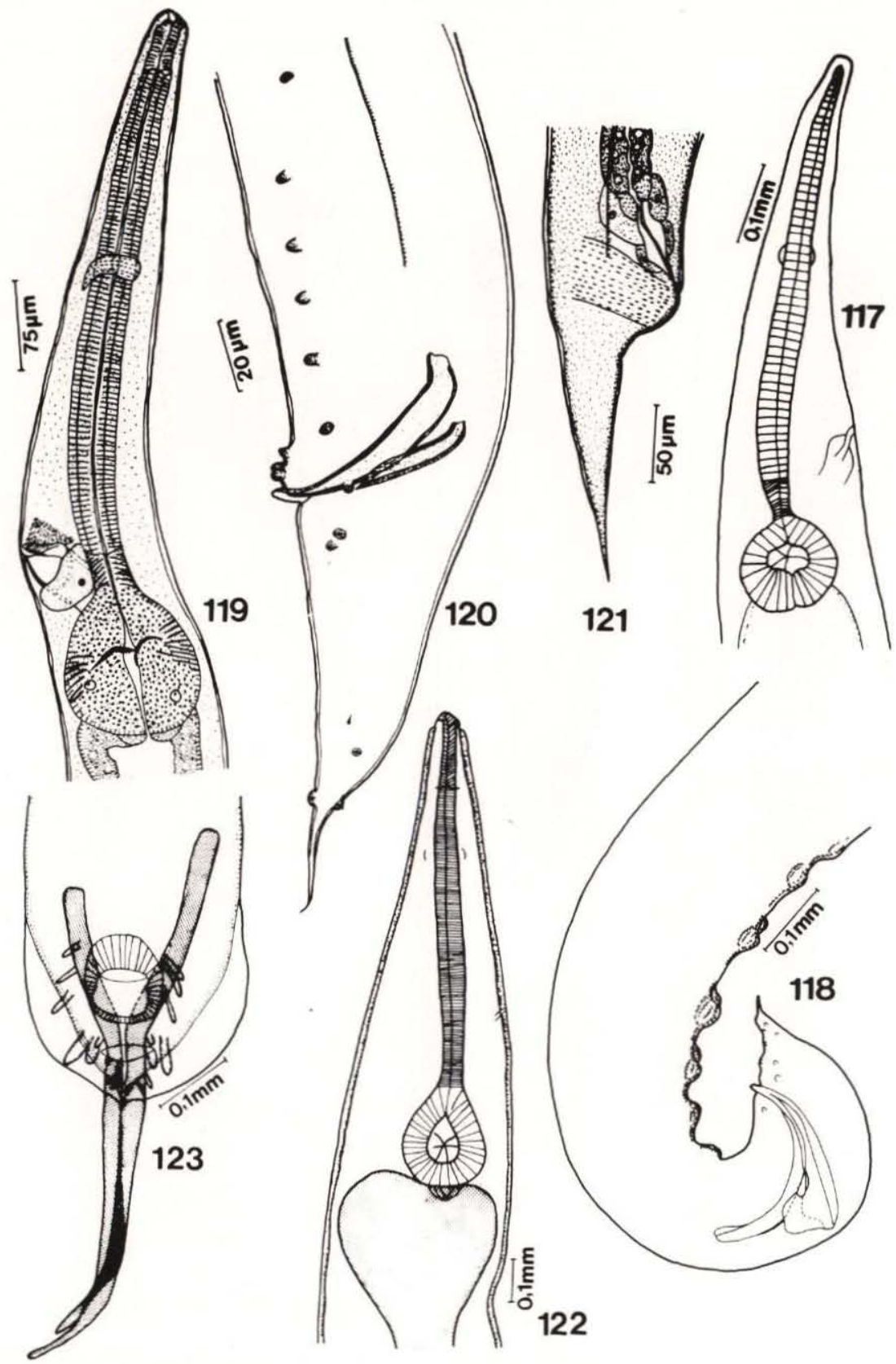

Figs 117-123. Cosmocerca rara. (117) Extremidade anterior; (118) extremidade caudal do macho, vista lateral (segundo Freitas \& Vicente, 1966). Dollfusnema amphisbaenia. (119) Extremidade anterior; (120) extremidade posterior do macho, vista lateral; (121) extremidade caudal da fêmea (segundo Baker, 1981). Strongyluris oscari. (122) Extremidade anterior; (123) extremidade posterior do macho, vista ventral (segundo Vicente, 1981). 


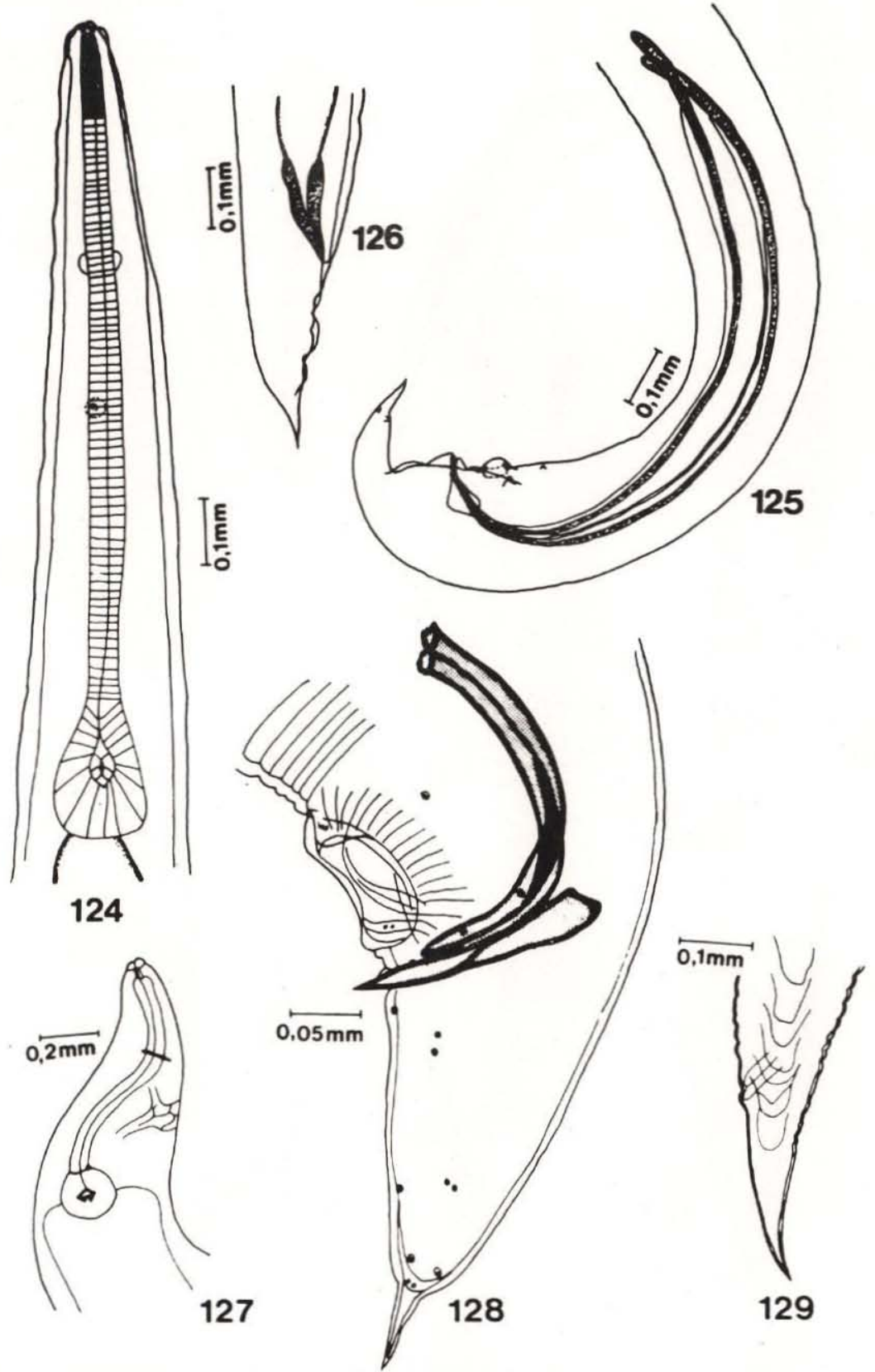

Figs 124-129. Bufonerakis rodriguesi. (124) Extremidade anterior; (125) extremidade caudal do macho, vista lateral; (126) extremidade caudal da fêmea (segundo Vicente, 1971). Spinicauda spinicauda. (127) Extremidade anterior; (128) extremidade caudal do macho; (129) extremidade caudal da fêmea (segundo Pereira, 1935). 

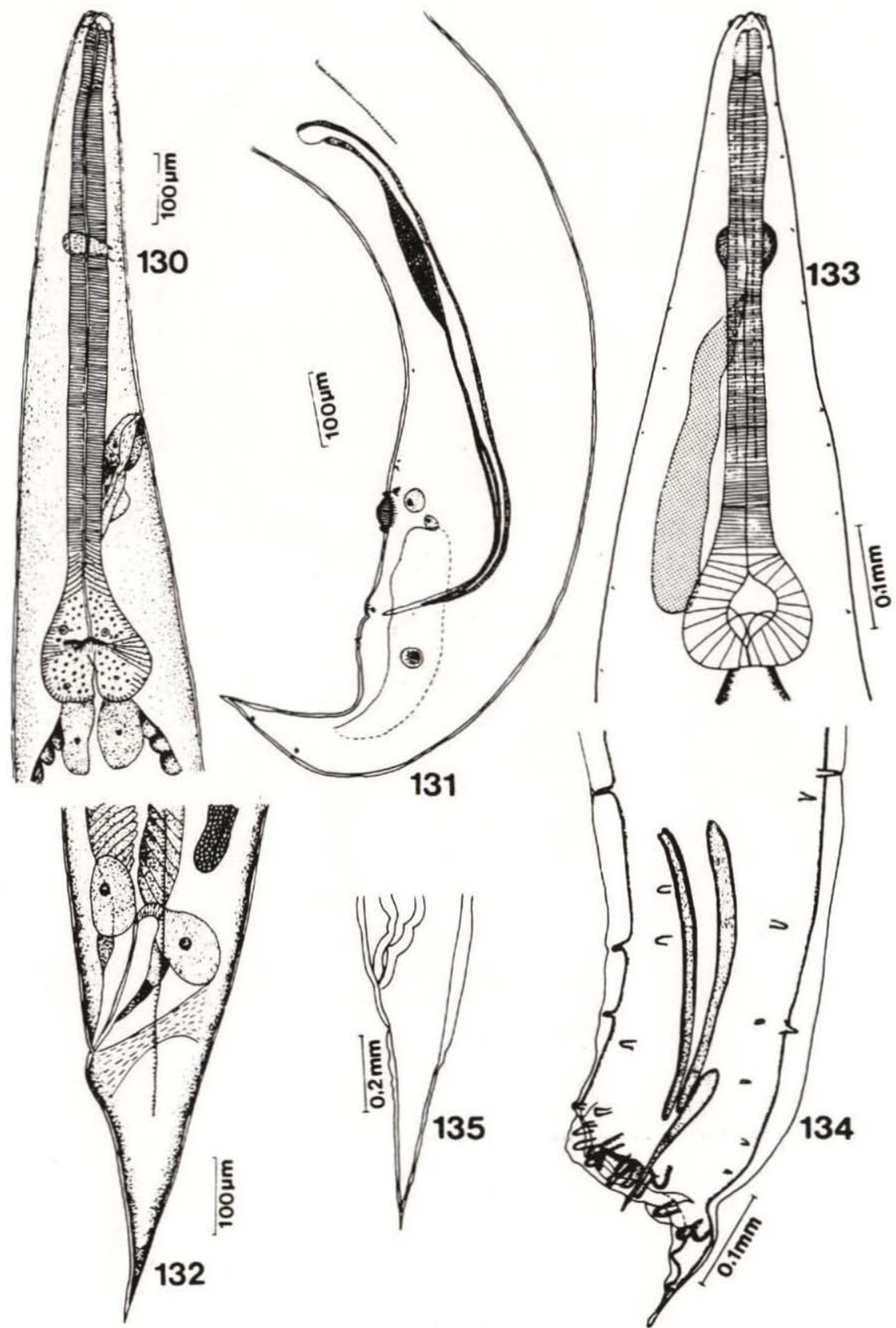

Figs 130-135. Africana chabaudi. (130) Extremidade anterior; (131) extremidade caudal do macho; (132) extremidade caudal da fêmea (segundo Baker, 1981). Moaciria alvarengai. (133) Extremidade anterior; (134) Extremidade caudal do macho; (135) extremidade caudal da fêmea (segundo Freitas, 1956). 

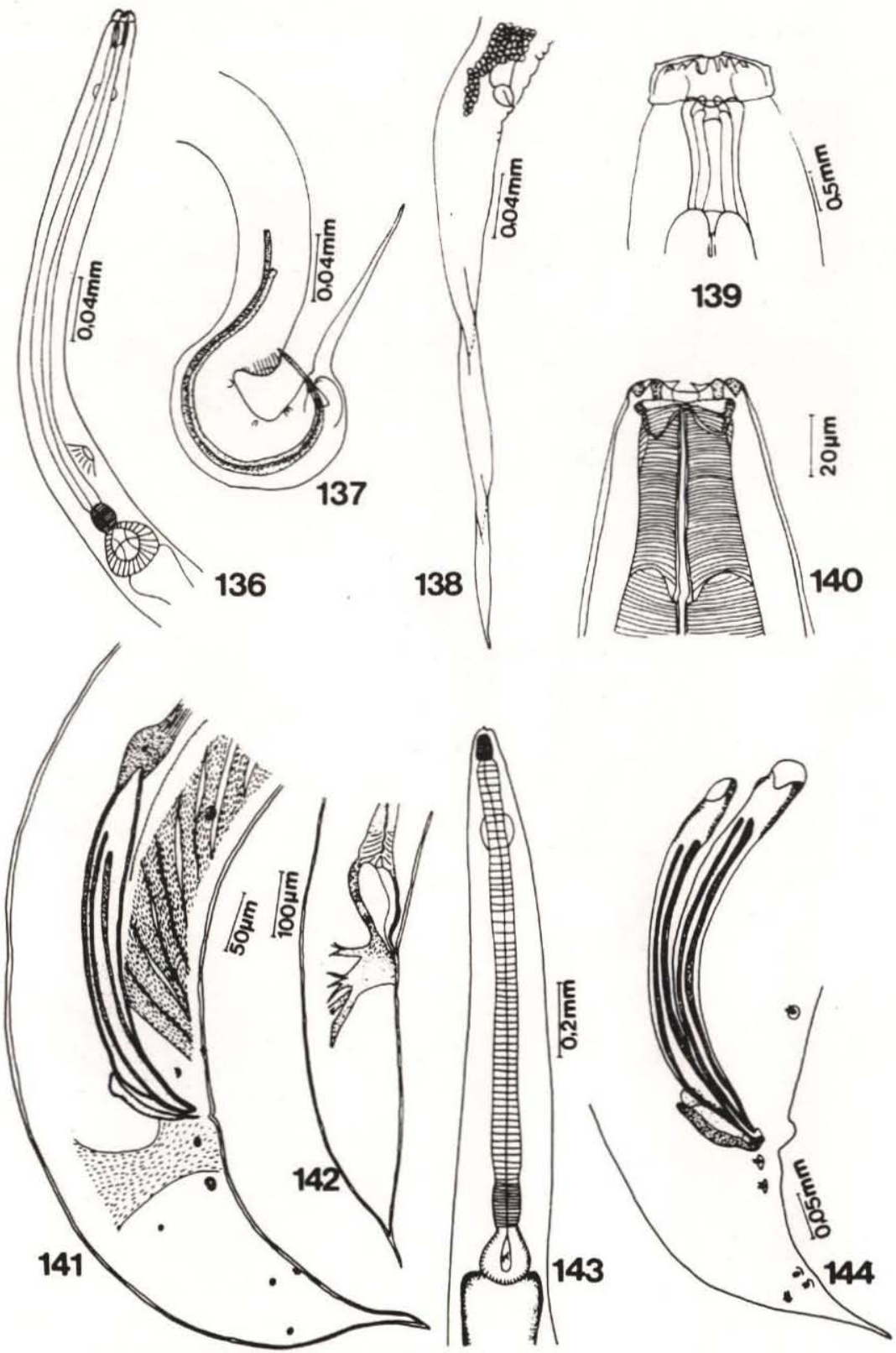

Figs 136-144. Tonaudia freitasi. (136) extremidade anterior; (137) extremidade posterior do macho, vista lateral; (138) extremidade caudal da fêmea; (139) detalhe da região cefálica (segundo Vicente \& Santos, 1968). Falcaustra belemensis. (140) Detalhe da região cefálica; (141) cauda do macho, vista lateral; (142) extremidade caudal da fêmea (segundo Baker \& Bain, 1981). F. mascula. (143) Extremidade anterior (segundo Vicente \& Gomes, 1966); (144) extremidade posterior do macho (segundo Freitas, 1955). 


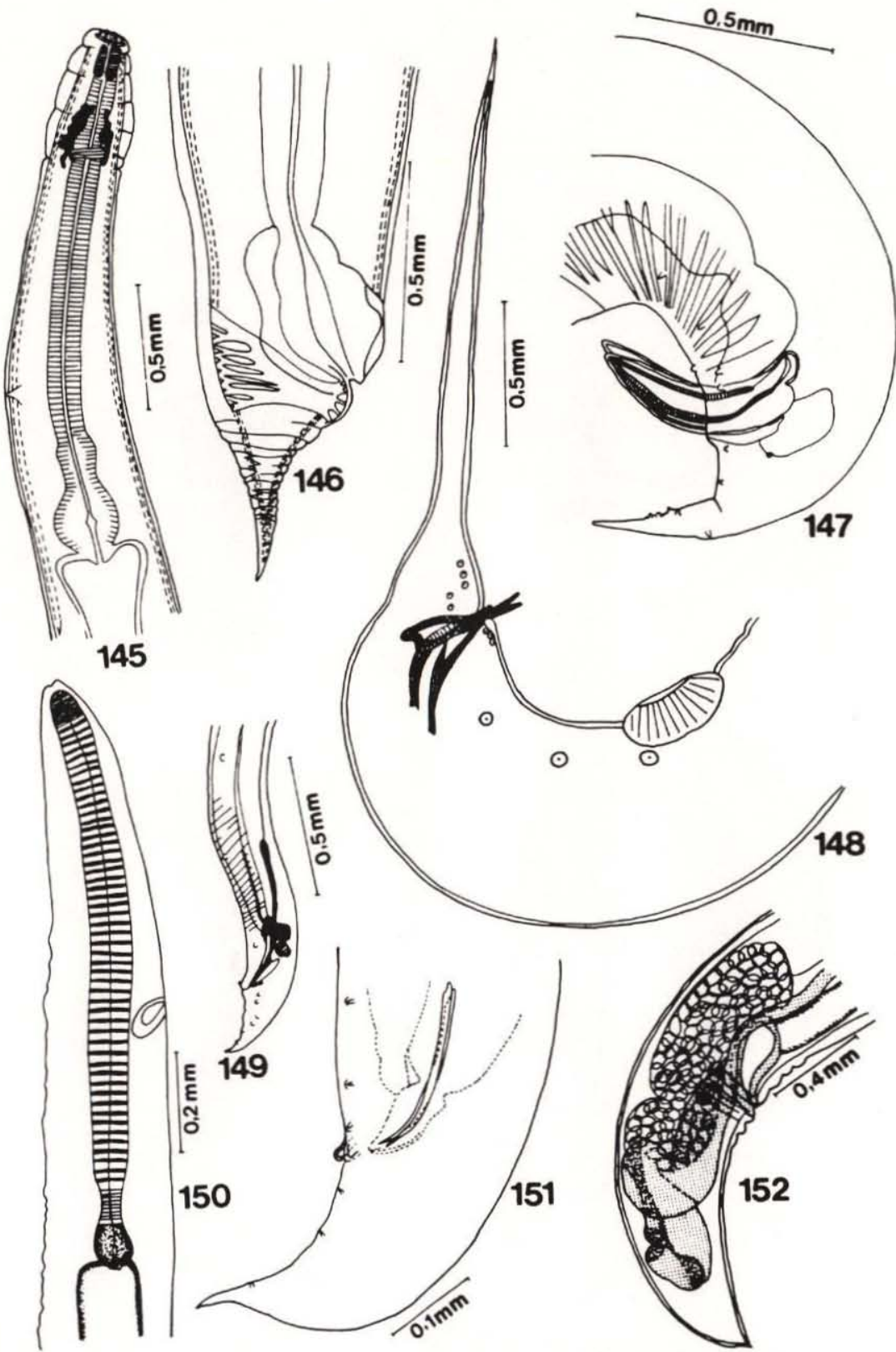

Figs 145-152. Falcaustra tikasinghi. (145) Extremidade anterior; (146) extremidade caudal da fêmea; (147) extremidade caudal do macho (segundo Schroeder, Schmidt \& Everard, 1977). Kathlania leptura. (148) Extremidade caudal do macho (segundo Travassos, 1917). Cruzia rudolphii. (149) Extremidade caudal do macho (segundo Ruiz, 1947). Oxyascaris oxyascaris. (150) Extremidade anterior; (151) extremidade caudal do macho; (152) extremidade caudal da fêmea (segundo Freitas, 1958). 


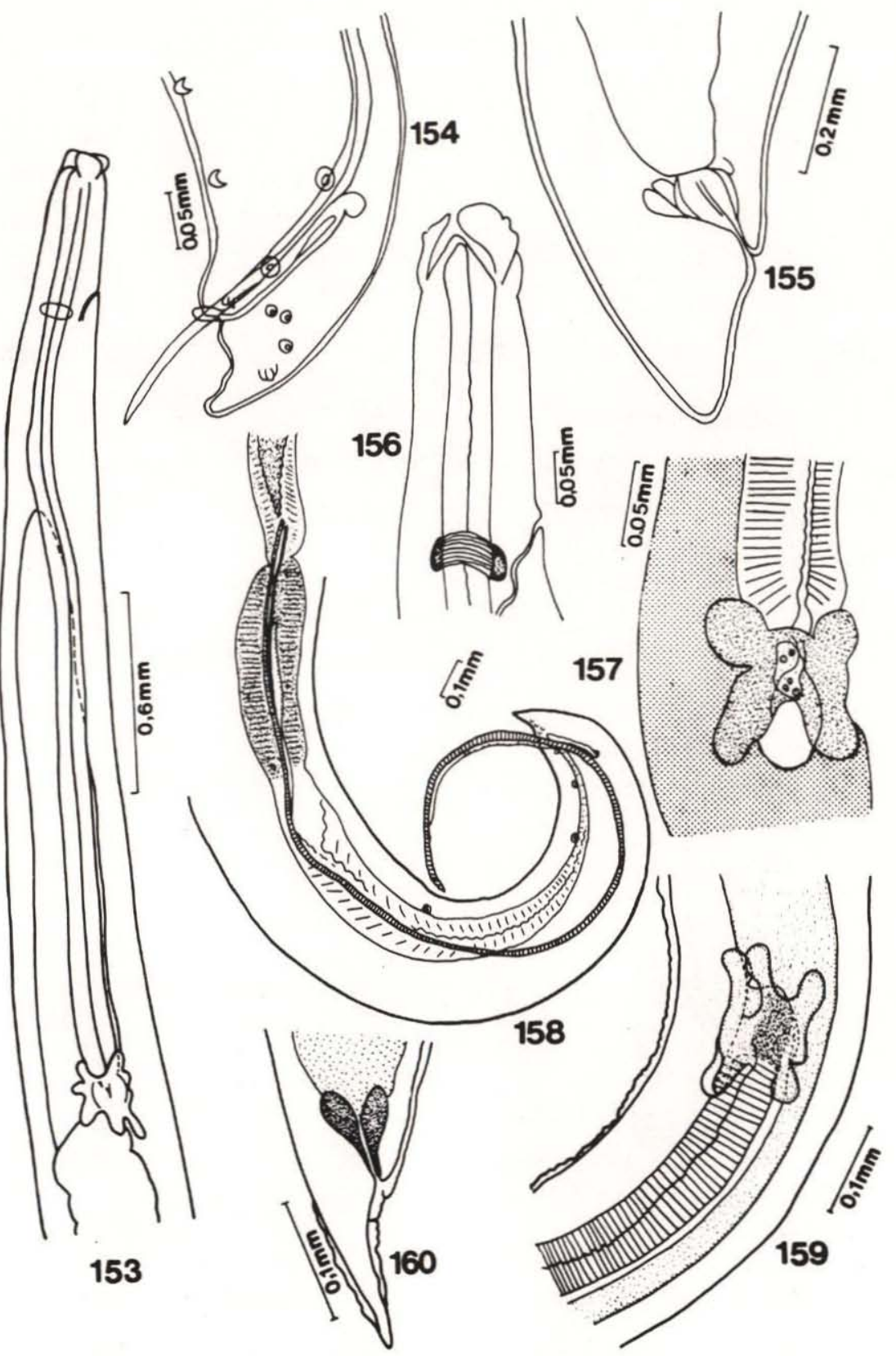

Figs 153-160. Brevimulticaecum baylisi. (153) Extremidade anterior; (154) extremidade caudal do macho; (155) extremidade caudal da fêmea (segundo Travassos, 1933). B. gibsoni. (156) Extremidade anterior; (157) região do ceco intestinal e divertículos esofageanos. B. pintoi. (158) Extremidade caudal do macho (segundo Sprent, 1979); (159) região do ceco intestinal e dos cecos esofageanos; (160) cauda da fêmea (segundo Pinto \& Barbosa, 1972). 

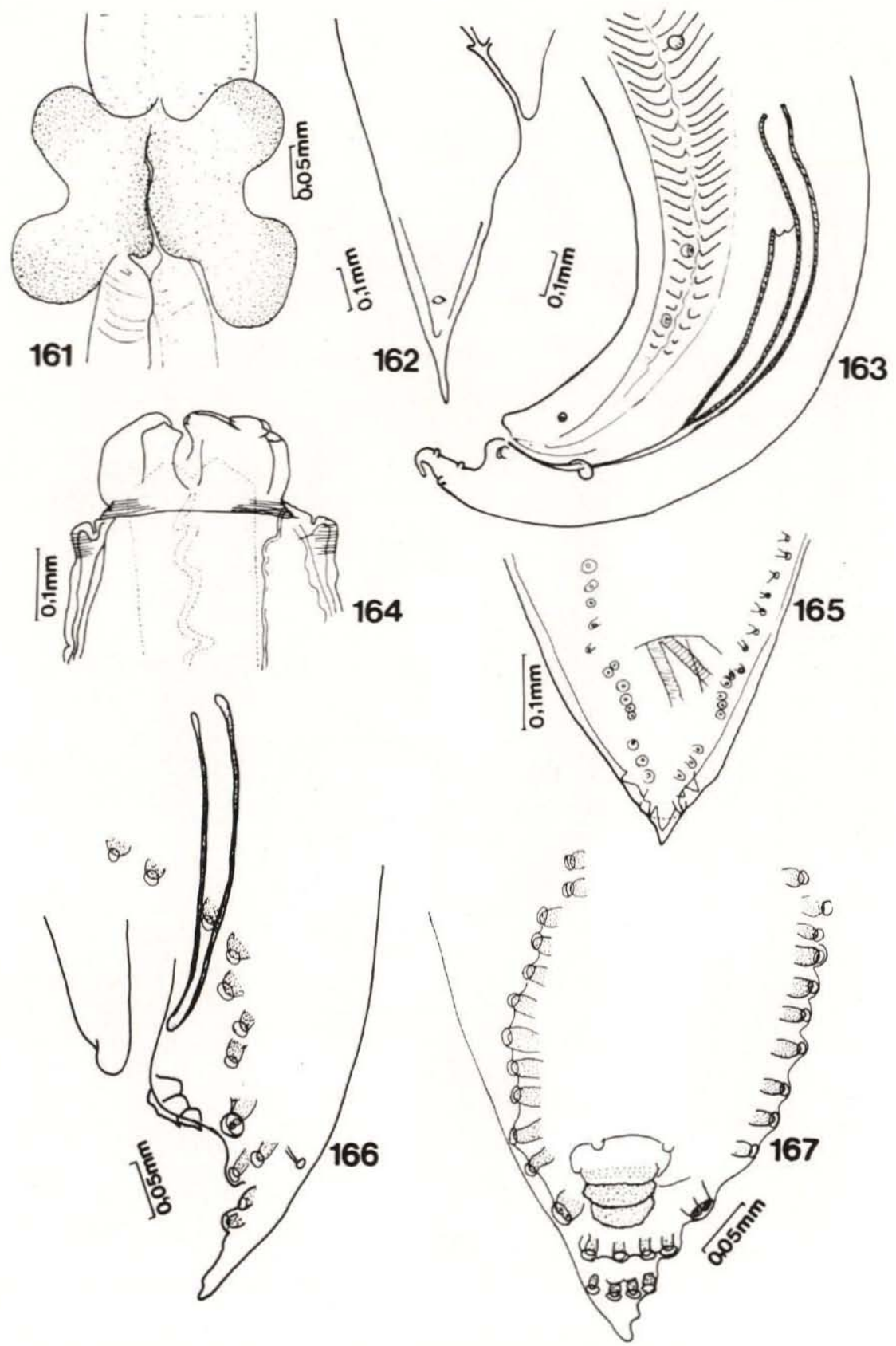

Figs 161-167. Brevimulticaecum stekhoveni. (161) Região ventricular; (162) cauda da fêmea; (163) cauda do macho (segundo Sprent, 1979). Contracaecum serpentis. (164) Extremidade anterior; (165) cauda do macho, vista ventral (segundo Araujo, 1970). Terranova lanceolata. (166) Cauda do macho, vista lateral; (167) cauda do macho, vista ventral (segundo Sprent, 1979). 


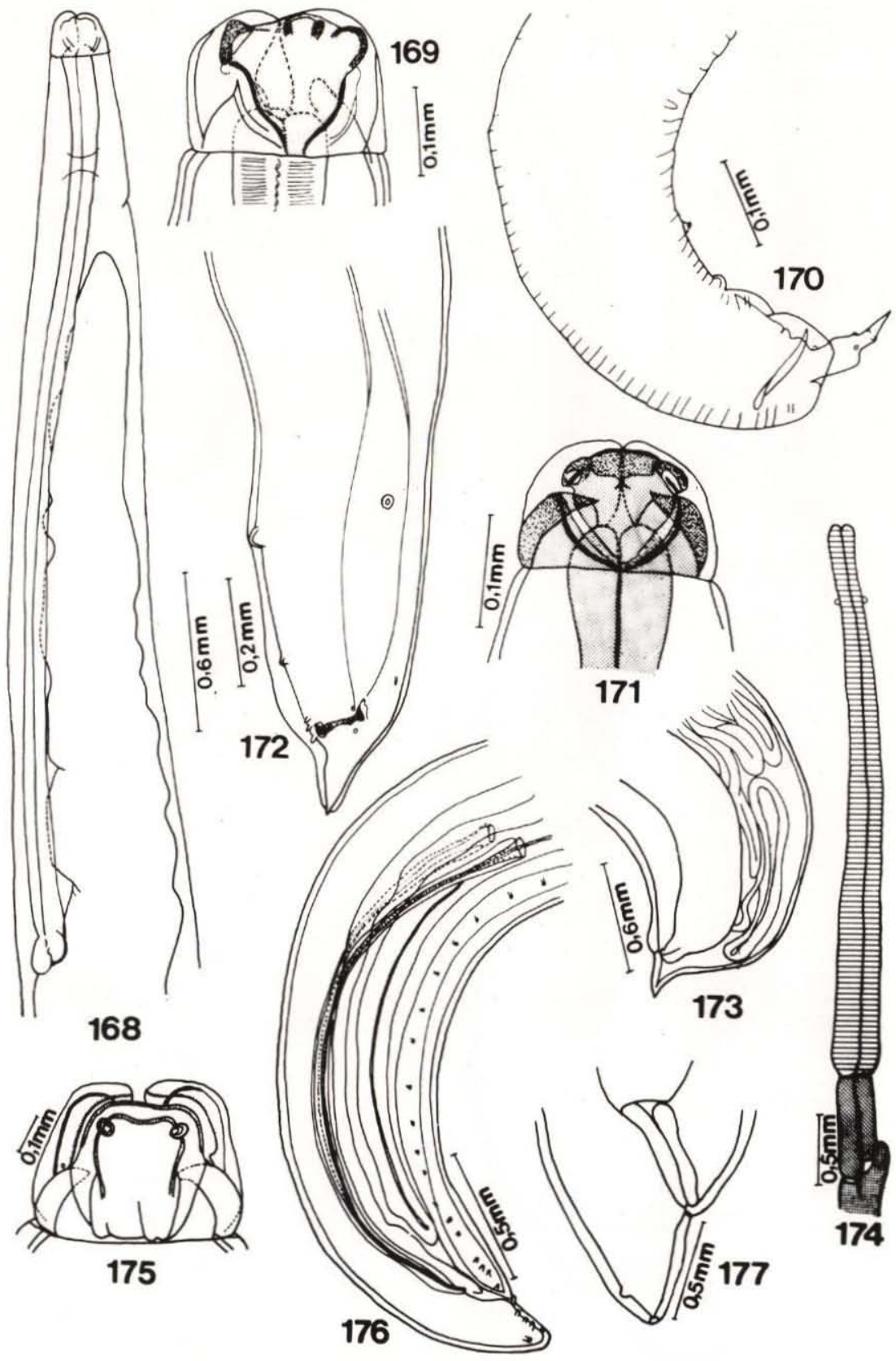

Figs 168-177. Dujardinascaris longispicula. (168) Extremidade anterior; (169) lábio dorsal; (170) cauda do macho, vista lateral. D. paulista. (171) Extremidade anterior; (172) cauda do macho, vista ventral; (173) cauda da fêmea (segundo Travassos, 1933). Sulcascaris sulcata. (174) Extremidade anterior; (175) lábios, vista dorsal; (176) cauda do macho; (177) cauda da fêmea (segundo Freitas \& Lent, 1946. 


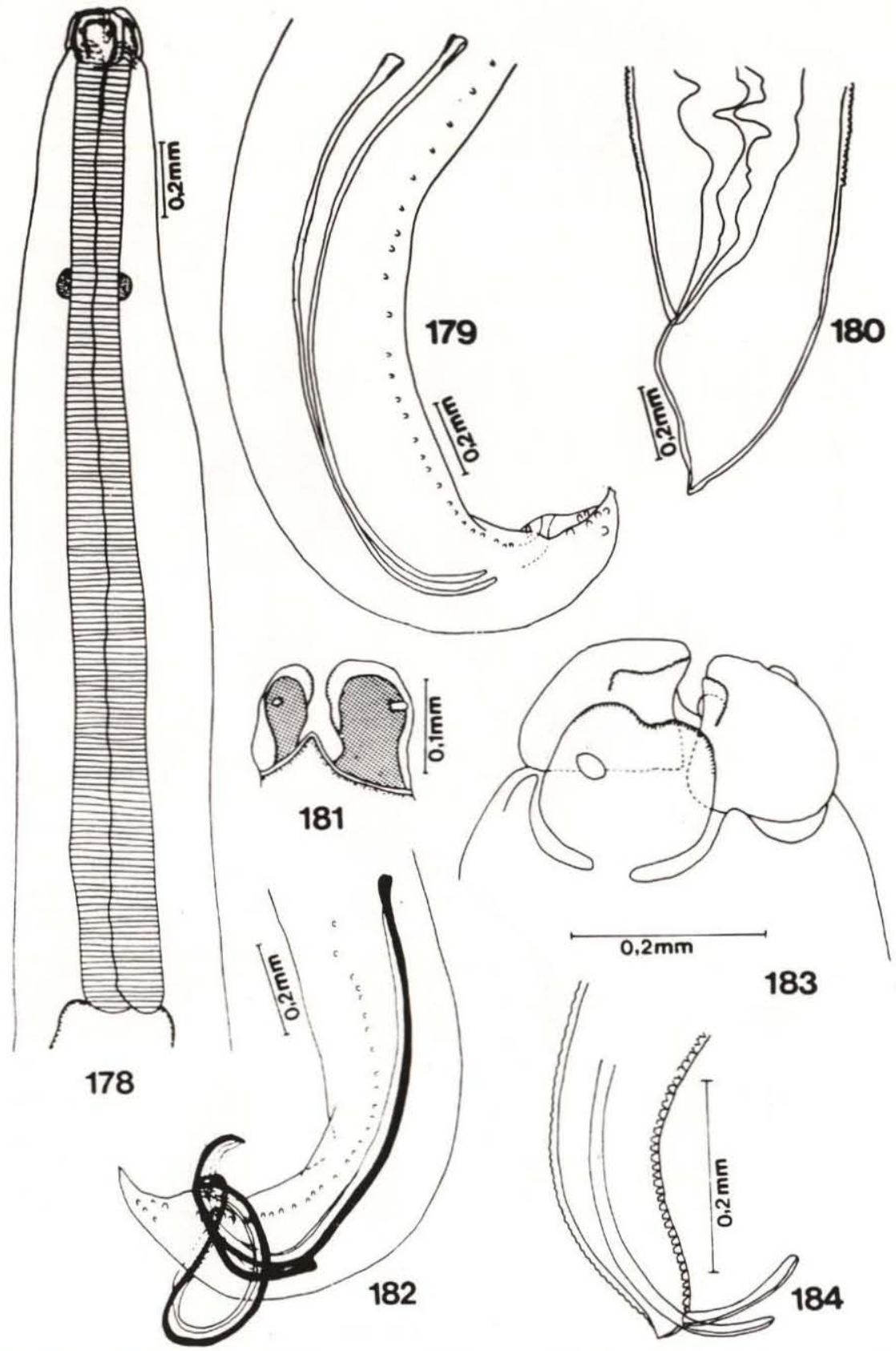

Figs 178- 184. Ophpidascaris arndti. (178) Extremidade anterior; (179) extremidade posterior do macho; (180) extremidade posterior da fêmea. O. cretinorum. (181) Extremidade cefálica; (182) cauda do macho (segundo Freitas, 1968). O. obconica. (183) Extremidade cefálica; (184) extremidade caudal do macho, vista lateral (segundo Baylis, 1916). 


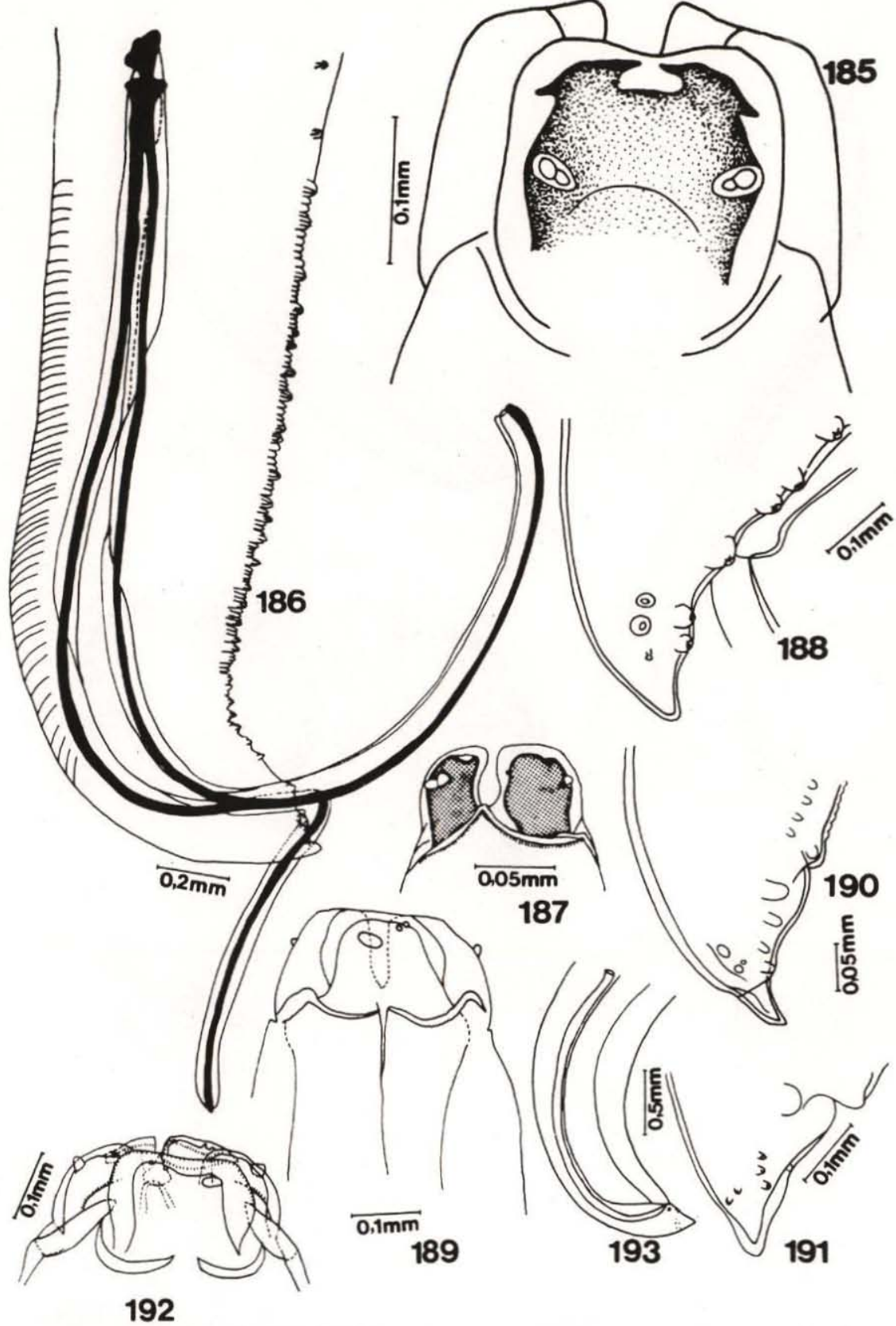

Figs 185-193. Ophidascaris sicki. (185) Extremidade cefálica; (186) cauda do macho, vista lateral (segundo Freitas, 1951). O. sprenti. (187) Lábio dorsal; (188) cauda do macho (segundo Araujo, 1969). O. travassosi. (189) Extremidade anterior, lábio ventro-lateral; (190) cauda do macho, vista lateral; (191) detalhe da extremidade caudal do macho (segundo Vaz, 1938). O. trichuriformis. (192) Extremidade cefálica; (193) cauda do macho, vista semi-lateral (segundo Freitas, 1968). 


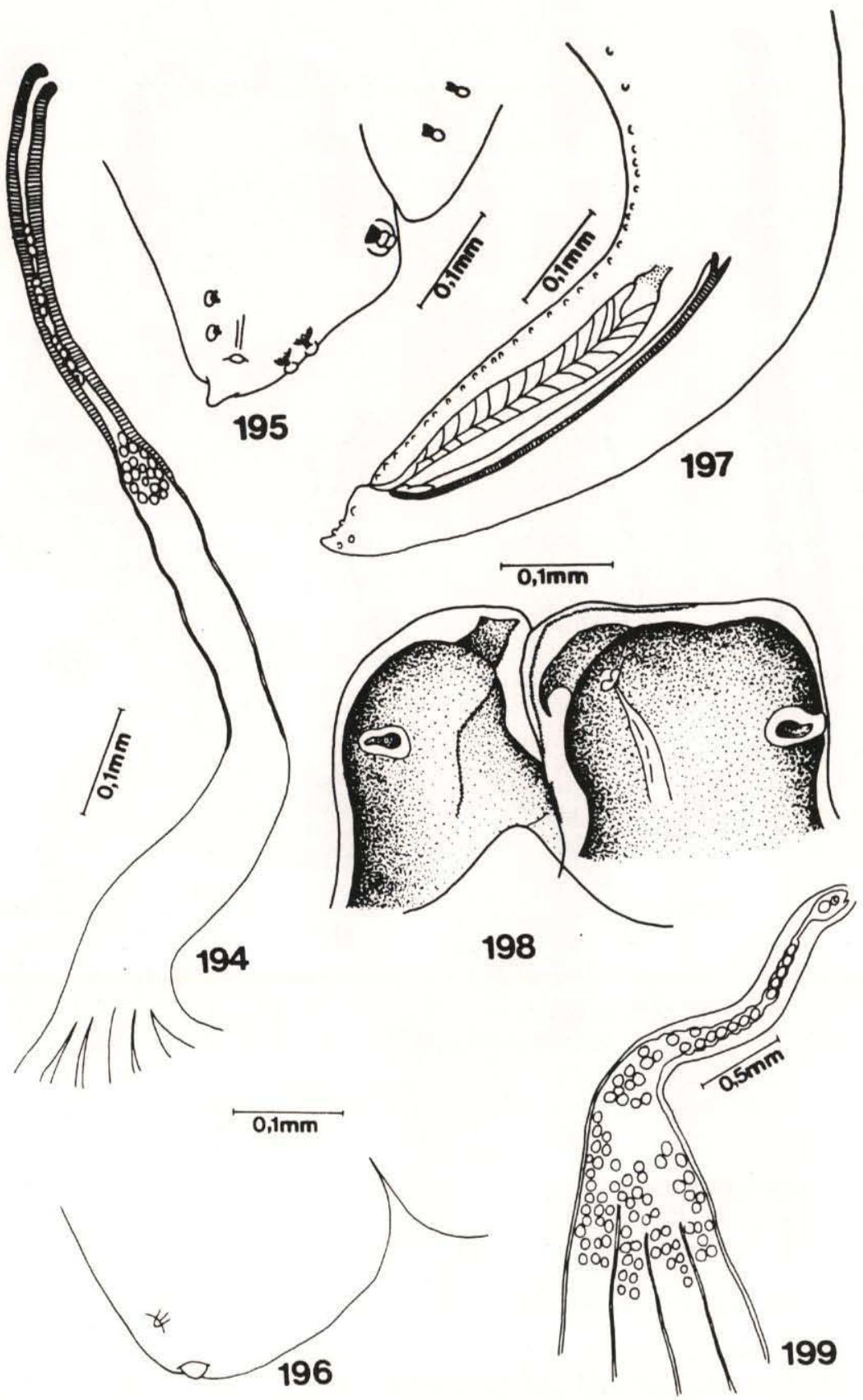

Figs 194-199. Hexametra boddaertii. (194) Vagina e útero; (195) extremidade caudal do macho; (196) extremidade caudal da fêmea. Travossosascaris araujoi. (197) Extremidade caudal do macho; (198) lábios, vista lateral; (199) vagina e útero (segundo Sprent, 1978). 


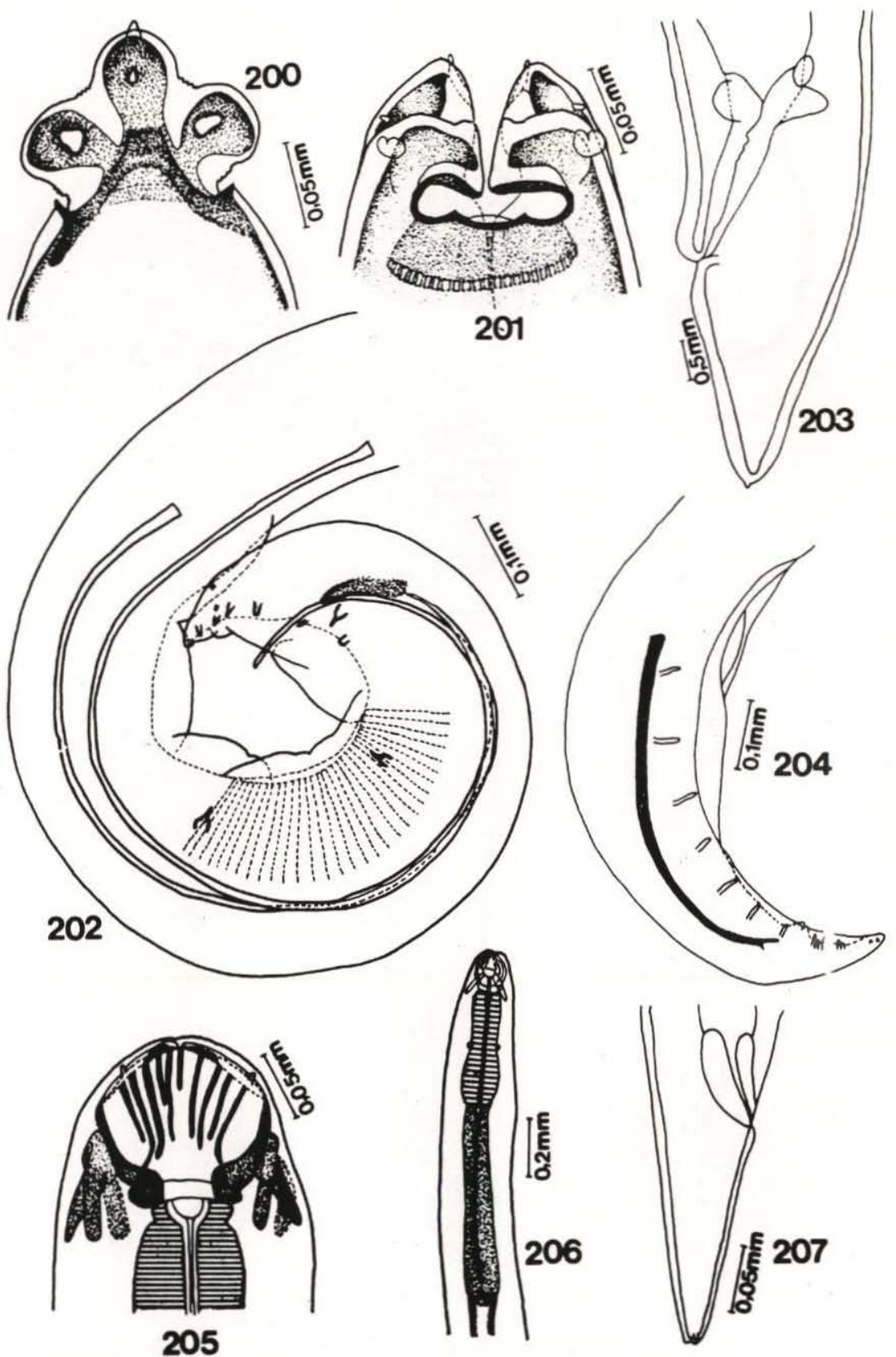

Figs 200-207. Spiroxys figueiredoi. (200) lábio, vista lateral; (201) boca, vista dorsal; (202) cauda do macho, vista lateral (segundo Freitas \& Dobbin Jr., 1962); (203) cauda da fêmea (segundo Vicente, 1966). Serpinema magathi. (204) Extremidade caudal do macho, vista lateral; (205) extremidade cefálica, vista lateral; (206) Extremidade anterior; (207) extremidade caudal da fêmea (segundo Freitas \& Dobbin Jr., 1962). 


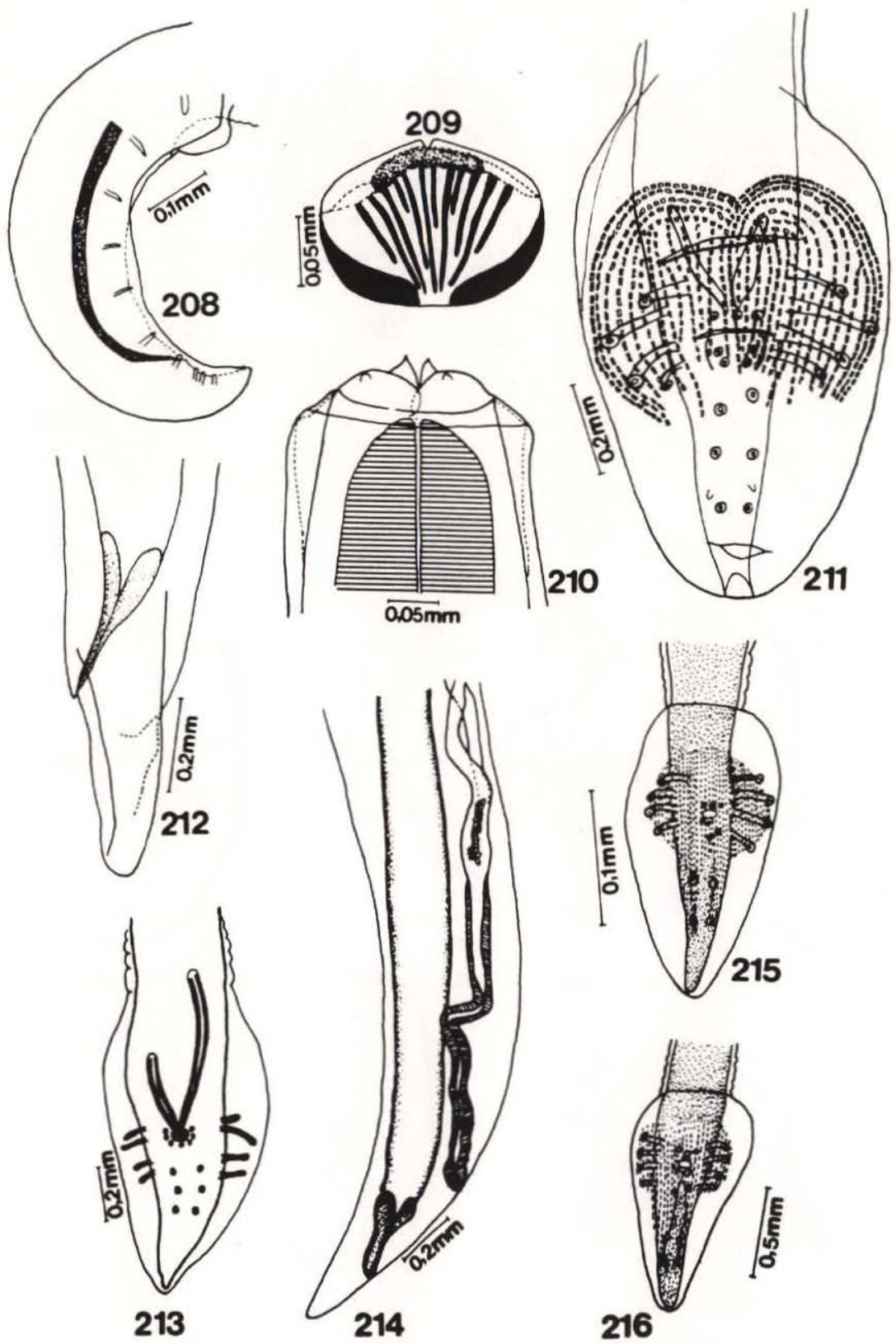

Figs 208-216. Serpinema monospiculatus. (208) Extremidade caudal do macho, vista lateral; (209) vulva (segundo Freitas \& Dobbin Jr., 1962). Physaloptera liophis. (210) Extremidade cefálica; (211) cauda do macho, vista ventral; (212) cauda da fêmea (segundo Vicente \& Santos, 1974). P. lutzi. (213) Extremidade caudal do macho; (214) extremidade caudal da fêmea (segundo Cristófaro, Guimarães \& Rodrigues, 1976). P. monodens. (215) Extremidade caudal do macho. P. obtusissima. (216) Extremidade caudal do macho (segundo Ortlepp, 1922). 

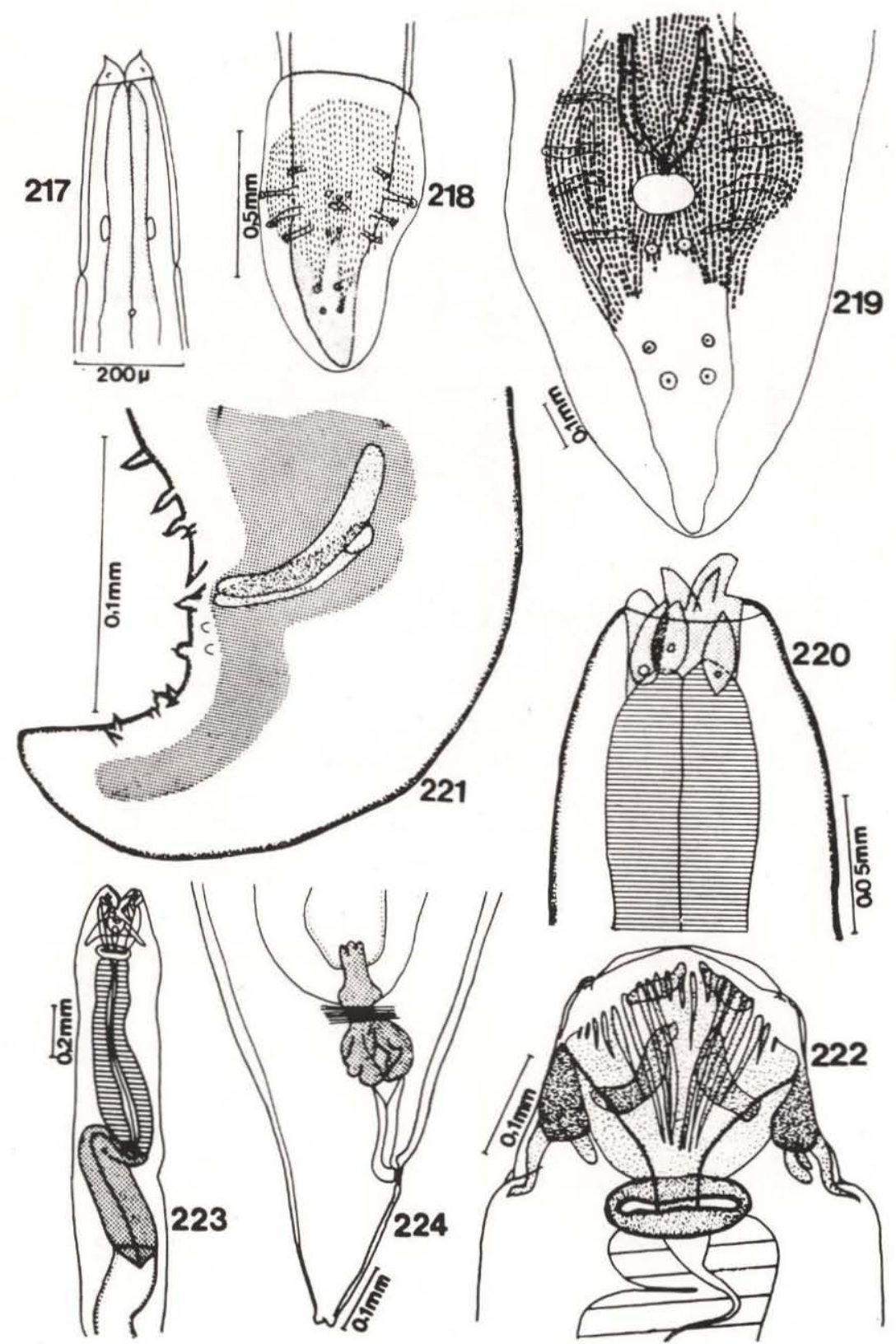

Figs 217-224. Physaloptera phrynosoma. (217) Extremidade anterior; (218) extremidade caudal do macho (segundo Ortlepp, 1922); P. retusa. (219) Cauda do macho, vista ventral (segundo Vicente \& Santos, 1967). Thubunea dactyluris. (220) Extremidade cefálica; (221) extremidade caudal, vista lateral (segundo Fábio \& Rolas, 1974). Camallanus amazonicus. (222) Extremidade cefálica, vista lateral; (223) extremidade anterior; (224) cauda da fêmea (segundo Ribeiro, 1940). 


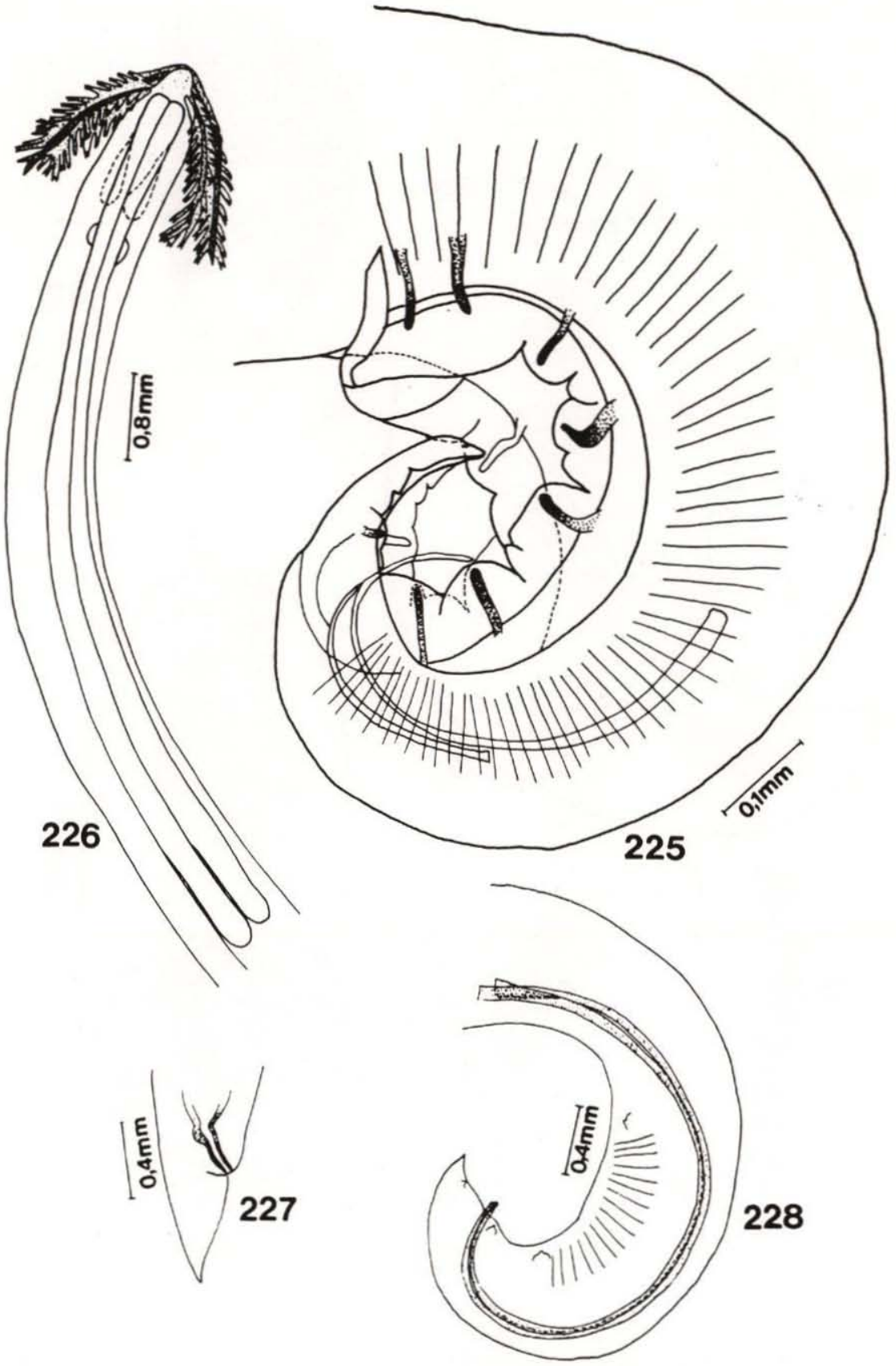

Figs 225-228. Camallanus amazonicus. (225) Cauda do macho. vista lateral (segundo Ribeiro, 1940). Ancyracanthus pinnatifidus. (226) Extremidade anterior; (227) extremidade caudal da fêmea; (228) extremidade caudal do macho, vista lateral (segundo Gomes \& Kohn, 1970). 

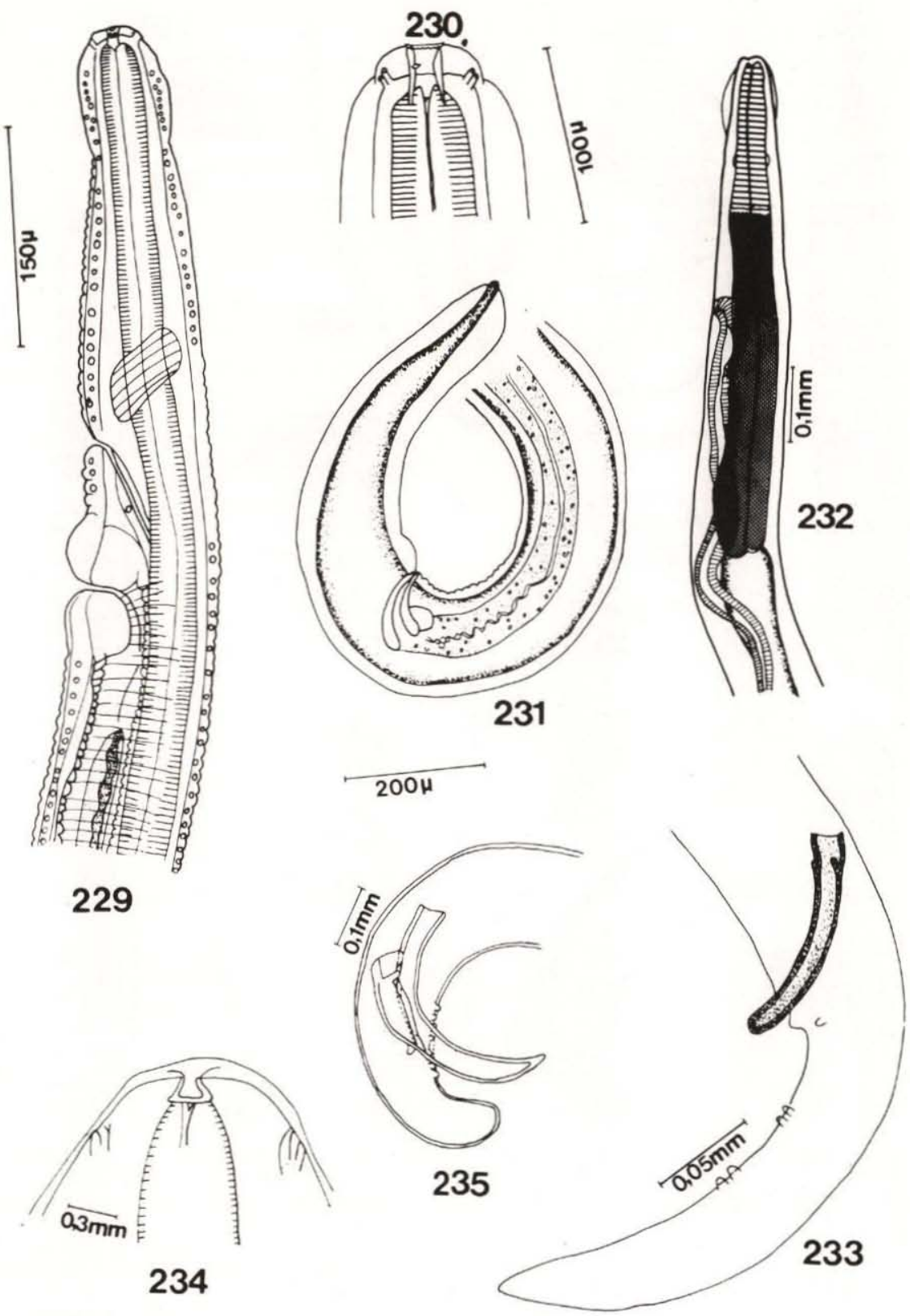

Figs 229-235. Skrjabinellazia galliardi. (229) Extremidade anterior da fêmea, vista lateral; (230) extremidade cefálica; (231) cauda da fêmea, vista latera! (segundo Chabaud, 1973). S. intermedia. (232) Extremidade anterior; (233) extremidade caudal do macho, vista lateral (segundo Vicente, 1981). Oswaldofilaria bacillaris. (234) Extremidade cefálica; (235) cauda do macho, vista lateral (segundo Travassos, 1933). 

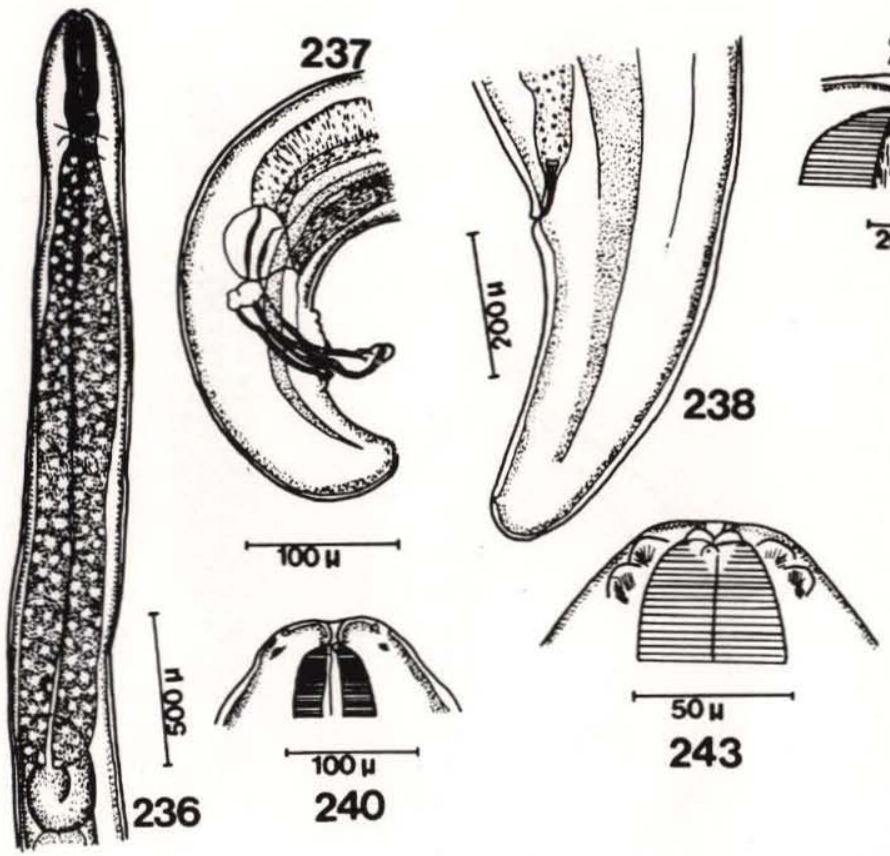

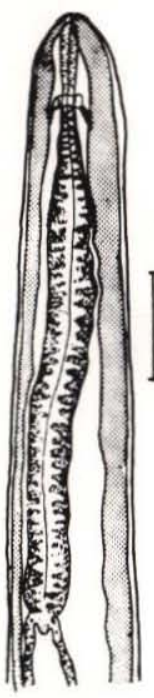

242

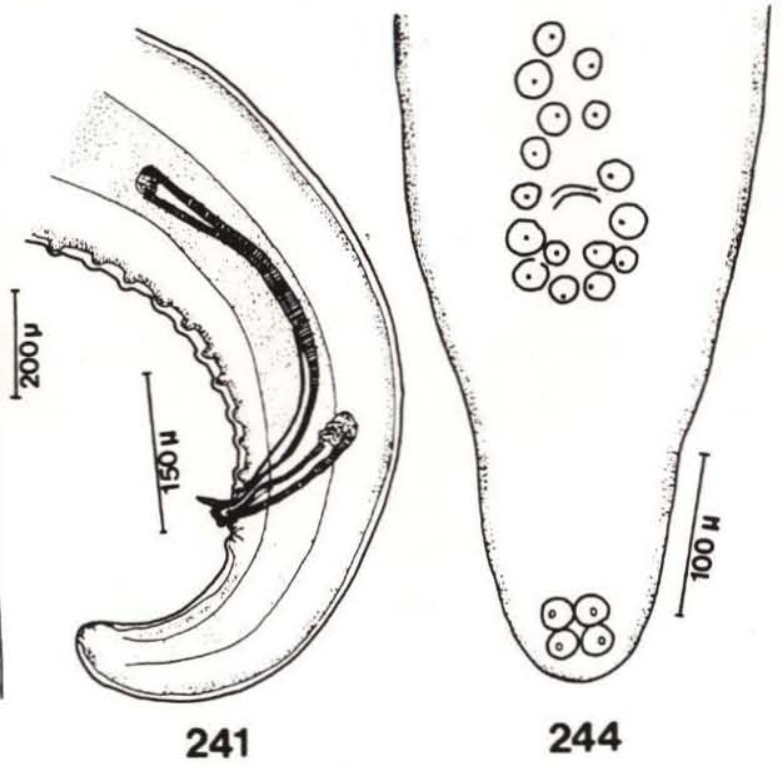

239
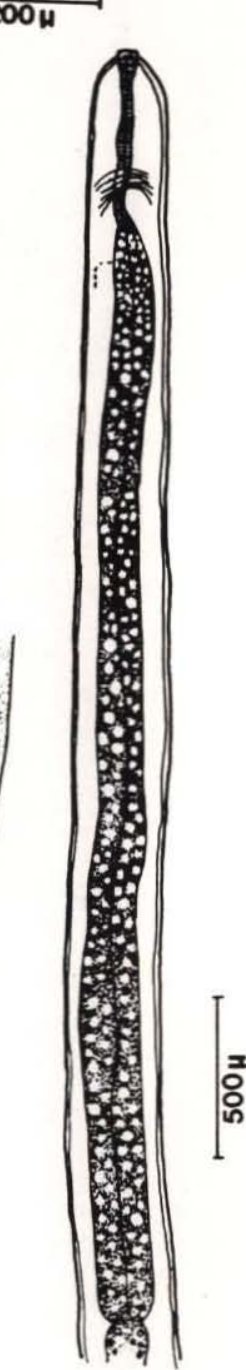

245

Figs 236-245. Oswaldofilaria azevedoi. (236) Extremidade anterior; (237) cauda do macho, vista lateral; (238) extremidade caudal da fêmea; (239) extremidade cefálica (segundo Bain, 1974). 0. belemensis. (240) Extremidade cefálica; (241) cauda do macho, vista lateral; (242) extremidade anterior. O. brevicaudata. (243) Extremidade cefálica; (244) extremidade caudal do macho, vista ventral; (245) extremidade anterior (segundo Bain \& Sulahian, 1974). 


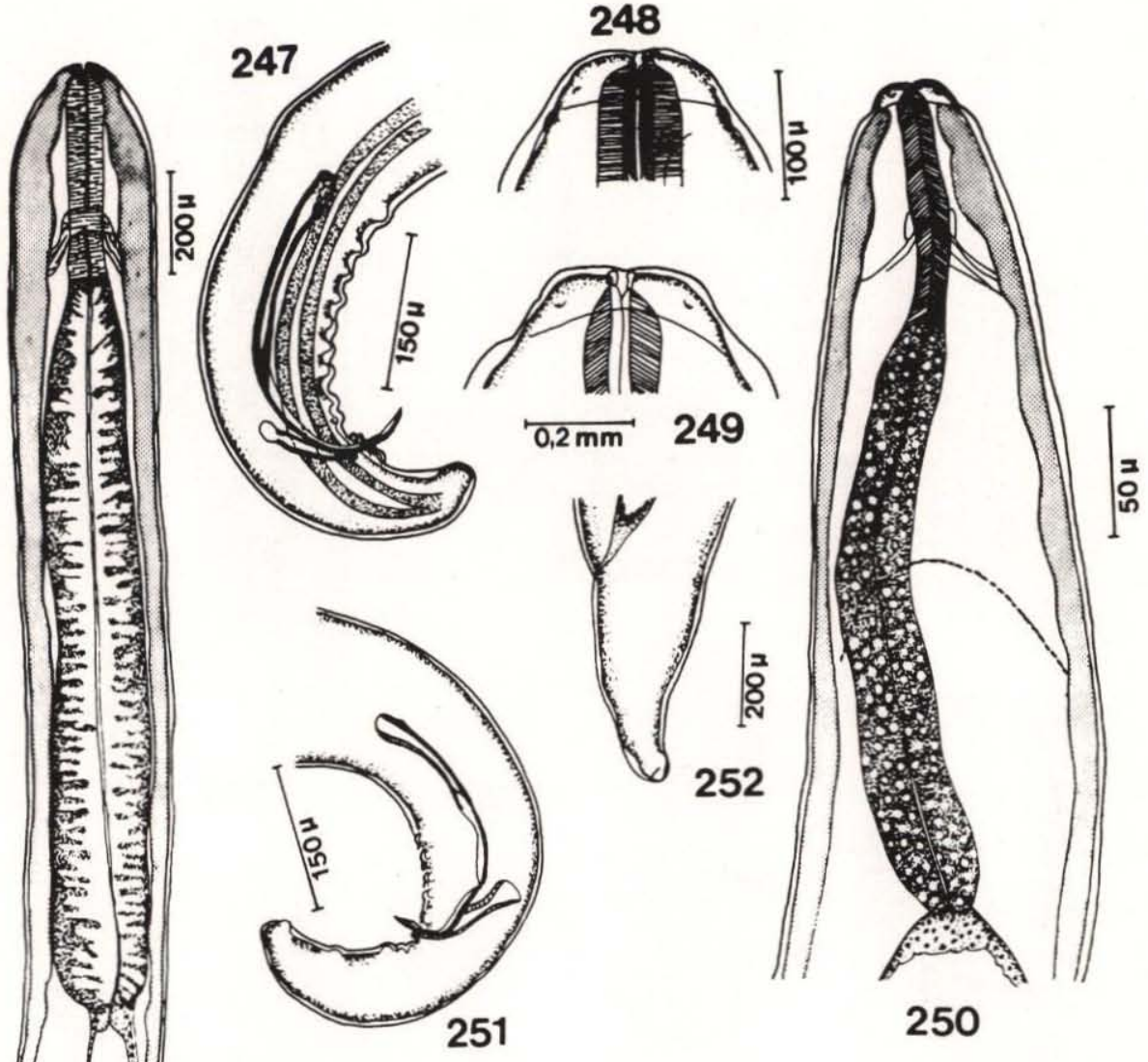

246

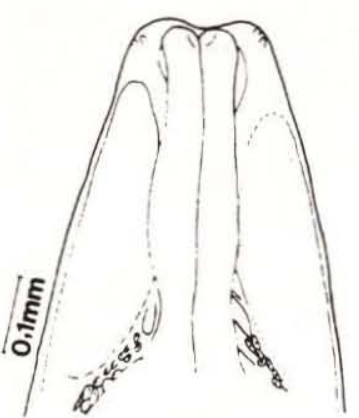

253

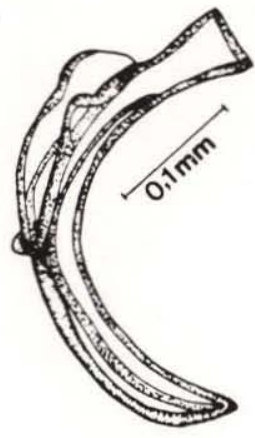

254

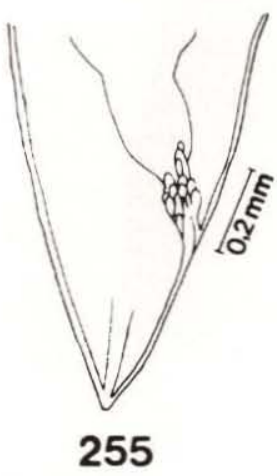

Figs 246-255. Oswaldofilaria petersi. (246) Extremidade anterior; (247) extremidade posterior do macho, vista lateral; (248) extremidade cefálica. O. spinosa. (249) Extremidade cefálica; (250) extremidade anterior; (251) extremidade caudal do macho, vista lateral; (252) cauda da fêmea (segundo Bain \& Sulahian, 1974). Micropleura vazi. (253) extremidade cefálica; (254) espículos; (255) extremidade caudal da fêmea (segundo Travassos, 1933). 

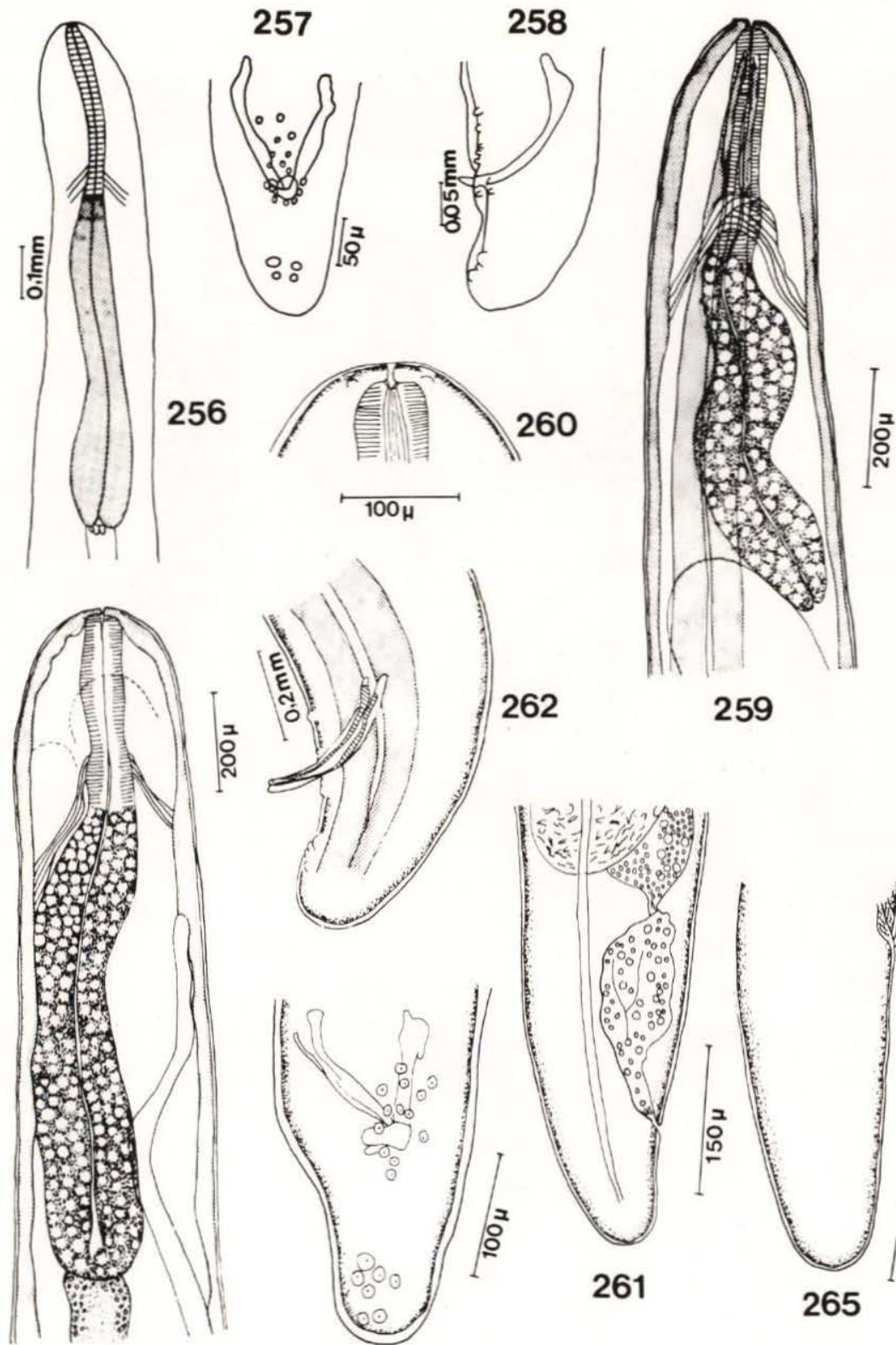

263

264
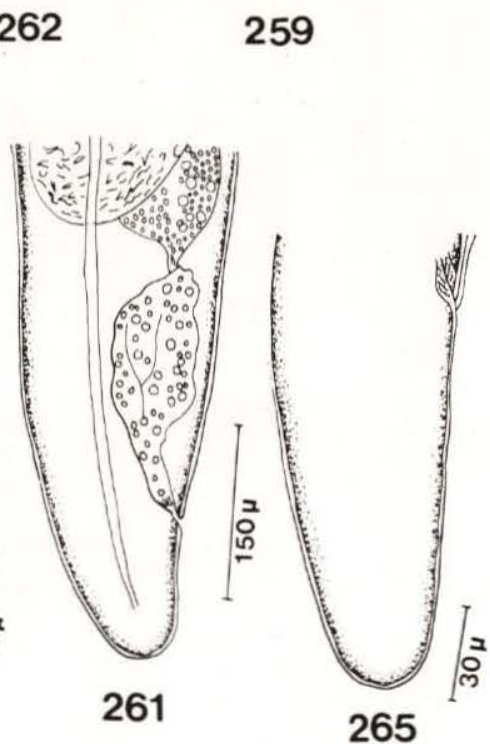

Figs 256-265. Piratuba digiticauda. (256) Extremidade anterior; (257) extremidade caudal do macho, vista ventral; (258) extremidade caudal do macho, vista lateral (segundo Lent \& Freitas, 1941). P. lainsoni. (259) Extremidade anterior; (260) extremidade cefálica; (261) extremidade caudal da fêmea; (262) extremidade caudal do macho, vista lateral. P. scaff. (263) Extremidade anterior; (264) extremidade caudal do macho, vista ventral; (265) extremidade caudal da fêmea (segundo Bain, 1974). 

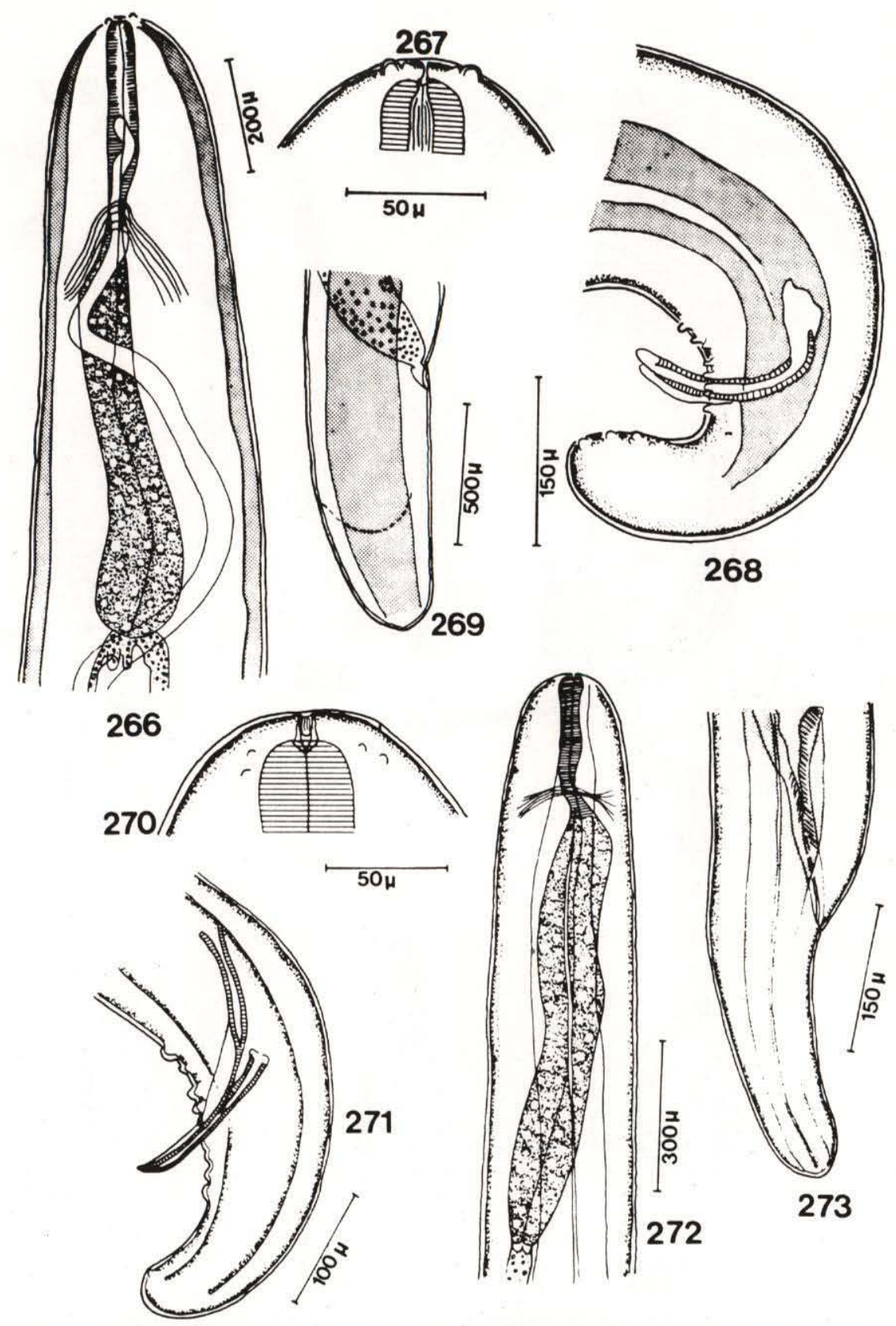

Figs 266-273. Piratuba shawi. (266) Extremidade anterior; (267) extremidade cefálica; (268) extremidade caudal do macho, vista lateral; (269) extremidade caudal da fêmea. P. zeae. (270) Extremidade cefálica; (271) extremidade caudal do macho, vista lateral; (272) extremidade anterior; (273) extremidade caudal da fêmea (segundo Bain, 1974). 

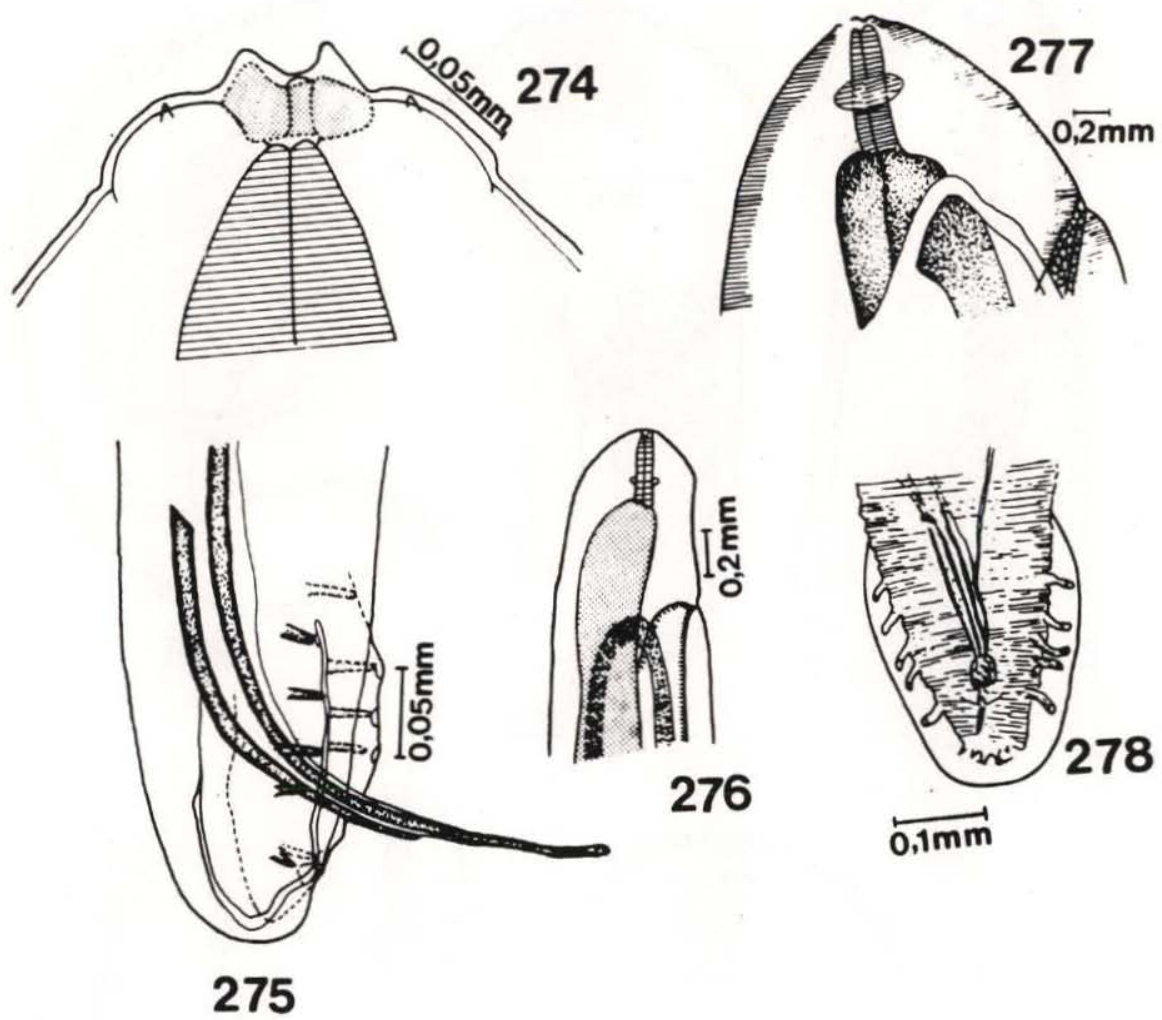

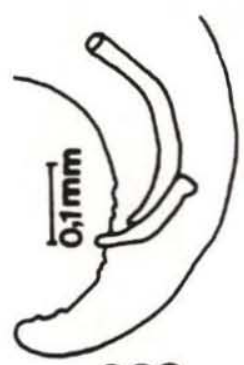

280

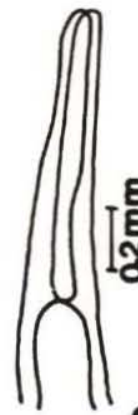

279

Figs 274-281. Hastospiculum digiticaudum. (274) Extremidade cefálica; (275) extremidade caudal do macho, vista lateral; (276) extremidade anterior (segundo Freitas, 1956). H. onchocercum. (277) Extremidade cefálica; (278) extremidade caudal do macho, vista ventral (segundo Chitwood, 1932). P. carinii. (279) Extremidade caudal do macho, vista lateral; (280) extremidade anterior (segundo Vaz \& Pereira, 1935); (281) extremidade caudal da fêmea. 

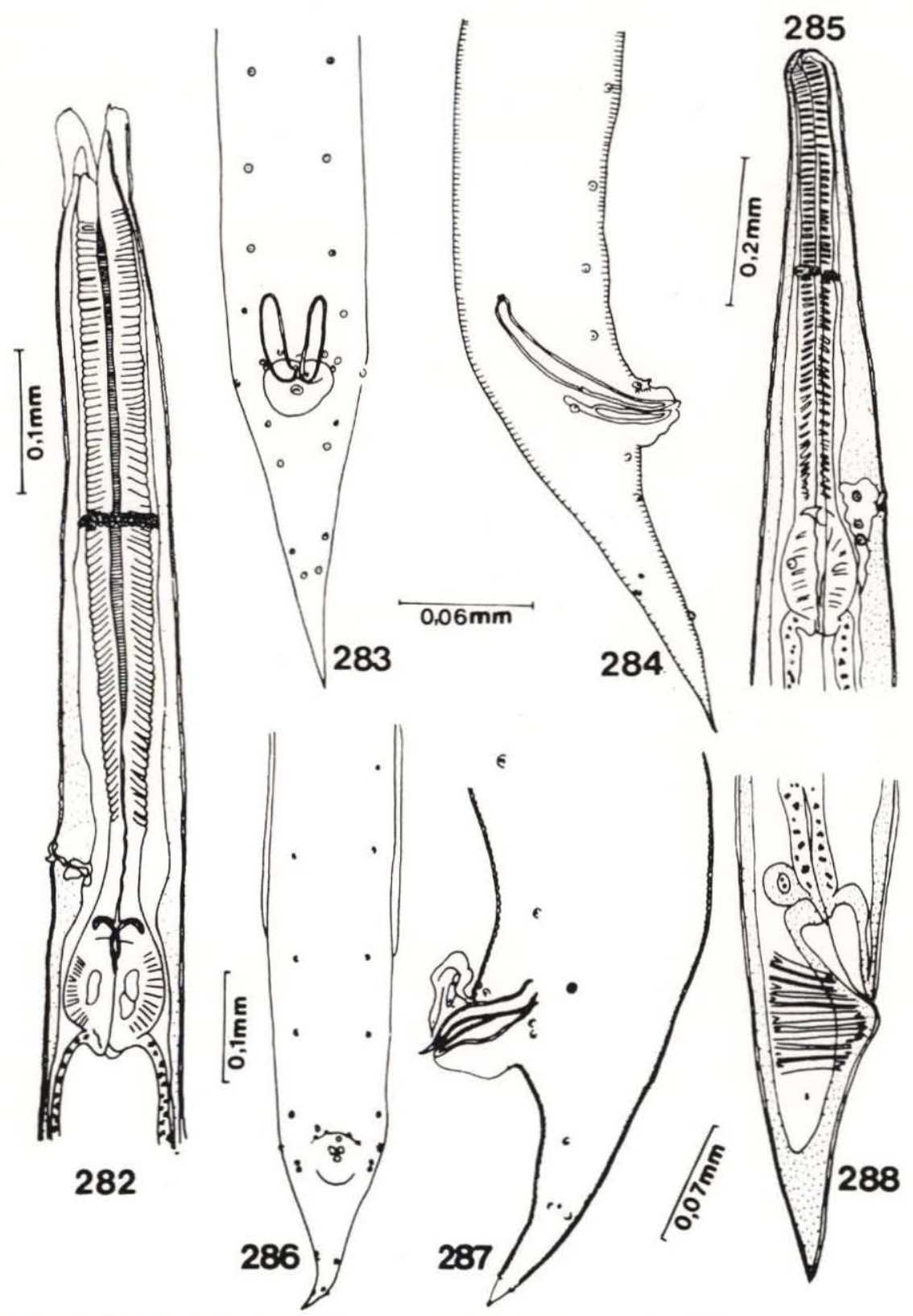

Figs 282-288. Maracaya belemensis. (282) Extremidade anterior; (283) cauda do macho, vista ventral; (284) cauda do macho, vista lateral. Aplectana albae. (285) Extremidade anterior; (286) cauda do macho, vista ventral; (287) cauda do macho, vista lateral; (288) extremidade caudal da fêmea, vista lateral (segundo Adamson \& Baccan, 1988). Figuras 283 e 284 na escala de $0,06 \mathrm{~mm}$; 287 e 288 na escala de $0,07 \mathrm{~mm}$. 


\section{ÍNDICE DOS NEMATÓIDES E RÉPTEIS HOSPEDEIROS}

acanthorhabdias, Acanthorhabdias ..........20, 21, 27, 28, 29, 30, 102, 118 acuminata, Aplectana .................................. 48 acuticauda, Multicaecum . ................................ 75 acutirostris, Polychrus ................................. 88,98

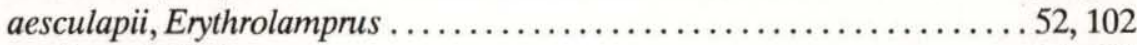
aestivus, Philodryas .................................... 103

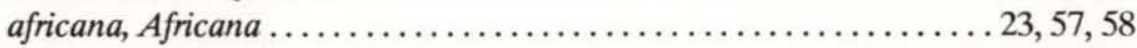
agile, Multicaecum ...................................... 76

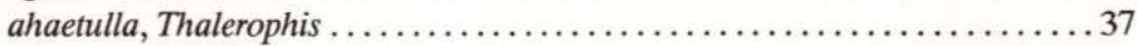

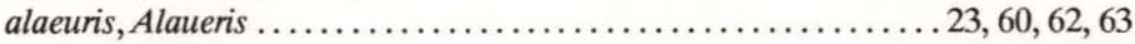

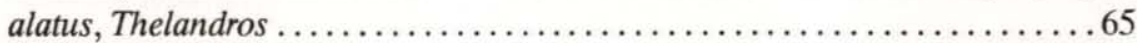
alba, Amphisbaena ............................... 45, 49, 100 albae, Aplectana ................................. 46, 49, 100, 157 Alligatoridae .......................................... 100 alternatus, Bothrops ................................... 38, 104 alvarengai, Moaciria .............................. 58, 59, 100, 138 alvarengai, Thelandros ........................ 23, 65, 67, 99, 100, 129 amarali, Capillaria .............................. 32, 59, 103, 120 amazonicus, Camallanus ..................24, 69, 83, 97, 150, 151, 165 ameiva, Ameiva ...................60, 65, 66, 67, 86, 87, 88, 89, 95, 99 Amphisbaena ................................. 45, 49, 100 amphisbaenia, Dollfusnema ....................22, 50, 51, 100, 136

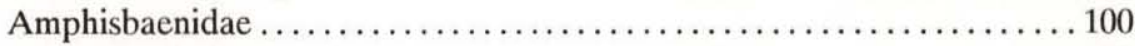

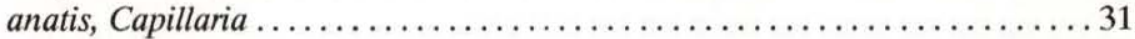
Ancyracanthus .................................... 81,82 andersoni, Bufonerakis .................................. 58 Anguidae ........................................... 99 angulatus, Helicops . . . . . . . . . . . . . . . . . . . . . 102 Angusticaecum ................................... 69, 73, 74 Anisakidae ..................................... 68, 69, 70 anoura, Polydelphis ..................................... 80

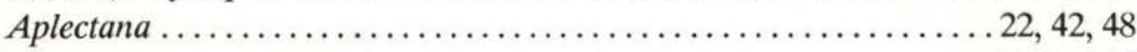
appendiculatus, Diaphanocephalus .......................... 37, 125 appendiculatus Kalicephalus .......................... 36, 37, 103 appendiculatus, Sclerostomum .....................37, 101, 102, 104 araujoi, Travassosascaris . ...................... $48,80,81,146$ arndti, Ophidascaris ......................... 24, 75, 78, 104, 144 Ascaridia .......................................... 69, 73

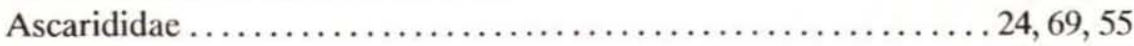
Ascaridoidea $\ldots \ldots \ldots \ldots \ldots \ldots \ldots \ldots \ldots \ldots \ldots \ldots \ldots \ldots \ldots \ldots \ldots \ldots \ldots \ldots, 23,68$ 
Atractidae $\ldots \ldots \ldots \ldots \ldots \ldots \ldots \ldots \ldots \ldots \ldots \ldots \ldots \ldots \ldots \ldots \ldots \ldots \ldots \ldots \ldots \ldots \ldots, 42,43$ Atractis ...................................... 42, 43 atrox, Bothrops $\ldots \ldots \ldots \ldots \ldots \ldots \ldots \ldots \ldots \ldots \ldots \ldots \ldots \ldots \ldots \ldots \ldots \ldots \ldots \ldots, 78,93,104$ azevedoi, Oswaldofilaria ....................... 25, 70, 93, 98, 151 bacillaris, Oswaldofilaria ..................... 25, 70, 93, 101, 151 bahiensis, Gynaecometra .......................23, 44, 61, 98, 131 baylisi, Brevimulticaecum ...................24, 56, 75, 100, 101, 141 belemensis, Falcaustra ................22, 25, 45, 46, 54, 93, 95, 99, 139 bivittatus, Dendrophidion .................................. 102

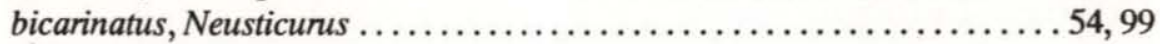
bifossatus, Dryadophis . ...................... 30, 38, 40, 56, 103 bifossatus, Eudryas .................................... 103 bifossatus, Mastigodryas ...................... 30, 37, 38, 40, 56, 103 bivittatus, Dendrophidion ............................... 101

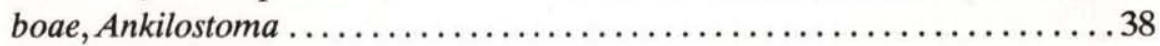
boae, Ankilostomum ........................................ 38

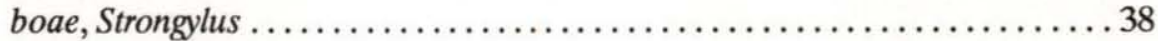

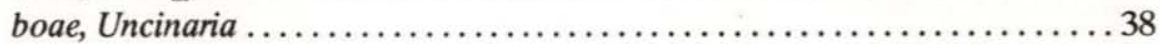
boddaertii, Hexametra .......................... 77, 78, 146 Boidae .......................................... 101 bothropis, Diaphanocephalus ................................. 37 brasiliensis, Oswaldocruzia ...................21, 34, 40, 97, 103, 122

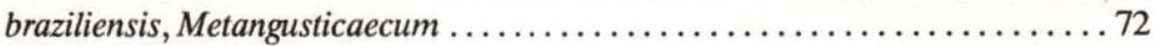
brevicaudata, Oswaldofilaria ................... 25, 60, 93, 95, 152 Brevimulticaecum ...........................24, 69, 73, 75

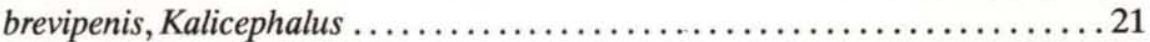
brevispiculum, Angusticaecum .................... 24, 74, 75, 96 Bufonerakis ........................................ 57, 58

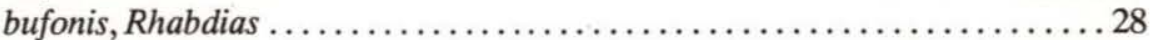

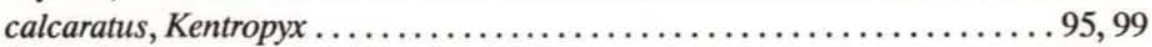
Camallanidae .................................... 83

Camallanoidea ................................ 27, 83

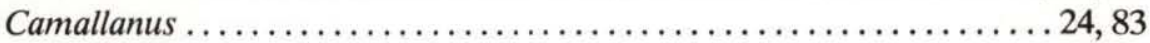
campanula, Heterakis ...................................... 59

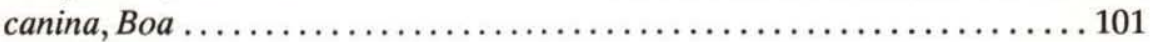
caninus, Corallus ...................................... 101

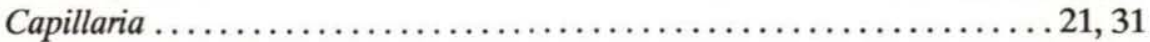
carinatus, Chironius .................................. 101 carinatus, Herpetodryas .............................. 56, 101

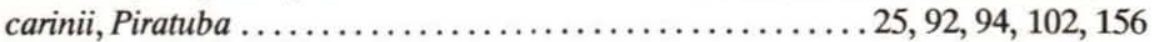
catenatus, Emyalius .............................. 40, 97 


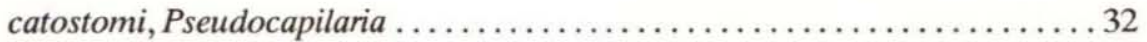
caudatus, Alaeuris ................................ 63, 64, 97, 128

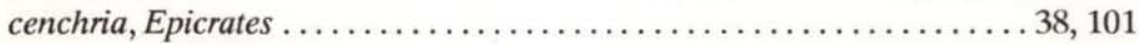
cesarpintoi, Capillaria .................................... 33 cesarpintoi, Pharyngodon ............................... 64, 66 cesarpintoi, Pseudocapillaria .....................21, 33, 34, 102, 121 chabaudi, Africana ............................... 58, 99, 138 Chapiniella ...................................... 41 Chelidae ........................................... 97

Chelonia ................................................. 57

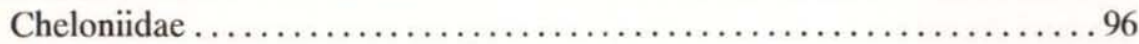

Chironius ........................................... 101

chitwoodi, Kalicephalus .................................... 38

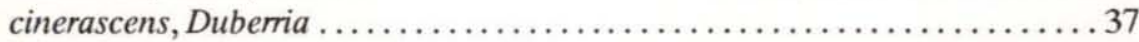

cirratus, Ozolaimus ............................ 63, 64, 98, 128

clausa, Physaloptera ..................................... 85

clelia, Clelia ........................................ 86, 101

Cobboldinidae ................................. 42, 43, 47

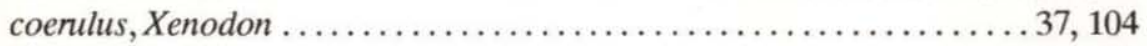

Coluber.......................................... 37, 101

Colubridae .......................................... 101

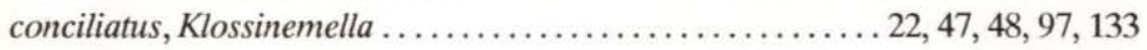

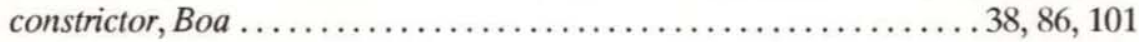

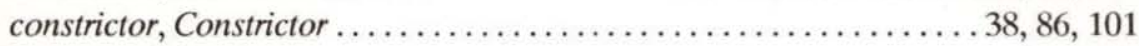

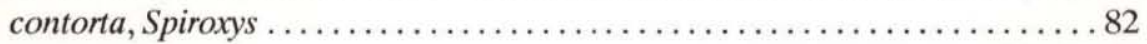

Contracaecum .................................... 68, 60

corais, Drymarchon ................................... 102

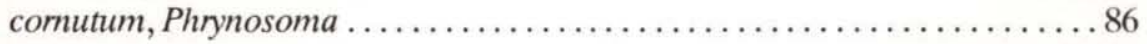

Cosmocerca ................................. 42, 48, 49

Cosmocercidae ................................. 42, 43, 47

Cosmocercoidea ................................... 26, 42

costatum, Sclerostomum ................................ 37

costatus, Diaphanocephalus . ............................... 37

costatus, Kalicephalus .................21, 37, 38, 101, 102, 103, 104, 125

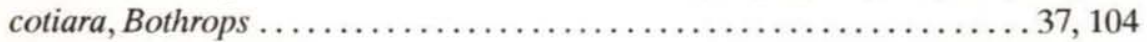

couperi, Drymarchon ................................. 102

crassus, Epicrates ................................... 37, 38, 101

cretinorum, Ophidascaris ..................... 24, 78, 79, 103, 144

Crocodilia ......................................... 100

crocodilus, Caiman .........................76, 77, 91, 92, 93, 100

crotali, Capillaria ...................................... 21 


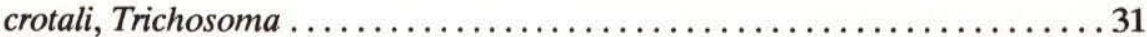

Crotalidae ......................................... 105

Crotalus ............................................. 73

cruciata, Atractis ............................ 22, 44, 100, 132

cruzi, Strongyloides ............................ 30, 97, 119

Cruzia .....................................22, 42, 52, 100

dactyluris, Atractis . ............................ 44, 87, 89, 149

decipiens, Terranova ...................................... 72

denticulata, Chelonoides ................................. 96

denticulata, Geochelone ...................... 42, 46, 47, 74, 96

denticulata, Testudo ................................... 96

Diaphanocephalidae .............................. 33

Diaphanocephaloidea ............................. 26, 33

Diaphanocephalus ............................... 21, 33, 34

diesingi, Diaphanocephalus ........................ 21, 35, 99, 123

digiticauda, Piratuba .......................... 25, 92, 94, 100, 154

digiticaudum, Hastospiculum .................... 25, 90, 91, 156

Diplotriaenidae ..................................... 89

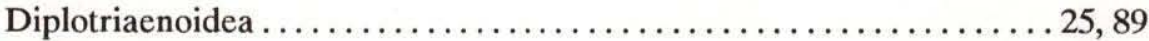

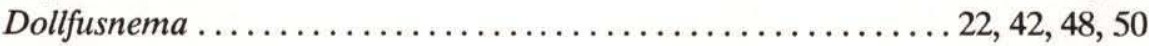

dracaena, Thorictis .................................... 99

Dracunculoidea .................................. 25, 90

dujardini, Dujardinascaris ...................... 24, 69, 73, 76

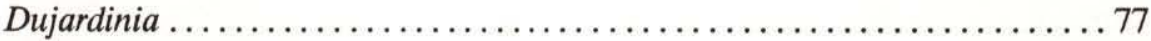

dumeriliana, Podocnemis ........................... 82, 97

durissus, Crotalus ................................... 73

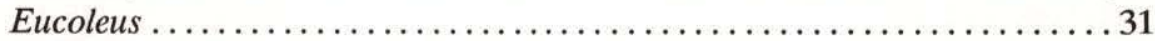

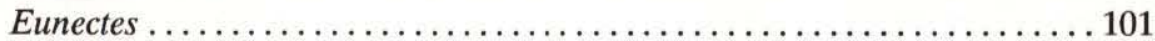

expansa, Podocnemis ........................ 47, 82, 83, 97

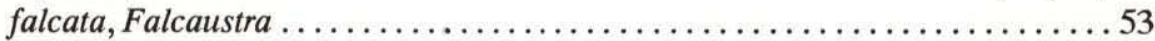

Falcaustra ........................................ 42, 52, 53

figueiredoi, Spiroxys ........................... 78, 82, 147

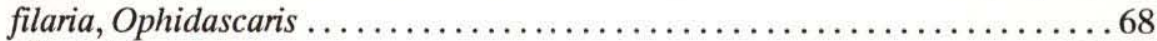

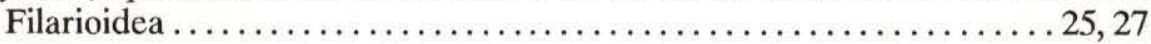

flexuosa, Ascaridia ................................ 73

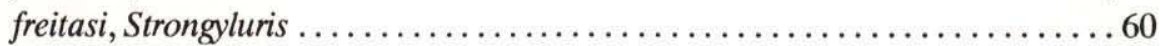

freitasi, Tonaudia ................................ 52, 54, 139

freitaslenti, Capillaria ............................ 32, 98, 120

freitaslenti, Echinocoleus . ................................. 31

freitaslenti, Eucoleus ..................................... 31

galeatum, Sclerostomum ............................... 35

Revta bras. Zool. 10 (1): 19-168, 1993 
galeatus, Diaphanocephalus ..................... 21, 35, 36, 100, 124

galliardi, Skrjabinellazia ............................ 68, 69, 97, 151

Gekgonidae .......................................... 97

Geochelone ........................................ 96

geoffroanus, Phrynops .................................... 97

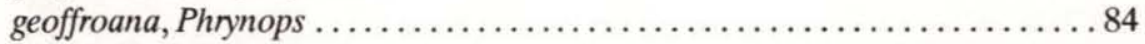

gibsoni, Brevimulticaecum ......................24, 56, 76, 101, 141

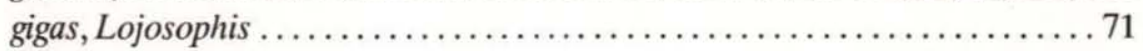

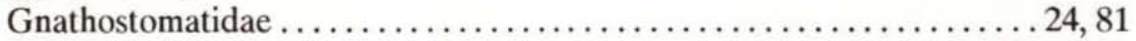

Gnathostomatoidea ........................... 24, 81

graciai, Maracaya .................................... 45

guentheri, Xenodon ...................................... 104

guianensis, Dracaena ...................................... 99

gulosa, Labduris ............................... 42, 45, 46, 96, 132

Gynaecometra .................................... 23, 60, 61

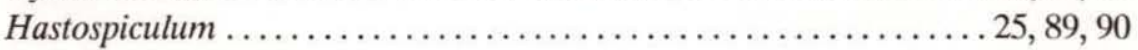

helicina, Multicaecum .............................. 76

hermafrodita, Ascaridia ............................... 73

Heterakidae ....................................... 57

Heterakoidea ................................... 23, 57

hexametra, Hexametra ............................. 24, 77

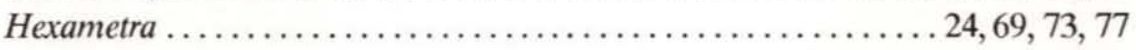

hexauterina, Hexametra ..................................... 77

holoptera, Angusticaecum .............................. 74

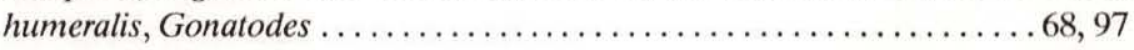

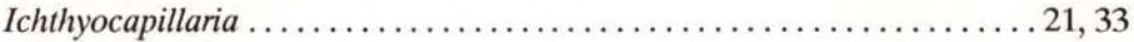

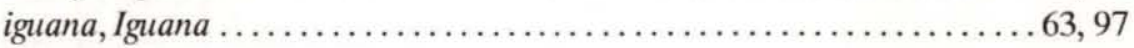

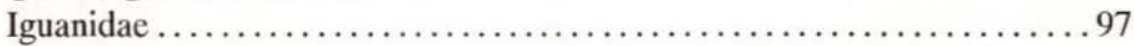

iheringi, Klossinemella ................................. 47

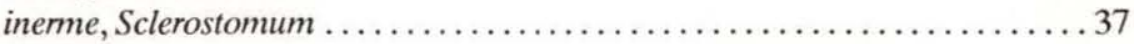

inermis, Diaphanocephalus ................................. 37

inermis, Kalicephalus . .................21, 37, 38, 101, 103, 104, 126

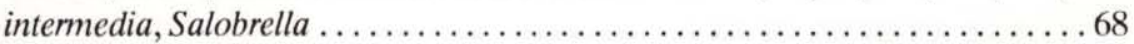

intermedia, Skrjabinellazia .....................23, 68, 70, 98, 151

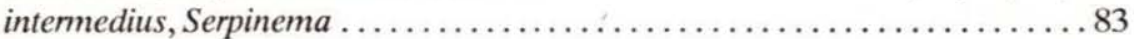

irineuta, Labiduris ................................ 42, 45, 47, 96

jacuruxi, Diaphanocephalus ........................21, 36, 99, 124

jararaca, Bothrops ..................................... 86

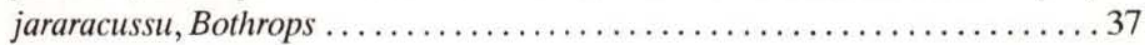

kalicephalum, Sclerostomum ............................... 37

Kalicephalus ........................... 21, 33, 36, 39, 100, 141 
Kathlania $\ldots \ldots \ldots \ldots \ldots \ldots \ldots \ldots \ldots \ldots \ldots \ldots \ldots \ldots \ldots \ldots \ldots \ldots \ldots \ldots \ldots \ldots \ldots \ldots, 42,52,53,55$

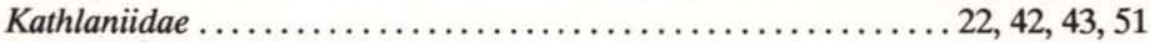

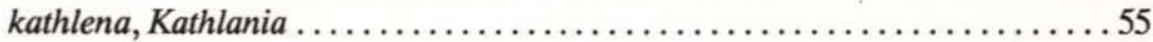

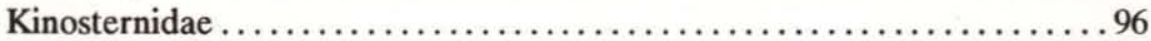

Klossinemella ............................... 42, 47, 48

labiata, Rhabdias ........................20, 28, 29, 103, 104, 117

Lacertilia ......................................... 97

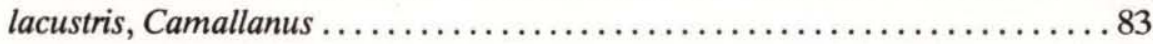

lagarda, Physaloptera ...................................... 87

lainsoni, Piratuba ....................... 94, 96, 97, 98, 154

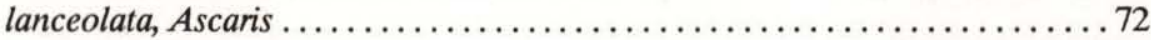

lanceolata, Terranova .......................... 24, 72, 74, 101, 142

largitor, Thelandros ........................ 65, 67, 97, 99, 130

latirostris, Caiman ................................. 100

lemniscatus, Cnemidophorus ..............................64, 99

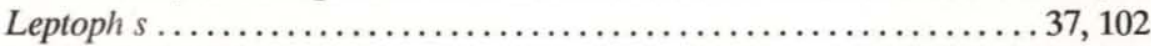

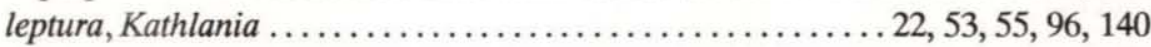

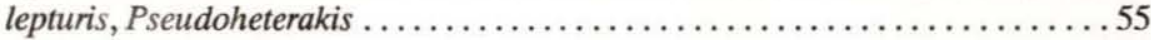

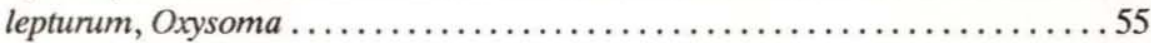

lessonae, Diploglossus . . . . . . . . . . . . . . . . . . . . . . 66, 99

liophis, Physaloptera ...................... 25, 28, 49, 85, 103, 148

longispicula, Dujardinia ........................... 74, 77

longispicula, Dujardinascaris . .................. 24, 74, 77, 100, 143

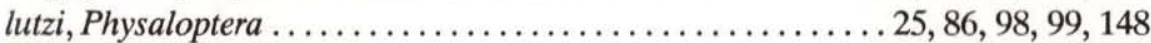

mabouia, Hemidactylus .................... 30, 40, 65, 68, 89, 97

mabouia, Mabuya ............................... 65, 94, 95, 100

maculata, Mabuya .................................. 59, 100

magathi, Camallanus .......................... 84, 85, 96, 147

Maracaya ............................ 42, 43, 45, 46, 100, 157

marmoratus, Polychrus . .......................... 93, 94, 98

mascula, Falcaustra .......................... 22, 53, 54, 102, 139

Mastigodryas ........................................ 56

mazzai, Oswaldocruzia ......................... 34, 40, 98, 122

megatyphlon, Ozolaimus .......................... 63, 64, 98, 128

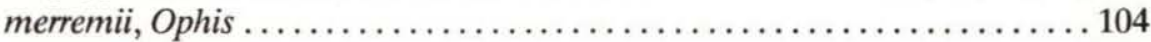

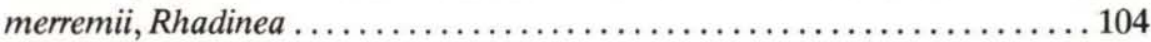

merremii, Waglerophis ................................ 104

merremii, Xenodon ............................. 78, 79, 80, 88

Meteterakis ........................................ 59

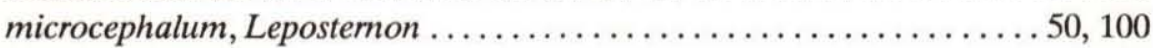

micronata, Physaloptera .................................. 87 
Micropleura $25,90,91,92,100,101$

Micropleuridae 25,90 miliaris, Liophis $28,29,32,37,38,80,85,102$ murinae, Ichthyocapillaria $33,34,136$ Moaciria $23,57,59$ Molineidae 23,39 monodens, Physaloptera $25,86,101,148$ monospiculatus, Serpinema $25,83,85,97,148$ mucronata, Physaloptera . 72,87 mucronatus, Diaphanocephalus .37 mucronatus, Kalicephalus 36,37

Multicaecum ... 76 murinae, Capillaria $34,36,101,121$

murinus, Eunectes 33, 101 muta, Lachesis 105 mydas, Chelone .96

mydas, Chelonia $55,57,71,96$ mabouia, Hemidactylus ..67 nasuta, Batrachemys 84,97

Neyraplectana .

necopinus, Oxyascaris . 56 neorectiphilus, Kalicephalus $21,38,101,103,126$ neuwiedii, Xenodon $37,49,104$ niger, Melanosuchus $72,76,93,101$ niger, Caiman 101

nigra, Champsa . 101

nigropunctatus, Tupinambis . $35,94,99$ obconica, Ophidascaris $24,79,102,144$

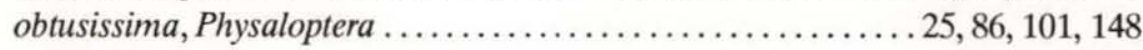
Onchocercidae. 25,92 onchocercum, Hastospiculum . $25,90,91,73,156$ Ophidascaris $24,69,73,77$

Ophidia . 78,101 ophidiae, Strongyloides $21,30,32,103,119$ ornata, Cosmocerca ................................... 50 oscari, Strongyluris .................................................. 60, 98, 99, 136

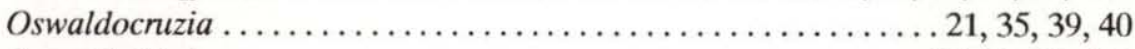
Oswaldofilaria ................................................. 92, 93, 152 oxyascaris, Oxyascaris . ................22, 42, 55, 56, 101, 102, 103, 140 Oxysomatium ....................................... 49 Oxyuridae. 


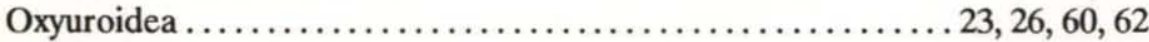

Ozolaimus ........................................ 60, 63

papillifera, Aplectana .........................22, 49, 50, 102, 104, 135

papillifera, Neyraplectana ................................ 49

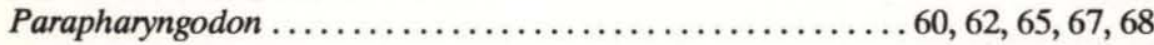

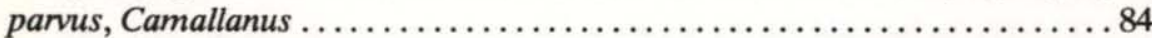

patagoniensis, Philodryas .............................. 38, 103

paulista, Dujardinascaris ....................... 24, 74, 77, 100, 143

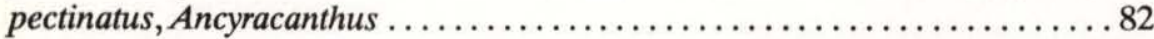

Pelomedusidae ....................................... 97

petersi, Oswaldofilaria ......................... 25, 94, 95, 99, 153

Pharyngodon .................................... 64, 65, 98, 129

Pharyngodonidae ................................. 60, 61

philodryadus, Kalicephalus ................................... 37

Philodryas ....................................... 28, 88, 103

phocaena, Lepostermon ............................. 50, 100

phrynosoma, Physaloptera ......................... 85, 87, 149

Physaloptera .................... 25, 84, 85, 87, 88, 98, 99, 100, 103, 104

Physalopteroidea $\ldots \ldots \ldots \ldots \ldots \ldots \ldots \ldots \ldots \ldots \ldots \ldots \ldots \ldots \ldots \ldots \ldots \ldots \ldots \ldots \ldots \ldots \ldots, 27,84$

Physalopteridae ............................. 84, 88, 97

pinnatifidus, Ancyracanthus . ....................24, 69, 82, 97, 150

pintoi, Brevimulticaecum ......................24, 72, 76, 100, 141

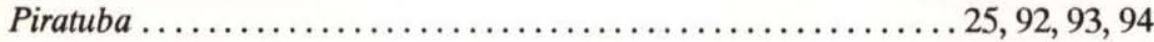

poecilogyrus, Leimadophis . ....................... $33,54,56,102$

Polydelphis .................................. 69, 73, 80

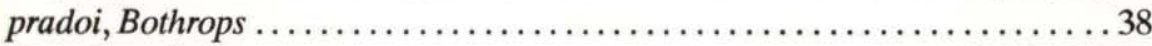

Pseudocapilaria .................................... 21, 31, 32, 33

pudica, Thubunacea ...................................... 88

pullatus, Spilotes ........................................ 103

punctatus, Anolis ................................. 94, 97

punctularia, Geomyda ................................ 96

pusilla, Aplectana ............................... 22, 46, 49, 100, 134

pusillum, Oxysomatium ................................... 49

quadrangularis, Ascaris ............................. 77,81

quadricomis, Hexametra .............................. 87,8

raillieti, Aplectana ........................... 22, 46, 49, 100, 134

rara, Cosmocerca .............................22, 50, 100, 136

rectiphilus neorectiphilus .............................. 38,141

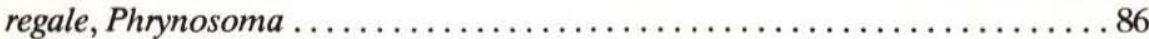

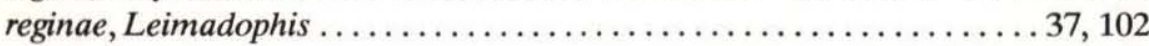

retusa, Physaloptera ......................... 25, 87, 98, 100, 149 
retusa, Spiroptera

Rhabdias $20,27,38$

Rhabdiasidae 20,27

Rhabditoidea $20,26,27$

Rhadinea 28

rhinostoma, Simophis $37,38,104$ rhombeata, Lachesis 105 rodriguesi, Bufonerakis $23,51,59,103,137$ rodriguesi, Meteteraklis

rudolphii, Cruzia $22,52,53,102,140$ sai, Strongyluris 60

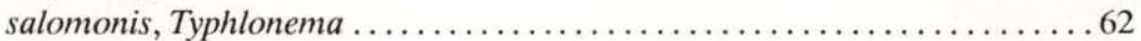

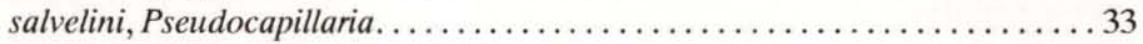
sauricola, Sauricola ...................... 39, 41, 42, 96, 127 scaffi, Piratuba ......................... 95, 96, 99, 154

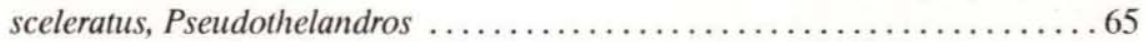
sceleratus, Thelandros ................. 23, 65, 67, 97, 98, 99, 130 schottii, Leimadophis ....................... 37, 102 Scincidae 100 scorpioides, Kinosternon $82,84,96$ scutipunctatus, Tapinurus ...................... 66, 98

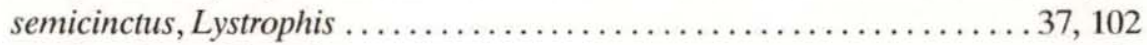

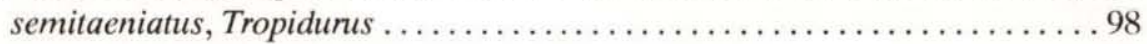

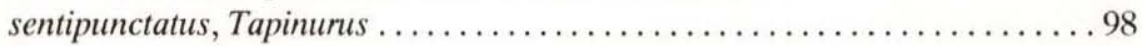

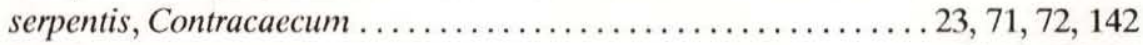
Serpinema ................... 25, 83, 84, 96

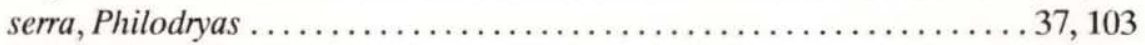

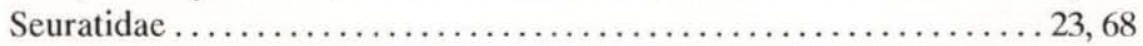

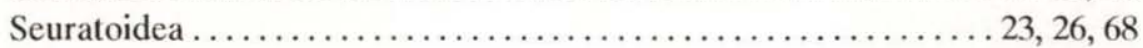
severus, Xenodon ......................... 78, 79, 104 shawi, Piratuba ..................... 96, 95, 96, 99, 155 sicki, Ophidascaris .................... 79, 104, 145

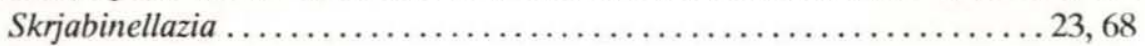

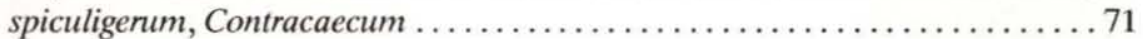

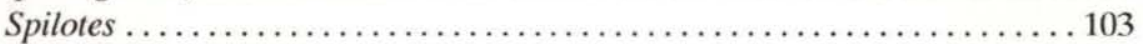

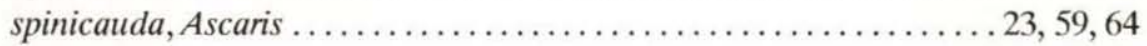
Spinicauda $23,57,58,59,99,100,137$ spinosa, Oswaldofilaria .......................... 92, 94, 100, 153

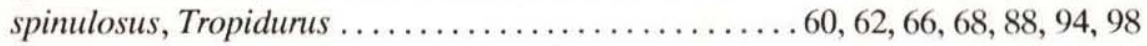

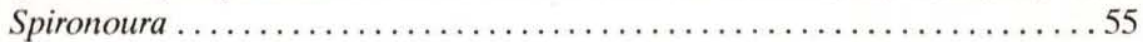

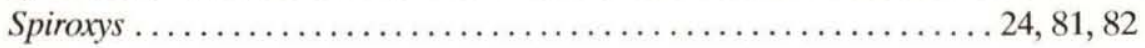




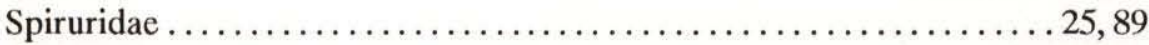

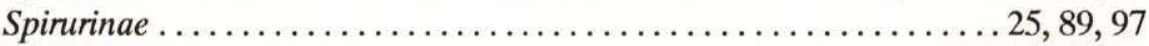

Spiruroidea ....................................... 27, 89

sprenti, Ophidascaris .......................... 79, 81, 145

stekhoveni, Brevimulticaecum ................24, 72, 76, 100, 101, 142

stekhoveni, Multicaecum ........................... 72, 76

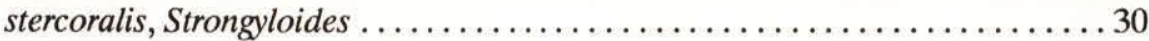

Strongylidae .................................. 41

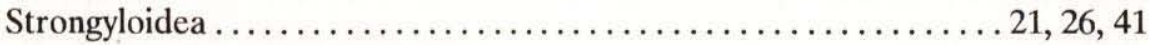

strongyloides, Diaphanocephalus ........................... 35

Strongyloides ...................................... 21, 29

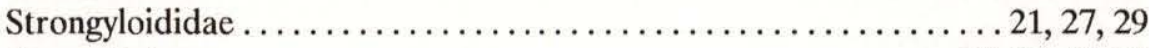

Strongyluris ................................... 57, 60, 98

Strongylus ....................................... 40

strumosus, Kalicephalus .................................... 37

subauricularis, Oswaldocruzia ......................21, 35, 40, 123

subulatus, Kalicephalus .......................21, 38, 39, 101, 127

Sulcascaris ................................ 68, 70, 71

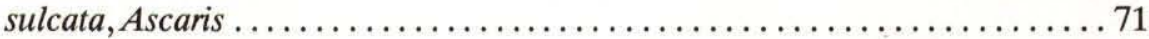

sulcata, Sulcascaris ........................ 24, 71, 75, 97, 143

sulcatum, Porrocaecum .................................. 71

superciliosa, Uranoscodon ............................ 58, 99

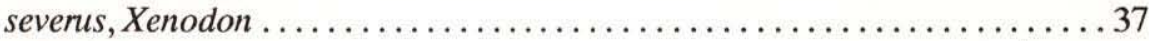

tabulata, Testudo ......................................... 96

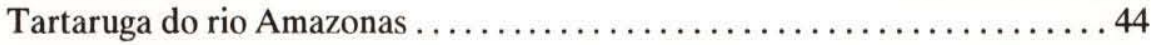

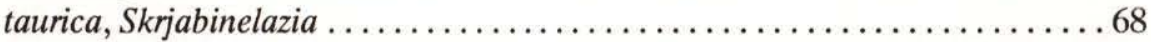

teguixin, Tejus .................................. 60, 99

teguixin, Tupinambis .................. 35, 39, 44, 52, 60, 87, 88, 92, 100

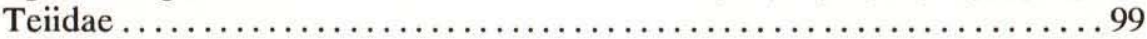

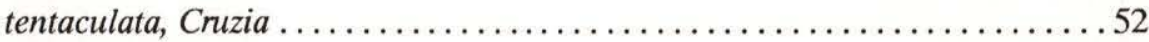

Terranova .................................... 69, 70, 71

terrificus, Crotalus ....................... 37, 38, 77, 79, 81, 90

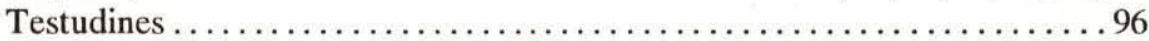

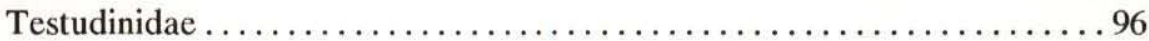

Thelandros $\ldots \ldots \ldots \ldots \ldots \ldots \ldots \ldots \ldots 23,60,62,65,66,67,68,97,98,99$

Thubunaea ....................................... 84,88

tikasinghi, Falcaustra ...................... 52, 55, 96, 140

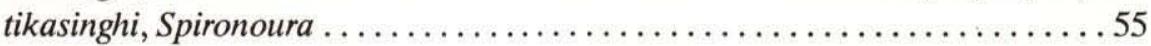

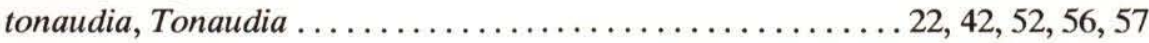

torquatus, Tropidurus ................ $31,40,60,65,66,68,86,87,94,98$

Travassosascaris .............................. 69, 73, 80 
travassosi, Aplectana $22,46,49,102,135$ travassosi, Freitasoxyascaris

travassosi, Klossinemella $22,47,48,96,133$ travassosi, Ophidascaris $79,81,145$

travassosi, Pharyngodon 65,66 travassosi, Strongyluris 60 trematophila, Atractis $22,44,45,97,133$ Trichostrongyoidea $21,26,39$ Trichuridae

trichuriformis, Ophidascaris . $24,80,81,103,104,145$ Trichuroidea . $21,26,31$ tricolor, Elapomorphus 94,102 trigemina, Pseudoboa . 59,103 trigeminus, Oxyrhopus . 28,103

Tropidurus 60,66 tuberculata, Batrachemys $84,93,97$

Tupinambis $44,52,60$ turgida, Heterakis .59

Typhlonema $.23,60,61,62,98$ typhlus, Dromicus 49, 102 unguiculata, Aplectana . $22,49,50,100,134$ unguiculatum, Oxysomatium ........................... 49

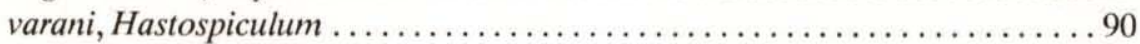
variabilis, Chapiniella ...................... 21, 39, 41, 42, 96, 127 variabilis, Deletrocephalus ............................. 42 vazi, Micropleura ..........................25, 91, 92, 101, 153 vellardi, Rhabdias $20,28,29,102,103,118$ venustissimus, Erythrolampus .......................... 102 verrucosus, Parapharyngodon .....................23, 44, 66, 99, 131 vicenti, Herpetodrias . ................................. 101 Viperidae ............................................ 104 vivipara, Micropleura ................................. 91 vogelsangi, Alaeuris .............................. 63, 66, 98, 129

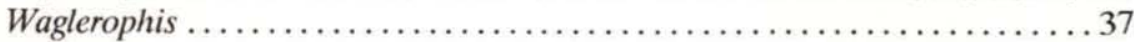
Xenodon ............................................ 49 zeae, Piratuba $26,91,95,100,155$ zschokkei, Labiduris $22,47,48,96,132$ 